\title{
Nevada
}

Environmental

Restoration Project

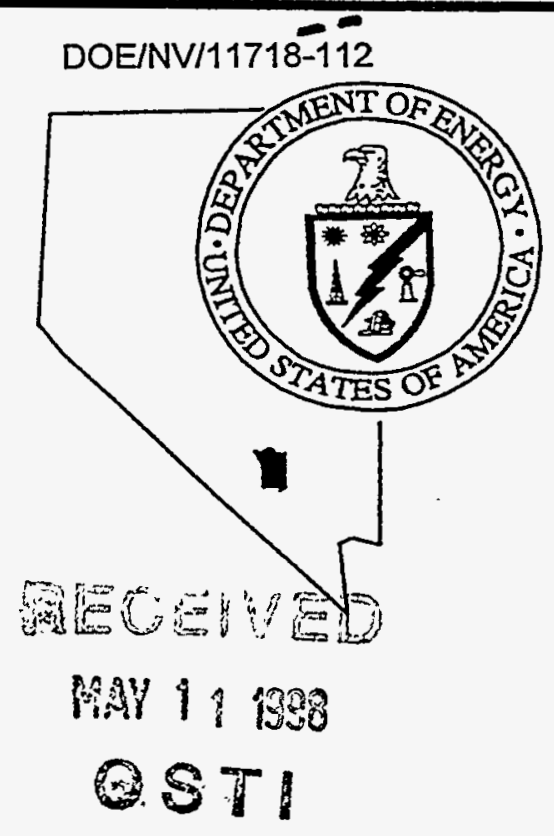

\section{Double Tracks}

Interim Corrective

Action Plan

June 1996

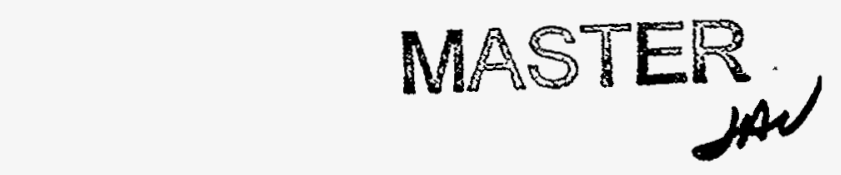

DISTRIBUTION OF THIS DOCUMENT IS UNLIMITED

Environmental Restoration

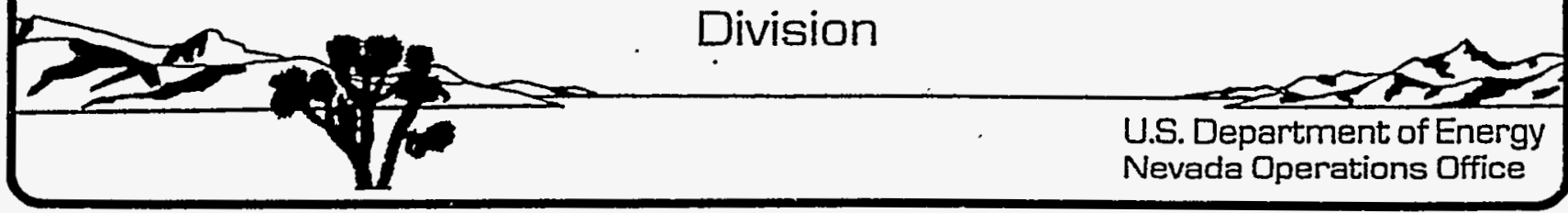




\section{DOUBLE TRACKS TEST SITE}

\section{INTERIM CORRECTIVE ACTION PLAN}

Bechtel Nevada Project No. ER211-9601 


\section{DISCLAIMER}

This report was prepared as an account of work sponsored by an agency of the United States Government. Neither the United States Government not any agency thereof, nor any of their employees, makes any warranty, express or implied, or assumes any legal liability or responsibility for the accuracy, completeness, or usefulness of any information, apparatus, product, or process disclosed, or represents that its use would not infringe privately owned rights. Reference herein to any specific commercial product, process, or service by trade name, trademark, manufacturer, or otherwise does not necessarily constitute or imply its endorsement, recommendation, or favoring by the United States Government or any agency thereof. The views and opinions of authors expressed herein do not necessarily state or reflect those of the United States Government or any agency thereof. 


\section{DISCLAIMER}

Portions of this document may be illegible electronic image products. Images are produced from the best available original document. 


\section{DOUBLE TRACKS TEST SITE INTERIM CORRECTIVE ACTION PLAN}

Submitted By:

Mónica L. Sanchez, Marnager

Date: $6 / 19 / 96$ Soils Media Operable Unit Subproject

Approved By:

Stephen A. Mellington, Project

Date: $6 / 19 / 96$ Manager

Nevada Environmental Restoration

Project 


\section{CONTENTS}

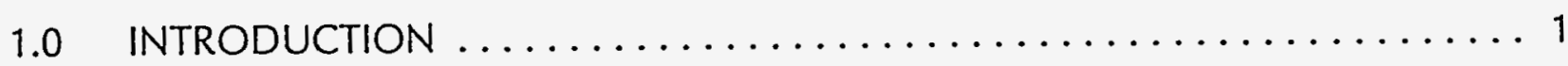

1.1 Site Location and Background $\ldots \ldots \ldots \ldots \ldots \ldots \ldots \ldots \ldots \ldots$

1.2 Proposed Interim Corrective Action Objectives ............. 4

1.3 Scope of Work ........................... 4

1.4 Project Organization/Personnel $\ldots \ldots \ldots \ldots \ldots \ldots \ldots \ldots \ldots \ldots \ldots$

1.5 Project Schedule . . . . . . . . . . . . . . . . . . . . 5

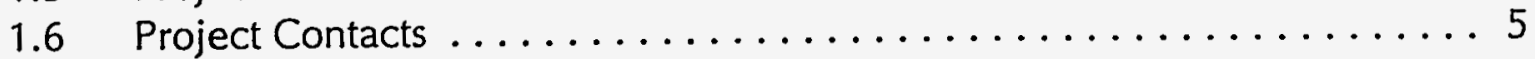

2.0 PROJECT PLANS/DELIVERABLES $\ldots \ldots \ldots \ldots \ldots \ldots \ldots \ldots \ldots \ldots \ldots \ldots$

2.1 Site-Specific Health and Safety Plan $\ldots \ldots \ldots \ldots \ldots \ldots \ldots \ldots \ldots$

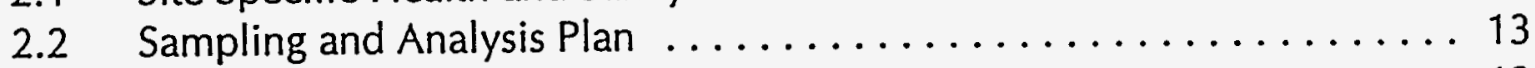

2.3 Quality Control/Performance Assurance $\ldots \ldots \ldots \ldots \ldots \ldots \ldots 13$

2.4 Environmental Protection Plan .................... 14

2.5 Performance Tracking System/Performance.Measurement System . . . . 14

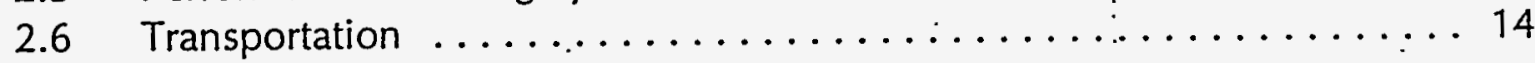

3.0 MOBILIZATION AND.FIELD SETUP $\ldots \ldots \ldots \ldots \ldots \ldots \ldots \ldots \ldots \ldots \ldots \ldots$

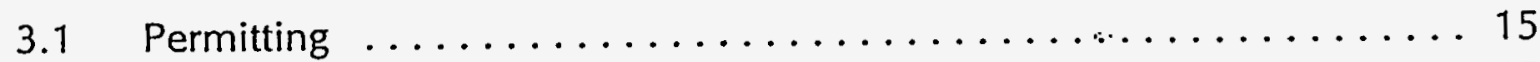

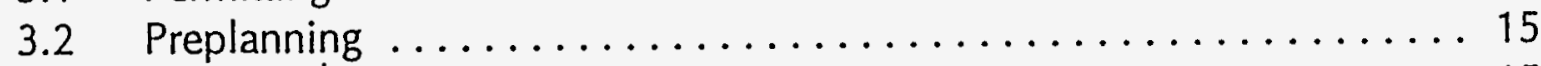

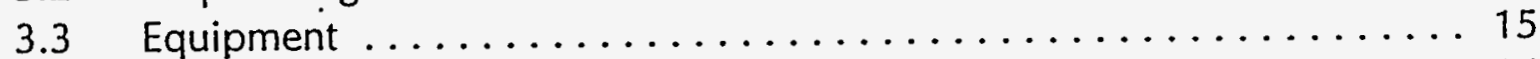

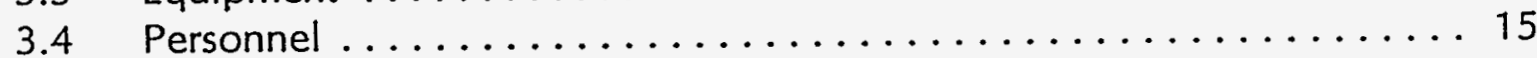

3.5. Temporary Facilities .......................... 16

3.6 General Construction and Management Activity ............ 16

3.6.1 Site Preparation .......................... 16

3.6.2 Decontamination Station .................... 17

3.6.3 Air Monitoring Plan ..................... 17

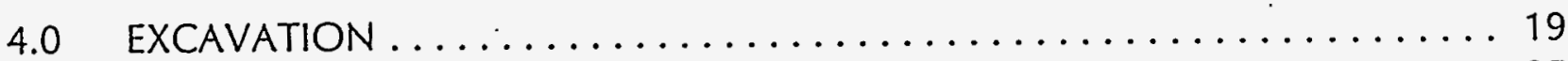

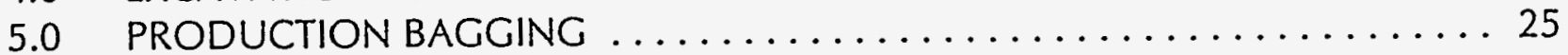

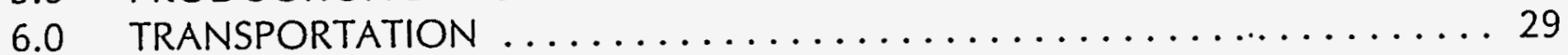

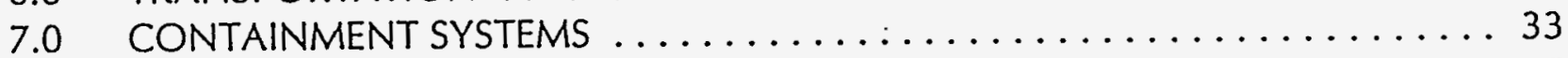

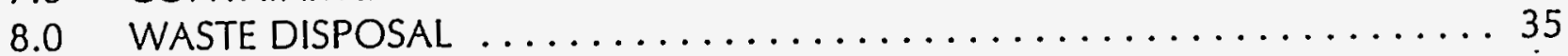

9.0 CERTIFICATION OF CLOSURE ........................ 37

9.1 Postexcavation Radiological Surveys . . . . . . . . . . . . . 37

9.2 Postexcavation Documentation .......................... 37 
CONTENTS

9.3 Decontamination $\ldots \ldots \ldots \ldots \ldots \ldots \ldots \ldots \ldots \ldots \ldots \ldots \ldots \ldots \ldots$

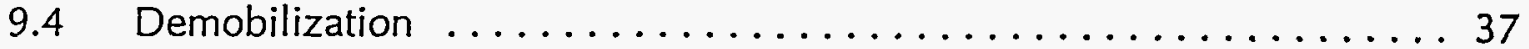

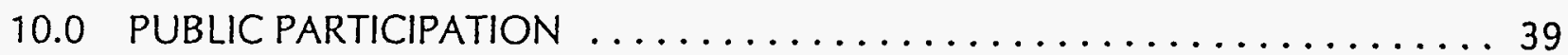

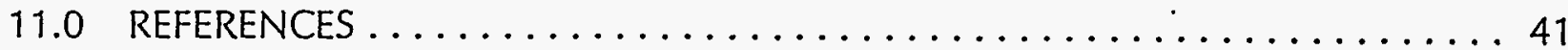

APPENDIX A APPENDIX B APPENDIX C APPENDIX D APPENDIXE APPENDIX F

APPENDIX G

APPENDIX H

APPENDIX 1 APPENDIX J APPENDIX K
HEALITH AND SÄFETY PLAN

SAMPLING AND ANALYSIS PLAN

ENVIRONMENTAL PROTECTION PLAN

TRANSPORTATION

AIR QUALITY OPERATING PERMITS

CHARACTERIZATION AND OPERATION OF THE CONVEYOR BELT Nal DETECTOR SYSTEM

OPERATIONAL STIPULATIONS TO RECEIVE SUPERSACK

CONTAINERS AT NTS UNDER NVO-325

REMOTE SENSING LABORATORY RADIOLOGICAL

CLEANUP VERIFICATION PLAN

REVEGETATION PLAN

SOIL EXCAVATION METHODS COMPARISON PLAN

AIR MONITORING PLAN

\section{List of Figures/Tables}

Figure $1-1 \quad$ Location of DOUBLE TRACKS Test Site $\ldots \ldots \ldots \ldots \ldots \ldots \ldots \ldots$

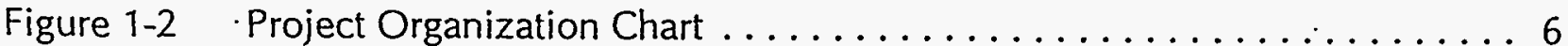

Figure $1-3$ Proposed Field Schedule $\ldots \ldots \ldots \ldots \ldots \ldots \ldots \ldots \ldots \ldots . \ldots \ldots$

Figure 4-1 Total Transuranic Isotope Activity of DOUBLE TRACKS Soil . . . . . . . . 20

Figure $4-2$ Excavation Schematic .......................... 22

Figure 4-2b Excavation Schematic ......................... 23

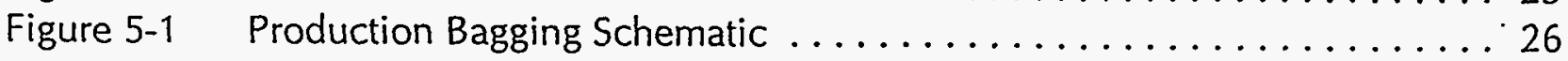

Figure $5-2 \quad$ Site Plan .................................. 27

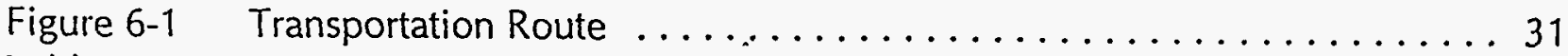

Table $1-1 \quad K e y$ Personnel Responsibility and Authority $\ldots \ldots \ldots \ldots \ldots \ldots$ 


\section{ACRONYMS}

BN

CADD

CAU

CFR

DOE

DOE/NV

EOD

EPP

$E Z$

HASP

MSDS

NAFR

NTS

P/FMP

PAMP

PMS/PTS

QA/QC

RWAP

RWMS

SAP

TTR

USAF
Bechtel Nevada Corporation

Corrective Action Decision Document

Corrective Action Units

Code of Federal Regulations

U.S. Department of Energy

Department of Energy/Nevada Operations Office

Explosive Ordnance Disposal

Environmental Protection Plan

Exclusion Zone

Health and Safety Plan

Material Safety Data Sheet

Nellis Air Force Range

Nevada Test Site

Project/Facility Management Plan

Performance Assurance Management Plan

Performance Measurement System/Performance Tracking System

Quality Assurance/Quality Control

Radioactive Waste Acceptance Program

Radioactive Waste Management Site

Sampling and Analysis Plan

Tonopah Test Range

U.S. Air Force 


\title{
DOUBLE TRACKS TEST SITE
}

\author{
INTERIM CORRECTIVE ACTION PLAN \\ Bechtel Nevada Project No. ER 211-9601
}

\subsection{INTRODUCTION}

This document, including its attachments and appendices, presents the implementation plan to conduct interim corrective actions at the DOUBLE TRACKS Test Site located on Range 71 North of the Nellis Air Force Range (NAFR). In addition to the interim corrective actions, this action is also intended to provide limited demonstration of other possible technical capabilities for remediating radioactive near-surface soil contamination in a cost-effective manner. The technical capabilities established during this project will be used to remediate three other Operation ROLLER COASTER sites, as well as other soil corrective action units (CAU).

The interim corrective action will remediate the DOUBLE TRACKS Test Site to an extent that it may be released for unrestricted use. The corrective action is labeled "interim" only by reference to the entire soil CAUs and does not imply that the cleanup will be temporary or incomplete. Upon completion of the interim corrective action, and when final cleanup levels are established for the CLEAN SLATE Sites, a Corrective Action Decision Document (CADD) will be prepared and is expected to recommend "no further action" for the DOUBLE TRACKS Test Site.

\subsection{Site Location and Background}

The selected information contained in this paragraph was taken from the draft DOUBLE TRACKS Test Site Characterization Report, dated March 1996.

The DOUBLE TRACKS Test Site is located on Range 71 North of the NAFR, northwest of the Nevada Test Site (NTS) (Figure 1-1). The nearest town is Goldfield, Nevada, located approximately 22 kilometers $(\mathrm{km})$ (14 miles [mi]) west of the site. By an existing road through the Tonopah Test Range (TTR) and U.S. Highways 6 and 95, Goldfield is approximately $132 \mathrm{~km}(82 \mathrm{mi})$, and Mercury, Nevada, is approximately $362 \mathrm{~km}(224 \mathrm{mi})$ from the DOUBLE TRACKS Test Site.

DOUBLE TRACKS was the first of four experiments that constituted Operation ROLLER COASTER. On May 15, 1963, weapons-grade plutonium and depleted uranium were placed on a 2.4 - by 2.4 - meter $(\mathrm{m})(8$ - by 8 -foot [ft]) steel plate that was supported by a $6.1-$ by $6.1-\mathrm{m}$ (20- by $20-\mathrm{ft}), 0.3-\mathrm{m}$ (I-ft)-thick reinforced concrete pad. The radioactive material was dispersed using 54 kilograms $(\mathrm{kg})$ (118 pounds [lbs]) of trinitrotoluene (TNT) explosive (Church, 1969; Shreve, 1965). The explosion occurred in the open, $0.3 \mathrm{~m}(1 \mathrm{ft})$ above the steel plate (Menker et al., 1966). No fission yield was detected from the test, and the total 


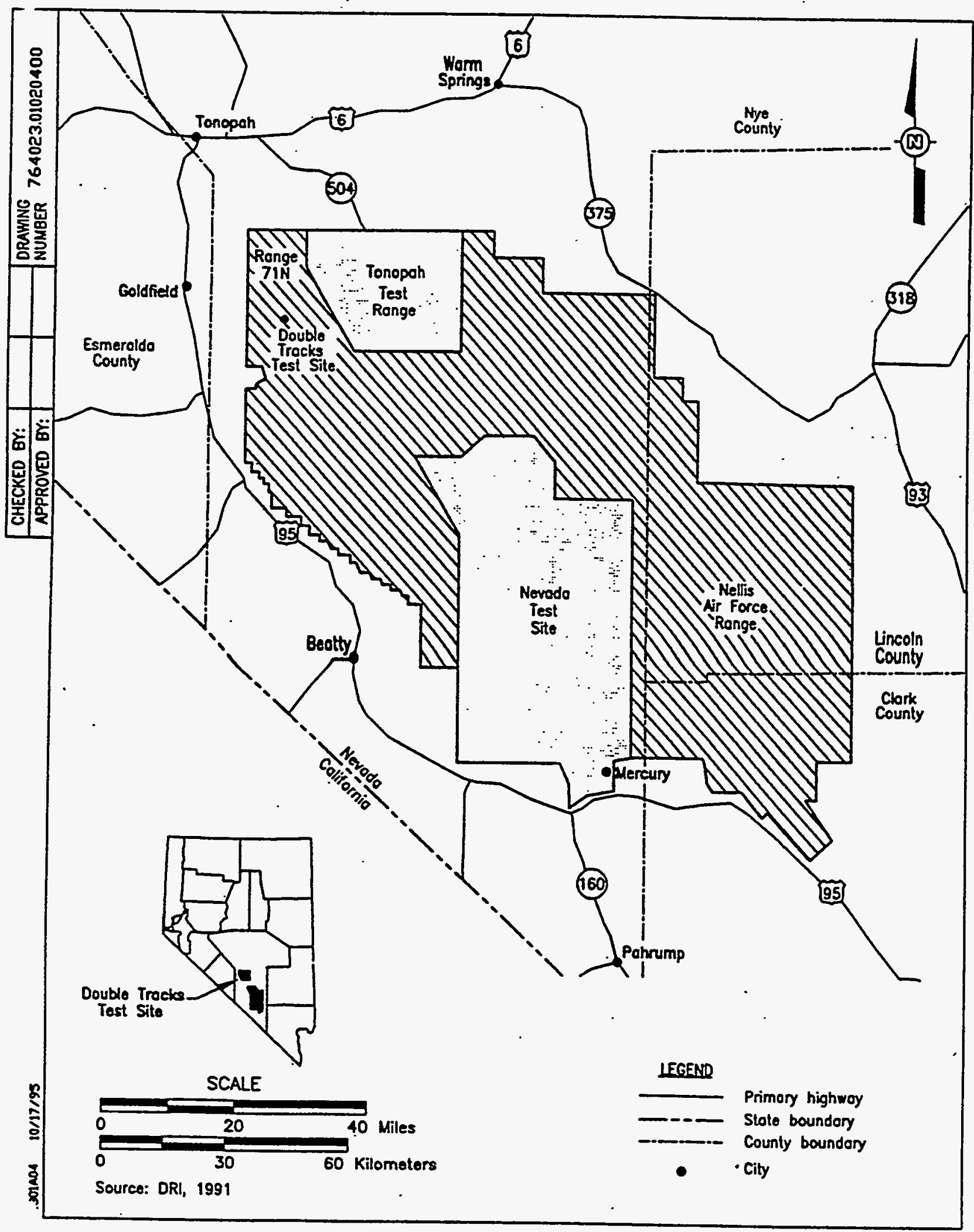

Figure 1-1 Location of DOUBLE TRACKS Test Site 
amount of plutonium deposited on the ground surface was estimated to be between 980 and 1,600 grams (Shreve, 1965). The test device was composed primarily of uranium-238 ${ }^{238} \mathrm{U}$ ) and plutonium-239 ${ }^{239} \mathrm{Pu}$ ). Menker et al. (1966) reported that the mass ratio of uranium to plutonium in the device was 4.35 .

The objectives of the DOUBLE TRACKS experiment were to evaluate the dispersal of radionuclides in the environment and the uptake and fate of plutonium in several animal species. The experiment scattered radioactive material, earth, and other material (concrete and metal) into the air. The debris and most of the dirt fell to earth at relatively short distances. However, some of the finer-grained material was spread over a larger area downwind, south of ground zero (GZ). The debris in the vicinity of $G Z$ and identified fragments to distances of 90 to $120 \mathrm{~m}$ ( 300 to $800 \mathrm{ft}$ ) were collected and buried near GZ. Contaminated surface soil in the vicinity of $G Z$ reportedly was scraped to a depth of several inches and mounded, covered with clean dirt, and compacted. The steel plate was buried in the CLEAN SLATE radiation disposal pit, but was later exhumed and transported to the NTS for analysis and disposal. Except for these postevent activities, no decontamination of the site was reported.

The site characterization was designed to adequately characterize the nature and extent of contamination at the DOUBLE TRACKS Test Site. The specific conclusions identified in the draft site characterization report were:

Contaminants of potential concern in soil at the DOUBLE TRACKS Test Site are americium-241 $\left({ }^{241} \mathrm{Am}\right)$ and plutonium-239/240 $\left({ }^{239-240} \mathrm{Pu}\right)$. Uranium and other, nonradiological metals are present only in background concentrations.

In situ measurements indicate that typically most of the total transuranic activity is present within the top $2.5 \mathrm{~cm}$ (1 in.) of the soil profile. Where significant amounts of plutonium (greater than $1,000 \mathrm{pCi} / \mathrm{g}$ ) are present, it can be assumed that the uppermost $5 \mathrm{~cm}$ ( 2 in.) of the soil profile is contaminated. (In situ radiological depth profiles were conducted on four hot spots during site characterization. These profiles indicated that 80 to 90 percent of the radioactivity was generally within the top 2 inches of the soil surface.) In the $G Z$ area, radiologically contaminated soil and possibly test debris are buried.

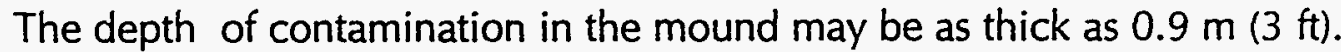

The contamination of surface soil at DOUBLE TRACKS appears to have been caused by local fallout and debris from the experiment, including relatively large metallic fragments. These metallic fragments were the source of most of the radioactive hot-spot activity identified during characterization.

The surface area with a total transuranic activity greater than $200 \mathrm{pCi} / \mathrm{g}$ is approximately 8,780 square meters $\left(\mathrm{m}^{2}\right)\left(95,400 \mathrm{sq} \mathrm{ft}\left[\mathrm{ft}^{2}\right]\right)$, based on an in situ radiological survey. 
The best estimate of the volume of contaminated soil to be removed from DOUBLE TRACKS is 1,243 cubic meters $\left(\mathrm{m}^{3}\right)\left(1,620\right.$ cubic yards [yd $\left.\left.\mathrm{d}^{3}\right]\right)$, based on a cleanup level of $200 \mathrm{pCi} / \mathrm{g}$. This estimate does not take into account soil expansion during excavation.

Based on the contaminants present, soil from the DOUBLE TRACKS Test Site will be classified as low-level radioactive waste. Soil contaminated with ${ }^{241} \mathrm{Am}$ and plutonium did not exhibit toxicity characteristic, based on Resource Conservation and Recovery Act (RCRA) metals TCLP data (see the DOUBLE TRACKS Site Characterization Report).

The metallic fragments which were located outside of $G Z$ area were collected and containerized during site characterization. This container is presently stored inside the exclusion zone and represents a very small volume of the transuranic material to be disposed.

Extensive volume reduction of contaminated soil is not a cost-effective alternative for the DOUBLE TRACKS Test Site because the amount of soil requiring corrective action is relatively small.

\subsection{Proposed Interim Corrective Action Objectives}

The objective of this corrective action is to reduce the potential risk to human health and the environment and to demonstrate technically viable and cost-effective excavation, transportation and disposal. To achieve these objectives, all soils with a total transuranic activity greater than $200 \mathrm{pCi} / \mathrm{g}$ will be excavated, packaged, and transported to NTS for disposal. The DOUBLE TRACKS Test Site has been established as Corrective Action Unit No. 411 in the Federal Facilities Agreement and Consent Order, FFACO, and as such, will require that a Corrective Action Decision Document (CADD) be prepared recommending appropriate cleanup. It is conservatively estimated that the $200 \mathrm{pCi} / \mathrm{g}$ cleanup level will be equal to or less than the acceptable criteria and the CADD will recommend "no further action". For a more complete discussion of the proposed action and cleanup level, see the "Environmental Assessment for the DOUBLE TRACKS Test Site" (DOE, 1996a).

\subsection{Scope of Work}

Bechtel Nevada (BN) will conduct an interim corrective action on the soils at the DOUBLE TRACKS Test Site by removing soil with a total transuranic activity greater than $200 \mathrm{pCi} / \mathrm{g}$, containerizing the soil in "supersacks," transporting the filled "supersacks" to the NTS, and disposing of them in the Area 3 Radioactive Waste Management Site (RWMS). During the interim corrective action, BN will also conduct a limited demonstration of an alternative method for excavating radioactive near-surface soil contamination.

The scope of work for this project consists of the following activities: 
Perform road maintenance on 9.5 miles of Sleeping Column Canyon Road from the Cactus Springs Gate through Range 71 North to the DOUBLE TRACKS Test Site.

Mobilize personnel and equipment to the site.

Characterize, handle, package, ship, and certify radioactive contaminated soil according to the Bechtel Nevada Application to Transfer Radioactive Waste at the Nevada Test Site and the Bechtel Nevada Waste Certification Program Plan for Radioactive Waste Storage or Disposal. Radioactive contaminated soil control and certification activities will be subject to a DOE/NV Radioactive Waste Acceptance Program (RWAP) on-site surveillance.

Provide limited demonstration of other technical capabilities for remediating radioactive near-surface soil contamination.

Remove, containerize, and transport to the NTS soil exceeding a total transuranic activity of $200 \mathrm{pCi} / \mathrm{g}$.

Dispose of containerized soil at the Area 3 RWMS.

Decontaminate all equipment.

Provide information for independent verification that the remaining surface soil on site does not exceed a total transuranic activity of $200 \mathrm{pCi} / \mathrm{g}$.

Stabilize and revegetate the site to conditions consistent with future use.

Demobilize personnel and equipment.

\subsection{Project Organization/Personnel}

An organizational chart is presented in Figure 1-2. Table 1-1 describes the responsibilities of the key project personnel assigned to the project.

\subsection{Project Schedule}

Excavation and soil processing will be initiated upon U.S. Department of Energy (DOE) approval of this implementation plan. Figure 1-3 shows the proposed field schedule.

\subsection{Project Contacts}

The following individuais will serve as primary contacts for this project: 
DOUBLE TRACKS TEST SITE

Interim Corrective Action

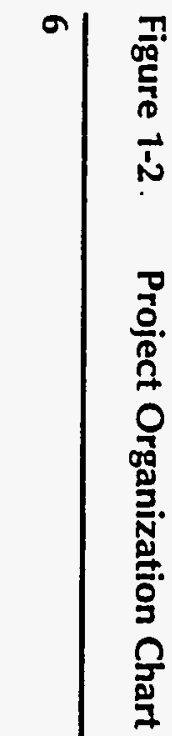

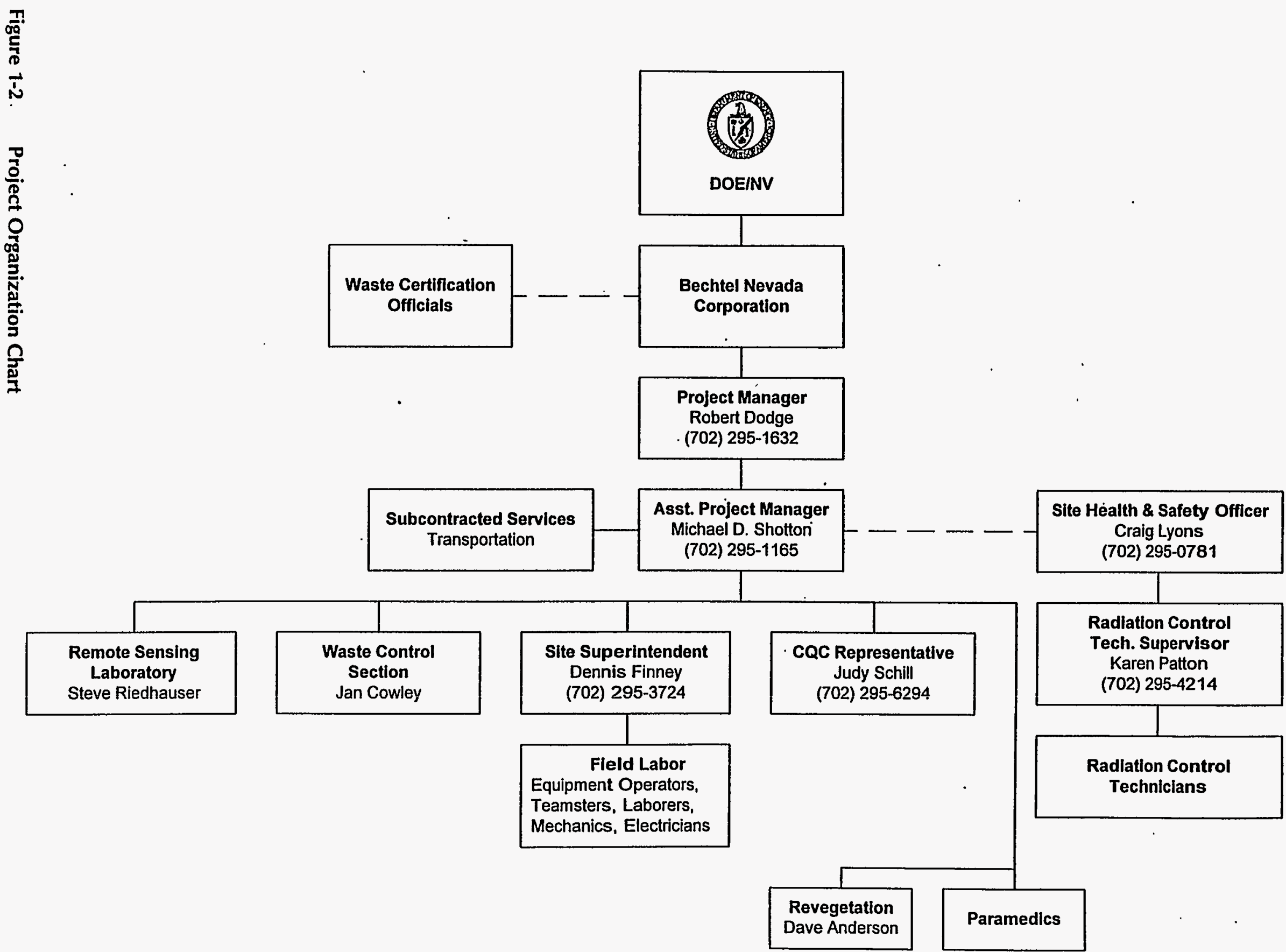




\begin{tabular}{|c|c|c|}
\hline Key Positions & Responsibility & Authority \\
\hline Project Manager & $\begin{array}{l}\text { Receive, administer, and manage applicable Task Agreement } \\
\text { - Ensurs. } \\
\text { - Provide program-wide continuity for the technical direction of } \\
\text { projects. } \\
\text { - Plan and schedule work. } \\
\text { - Manage project-wide costs, quality control, and contractual } \\
\text { requirements. } \\
\text { - Provide information to DOE Project personnel. } \\
\text { - Fulfill administrative and financial contractual reporting } \\
\text { requirements. } \\
\text { - Serve as part of the Technical Staff on Projects as necessary. } \\
\text { - Ensure Project Teams are established with properly trained } \\
\text { - Support job planning and execution. } \\
\text { - Monitor Task Agreement Plan progress. } \\
\text { Maintain awareness of all applicable regulatory requirements for } \\
\text { - Such Task Agreement Plan. } \\
\text { - Serve as Corrective Action Manager.for BN. }\end{array}$ & $\begin{array}{l}\text { - Commit corporate resources to accomplish project } \\
\text { objectives. } \\
\text { - Resolve work load conflicts on a project-wide basis. } \\
\text { - Negotiate and execute Task Agreement Plans. } \\
\text { - Negotiate and execute Change Control. } \\
\text { - Select Assistant Project Managers. } \\
\text { - Approve project policies and procedures. } \\
\text { - Approve all expenditures. } \\
\text { - Segotiate and approve subcontract agreements. } \\
\text { - Rect Technical Staff. } \\
\text { - Review and approve all deliverables. }\end{array}$ \\
\hline Assistant Project Manager & 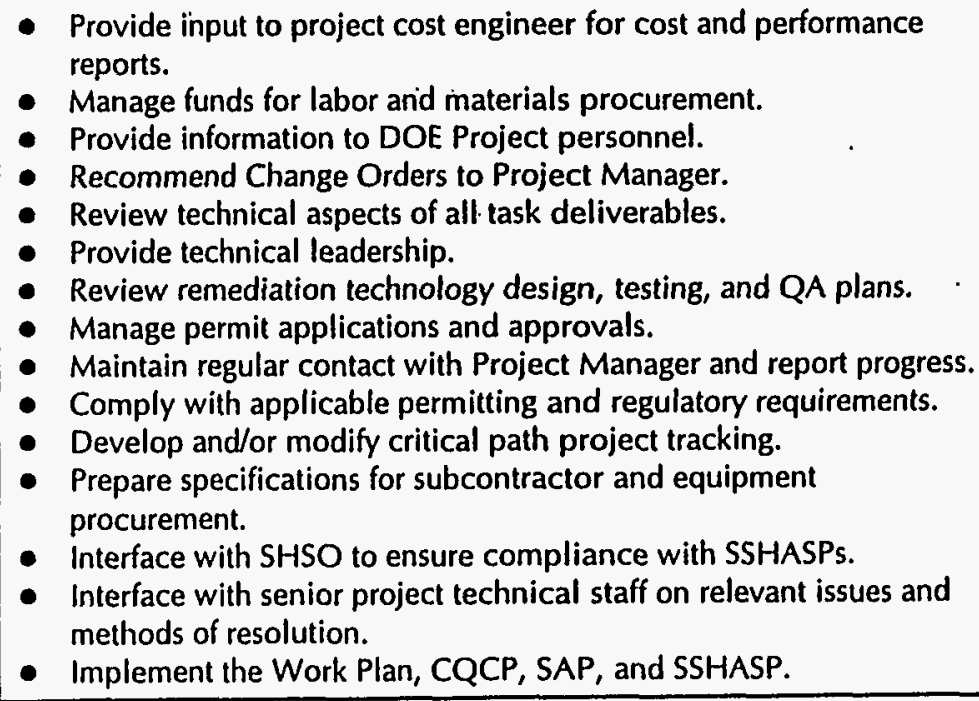 & $\begin{array}{l}\text { - Approve remediation technology design, testing, and QA } \\
\text { plans. } \\
\text { - Allocate budget among work elements as identified in the } \\
\text { Work Plan. } \\
\text { - Approve/disapprove all labor, materials, equipment, and } \\
\text { subcontractor charges to the Project. } \\
\text { - Establish and enforce work element milestones for timely } \\
\text { completion of Task Agreement Plan. } \\
\text { - Authorize assignment of field operations personnel to the } \\
\text { Project. } \\
\text { - Approve/disapprove any technical deliverable for each } \\
\text { work element. } \\
\text { - Communicate daily with Project Control as to day-to-day } \\
\text { progress and direct all technical activities. } \\
\text { Select technical staff. }\end{array}$ \\
\hline
\end{tabular}




\begin{tabular}{|c|c|c|}
\hline Key Positions & Responsibility & Authority \\
\hline Site Superintendent & $\begin{array}{l}\text { - Schedule and commit resources for all operational work efforts. } \\
\text { - Supervise the conduct of construction field operations. } \\
\text { - Ensure adherence to CQCP, SSHASP, and SOPs. } \\
\text { - } \text { - Repmunicate daily with PM and Assistant PM. } \\
\text { - Prepare daily activily logs, including volumes of soils or water } \\
\text { - Comoved, treated, or disposed. } \\
\text { - } \text { - End other operations such as sampling or disposal. } \\
\text { - Direct supervision of field personnel. } \\
\text { - Recommend corrective action to Assistant PM in event of } \\
\text { - } \text { - Exoblems in subcontractor performance. }\end{array}$ & $\begin{array}{l}\text { - Resolve site problems and inform Assistant PM of } \\
\text { difficulties and support requirements. } \\
\text { - Immediate shutdown of operation because of observed } \\
\text { safety hazard or failure to comply with CQCP. } \\
\text { - Immediate dismissal of any contractor personnel for failure } \\
\text { to comply with SSHASP, CQCP, SAP, or SOPs. } \\
\text { - Select equipment to conduct operation in accordance with } \\
\text { SOPs and Work Plan. } \\
\text { - Approve/disapprove all materials and labor costs for site } \\
\text { operations. }\end{array}$ \\
\hline CQC Representative & $\begin{array}{l}\text { Monitor/audit field and laboratory operations to ensure } \\
\text { compliance with CQCP procedures. } \\
\text { - Review all project field/laboratory data. } \\
\text { - Ensure that adequate QC documentation is provided. } \\
\text { and are identified to Project Superintendent and PM. } \\
\text { - Develop and implement QC plans and inspection system. }\end{array}$ & $\begin{array}{l}\text { Conduct unannounced audits of field/laboratory } \\
\text { procedure. } \\
\text { Approve/disapprove all field/laboratory data. } \\
\text { Immediately stop field/laboratory operations which are not } \\
\text { in compliance with CQCP. } \\
\text { Communication with DOE project personnel regarding } \\
\text { matters of data validation and other CQCP considerations. }\end{array}$ \\
\hline $\begin{array}{l}\text { Waste Minimization and } \\
\text { Control Section }\end{array}$ & $\begin{array}{l}\text { - Characterize radioactive soil. } \\
\text { - Quantify via the radio assay system mounted on the conveyor the } \\
\text { radionuclide activity of each bag of soil. } \\
\text { - Package and prepare bags of soil for shipment. } \\
\text { Ship soil for disposal. }\end{array}$ & $\begin{array}{l}\text { - Approve waste characterization documents for Double } \\
\text { Tracks Waste Stream. } \\
\text { - Complete waste packaging and traceability } \\
\text { documentation. } \\
\text { - Complete shipping documentation. } \\
\text { - Immediate shut down of operations because of observed } \\
\text { problems with radio assay detection system. }\end{array}$ \\
\hline $\begin{array}{l}\text { Waste Certification } \\
\text { Official }\end{array}$ & $\begin{array}{l}\text { - Certify all waste packages (i.e. bags of soil). } \\
\text { - Certify waste shipments. }\end{array}$ & $\begin{array}{l}\text { Immediate shutdown of operations of observed } \\
\text { deficiencies in any characterization, packing, handling and } \\
\text { shipping activities that could adversely impact certification } \\
\text { of waste or shipments. } \\
\text { - Perform oversight of all waste characterization } \\
\text { /quantification, handling, packing, and shipping activities. }\end{array}$ \\
\hline
\end{tabular}


Table 1-1 (continued)

\begin{tabular}{|c|c|c|}
\hline Key Positions & Responsibility & Authority \\
\hline $\begin{array}{l}\text { Site Health and Safety } \\
\text { Officer }\end{array}$ & $\begin{array}{l}\text { - Monitor field/laboratory procedures to ensure compliance with } \\
\text { - SSHASP and corporate'HSP. } \\
\text { - Brief all field/laboratory personnel regarding special hazards that } \\
\text { - May be associated with project operations. } \\
\text { - Monitor the labeling, shipping, and control of hazardous or } \\
\text { - Monitilly hazardous samples. } \\
\text { - Coordinate site health and safety requirem. } \\
\text { - Euperintendents or Assistant PM. } \\
\text { - Ensure maintenance of all health and safety monitoring and } \\
\text { personnel protective equipment. } \\
\text { - Collect all required air and personnel monitoring data. } \\
\text { - Report all health and safety monitoring results to CIH. }\end{array}$ & $\begin{array}{l}\text { - Immediately shut down field/laboratory operations if a } \\
\text { violation to SSHASP or unsafe condition exists. } \\
\text { - Conduct unscheduled safely audits. }\end{array}$ \\
\hline
\end{tabular}




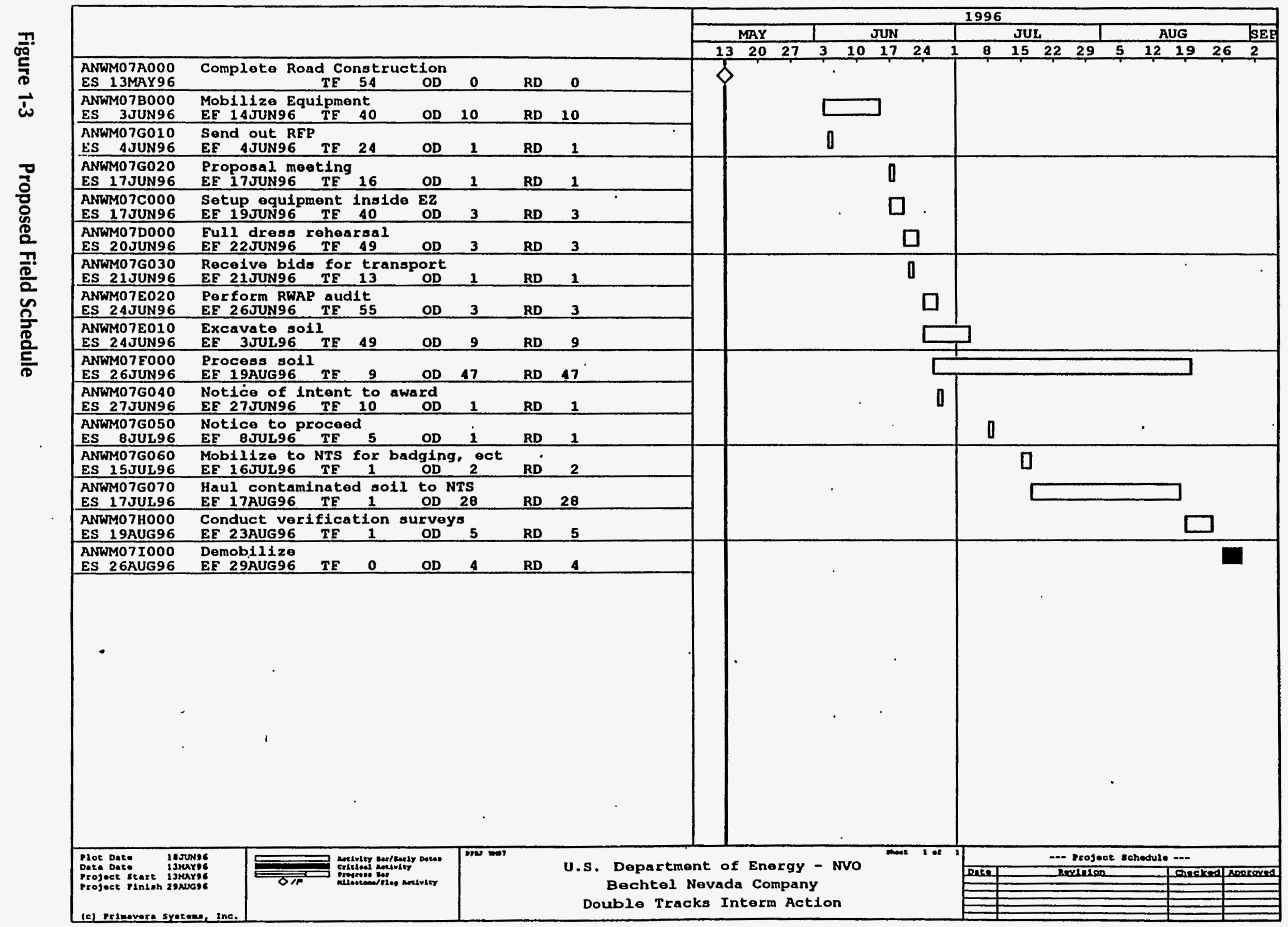


Project Manager-Department of Energy Project Manager-BN

Assistant Project Manager-BN

Site Health and Safety-BN
Monica Sanchez (702) 295-0160

Robert Dodge (702) 295-1632

Mike Shotton (702) 295-1165

Field (702) 295-8346

Craig Lyons (702) 295-0781

Field (702) 295-8346 
This Page Intentionally Left Blank 


\subsection{PROJECT PLANS/DELIVERABLES}

As part of the task agreement plan, the following documents have been or will be prepared:

\subsection{Site-Specific Health and Safety Plan}

The Site-Specific Health and Safety Plan (SSHASP) is a detailed, job-specific plan covering protection against accidental or other exposure of workers to contamination. It also discusses weather/air monitoring, accident reporting, emergency procedures, and physical hazards, and is included as Appendix A-1. The work will also be performed in accordance with the DOE Nevada Environmental Restoration Project Health and Safety Plan.

\subsection{Sampling and Analysis Plan}

A Sampling and Analysis Plan (SAP) describing the rationale to sample for organics and RCRA metals contamination, sample collection procedures, analytical methods, and sampling and analytical Quality Assurance/Quality Control (QAQC) protocols associated with the interim corrective action and verification is included as Appendix B.

\subsection{Quality Control/Performance Assurance}

Quality control/performance assurance falls into three key areas:

Implementation of the requirements of DOE Order 5700.6C, Quality Assurance Program, and follow-on documents;

Internal management assessment, during the actual operation of the project, of the effectiveness of implementation of the requirements of DOE Order $5700.6 \mathrm{C}$ (i.e. the Project/Facility Management Plan); and

Development of a comprehensive documents and records management program to create a complete history of the project.

The company document that implements the requirements of DOE Order $5700.6 \mathrm{C}$ is the BN Performance Assurance Management Plan (PAMP), No. B-A20/9601. The requirements of the PAMP have been met by the completion of this Interim Corrective Action Plan.

A formal internal management assessment is required by the BN PAMP. It involves an assessment, during actual project operation, of the effectiveness of the implementation of the DOUBLE TRACKS Project Management Plan. A management assessment will be scheduled during operations.

A comprehensive documents and records management program to create a complete history of the project will be accomplished during the project execution. 


\subsection{Environmental Protection Plan}

An Environmental Protection Plan (EPP) describing the methods and rationale used to protect the environmental resources at the DOUBLE TRACKS Test Site is included as Appendix D. A NEPA Enviornmental Assessment of the project resulted in a Finding of No Significant Impact.

\subsection{Performance Tracking System/Performance Measurement System (PTS/PMS)}

PTS/PMS include the technical progress report and the cost performance reports. Information will be updated at least weekly, and will be reviewed monthly.

\subsection{Transportation}

Transportation will be conducted by a subcontractor licensed to haul low-specific activity radioactive material. A copy of the Transportation Plan and the BN Transportation Services Request for Proposal are included as Appendix E. 


\subsection{MOBILIZATION AND FIELD SETUP}

BN will mobilize the necessary equipment and personnel to the DOUBLE TRACKS Test Site to be entirely self-reliant, with the exception of fuel, water, billeting, messing, and miscellaneous minor logistics support which are available at TTR either from the 99th Range Support Group or Sandia. BN will mobilize equipment and personnel from the NTS.

\subsection{Permitting}

A copy of the State of Nevada Air Quality Operating Permit No. 1476 issued for the DOUBLE TRACKS environmental restoration project is included as Appendix $E$.

\subsection{Preplanning}

Prior to commencing field activities, several meetings were held both on- and off site with personnel involved with the interim corrective action. The meetings included discussions to develop an understanding of the administration of the health and safety program, submittals, and approach and execution of the task agreement plan.

\subsection{Equipment}

BN will transport large pieces of equipment and basic supplies from the NTS to the DOUBLE TRACKS Test Site.

\subsection{Personnel}

As equipment is being mobilized, $\mathrm{BN}$ will concurrently mobilize personnel to be on site to unload and stage the arriving equipment. BN will mobilize personnel, both from the NTS and its North Las Vegas facilities, who will travel either by personal vehicle or government vehicle to the main gate of the TTR. From the main gate forward, transportation will be limited to nonprivately owned vehicles only. Unless otherwise approved by the 99th Range Support Group security officer, all personal vehicles will be stored in the parking area outside of the main gate.

The initial mobilization and setup will require the following personnel:

Assistant Project Manager (1)

Site Health and Safety Officer (1)

Job Superintendent (1)

Equipment Operators (3)

Mechanic (1)
Administration (1)

Teamsters (6)

Laborers (5)

Electricians (2)

Radiation Technician (1)

These personnel will be responsible for the unloading of equipment, the staging and construction of the processing equipment, and the setup of the support facilities outside of the 
exclusion zone. The peak number of personnel on site during the soil excavation, processing, and bagging operations will be approximately 40 .

BN will certify that all personnel who will be performing work under this task agreement plan, or who will have access to facilities and information for which BN is responsible, are citizens of the United States.

Housing and meals on TTR for $B N$ personnel will be provided as identified in the DOUBLE TRACKS Support Estimate and Project Support Plan. The U.S. Air Force (USAF) has agreed to direct-bill BN for these services and they will be paid for with project funds.

\subsection{Temporary Facilities}

A temporary field construction office and support camp will be established outside the exclusion zone during mobilization activities. The location of the trailers and equipment will be predetermined. A sign will be placed on the site office trailer depicting the business phone number, contact person, and emergency phone number. Facilities will be appropriately anchored. Electricity will be provided through on-site generators and distribution system. Potable water will be brought in daily. Phone lines are not accessible at the location, so communication will be via radio on predetermined frequencies. Phones lines both for telephone and facsimile will be available in a support building (TTR Area 3 Building 3-78) located in the Sandia compound.

\subsection{General Construction and Management Activity}

The following sections discuss the construction and management activities that will be implemented by $\mathrm{BN}$ to successfully complete the interim corrective action at the site.

\subsubsection{Site Preparation}

Site preparation will consist of the following activities:

Perform road maintenance on 9.5 miles of Sleeping Column Canyon Road from the Cactus Springs Gate through Range 71 North to the DOUBLE TRACKS Test Site;

Implement site security, health and safety procedures, and dust control activities;

Identify and report any unexploded ordnance which might be uncovered during site preparation to the USAF Explosive Ordnance Disposal (EOD) team. The site was surveyed in October 1994 and cleared of live ordnance by an EOD team. Another EOD survey of the site will be conducted prior to excavation. All inert ordnance within the fenced area of the site will be removed; 
Establish temporary facilities including, but not limited to, the following:

Sanitary facilities

Water

Power

Radio

Material and equipment storage area

Decontamination area

Personnel hot line.

\subsubsection{Decontamination Station}

A mobile personnel decontamination station consisting of a hand wash station will be set up near the site entry access gate. A lined decontamination pad will be constructed on which equipment and vehicles that come in contact with contaminated material will be decontaminated prior to exiting the exclusion zone. Decontamination of equipment and vehicles will consist of pressure washing. Contaminated water volume will be reduced through the use of a water recycler designed to filter out contaminants. The collected decontamination water will be allowed to evaporate.

\subsubsection{Air Monitoring Plan}

Air monitors will be deployed at the perimeter of the exclusion zone to monitor airborne particulate matter during excavation operations. The air monitoring plan is included as Appendix K. 
This Page Intentionally Left Blank 


\subsection{EXCAVATION}

The areas with a total transuranic activity greater than $200 \mathrm{pCi} / \mathrm{g}$ will be excavated. These areas include the circular mound area at GZ and the linear plume area which extends south from GZ (see Figure 4-1). These areas were previously defined during site characterization. Survey markers will be placed at the boundaries of the plume and the GZ mound prior to excavation.

During site characterization, in situ contamination measurements were made at four hot spots. One-inch layers of soil were removed and the radioactivity measured again. These measurements indicated that 80 to 90 percent of the radioactivity was generally in the upper 2 inches of soil. Based on this data, it is believed that the contamination can be removed by excavating the area to a depth of approximately $3 " \pm 1 "$. The soil will be removed by excavating layers approximately $1 \frac{1}{2}$ inches thick. A radiological survey of the excavated area will then be conducted to determine if the proposed cleanup level of $200 \mathrm{pCi} / \mathrm{g}$ has been achieved. If the radiological activity level remains above $200 \mathrm{pCi} / \mathrm{g}$, additional layers of soil will be removed until the proposed cleanup level has been achieved. If it is determined that only small areas require additional excavation, this may be accomplished using a front-end loader. This process of removing the soil in layers will minimize the volume of soil to be processed and disposed.

Prior to excavating, the ground surface will be wetted with a water pull to reduce dust. Soil excavated with a motor grader will be bladed into windrows. Windrowed soil will be picked up and stockpiled with a front-end loader. Soil excavated with a scraper will also be stockpiled with the assistance of a front-loader. The stockpiled soil will be kept moist to reduce dust. A schematic depicting the planned excavation process is shown in Figure 4-2. The cement slab will be broken by a hoe ram and containerized as bulk material. During the excavation phase, BN will have captive, in the exclusion zone (EZ), a motor grader, a scraper, water pull, and a front-end loader. During camp setup, BN will locate both the fuel source and process water sources so the captive equipment can be serviced with these products without having to decontaminate the equipment and leave the EZ each time service is required.

Prior to the startup of full-scale excavation, BN will demonstrate and evaluate two methods of excavation. One excavation method will use a scraper in a selected area. The demonstration will consist of setting the depth of cut for the scraper to a prescribed depth and proceeding with soil removal until the hopper is filled. The soil will then be transported to the stockpile area where it will be deposited for future processing. The second method will use a motor grader to blade soil into windrows. The windrowed soil will be picked up and stockpiled with a front-end loader. In addition, the scraper will also be used to pick up soil which has been windrowed using the motor grader. The effectiveness of these methods will be evaluated using the Soil Excavation Methods Comparison Plan, Appendix J, which was developed based on input from the Desert Research Institute. 


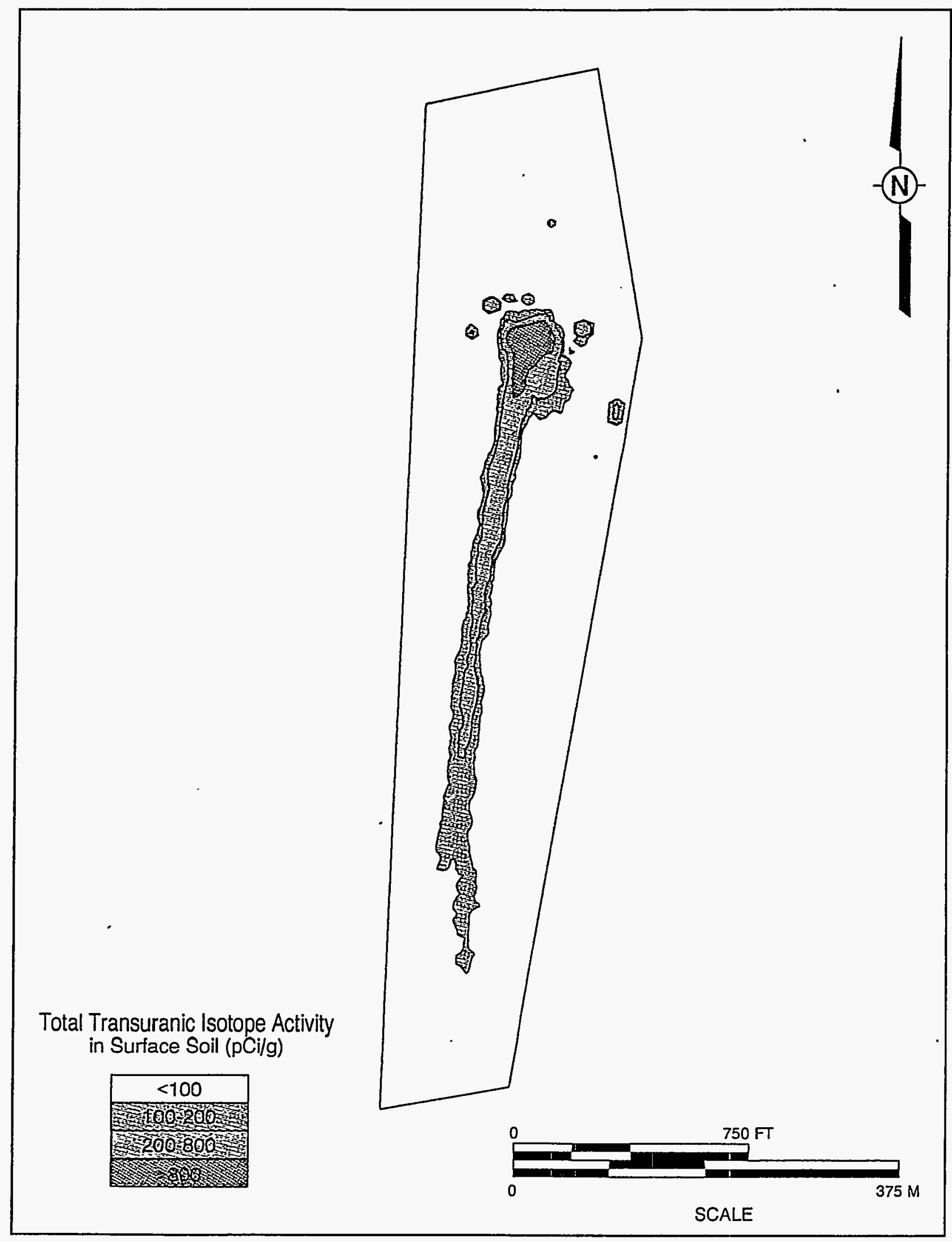

Figure 4-1 Total Transuranic Isotope Activity of DOUBLE TRACKS Soil (based on 1995 EG\&G Ground Survey) 
This Page Intentionally Left Blank 

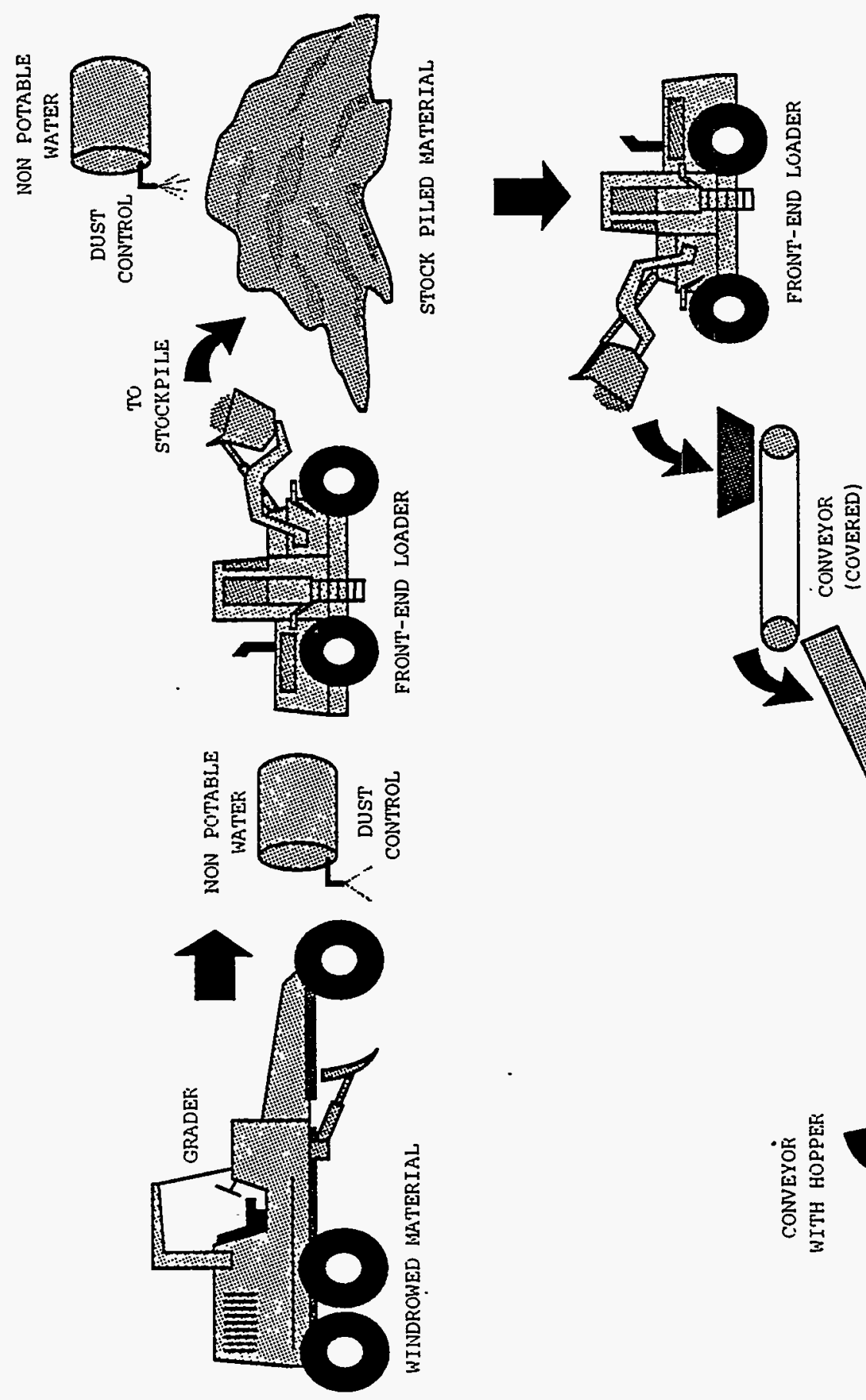

然

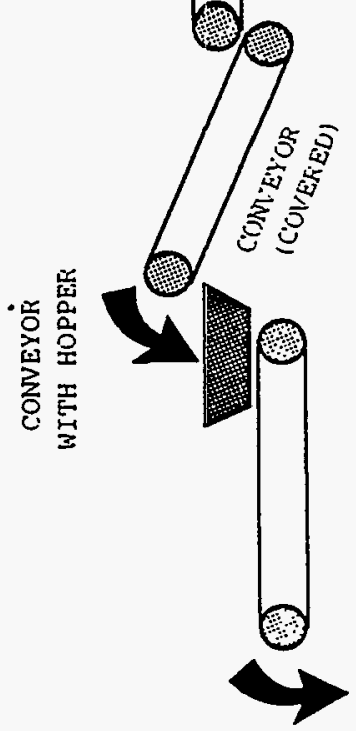

Figure 4-2 Excavation Schematic 


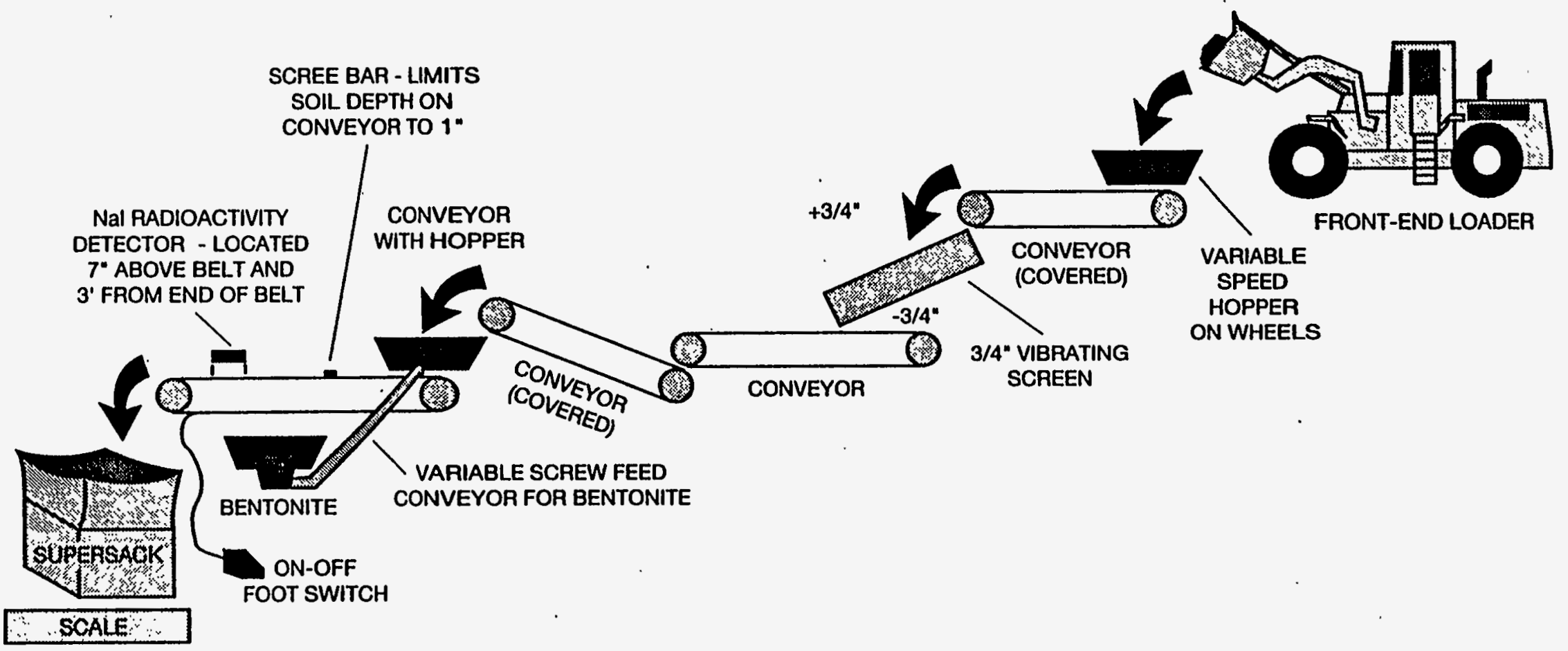


The excavation phase will be ongoing concurrent with the NVO-325 audit phase. The material will be stockpiled in anticipation of the go-ahead from the RWAP team to process and bag the soil for transport and disposal. 


\subsection{PRODUCTION BAGGING}

The equipment needed to process and bag the excavated soil is identified in the State of Nevada Air Quatity Permit, Appendix E.

A schematic depicting the planned production bagging system is shown in Figures 4-2 and 5-1. Production bagging will be accomplished by laborers in the contaminated area who will prepare and fill supersacks from the aggregate system. The aggregate system will be fed by a front-end loader from the stockpile of excavated soil. Dust control will be accomplished by keeping the stockpiled material moist and moisture will be controlled by metering of bentonite pellets (an absorbent) into the process stream. BN does not anticipate using water sprays on the conveyors or transfer points. The aggregate system will segregate soil particles which are greater than 3/4-inch in diameter. This segregated soil will be stockpiled on site and used to stabilize the excavated area.

A sodium iodide (Nal) detector system will be used to monitor the amount of radioactivity contained in each supersack bag. The detector will be mounted on the conveyor system transpoting soil to the supersack bags and will record the ${ }^{241} \mathrm{Am}$ activity level in each bag as the bag is being filled. The plutonium activity can be calculated based on the americium:plutonium ratio which was measured during site characterization. The $\mathrm{Nal}$ detector system is described in more detail in Appendix F.

Once a supersack has been filled, a $21 / 2$-ton forklift will remove it from the platform scale and move it to a holding area where a waste control person will document the package, close and band the supersack to a pallet, and swipe the outside of the sack to determine if there is any external contamination. If the sack is deemed acceptable, the forklift will load it into a Sealand ${ }^{\oplus}$ container or place it in a holding area to await loading into a Sealand ${ }^{\circledR}$ container. If it is deemed unacceptable, it will be set aside for reprocessing.

The Sealand ${ }^{\oplus}$ containers will be placed in the exclusion zone as depicted in the site layout drawings, and loaded at ground level with the forklift. The loaded Sealand ${ }^{\circledast}$ containers will be sealed and then lifted and loaded onto the highway trucks with a 25-ton forklift. A 3-ton forklift will remain in the clean area to service the camp, as required.

The location of the processing equipment, the decontamination pad, control trailer, office trailer, Health Physics Department (HPD) trailer, counting van, and other associated equipment are depicted on Figure 5-2.

Approximately $1,620 \mathrm{yd}^{3}$ of soil will be excavated. It is estimated that the volume will be reduced 25 percent by removing material with a diameter greater than 3/4-inch. Some expansion of the soil volume, estimated to be 25 percent, will occur during soil processing and bagging. Approximately $27 \mathrm{yd}^{3}$ bentonite will be added to preclude free liquid from occurring in the bagged soil. Therefore the net volume of soil to be bagged and shipped as waste will still be on the order of 1,620 $\mathrm{yd}^{3}$. 


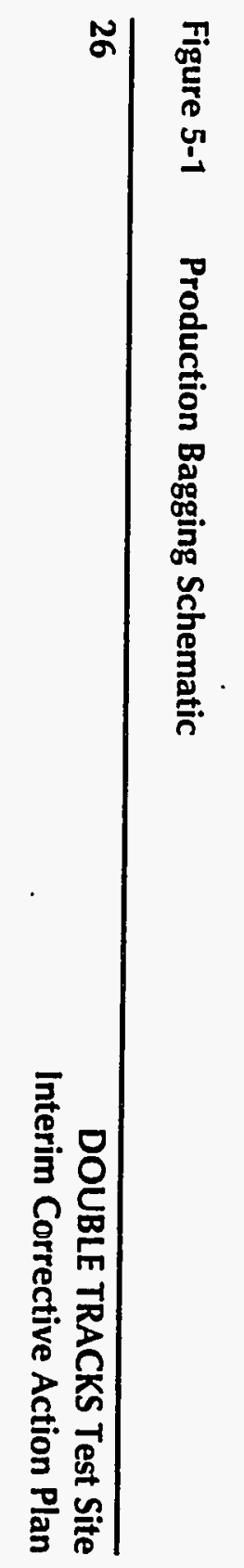

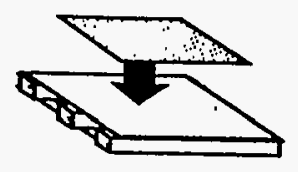

S'TAPLE CARDBOARE

TO PALLET

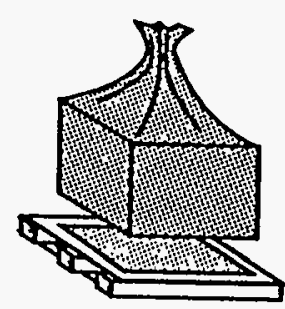

PLACE SUPER-SACK

ON PALLET

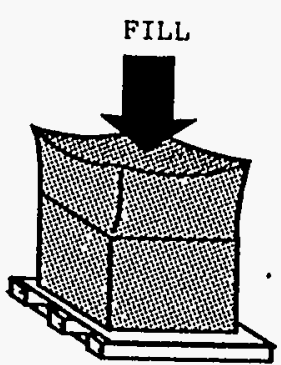

FILL SUPER-SACK

ADD SORBANT

AS APPROPRIATE AND WEIGH
ID RAD

SWIPE \& HOLD

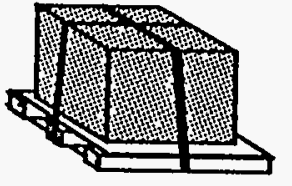

CLOSE

AIND BAND

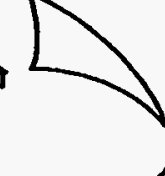

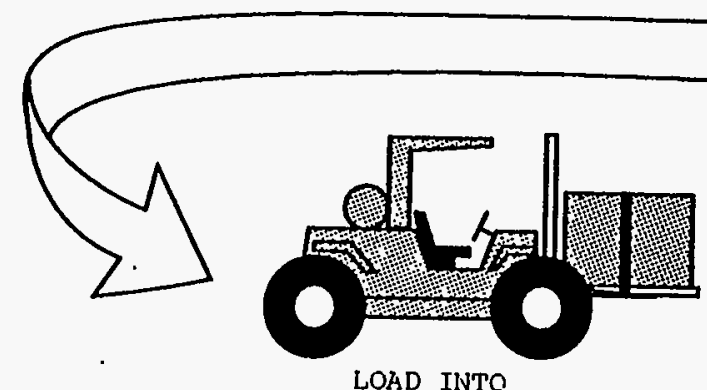

SEALAND CONTAINER
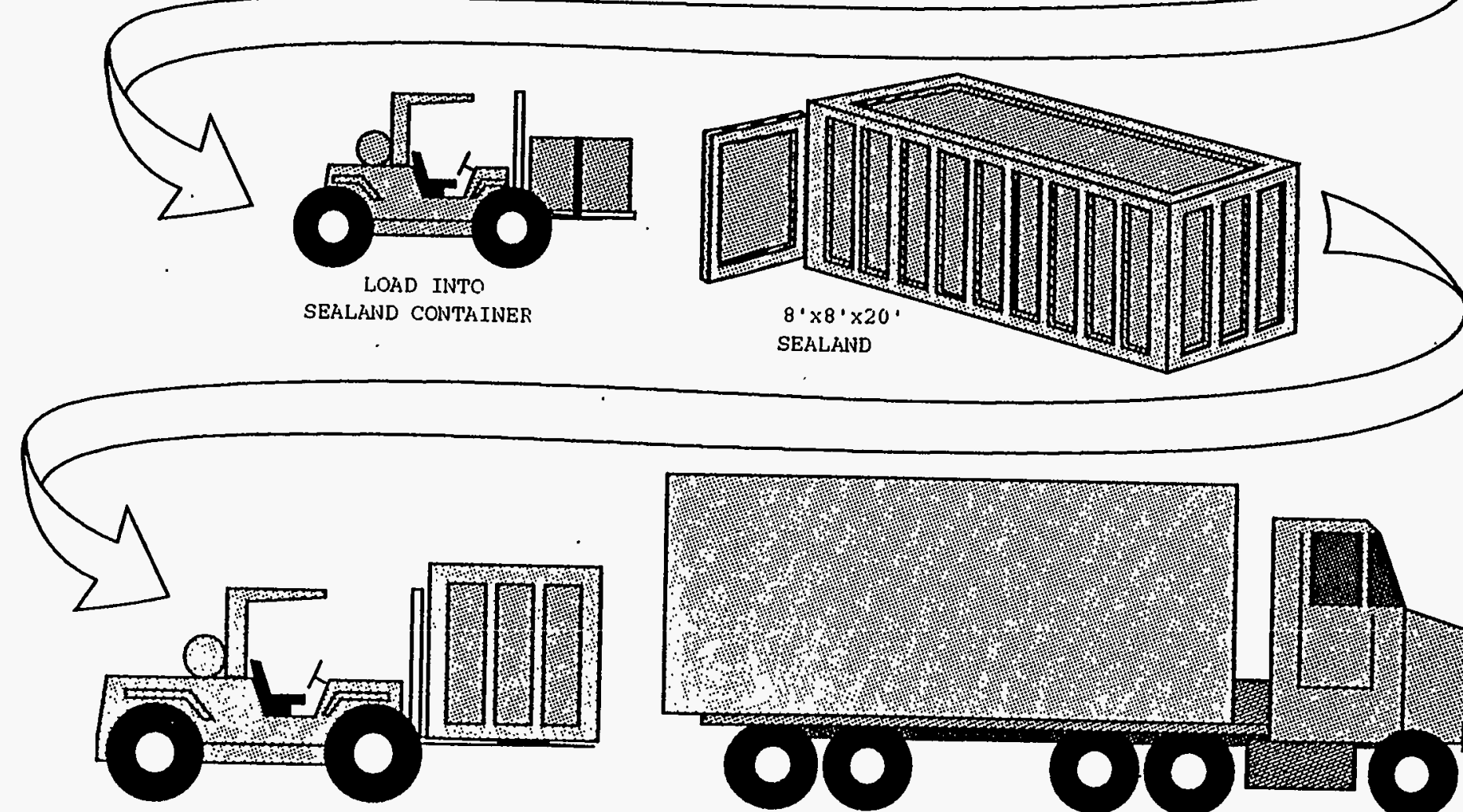

25 TUIN FURKLIFT

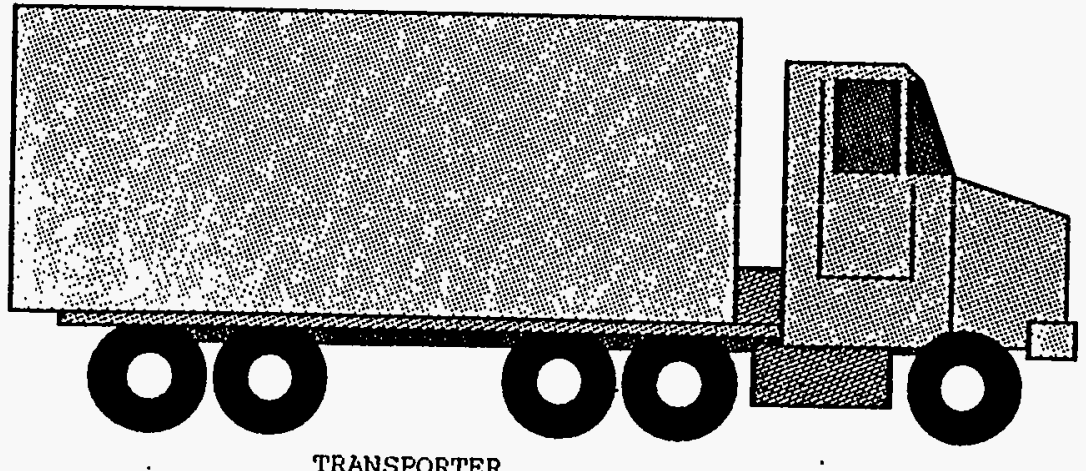

TRANSPORTER 


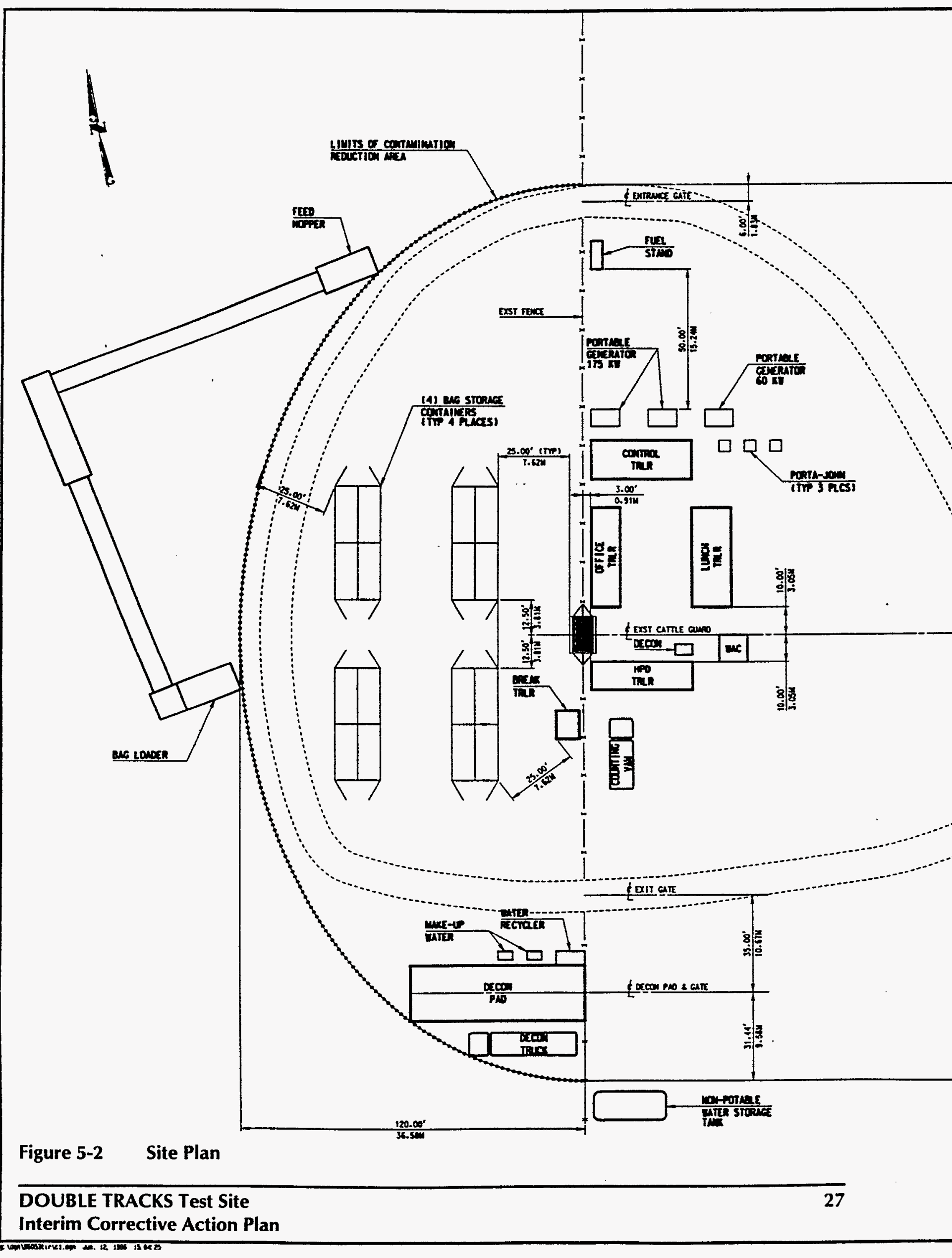




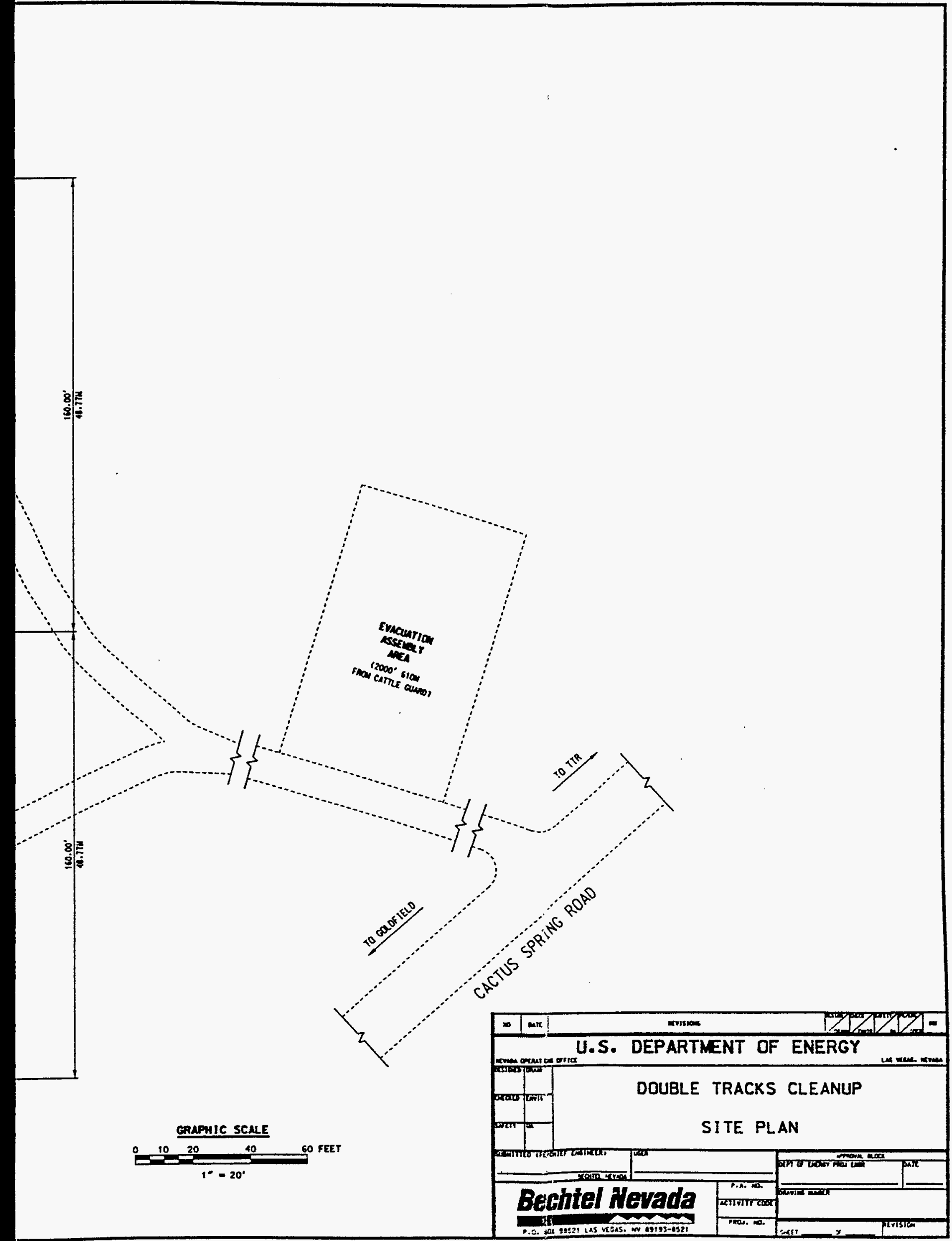




\subsection{TRANSPORTATION}

Transportation will be accomplished by a licenšed radiological waste carrier in accordance with U.S. Department of Transportation regulations. The route from the DOUBLE TRACKS site will be via 17 miles of dirt road to the Main Road of the TTR; then 5 miles on Main Road to a hold point at a support facility in the Sandia compound. At the Sandia Compound, information on the shipment will be loaded into the Haztrack system and the carrier will conduct a safety inspection of the tractor/trailer rig. A proposed checklist, to be used by the carrier as a guide only, is included in Appendix D.

The carrier will then proceed north to Highway 6, west to Highway 95, and south to the Mercury entrance of the NTS as shown on the suggested transportation route (Figure 6-1). The carrier will enter the NTS via the Mercury gate and, once cleared to proceed, will continue north to the Area 3 RWMS, approximately 35 miles from the entry point.

The loads will consist of 8 - by 8 - by 20 -foot Sealand ${ }^{\circledR}$ cargo containers containing radioactively contaminated soil, further contained in woven polypropylene (supersack) bags. Ten supersacks will be loaded in each Sealand ${ }^{\circledR}$ container. The soil will be classified as "lowspecific activity" radiological waste. Two containers will contain bulk material such as broken concrete. The contents of the Sealand ${ }^{\circledR}$ containers will be off-loaded by NTS personnel.

In the event of a spill, the carrier is ultimately responsible for cleanup. However, if requested to assist either by an official from the carrier or by an appropriate emergency management person, $\mathrm{BN}$ personnel will respond (on a cost-reimbursable basis) to assist with preliminary cleanup in accordance with the Emergency Response Procedure included in Appendix A.

The carrier will return to the project site with the empty containers where they will be removed and. replaced with full containers by BN personnel. The carrier is responsible for securing the loads. Appropriate paperwork including completed shipping papers and placarding will be provided by $\mathrm{BN}$.

This sequence will continue until all processed material is removed. Once BN determines the Sealand ${ }^{\circledR}$ containers are being used for their final trip, the transporter will take them (after they are off-loaded at the Area 3 RWMS) to the Area 6 Decontamination Facility where BN will remove them for storage.

In addition, the carrier will transport two Sealand ${ }^{\circledR}$ containers of bulk low-level radioactively contaminated material (primarily broken concrete) to the Area 6 Decontamination Facility. The route will be the same as above, with the exception of the final destination.

The Transportation Plan and the BN Transportation Request for Proposal are included in Appendix D. 


\section{This Page Intentionally Left Blank}




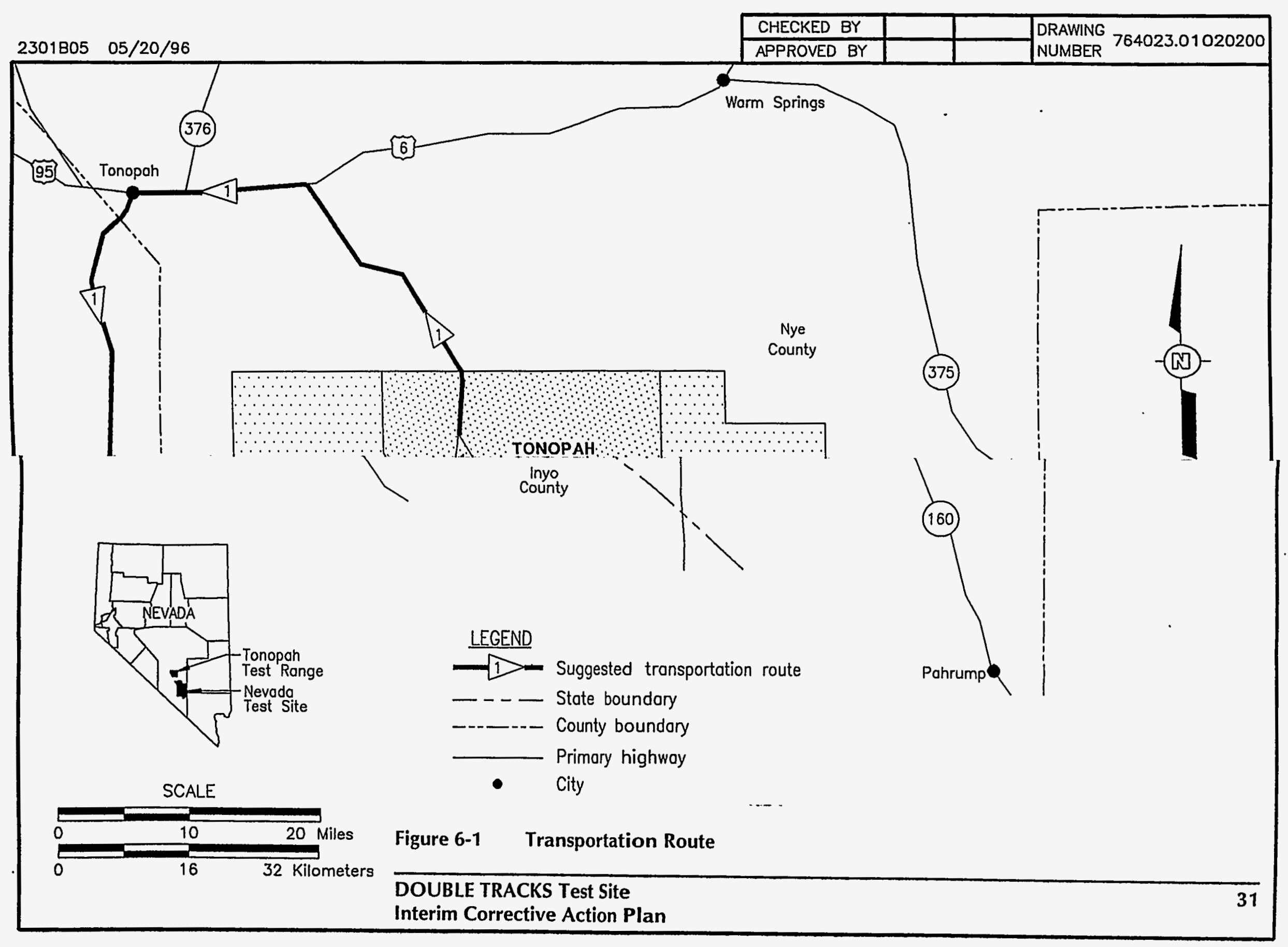




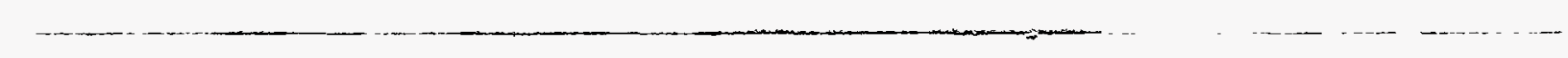




\subsection{CONTAINMENT SYSTEMS}

The main concern during excavation and production bagging is the possible resuspension of airborne particulates. The ground surface will be wetted during excavation to control dust. Once the material is stockpiled, the stockpile will be wetted regularly to control dust.

Once excavation is complete, short-term soil stabilization will be accomplished via soil stabilizing agents. Long-term stabilization will be via revegetation in accordance with a reclamation plan currently under development. 
This Page Intentionally Left Blank 


\subsection{WASTE DISPOSAL}

The excavated, processed soil will be removed from the DOUBLE TRACKS site and transported to the NTS Area 3 RWMS for disposal as low-level radioactive waste in accordance with the NVO-325 waste acceptance criteria. Approximately two Sealand ${ }^{\circledR}$ containers of bulk material (primarily broken concrete) will be transported to the Area 6 Decontamination Facility for futher characterization prior to disposal. The waste must meet the characterization, packaging, and shipping waste acceptance criteria established in DOE/NV Standard, Nevada Test Site Defense Waste Acceptance Criteria, Certification, and Transfer Requirements (NVO325, Rev. 1). In order to meet the NVO-325 waste acceptance criteria, the soil must be characterized, handled, packaged, shipped, and certified according to the BN Application to Transfer Radioactive Waste at the Nevada Test Site and the BN Waste Certification Program Plan for Radioactive Waste Storage or Disposal.

The methods that will be used to characterize the waste (count the radioactivity level in each bag) are discussed in Section 5.0 and Appendix $F$. The operational stipulations for receiving the bagged waste at Area 3 RWMS are included as Appendix G.

BN Waste Minimization and Control Section will prepare characterization documents (e.g., Material Evaluation Form) to demonstrate that the radioactive contaminated soil meets the waste acceptance criteria of NVO-325 (Rev. 1).

The BN Waste Certification Office personnel will review the waste characterization documentation and observe all handling, packaging, and shipping activities in order to certify waste packages (i.e., soil in supersacks) and shipments.

Prior to full-scale processing, the DOE/NV Waste Management RWAP will perform an on-site surveillance of all contaminated soil handling, surveying, packaging, shipping, and certification activities. Any adverse findings resulting from the RWAP surveillance must be resolved to the satisfaction of DOE/NV prior to the commencement of full-scale operations.

\section{Hydrocarbon Spills}

The excavation equipment and the electrical generators will be fueled on site with diesel; therefore, there is the potential for accidental hydrocarbon spills. Accidental spills of petroleum hydrocarbons will be handled according to Bechtel Procedure No. 4.2.9, "Response to Spills of Known Substances." Hydrocarbon-stained soil will be cleaned up so that no visible stain remains. The stained soil will be placed in plastic-lined 55-gallon drums for shipment to the NTS Area 6 decontamination pad to await future disposal. 
This Page Intentionally Left Blank 


\subsection{CERTIFICATION OF CLOSURE}

The closure of this site will be predicated on the state of Nevada approving a corrective action decision document recommending a "no further action" or completion of a required corrective action. The DOE-proposed level of $200 \mathrm{pCi} / \mathrm{g}$ for this interim remedial action is in anticipation of a level that will be acceptable for closure.

\subsection{Postexcavation Radiological Surveys}

Postexcavation radiological surveys will be accomplished in accordance with the Remote Sensing Lab Radiological Verification Plan included as Appendix $\mathrm{H}$. During excavation, packaging, and transportation operations, all excavated soil less than 3/4-inch in diameter will have been removed from the site. BN will conduct both periodic and final radiological surveys inside the fenced boundary of the site to assess levels of activity still remaining. If BN discovers areas of total transuranic activity greater than $200 \mathrm{pCi} / \mathrm{g}$, additional soil excavation in the noncompliant areas will be conducted. The data from these surveys will also be used to evaluate the efficiency of the two excavation methods. After confirmation by the final survey, the equipment and crews will be released.

\subsection{Postexcavation Documentation}

BN will write a formal report describing the final radiological survey results. The customer review version of this report should be available within four (4) months after the field work is complete. The final version of the report will be ready one to two months after the customer review is complete. As with the DOUBLE TRACKS Site Characterization Report (written by IT Corporation), the final radiological data report will be included as an Appendix in the DOUBLE TRACKS Site Closure Report. A description of the other measurements (e.g., conveyor belt monitoring) will also be included in this report.

\subsection{Decontamination}

All equipment which is involved with the handling and processing of the contaminated soil will be radiologically surveyed, decontaminated, and cleared. If there is surface contamination on the equipment, it will be cleaned with water using a mobile decontamination truck. Decontamination water will be collected and processed through a water recycler.

Any equipment that cannot be cleaned to uncontrolled release limits will be cleaned to the point where it can be safely transported back to the NTS Decontamination Pad in Area 6, where a more thorough decontamination will be conducted.

\subsection{Demobilization}

Once the project is complete and the area has be declared radiologically acceptable, the equipment and remaining supplies will be returned to the NTS in approximately the same 
order they arrived on site. If there is a possibility that some of the equipment will be targeted for the CLEAN SLATE remediation projects, negotiations will ensue to store the equipment at the Sandia compound. 


\subsection{PUBLIC PARTICIPATION}

A briefing was given to the Nevada Test Site Community Advisory Board on June 7, 1995. The briefing presented information on the DOUBLE TRACKS remediation plan, schedule, and transportation alternatives.

A briefing on the project was presented to the Community Technical Liaison Officers of the rural communities of Tonopah, Beatty, Goldfield, and Amargosa Valley, on July 31, 1995. At this briefing the attendees were asked for input on:

the communities' understanding of the different types of radioactive waste;

the capabilities of the counties' / communities' emergency response personnel; preferences on specific time periods or days of the week for shipments of waste through the communities; and

were there specific citizens or groups that would want more information on the DOUBLE TRACKS project.

Informational briefings to Nye County and Esmeralda County were conducted on February 5 and 6,1996, respectively. Information was presented on the DOUBLE TRACKS project and the National Environmental Policy Act process to follow.

The NTS Hazardous Material First Responder personnel have conducted training for the First Responder personnel of the communities of Goldfield, Beatty, Amargosa Valley, and Tonopah. The training focused on the treatment and handling of low-activity radioactive material should a spill occur during transport of the waste material from DOUBLE TRACKS to NTS. 
This Page Intentionally Left Blank 


\subsection{REFERENCES}

Church, H. W., Sandia National Laboratories, 1969. Cloud Rise from High-Explosives Detonations, SC-RR-68-903. Albuquerque, NM.

Meneder, H. E., J. C. Armstrong, E. J. Forslow, and B. H. Sorensen, Hazelton-Nuclear Science Corporation, 1966. Operation Roller Coaster, Project Officers Report - Project 5.2/5.3s, Radiochemical Analysis of Biological and Physical Samples, POR-2515. Palo Alto, CA.

Shreve, J. D. , Jr. Sandia Corporation, 1965. Operation Roller Coaster, Scientific Director's Summary Report, DASA-1644. Albuquerque, NM.

U.S. Department of Energy, 1996a. Draft Double Tracks Test Site Environmental Assessment, Environmental Restoration Division. October.

U.S. Department of Energy, 1996. Double Tracks Test Site Characterization Report, Environmental Restoration Division. May.

Bechtel Nevada Procedure No. 4.2.9, "Response to Spills of Known Substances."

Bechtel Nevada Procedure No. B-A20/9601, "Performance Assurance Management Program." 


Proposed Dates of Project: $\quad$ Beginning Date: $\quad$ May 11996

\begin{tabular}{|c|c|c|c|c|}
\hline Name: & Monica Sanchez & Organization: & DOE/ER & Date: $\& / 2$ \\
\hline Name: & Larry Skousen & Organization: & DOE/S\&H & Date: $6 / 28 / 96$ \\
\hline Name: & & Organization: & & Date: \\
\hline Name: & & Organization: & & Date: \\
\hline
\end{tabular}

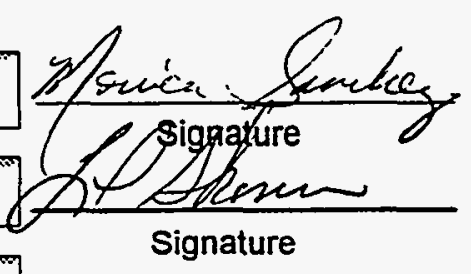

Signature Date $\frac{6-6-96}{\text { Date }}$

I have read and approve this Site Specific Health and Safety Plan (HASP) with respect to hazards present, relevant regulations, DOE and OSHA requirements, and site procedures,

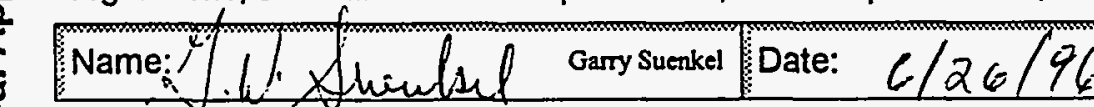

\section{Lead Organization Health and Safety}

$\stackrel{1}{\leftarrow}$

\section{Representative}

Production Date and Time:

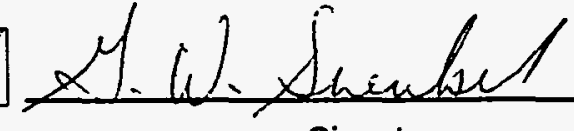

Signature 


\section{Declaration of uriderstanding}

Site Specific Health and Safety Plan Acknowtedgement

I have read and understand this Health and Safety Plan (HASP), and agree to abide by the procedures and limitations specified here and in the Nevada ERP Health and Safety Plan. Personnel unable to read this document must have their supervisor explain the contents of this document prior to working on this site. Individuals who have questions on information found in this HASP should discuss their questions with their Supervisor for clarification.

\begin{tabular}{|c|c|c|c|c|}
\hline Name & Signature & Employer & Employee Number & \\
\hline & & & & \\
\hline & & & & \\
\hline & & & & \\
\hline & & & & \\
\hline & & & & \\
\hline & & & & \\
\hline & & & & \\
\hline & & & & \\
\hline & & & & \\
\hline & & & & \\
\hline & & & & \\
\hline & & & & \\
\hline & & & & \\
\hline & & & & \\
\hline & & & & \\
\hline & & & & \\
\hline
\end{tabular}

\section{NOTES:}

1. All personnel signing above must appear in Section G. Personnel Catagorization.

2. All sub-contractors must abide by the specifications and limitations specified in this HASP

3. All personnel working on this sile must sign this form.

4. This HASP is to be used in conjunction with the Nevada ERP Health and Safety Plan and Tailgate Safety Briefing Form.

เ 
APPENDIX A

\section{HEALTH AND SAFETY PLAN}




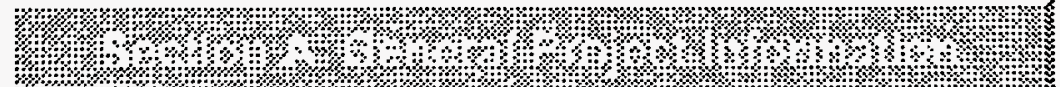

at the Area-3 RWMS. Specific activities include:

1. Establish a base camp outside the exclusion area.

2. Upgrade the roads to the site for heavy equipment and truck trafic.

3. Operate heavy equipment within the EZ to excavate, package and transport soil.

4. Decontaminate vehicles and equipment for release from the site.

5. Conduct a radiological safely operation which includes instrument surveys, air sampling, Anti-contamination clothing, respiratory protection and bioassay sampling

6. Conduct mobile and in-situ radiological surveys to release the site

7. Stabilize and revegetate the disturbed area.

Project Background Review:

Complete $\bigcirc$ Not Available $\bigcirc$ Preliminary $\bigcirc$ Further study required $O$

29 CFR 1910.120 Regulated Site:

\begin{tabular}{lllllll}
\hline Yes & 0 & No & $O$
\end{tabular}

\section{Project HASP Summary}

Leveis of Protection:

\begin{tabular}{|l|l|l|l|l|l|l|}
\hline$A$ & $B$ & $C$ & $D$ & Anti-C O & Mixed O & Modified $O$ \\
\hline
\end{tabular}

\section{Overall Hazard Estimate:}

High OModerate $\mathrm{O}$ Low 0 Unknown 0

Additional Documentation Attached (describe): Radiological Work Permits -

Hlazard Identification and Mitigation Tables

Lists of procedures - Bechtel Nevada Corp. 


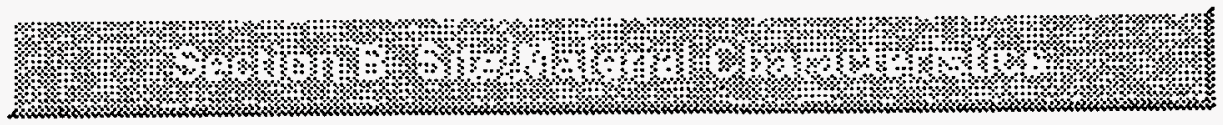

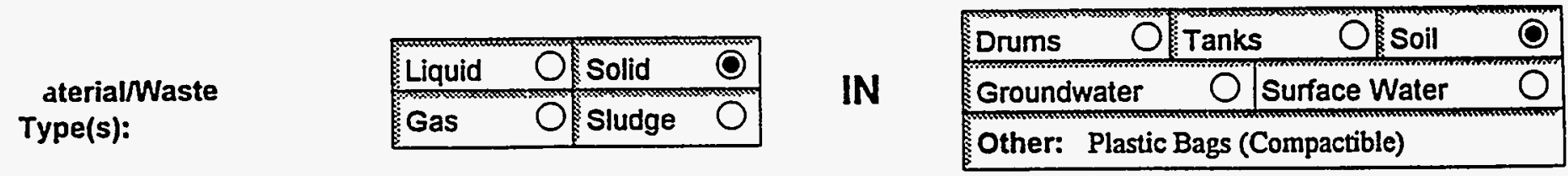

Characteristics:

Ignitable $O$ Toxic $O$ Corrosive $O$ Reactive $O$ Radioactive $O$

Note:

1

Facility:

Type: Plutonium Dispersion Experiment

Open $O$ Closed $O$ Closed when? January/1964

Is this site indoors?

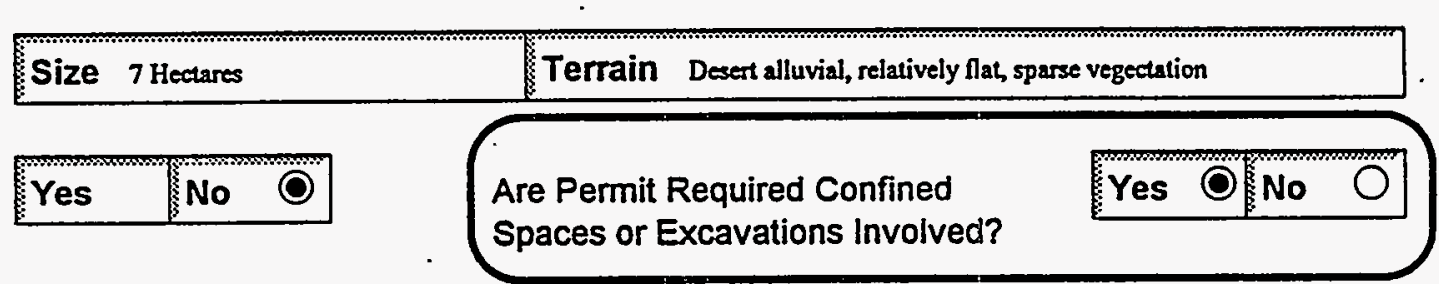

Describe any confined spaces which will be entered, or excavation/trenching activity: The mound at $G Z$ will be excavated ising a front end loader to remove the concrete pad used during the original experiment. The excavation should be to the grade of the remainder of the site. If a burial rench is found, the excavation will continue with heavy equipment. A surfance disturbance permit will be completed and approved before operations begin. The trench fo will be excavaled such that it does not meet the requirements for a confined space entry permit.

Investigation derived waste handling: Investigation -Derived Waste (IDW) will not be generated. Remediation waste will consist of typical hotline material including plastic gloves, disposable coveralls, plastic bags, used respirator cartridges and masking tape. Additional wipes, foil and soil sampling tools may also be included from verification activiles. The compactible waste will be bagged, sealed and tagged by the RCTs according to NVO-325 procedures. The bags will be accumulated in a Waste Accumulation Container (WAC) before transport to the NTS. All personnel must have approval from a RCT before depositing any material in a hotline bag.

Iligh-activity fragments and soil will be collected and containerized during excavation and packaging activities. The material will be placed in 55 -gallon drums for interim storage within the EZ. The drums will be locked, labelled and numbered. These drums will eventually be transported to the NTS and stored at the Area-5 RWMS TRU Pad.

Site History: Double Tracks was part of Operation Roller Coaster. This Operation was conducted to provide data to establish criteria for transportation and storage of plutonium bearing weapons. The Double Tracks event was conducted in 1963 and involved the detonation of high explosive in a depleted uranium and plutonium bearing device. Ground deposition and airborne sampling arrays were employed to obtain data on the aerosol/particulate cloud and to deternine surface deposition phenomena. Three hundred dogs, sheep and burros were used during Double Tracks to study the lung retention of the plutonium aerosol.

The ground zero area consisted of a concrete pad 1 foot thick which measured 20' X 20'. The surface soil was stabilized with an oil-based emulsion "Golden Bear" to a radius of 50 feet. The debris in the vicinity of the ground zero mound was collected and buried near ground zeto. The contaminated surface of the compacted areas around the ground zero was scraped to a depth of several inches. The spoil was placed in the debris hole or mounded, covered with dirt, compacted and watered. It is possible that the ground zero area may have been disturbed by such activities to a radius of 125 yards.

Iellis Airforee Subrange 71 is located in Stonewall Flat west of TTR. Subrange 71 is currently used to cvaluate weapons systcms, train air crews and for radar bombing raining. The nearest town is Goldfield, Nevada, located approximately 14 miles wert of the Double Tracks site. 


\section{Evaluation of the principal hazards for each site or activity identified in the work plan.}

\section{Chemical Substances: None found at site.}

Those used for the project include: Liquid nitrogen for the high purity Germanium detectors. P-10 gas for the Protean low-background radiological counter.

Physical Agents: Heat stress : Potential is increased due to a combination of summertime high temperatures, potential high humidities, protective clothing and . respirators. Prevention measures include fluid replacement, frequent breaks and a prescribed work-rest regimen.

Sunbum: It is highly recommended that personnel bring clothing which can be easily layered for cool mornings, hot afternoons and wind protection. The site elevation is about 5,000 feet and the sun can cause sunbum faster than normal. Sunscreen with at least a 15 protection factor is recommended.

Slip and Trip: Some of the heavy equipment will have ladders for access to the cab or to a raised platform. All heavy equipment which is decontaminated for final release will have wet surfaces and ladders.

Electrical energy: Portable generators will be used for the base camp trailers and Supersack loading system.

Collisions: Heavy equipment operators may be wearing respirators for some work. This will limit their vision, especially peripheral, and requires other ptrsonnel in smaller vehicles and on the ground to yield the right-of-way.

Explosions: Buried ordnance may be encountered during excavation. All activities will be halted and personnel evacuated from the exclusion zone to a minimum distance of 2000 feet from the item until a certified ordnance specialist has examined and removed the object.

"adiological: 1. Double Tracks is known to be contaminaled with plutonium, americium and depleted uranium. The primary mode of exposure to personnel is Ilatior. Respirarory protection will be required for those areas with soil concentrations exceeding 1,000 pieocuries per gram. This will include all the area around the Ground :o insice the inner fence posts. No respirators will be required for the remainder of the remediation area unless personal air sample results or dust loading measuremnts exceed action levels. The ALARA goal for total planned inhalation exposure will be $100 \mathrm{mrem}$ per individual and 1,000 mrem collective dose. Inhalation doses will be estimated and recorded daily from air sample results. Other work locations within the exclusion zone will be evaluated for respiratory protection requirements as equipment is positioned and operated.

2. Skin and clothing contamination do not represent a hazard to personnel since the radionuclides are alpha emitters. The alpha particles will be attenuated by the dead skin layer or clothing. The ALARA goal for the operation is for no reportable skin or clothing contaminations. High activity metal fragments were detected and collected during the characterization of the site. They represent the highest potential for contamination, ingestion and inhalation exposures to personnel. Personnel will use handling tools to pick up fragments and place them in containers as soon as possible.

3. All personnel are required to wear their NTS TLDs when inside the exciusion zone. The TLDs are capable of measuring doses from the low-energy gamma and X-rays from the Americium and Plutonium although no reportable doses are expected based on previous TLD results after ctaracterization studies.

Biological: Poisionous snakes - Ratllesnakes

Poisionous spiders - Black widows

Rodents - Hantavirus has been detected in deer mice populations in this area. All facilities have been inspected for rodents and nests before transport to the Double Tracks sile. Because of the excavation activities, some rodents may seek sheiler in trailers, vehicles or equipment. Inform the site supervisor or superintendant if a rodent or nest is found. Only trained personnel may capture animals and clean the affected area.

Wild Horses - A number of horses utilize Cactus Springs Ranch as a water source. They may be a travel hazard, especially in the moming and evening hours. They may possibly be attracted to water sources and revegetation plots near the work site.

Environmental: Temperature - Temperatures should range from $50-95$ degrees $F$. Extremes could be a low of 40 and a high of 100 . The work schedule is designed to take advantage of the cool mornings. As the day progresses, more frequent and longer work breaks will be required for both respirator users and those in Anti-Cs only. Respirator usage will be limited when temperatures exceed 90 degrees $F$.

Ilumidity - In combination with higher temperatures, higher humidity will require workers to take longer and more frequent breaks. Fluid replacement will be stressed.

Wind. The prevailing winds ( $>50 \%$ ) are generally from a N-WNW or SSW-SE direction. Dust stoms are common in the spring and dust devils are common in the summer. it devils will not halt operations but high, sustained winds from a cold front or thunderstorm will cause a shutdown. Dust measurements taken during windy days will mine the work schedule and activities.

Thunderstorms - Summer storms are probable. All personncl will evacuate the EZ and wait out the storm inside the support trailers or vehicles. 


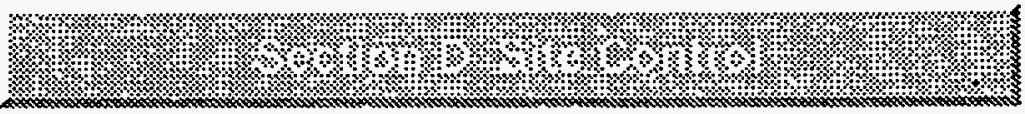

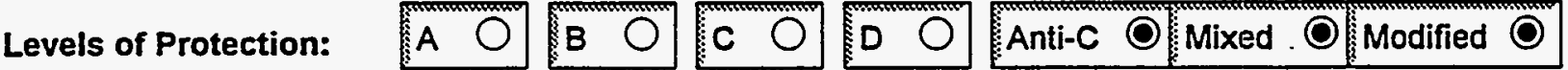

NOTE: Minimum Level $D$ equipment is hardhat, safety-toe boots, safety glasses, and. substantial work clothing. All hardhats, glasses, and boots must be ANSI-approved.

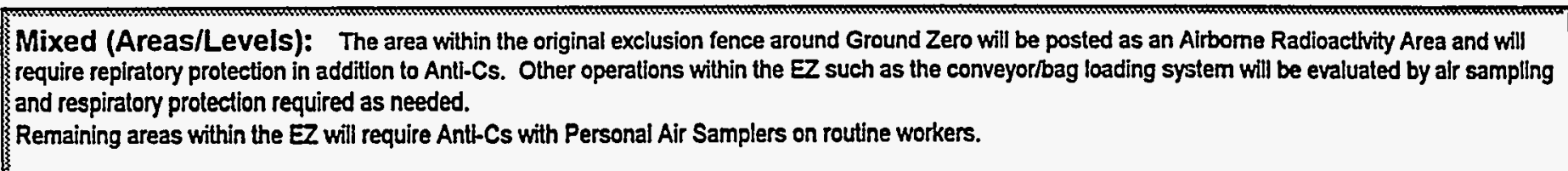

Modified (Give modifications): All personnel will wear two pair of gloves. Different combinations will be allowed to fit the task being performed by the worker.

The Anti-C coveralls will be considered equivalent to work clothing, such that workers entering the EZ routinely may wear shorts and T-shirts or company provided hospital smocks underneath their coveralls for comfort.

Additional personal protective equipment information: Respirators for radiological protection include a full-face resplrator with a Powered Air Purifying Respirator (PAPR) unit with HEPA fitters or a HEPA filter canister/ full-face respirator combination.

Repirators for fugitve dust prolection may be a, half-mask with cotton dust filters.

NOTE: Half-mask respirators will NOT be worn for radiological protection purposes and their protection factors will not be used for calculating estimated doses from air sample results:

\section{Surveillance Equipment:}

\begin{tabular}{|c|c|c|}
\hline TLD & PID & Lamp Energy \\
\hline FID & Radiation & Electra, MicroRem meter, FIDLER \\
\hline Oxygen & Detector Tubes & Tube Type: \\
\hline Explosimeter $\quad O$ & Toxic Gas & Gas(ses): \\
\hline O & Particulates & OtherPersonal Air Samplers, Satellite Air Sampler, WBGT monitor \\
\hline
\end{tabular}

Surveillance Notes: Personal Air Samplers (Gilian GilAir 5 Pump s or ALPHA-1 air sample pumps) will be lssued to most personnel entering the Exclusion Zone. This will be the primary survellance instrument for estimating inhalation doses in the work environment. The pumps will run all shift with the filters collected at the end of the day and counted during off-hours. The results will evaluated by the site Health \& Safety coordinator to change protection levels in the work area to keep inhalation doses ALARA.

The Satellite air sampler will be stationed at the EZ fence within the trailer park and will run thru the shift. The filter will be counted to assess any potential doses to support personnel from fugitive dust generated within the EZ. 


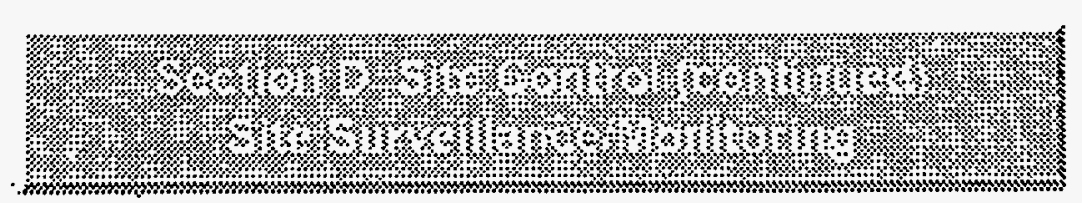

\begin{tabular}{|c|c|c|c|}
\hline Instrument & Surveillance Frequency & Monitoring Location & Calibration \\
\hline
\end{tabular}

\begin{tabular}{|c|c|c|c|c|}
\hline \multirow{5}{*}{$\begin{array}{l}\text { NE Tech. Electra alpha/beta } \\
\text { surveys }\end{array}$} & Every & minutes & $\begin{array}{l}\text { Other: Work area equipment, break } \\
\text { area water container and benches, whole } \\
\text { body frisks, equipment and truck releases }\end{array}$ & Manufacturer specs \\
\hline & \multirow{2}{*}{\multicolumn{2}{|c|}{$\begin{array}{l}\text { Hourly } \\
\text { Daily at shift start }\end{array}$}} & \multirow{4}{*}{$\begin{array}{l}\text { Other: Work area equipment break } \\
\text { area water container and benches, whole } \\
\text { body frisks, equipment and truck releases }\end{array}$} & Per SOP \#: $\quad 6209-005 . A$ \\
\hline & & & & Start of Shift \\
\hline & \multicolumn{2}{|l|}{ Daily at shift end } & & End of shift check \\
\hline & Other: & Twice per shin & & Source Check \\
\hline \multirow{5}{*}{ FIDLER/ESP-2 } & Every & minutes & Breathing Zone & Manufacturer specs \\
\hline & Hourly & & \multirow{4}{*}{$\begin{array}{l}\text { Other: Fragment and hot spot location } \\
\text { and removal. }\end{array}$} & Per SOP \#: \\
\hline & Daily at shift start & & & Start of Shift \\
\hline & Daily at shift end & & & End of shift check \\
\hline & Other: & As needed & & Source Check \\
\hline \multirow{5}{*}{ Bicron Micro Rem meter } & Every & minutes & Breathing Zone & Manufacturer specs \\
\hline & Hourly & & \multirow{4}{*}{$\begin{array}{l}\text { Other: Dose rate (low-energy, }<100 \\
\text { keV) measuremenls from fragments and } \\
\text { high 2etivity areas. }\end{array}$} & Per SOP \#: \\
\hline & Daily at shift start & & & Start of Shift \\
\hline & Daily at shift end & & & End of shift check \\
\hline & Other: & As needed & & Source Check \\
\hline \multirow{5}{*}{$\begin{array}{l}\text { GilAir } 5 \text { Air Sample Pump, } \\
\text { ALPHA-1 Air Sample } \\
\text { Pump }\end{array}$} & Every & minutes & Breathing Zone & Manufacturer specs \\
\hline & Hourly & & \multirow[t]{4}{*}{ Other: } & Per SOP \#: \\
\hline & Daily at shift start & & & Start of Shift \\
\hline & Daily at shift end & & & End of shift check \\
\hline & Other: & Thru Shin & & Source Check \\
\hline \multirow{5}{*}{ QUEST Sound Level Meter } & Every & minutes & Breathing Zone & Manufacturer specs \\
\hline & Hourly & & \multirow[t]{4}{*}{ Other: Area Monitoring } & Per SOP \#: \\
\hline & Daily at shift start & & & Stant of Shift \\
\hline & Daily at shift end & & & End of shift check \\
\hline & Other: & As needed & & Source Check \\
\hline
\end{tabular}




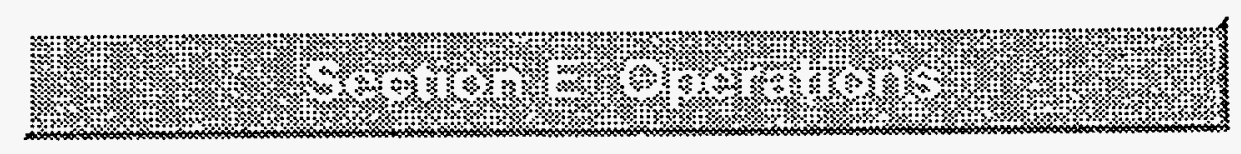

Initial Hotline Location:

At Cattleguard

Initial Command Post Location:

Office Trailer oulside EZ, near catlerguard

Notes: Additional acess and exit gates will be cut into the fence for heavy equipment and waste trucks. Personnel, smail equipment and some vehicles will enter and exit at the catlleguard.

$1 \quad$ Bechtel HPD procedures are attached. 4

Decontamination

1
2

3

W

Heavy Equipment

Decontamination

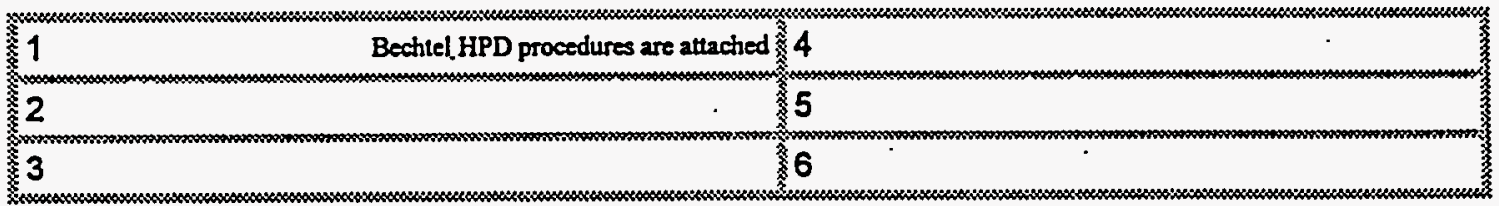

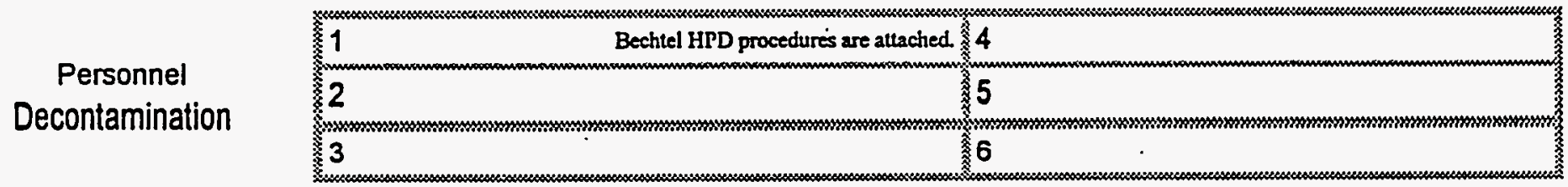

Site Entry Procedure: Task or contractor supervisor confirms worker's training requirements and baseline bioassay

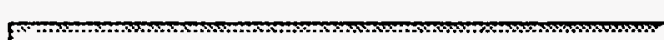

Team Size:

\footnotetext{
Work Schedule: $\quad$ Monday thru Saturday - 10 hour shils. Time -0500 to 1530 hours. 'her Information: Work shift times may change after the Ground Zero excavation is completed and respirators are only reeded for specific lasks. A swing
.may be needed for Supersack filling, radiation counting and palletizing if productions rates cannot keep up with transport requirements.
} 


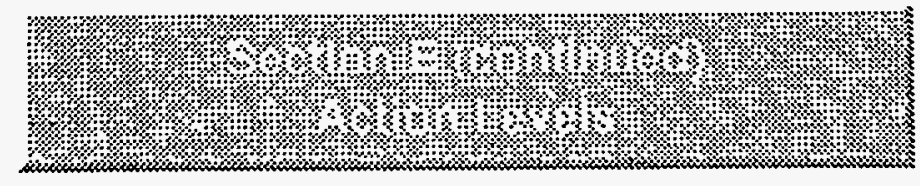

\begin{tabular}{|c|c|c|c|}
\hline Parameter & & Value & Action \\
\hline Personal air sample filter. Counting & Greater than & $8 \mathrm{DPM}$ or 10 mrem & Upgrade to \\
\hline \multirow[t]{4}{*}{ result from previous day activities } & Less than & & Downgrade to \\
\hline & Equal to & & Evacuate to \\
\hline & & & Health \& Safety officer \\
\hline & & & Other action: \\
\hline \multirow[t]{5}{*}{ Personnel frisk at hotline or break area } & Greater than & 500 DPM alpha & Upgrade to \\
\hline & Less than & & Downgrade to \\
\hline & Equal to & & Evacuate to \\
\hline & & & Stop and notify $\quad$ Health \& Safety officer \\
\hline & & & Other action: Decon \& Occurrence Report \\
\hline \multirow[t]{5}{*}{ Dust measurement } & Greater than & .010 grams/ cubic meter & Upgrade to \\
\hline & Less than & & Downgrade to \\
\hline & Equal to & & Evacuate to \\
\hline & & & Stop and notify \\
\hline & & & Other action: \\
\hline Ambient temperature and humidity & Greater than & & Work/rest regimen \\
\hline \multirow[t]{4}{*}{ measurements } & Less than & & Downgrade to \\
\hline & Equal to & Heat stress thresholds & Evacuate to \\
\hline & & & Stop and notify \\
\hline & & & Paramedic monitoring \\
\hline Individual dose estimate from pcrsonal & Greater than & & Upgrade to \\
\hline \multirow[t]{4}{*}{ air sample results (cumulative) } & Less than & & Downgrade to \\
\hline & Equal to & $100 \mathrm{mrem}$ & Evacuate to \\
\hline & & & Site supv. / H\&S officer \\
\hline & & & Worker stays out of $E Z$ \\
\hline Collective cstimated doses for all & Greater than & & Upgrade to \\
\hline \multirow[t]{4}{*}{ workers inside the EZ } & Less than & & Downgrade to \\
\hline & Equal to & $1000 \mathrm{mrem}$ & Evacuate to \\
\hline & & & Site supv. / H\&S oflicer \\
\hline & & & Other action: \\
\hline
\end{tabular}


FIRE:

Fight small fire with fire extinguisher. If the fire cannot be contained, evacuate the site to an upwind location and notify the fire departunent. Note that evacuation routes and assembly areas are to be communicaled during the Tailgate safety briefing.

EXPLOSION: $\quad$ Evacuate site to 2000 feet after an explosion or the discovery of unexploded ordnance. Call emergency services and fire department.

WEATHER: $\quad$ In inciement weather, (i.e. lightning, heavy rain, high wind) cease operations, evacuste site and seek shelter in base cump trailers or vehicles. In heavy rainfall, seek high ground in case of flach flooding. This also applies to travel on the aceess raad to the sile since portions of the road are in a wash.

INJURY:

Render first aid to the injured party and contact energency services as appropriate if injury is severe. Anti-contamination clothing will remain on the victim when its removal may aggravate the injury.

SPIUL:

Follow the manufacturets directions as out-lined in the MSDS. Soils potentially contaminated with hazardous materials will be collected and containerized separately from the low-level waste soils. They will be sampled and analyzed under the requirements for shipment of hazardous waste to str-site facilities. The radiological constituents in the soil cannot exced world-wide fallout levels or the soils will be considered mixed wastes under that program.

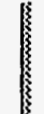

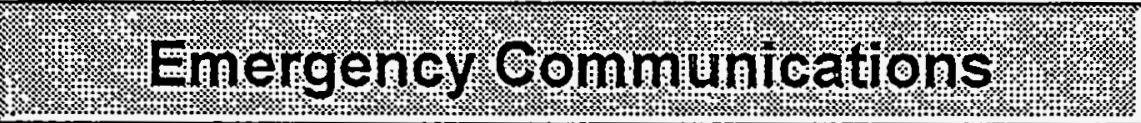

\begin{tabular}{|lr|r|}
\hline Police & 911 or "Mayday" 3X on radio & DOE/ERP H\&S Manager \\
\hline Fire & 911 or "Mayday" 3X on radio & DOE Subproject Manager \\
\hline Medical & 911 or "Mayday" 3X on radio & Other \\
\hline Other & 911 or "Mayday" 3X on radio & Other \\
\hline
\end{tabular}

Other Emergency Information By radio, can either broadeast "Mayday", contact Range Control "Blackjack" or contact Range Security "Cactus".
ASI Security handles all emergencies and can be reached by telephone at 295.8285.

ASI Security handles all emergencies and can be reached by telephone at 295.8285 


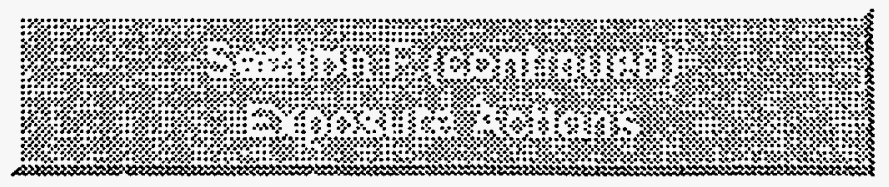

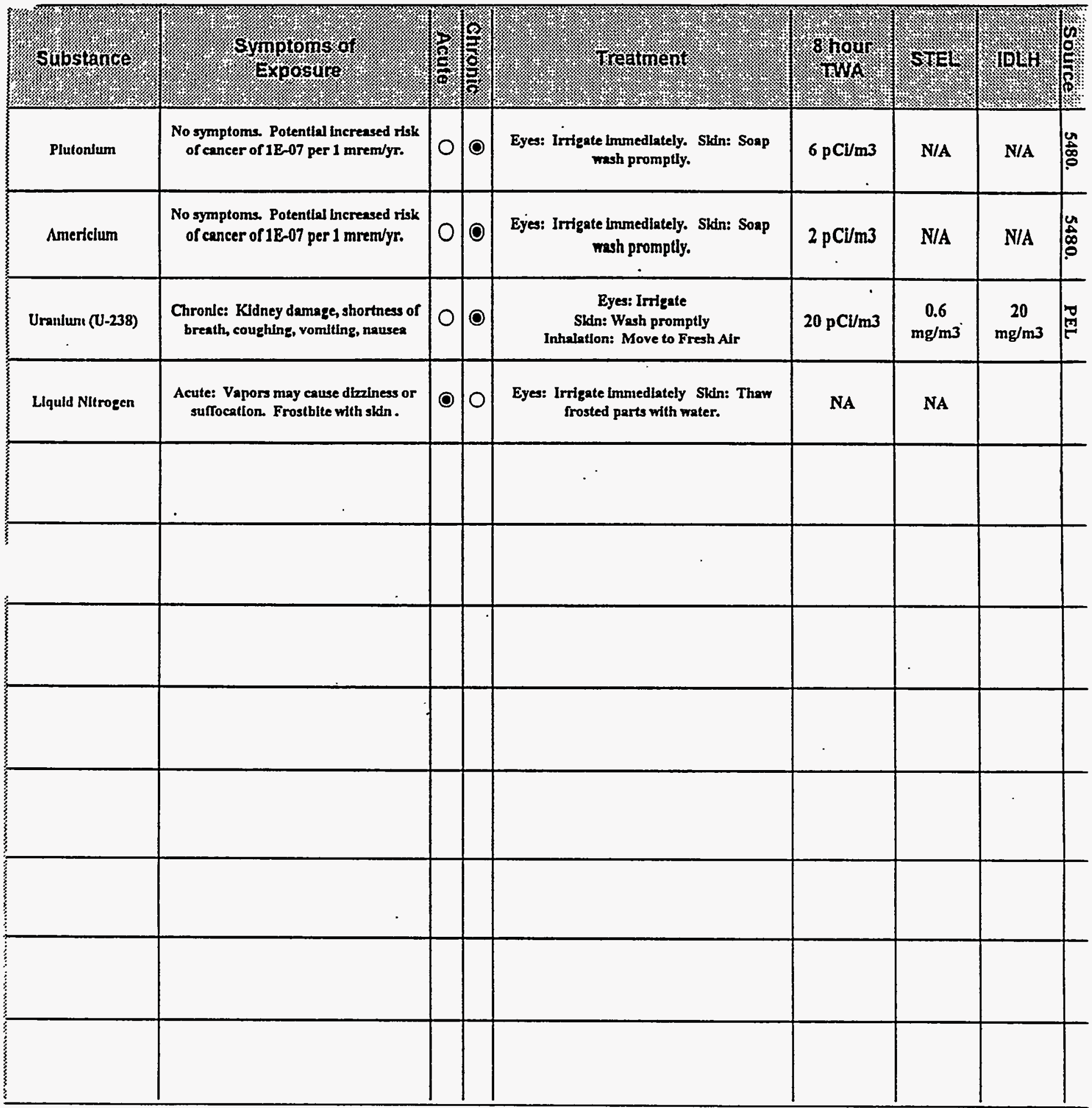

PEL - Permissable Exposure Limit (OSHA)

REL - Recommended Exposure Limit (NIOSH)

- Thireshold Limit Value (ACGIH)

A - Time Weighted Average (over an 8 hour workday) ppm - parts per million

$\mathrm{mg} / \mathrm{m} 3$ - milligrams of contaminant per cubic meter of air 

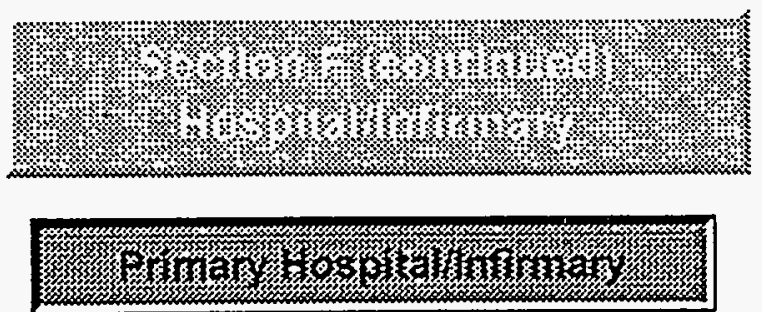

Name

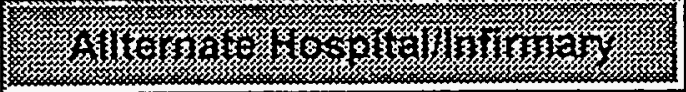

\begin{tabular}{|llll} 
Nye County Regional \\
Medical Center
\end{tabular}

\footnotetext{
Other Emergency Information:

The route from the Double Tracks site is to travel southwest for approximately 2 miles, tum Ic』 at the Cactus Springs road and travel east 15.5 miles to the TTR main road, tum left and travel the Main road north for 5 miles to the Sandia compound or 12 miles north to the TTR main gate.
} 


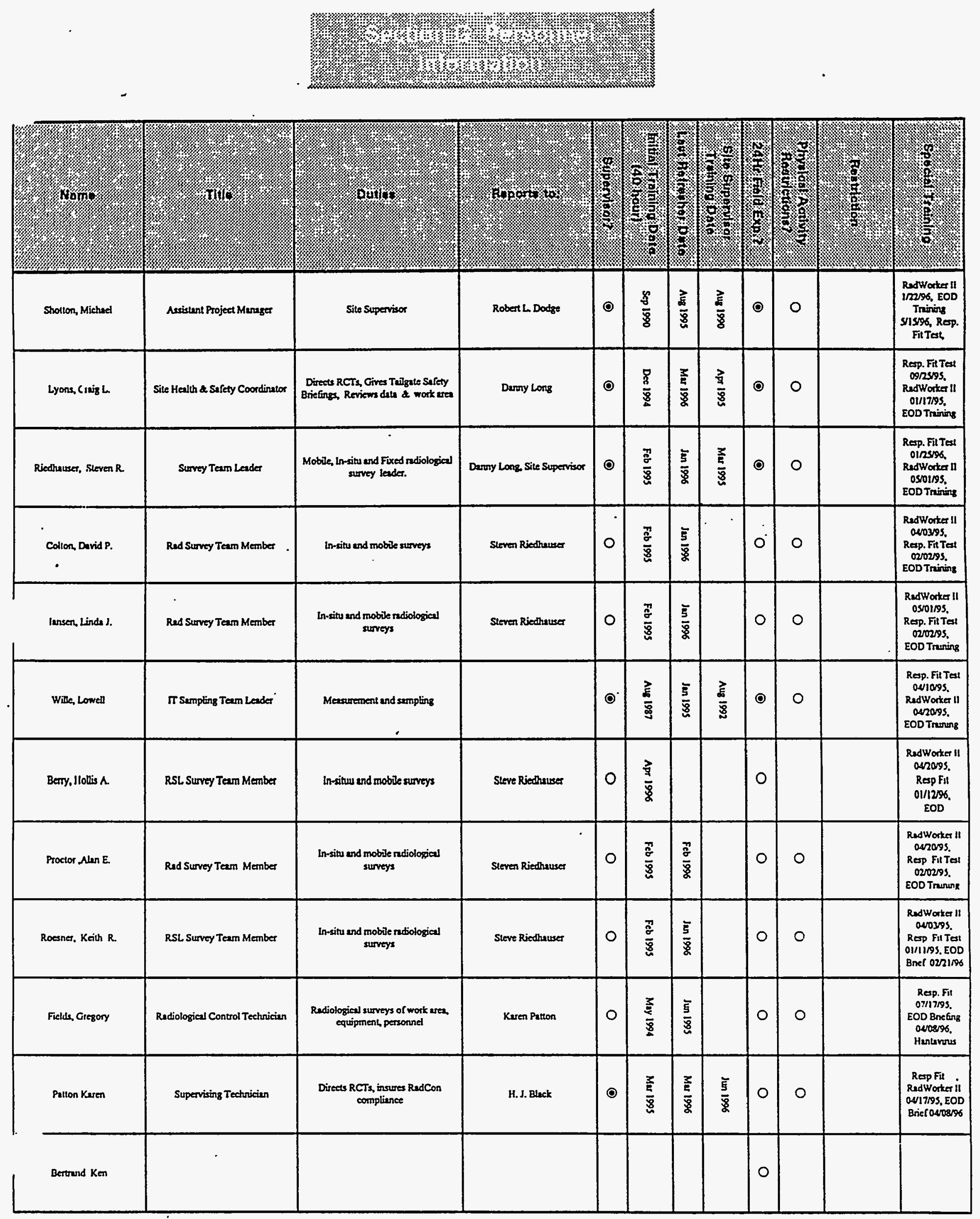



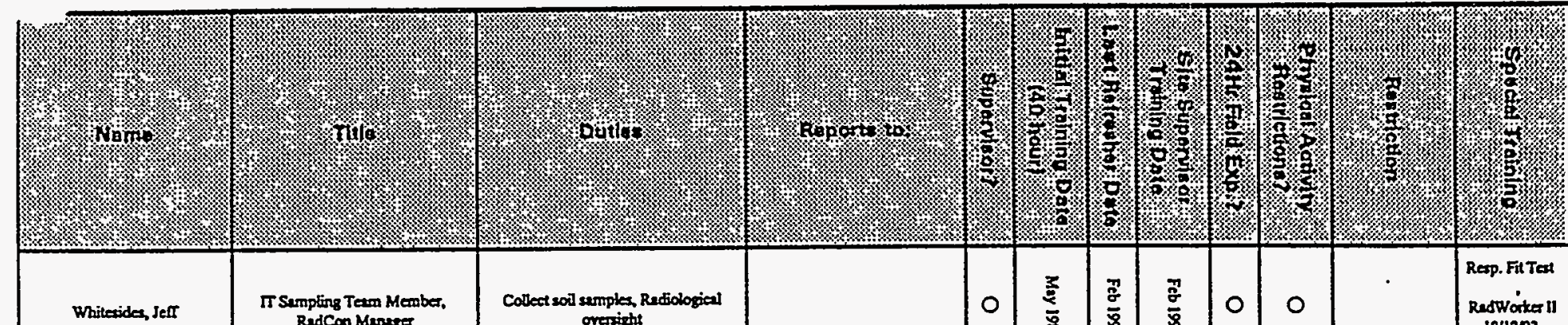

IT Sumpling Tean Member.

Cotect sol samples, Rediologial oreright

0

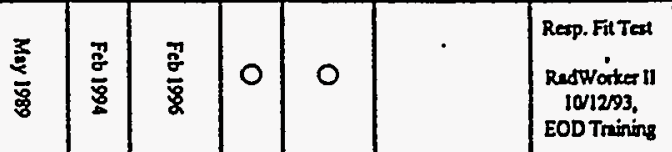

Anderson, David

Scientiat

Boitogiad surveys, rectemetion

0

$\frac{2}{2}$

Keren Puton

0

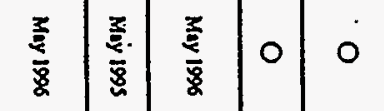

Groes, Ginetle

Radiologienl Control Tecturicien

Peforms surveys

Karen Patton

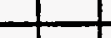

Sorken Cobeen

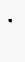

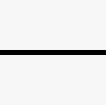

Scientist

Lester Sharon

Puredis, Leonel

Radjologial Control Techricien

Pefforms surveys

Keren Patton

Biologial surveys, ramation

.

$+$

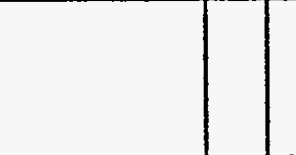

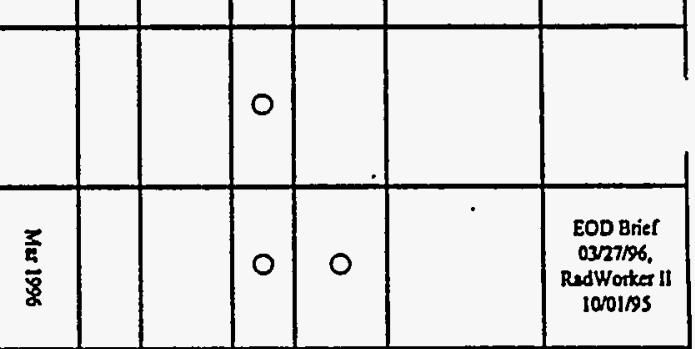

(1)




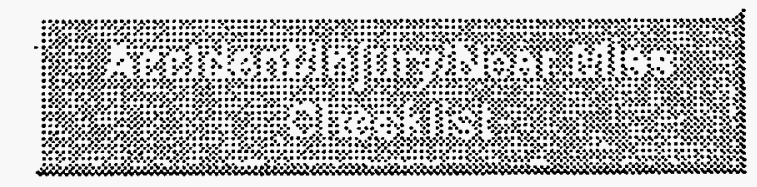

Name of person(s):

Job title:

Date of incident:

Exact location of incident:

Time of incident:

Job number:

Supervisor:

Printed Name

Signature

Employees are required to report ALL injuries, accidents, illnesses and near-misses.

\begin{tabular}{|c|c|c|}
\hline Step & Action/Requirement & $\begin{array}{l}\text { Date/Time } \\
24 \text { hour clock }\end{array}$ \\
\hline 1 & $\begin{array}{l}\text { Perform first aid/CPR, as appropriate, and get injured or ill personnel to medical } \\
\text { care immediately, if required. }\end{array}$ & \\
\hline 2 & $\begin{array}{l}\text { Isolate and protect the scene of the accident. If the event is an automobile } \\
\text { accident, remove the vehicle(s) from traffic lanes. Ask witnesses NOT to discuss } \\
\text { the incident among themselves. }\end{array}$ & \\
\hline 3 & $\begin{array}{l}\text { Report incident by telepinone to the Contractor Project Manager and the Nevada } \\
\text { ERP Health and Safety Manager immediately after the situation is under control, } \\
\text { and further harm is prevented. }\end{array}$ & \\
\hline 4 & Complete appropriate form(s) [Contractor specific] & \\
\hline 5 & $\begin{array}{l}\text { Initiate accident/incident investigation, examining the scene, and begin interviews } \\
\text { of witnesses. }\end{array}$ & \\
\hline $6^{\circ}$ & Submit draft accident/investigation report to. DOE/NV & \\
\hline 7 & Turn this form in to the DOE/NV ERP Health and Safety Manager. & \\
\hline
\end{tabular}


In the event of an emergency ( serious injury, serious illness, fatality, serious property damage, serious spill, etc.) notify the following personnel at once in the following order:

\section{Lead Organization Project Manager}

\begin{tabular}{|ll|}
\hline Name: & Robert L Dodge \\
\hline Office Phone: & $702-295-1632$ \\
\hline Home Phone: & $702-$ \\
\hline
\end{tabular}

(The Lead Organization Project Manager is to assess the severity of the incident, and notify the NV ERP Sub-Project Manager)

\section{NV ERP Sub-project Manager}

\begin{tabular}{|l|l|}
\hline Name: & Monica Sanchez \\
\hline Office Phone: & $295-0160$ \\
\hline Home Phone: & $254-3643$ \\
\hline
\end{tabular}

(The NV ERP Sub-project Manager is to notify the NV ERP H\&S Manager)

\section{NV ERP H\&S Manager}

\begin{tabular}{|ll|}
\hline Name: & Thomas Greenc \\
\hline Office Phone: & $295-0513$ \\
\hline Home Phone: & $645-0512$ \\
\hline
\end{tabular}

(The NV ERP H\&S Manager is to advise the Contractor and NV ERP Sub-project Managers on the proper course of action and coordinate notification of other governmental agencies and personnel, as necessary)

\section{Other}

TITLE:

Deputy Range Commander

NAME:

Major Jason Allchek

OFFICE PHONE:

(702) 652-4247 Becper 794-6294

HOME PHONE:

(702) 269-2036

RESPONSIBILITIES: USAF point of contact for any emergencies or unusual occurrences which would also require notification of DOE and Bechtei managers. TITLE:

NAME: 
In the event of an emergency ( serious injury, serious illness, fatality, serious property damage, serious spill, etc.) notify the following personnel at once in the following order:

\section{Lead Organization Project Manager}

\begin{tabular}{|ll|}
\hline Name: & Robert L. Dodge \\
\hline Office Phone: & $702-295-1632$ \\
\hline Home Phone: & $702-$ \\
\hline
\end{tabular}

(The Lead Organization Project Manager is to assess the severity of the incident, and notify the NV ERP Sub-Project Manager)

\section{NV ERP Sub-project Manager}

\begin{tabular}{|ll|}
\hline Name: & Monica Sanctiez \\
\hline Office Phone: & $295-0160$ \\
\hline Home Phone: & $254-3643$ \\
\hline
\end{tabular}

(The NV ERP Sub-project Manager is to notify the NV ERP H\&S Manager)

\section{NV ERP H\&S Manager}

Name:

Office Phone:

Home Phone:

(The NV ERP H\&S Manager is to advise the Contractor and NV ERP Sub-project Managers on the proper course of action and coordinate notification of other governmental agencies and personnel, as necessary)

\section{Other}

TITLE:

NAME:

OFFICE PHONE:

HOME PHONE:

RESPONSIBILITIES:

TITLE:

NAME:

OFFICE PHONE:

HOME PHONE:

RESPONSIBILITIES: 


\section{Reynolds Electrical \& Engineering Co., Inc. RADIOLOGICAL WORK PERMIT NV/YMP}

\begin{tabular}{|c|c|c|c|}
\hline \multirow{4}{*}{$\begin{array}{l}\text { R } \\
\text { E } \\
Q \\
U \\
\text { E } \\
S \\
T \\
E \\
R\end{array}$} & RWP No.: & \multirow{3}{*}{$\begin{array}{l}\text { Requester Name: Craig Lyons } \\
\text { Phone No.: } 5-0781 \\
\text { ws: NLU } 082\end{array}$} & $\begin{array}{l}\text { Location: NAFR - Double Tracks } \\
\text { (BlogJArea) }\end{array}$ \\
\hline & Issue Date: $5 / 3196$ & & Work Deser \\
\hline & Explre Date: $12 / 30 / 96$ & & and Stabilization 1 \\
\hline & $\begin{array}{l}\text { STANDING RWP } \\
\text { OPERATIONPROJECT RWP }\end{array}$ & $\begin{array}{l}\text { USER ORGANIZATION: } \\
\text { (other than AEECO) }\end{array}$ & \\
\hline
\end{tabular}

\section{RADIOLOGICAL INFORMATION}

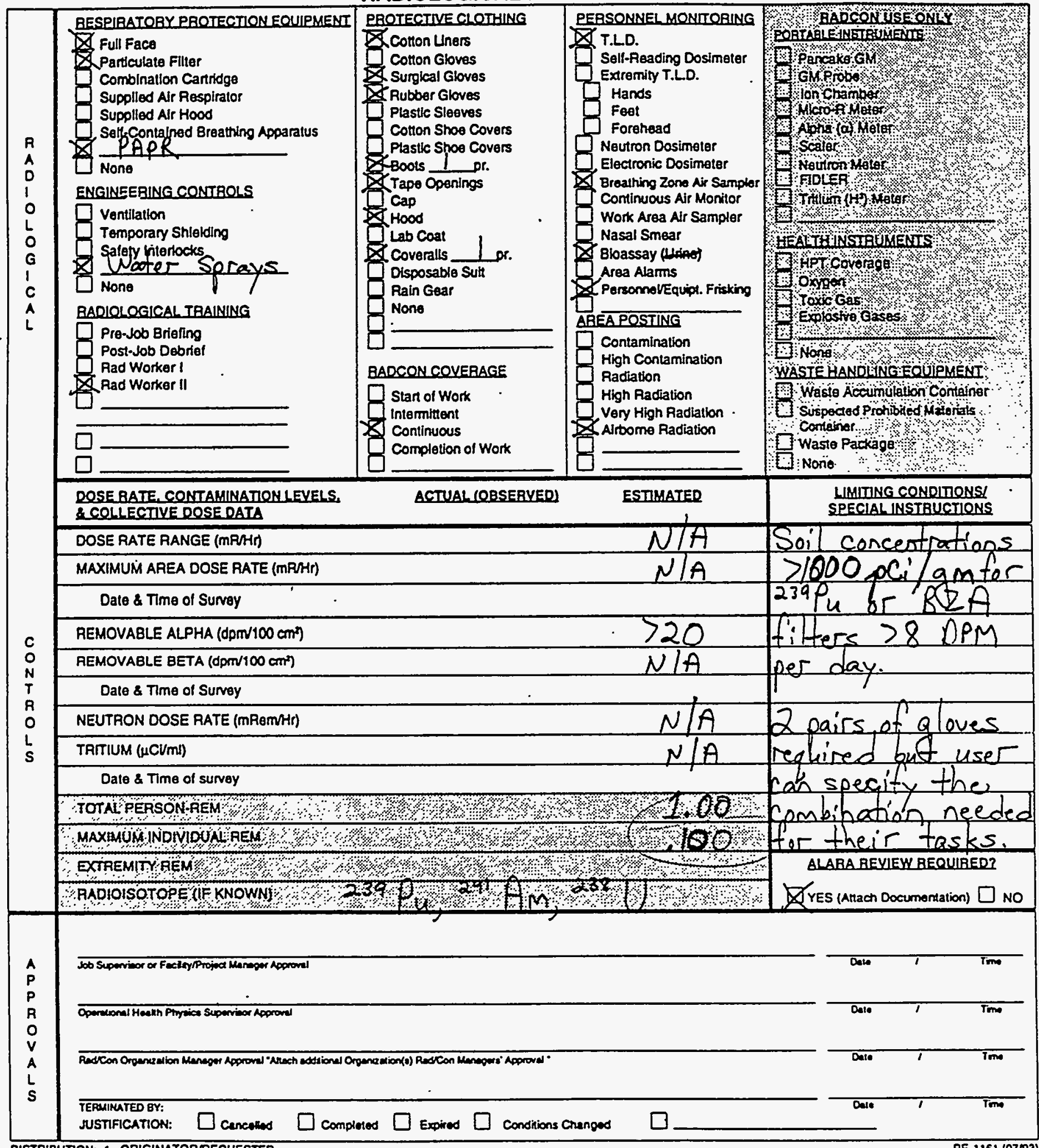




\section{Reynolds Electrical \& Engineering Co., Inc. RADIOLOGICAL WORK PERMIT NVMMP}

\begin{tabular}{|c|c|c|c|}
\hline \multirow{4}{*}{$\begin{array}{l}\text { A } \\
E \\
Q \\
U \\
E \\
S \\
T \\
E \\
\text { A }\end{array}$} & FWP No.: & \multirow{3}{*}{$\begin{array}{l}\text { Requester Nama: Craig Lyons } \\
\text { Phone No.: } 5-0789 \\
\text { ms: NLU }-082\end{array}$} & Location: $N A F R$ - Double Tracks \\
\hline & Issue Date: $5 / 31 / 96$ & & Work Description/P \\
\hline & Explro Data: $12 / 30 / 96$ & & \\
\hline & $\begin{array}{l}\text { STANDING RWP } \\
\text { OPERATIONPROJECT }\end{array}$ & (other & $\underset{\text { (Attach Extra Sheots) }}{\text { and }}$ St \\
\hline
\end{tabular}

\section{RADIOLOGICAL INFORMATION}

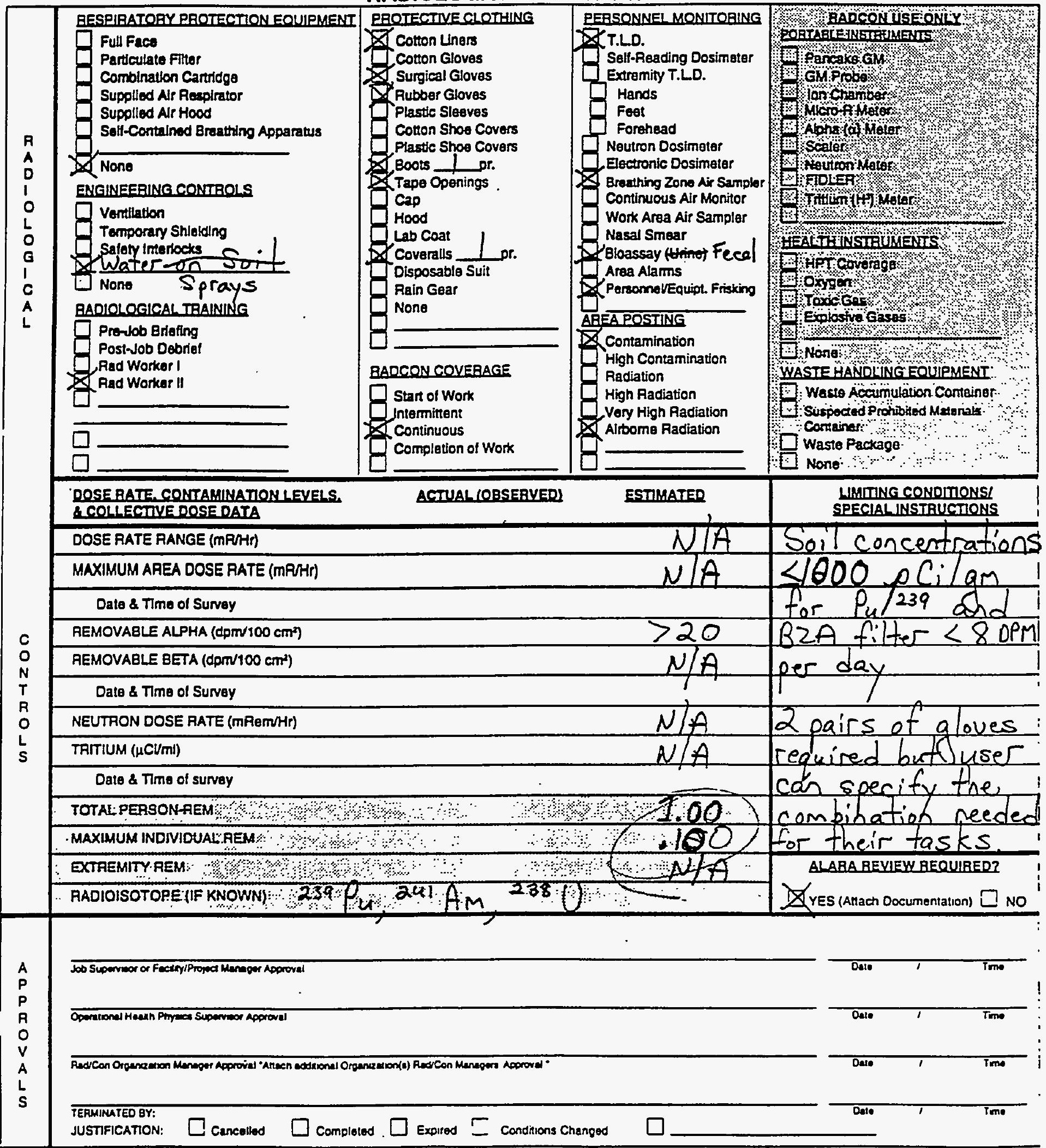




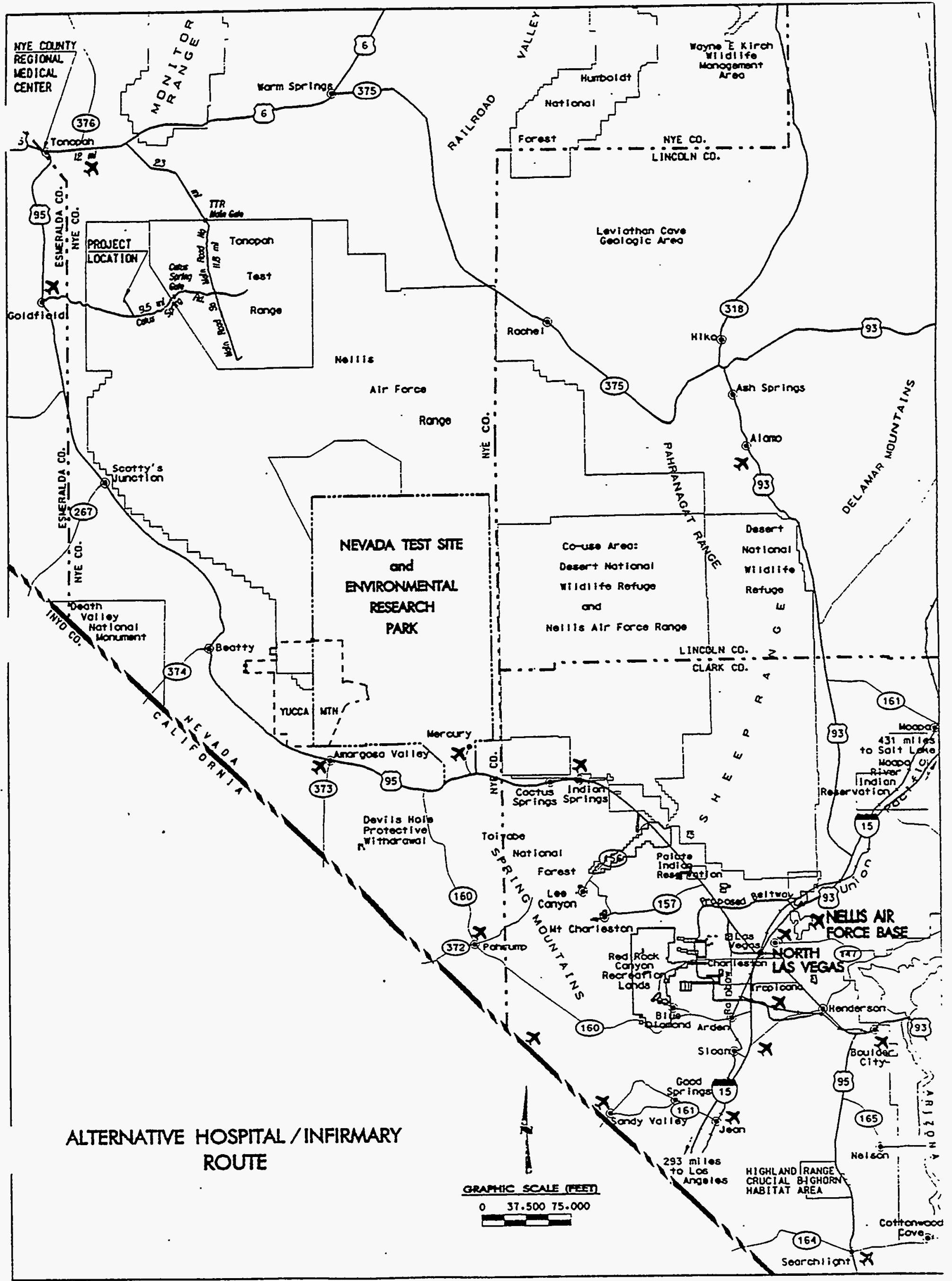




\section{STATEMENT OF WORK}

\section{PROJECT DESCRIPTION}

Double Tracks Site Remediation.

BILLING INFORMATION
Charge \# C1320000 24 CLL $6 / 18 / 96$
Organization \# E110

PROJECT CONTACTS

Primary: Craig Lyons

M/S: $\quad$ NLV-082

Telephone: 295-0781

Fax No.: $\quad$ 295-1313 Fax No.: 295-1313.
Secondary: NLV-082 Michael Shotton che 6/18/95
M/S:

Telephone: $295-0549 \cdot 1165$

Fax No.: 295-1313

Analytical Services:

Rad Chem: Lynn Jaussi .

Telephone: 295-7592

Fax No.: 295-4773

\section{CHAIN-OF-CUSTODY (COC) AND SAMPLE RECEIPT}

All samples transported to the laboratory will be accompanied by a Services Request and Chain-of-Custody (COC). Samples are to be delivered to Building 650 in Mercury. Samples should be relinquished to Sample Management Personnel (Catherine Castaneda 295-7884, Ted Redding 295-7220, Lynn Jaussi 295-7592 or Robert Elkins 295-5381) during regular work hours 7:00 AM to 5:30 PM. Samples delivered after hours may be left in the drop box near sample receiving on the back side of Building 650 and must be relinquished (signed on the $\mathrm{COC}$ ) to the drop box with date and time.

Note: All non-bioassay samples must be screened through ramatrol and have a rad material clearance sticker or tag present prior to submission to the laboratory. 


\section{ANALYSIS SPECIFICATIONS}

1. Approximately 40 baseline fecal samples will be ashed and stored.

2. Final or post project fecal samples will be analyzed for Plutonium-238,239/240. If a final sample is positive and the calculated dose exceeds $10 \mathrm{mrem}$, the worker's baseline sample will be analyzed for Plutonium-238,239/240 by alpha spectrometry. Result units will be pCi/sample. Additional samples and analysis will be determined by Dosimetry and the Primary Contact.

3. Air filters will be gamma scanned for 20 minutes (Am-241 is the nuclide of concern). The air sample will also be analyzed for plutonium by alpha spectrometry. The reporting units will be $\mu \mathrm{Ci} / \mathrm{cc}$.

4. Soil samples will be submitted in $500 \mathrm{ml}$ Nalgene bottles filled to capacity and gamma scanned. If the sample is expected to have detectable plutonium and americium activity from process knowledge, and/or the gamma scan detects americium-241 above $20 \mathrm{pCi} / \mathrm{gm}$, then Ramatrol will aliquot up to $5 \mathrm{~g}$, with alpha activity confirmed by the Electra frisking instrument will be analyzed for plutonium.-238,239/240 by alpha spectroscopy. The reporting units will be pCi/gm.

5. Water samples will be gamma scanned $(500 \mathrm{~mL}$ aliquot) and then analyzed for plutonium-238, 239/240 and americium-241 using alpha spectroscopy. The reporting units will be $\mu \mathrm{Ci} / \mathrm{ml}$.

Required Detection Limits are:

1. Americium-241 by Gamma scan $=<1 \rho \mathrm{pCi} / g m$ for soil and $<1 \mathrm{E}-08 \mu \mathrm{Ci} / \mathrm{cc}$ for air with air volume not less than $1 \mathrm{E} 05 \mathrm{cc}$ and $1 \mathrm{E}-07 \mathrm{uci} / \mathrm{cc}$ for water (300 min. count).

2. Plutonium-238, $239 / 240$ analysis $=<0.5 \rho \mathrm{Ci} / \mathrm{gm}$ for soil and $<1 \mathrm{E}-12 \mu \mathrm{Ci} / \mathrm{cc}$ for air with air volume not less than $1 \mathrm{E} 05 . \mathrm{cc}$ and $<1 \mathrm{E}-08 \mu \mathrm{Ci} / \mathrm{ml}$ for water. Note: Minimum volume of air required would be 4E04 cc.

\section{DELIVERABLES TURNAROUND TIME (TAT)}

Preliminary Results:

Operational (special) fecal sample results due in 10 calendar days (Overtime may be required). 
Air sample results- by gamma 4 working days (unscreened), plutonium by alpha spectroscopy, 45 calendar days.

Soil sample results- gamma 4 working days (unscreened), plutonium by alpha spectroscopy 45 calendar days.

Water sample results- gamma 4 working days (unscreened), plutonium 45 calendar days.

Post fecal sample results: Customer will specify one batch where preliminary results will be due in 30 calendar days from receipt. The remainder will be due 60 days from receipt.

Final results due in 60 calendar days after receipt of sample.

Additional charges may be incurred for TATs shorter than 60 days.

\section{DELIVERABLE REQUIREMENTS}

A final level 1 report, is required 60 days after receipt of samples. A statement of services which identifies charges against a charge number will accompany the Level 1 report.

Preliminary and final results wil be reported to Craig Lyons.

Service statement will be sent to Craig Lyons.

\section{QUALITY ASSURANCE/QUALITY CONTROL (QAVC)}

Laboratory quality control samples will be performed as required by the Analytical Services procedure. Analytical results for these QAVC samples will be included with the Level 1 report.

\section{SAMPLE DISPOSAL}

Unprocessed soil samples will be disposed of by the client.

Processed samples and residues from chemistry shall be disposed of by the laboratory.

A Waste Disclaimer Form is attached to this statement of work.

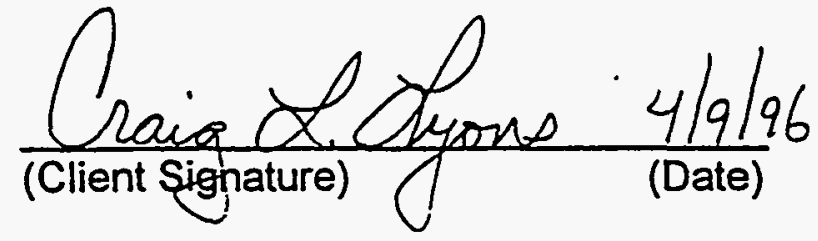


$\therefore$

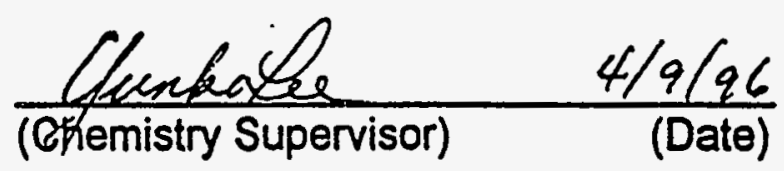

$\frac{\text { Lupmalacess }}{\text { (Ghent Service Representative) (Date) }}$

st $\frac{\text { Robert } \rho \text {. Dodge } 4 / 5 / 96}{\text { (Project Manager) }}$ 
1. Sample residue is routinely retained for 90 days post analysis by the Environmental Services Department (ESD) for reference and/or reanalysis.

2. Subsequent to analysis, all remaining sample and associated residue waste shall be disposed of by ESD. From process knowledge and/or prior analysis, I attest that the only potentially hazardous or radioactive components in the samples presented to the ESD under this Statement of Work (SOW) are those analytes requested for analysis.

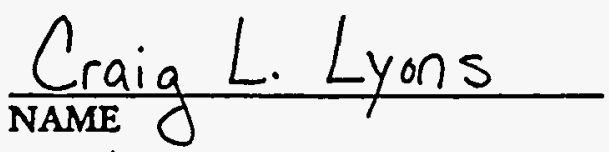

Sciestist TITLE

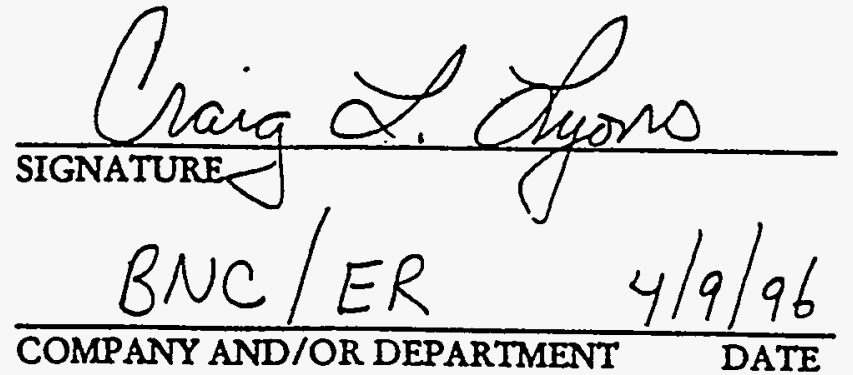

3. Subsequent to analysis, all remaining sample and their associated residue waste shall be disposed of by ESD. From process knowledge and/or prior analysis, the samples delivered under this SOW contain hazardousand/or radioactive components as detailed in Attachment . I attest that the only potentially hazardous or radioactive components in the samples presented to the ESD under this SOW, in addition to those detailed in Attachment are the analytes requested for analysis.

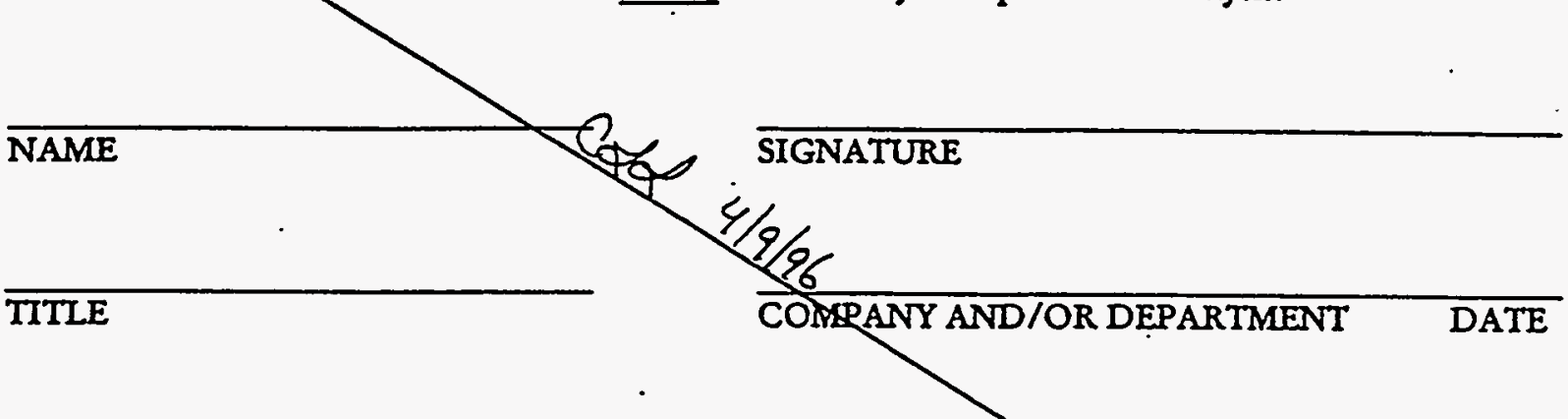

4. Subsequent to analysis, all remaining sample and associated residue saste shall be disposed of by ESD. ESD is authorized to perform all analyses necessary on the samples delivered to them under this SOW to fully characterize them for appropriate waste disposal. All charges associated with wate characterization analysis shall be charged to the same work order number as provided for the requested analyses.

NAME SIGNATURE

TITLE COMPANY AND/OR DEPARTMENT DATE soil cul

5. All remaining sample materials and associated analysis residues shall be returned to the originator for waste disposal.

$\frac{\text { Mraig L. Lyons }}{\text { NAME }}$

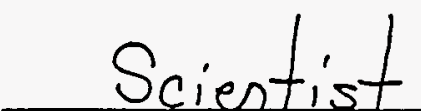

TITLE

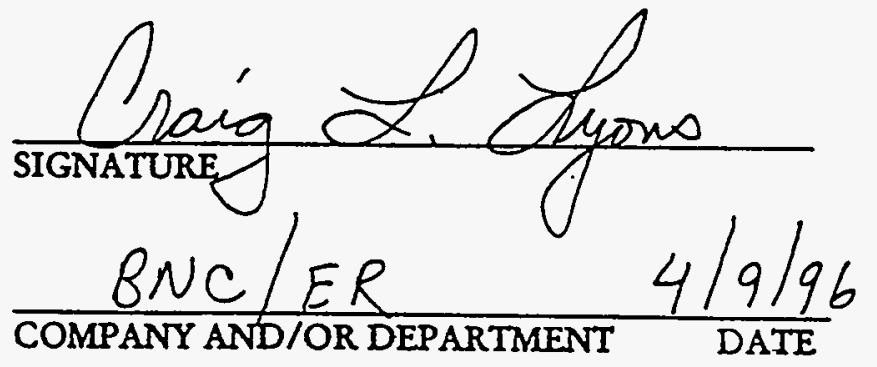




\begin{tabular}{|c|c|c|c|}
\hline \multicolumn{4}{|c|}{ Hazard Identification and Mitigation } \\
\hline Hazard & Category & HACs & Acceptability/Mitigation \\
\hline $\begin{array}{l}\text { 1. Exposure to dusts } \\
\text { contaminated with plutonium, } \\
\text { depleted uranium and trace } \\
\text { amounts of other radionuclides } \\
\text { during excavation. }\end{array}$ & High & $3 \mathrm{~A}$ & $\begin{array}{l}\text { Continuous monitoring must be accomplished throughout the } \\
\text { operation at the TTR. Exposure to contaminated dusts will be } \\
\text { the focus point on this project. }\end{array}$ \\
\hline Mitigation & Very Low & $4 \mathrm{C}$ & $\begin{array}{l}\text { The use of the water master will aid in the reduction of dusts } \\
\text { during excavation of soils. However, after the soils are collected } \\
\text { and stock piled, the method of conveying the contaminated soils } \\
\text { to the hopper is of concern. Controls will be implemented to } \\
\text { reduce the amount of dusting and ensure that minimal exposure } \\
\text { to personnel as the material is bagged and prepared for shipment. }\end{array}$ \\
\hline $\begin{array}{l}\text { 2. Unexploded Ordnance and } \\
\text { ordnance not otherwise identified. } \\
\text { Extreme care and caution must be } \\
\text { taken when ordnance are } \\
\text { discovered. }\end{array}$ & Medium & 3B & $\begin{array}{l}\text { Unexploded ordnance may be discovered during the removal of } \\
\text { soils. All personnel shall be trained in the recognition and } \\
\text { procedure of how to approach and steps to take when the } \\
\text { ordnance item is discovered. }\end{array}$ \\
\hline Mitigation & Very Low & 4D & $\begin{array}{l}\text { The area has been surveyed for unexploded ordnance. Should an } \\
\text { ordnance item be discovered a fall back position will be taken. } \\
\text { All personnel will vacate the area to a safe haven of at least } 2,000 \\
\text { feet away. All ordnance items will be handled by an explosives } \\
\text { expert and will deem the item(s) to be inert or the item(s) } \\
\text { removed to an ordnance holding area. }\end{array}$ \\
\hline $\begin{array}{l}\text { 3. Heat Stress will be a factor } \\
\text { during project operation }\end{array}$ & Medium & 3B & $\begin{array}{l}\text { The climatic conditions at this time of the year predispose } \\
\text { workers to an environment that may be harmful to their health } \\
\text { due to heat stress. }\end{array}$ \\
\hline Mitigation . & Very Low & $4 \mathrm{C}$ & $\begin{array}{l}\text { All personnel shall be trained in the recognition of heat stress. } \\
\text { Operations will be conducted during the cooler hours of } \\
\text { operation. IH will monitor the working conditions on a regular } \\
\text { basis. Heat stress cannot be a factor in prescribing or not } \\
\text { preseribing the use of respiratory protection. Once the Health } \\
\text { Physicist and the ALARA committee prescribe the levels of PPE } \\
\text { to be used. Industrial Hygiene will develop a work/rest regime } \\
\text { based on the Wet Bulb Globe Temperature (WBGT) } \\
\text { measurements and the recommendations made in the ACGIH } \\
\text { TLV guide. }\end{array}$ \\
\hline $\begin{array}{l}\text { 4. Exposure to Hantavirus is a } \\
\text { critical concem. One fatality has } \\
\text { been attributed to Hantavirus at } \\
\text { the Tonopah area. }\end{array}$ & Medium & $3 \mathrm{~A}$ & $\begin{array}{l}\text { One Hantavirus death occurred in 1995. All precautions will be } \\
\text { taken to avoid an occurrence. Mandatory education on } \\
\text { Hantavirus must be accomplished. Several employees should be } \\
\text { trained in the removal of suspected Hantavirus material. }\end{array}$ \\
\hline Mitigation & Very Low & $4 \mathrm{C}$ & $\begin{array}{l}\text { Hantavirus awareness will be mandatory training for all on-site } \\
\text { participants of Double Tracks. IH has prepared a video cassette } \\
\text { that can be used for training. Hantavirus decontamination on-site } \\
\text { should be handled by Bechtel employees so as not to bring the } \\
\text { project to a slowdown or a critical path. }\end{array}$ \\
\hline
\end{tabular}




\begin{tabular}{|c|c|c|c|}
\hline $\begin{array}{l}\text { 5. Working around machinery } \\
\text { and heavy equipment will be a } \\
\text { Noise Hazard } \\
\text { Mitigation }\end{array}$ & Very Low & $3 C$ & $\begin{array}{l}\text { All areas that exhibit an } 85 \mathrm{dBA} \text { noise reading shall be designated } \\
\text { as an area that requires hearing protection. } \\
\text { This project must comply with } 29 \text { CFR } 1910.95 \text { using a baseline } \\
\text { of } 85 \mathrm{dBA} \text { for an } 8 \text {-hour exposure. This will require a medical } \\
\text { evaluation, and a hearing test. Hearing protection will be } \\
\text { required in areas where noise levels are greater than } 85 \mathrm{dBA} \text {. }\end{array}$ \\
\hline $\begin{array}{l}\text { 6. Solvents, oils, and furls will be } \\
\text { used in the Double Tracks project. } \\
\text { Potential exposure to skin, } \\
\text { inhalation, and possible risk of } \\
\text { fire. }\end{array}$ & Medium & $3 B$ & $\begin{array}{l}\text { All personnel shall be trained in Hazard Communication. In- } \\
\text { accordance-with } 29 \text { CFR } 1910.1200\end{array}$ \\
\hline Mitigation & Medium & $3 \mathrm{~B}$ & $\begin{array}{l}\text { A written Hazard Communication program must be in } \\
\text { compliance with } 29 \text { CFR } 1920.1200 \text {, is mandatory for all } \\
\text { participating organizations involved with Double Tracks. This } \\
\text { requires Material Safety Data Sheets (MSDS, hazardous } \\
\text { chemical lists, Hazard Communication training, and site specific } \\
\text { HAZCOM training). }\end{array}$ \\
\hline $\begin{array}{l}\text { 7. Safety hazards such as: slips, } \\
\text { trips, falls, and overhead, will } \\
\text { require the use of hard hat, safety } \\
\text { toed shoes; protective gloves; and } \\
\text { protective eyewear (including } \\
\text { spectacle kits for full face } \\
\text { respirators consistent with the } \\
\text { hazard(s) they will encounter. }\end{array}$ & Medium & 3B & $\begin{array}{l}\text { All personnel shall wear approved PPE. All workers will wear } \\
\text { approved PPE as dictated by the hazards associated with Double } \\
\text { Tracks. }\end{array}$ \\
\hline $\begin{array}{l}\text { 8. Workers may experience the } \\
\text { need for immediate first aid care } \\
\text { as a result of an injury or medical } \\
\text { emergency. }\end{array}$ & Low & $3 B$ & $\begin{array}{l}\text { At least two workers shall be trained in First Aid and CPR and } \\
\text { remain on-site during the work shift }\end{array}$ \\
\hline Mitigation & Low & $3 B$ & $\begin{array}{l}\text { NTS will provide Emergency Medical Technicians (EMS) at the } \\
\text { Double Tracks job site during working hours. Should a life } \\
\text { threatening situation occur a worker can be air lifted to an } \\
\text { appropriate medical care provider. }\end{array}$ \\
\hline $\begin{array}{l}\text { 9. The hopper system has the } \\
\text { potential to produce fugitive dust } \\
\text { and may expose employees to } \\
\text { plutonium and other } \\
\text { radionuclides. }\end{array}$ & Medium & $2 B$ & $\begin{array}{l}\text { The ALARA committee needs to review an provide approval on } \\
\text { the set-up and design of the conveyor system. Significant } \\
\text { exposure can occur at this location. A thorough review of the } \\
\text { design must be accomplished by all discipines and the workers } \\
\text { that will accomplish the task. }\end{array}$ \\
\hline Mitigation & Low & $3 B$ & $\begin{array}{l}\text { The design of the hopper system will meet strict review from } \\
\text { safety and health and other disciplines. Design will be consistent } \\
\text { with the ALARA concept As Low As Reasonably Achievable. } \\
\text { Fugitive dust must be kept to the lowest possible level for the } \\
\text { worker and the environment. Attention shall be given to the } \\
\text { moisture content of the soils being processed to enhance worker } \\
\text { protection. }\end{array}$ \\
\hline
\end{tabular}




\begin{tabular}{|c|c|c|c|}
\hline $\begin{array}{l}\text { 10. The Super Sscks } \\
\text { configuration, relative to the } \\
\text { hopper system, is a source of } \\
\text { personnel injury, and exposure to } \\
\text { contaminated soil } \\
\text { Mitigation }\end{array}$ & Medium & $3 B$ & $\begin{array}{l}\text { It is probable that contamination to workers will occur at this } \\
\text { location in the soil processing. A complete review of the system } \\
\text { needs to address the weakest chain the process, and appropriate } \\
\text { mitigation will be required. } \\
\text { After review and the Administrative controls that are in place, no } \\
\text { worker should receive a dose not permitted by the ALARA } \\
\text { committee and the Rad Con Manual whichever is more } \\
\text { restrictive. }\end{array}$ \\
\hline $\begin{array}{l}\text { 11. Potential hazards exist in } \\
\text { loading, unloading, and entry into } \\
\text { the Conex storage containers. }\end{array}$ & Low & $3 C$ & $\begin{array}{l}\text { The ALARA committee and project procedures will designate the } \\
\text { method of entry and list all appropriate restrictions }\end{array}$ \\
\hline Mitigation & Very Low & $4 C$ & $\begin{array}{l}\text { The loading, unloading, and entry into the storage containers will } \\
\text { be reviewed by safety and other disciplines to ensure that not } \\
\text { injury or exposure will occur to workers or the public. }\end{array}$ \\
\hline $\begin{array}{l}\text { 12. Over-the-road drivers hauling } \\
\text { waste to NTS may become } \\
\text { involved in a traffic accident and } \\
\text { their load scattered on the } \\
\text { highway or terrain. }\end{array}$ & Low & $3 B$ & $\begin{array}{l}\text { All drivers that drive over public highways are required to have a } \\
\text { commercial drivers license and meet the CDL requirements. All } \\
\text { drivers will be trained in appropriate procedures in the case of an } \\
\text { accident and be in communication with the appropriate dispatch. } \\
\text { The designated communities leaders and responsible parties have } \\
\text { received education training regarding the TTR project and it's } \\
\text { hazards and how to mitigate a spill or traffic accident. }\end{array}$ \\
\hline
\end{tabular}




\title{
Bechtel Nevada
}

\author{
EMERGENCY \\ RESPONSE PROCEDURE \\ FOR \\ DOUBLE TRACKS \\ SOILS REMEDIATION PROJECT
}

Revision 0

June 17, 1996

Prepared By

Bechtel Nevada

Emergency Services Section 


\section{EMERGENCY}

\section{RESPONSE PROCEDURE}

FOR

DOUBLE TRACKS

\section{SOILS REMEDIATION PROJECT}

APPROVED BY:

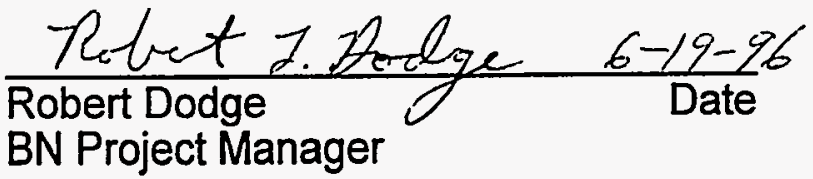

APPROVED BY:

$\frac{\text { Ahlial D. Alotton 6-18-96 }}{\text { Michael D. Shotton }}$

BN Asst. Project Manager

APPROVED BY:

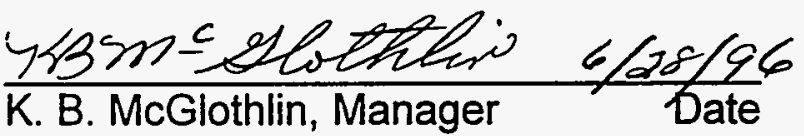

Emergency Services Section

Reviewed for Classification

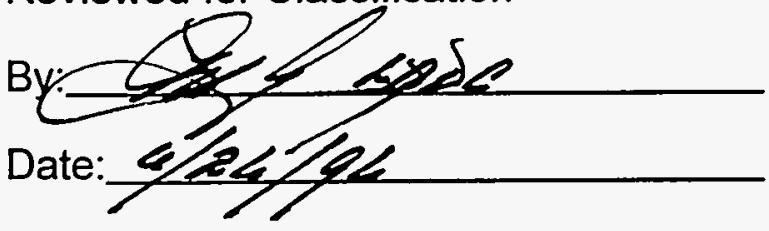




\section{TABLE OF CONTENTS}

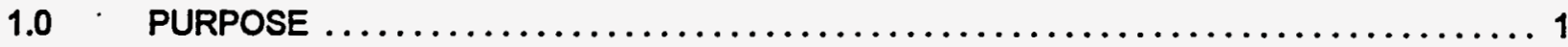

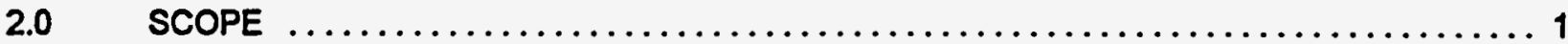

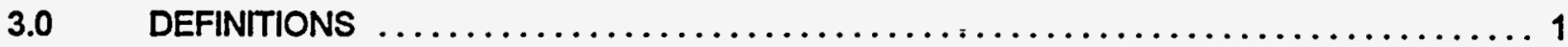

$4.0 \quad$ AUTHORITIES AND RESPONSIBILITIES $\ldots \ldots \ldots \ldots \ldots \ldots \ldots \ldots \ldots \ldots \ldots \ldots$ Figure 4-1 Project Management Organizational Structure $\ldots \ldots \ldots \ldots \ldots \ldots \ldots \ldots \ldots \ldots \ldots \ldots, 8$

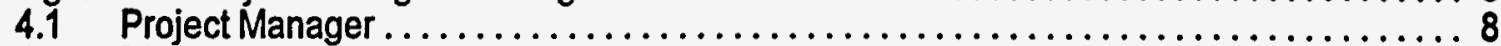

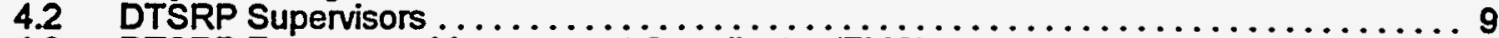

4.3 DTSRP Emergency Management Coordinator (EMC) $\ldots \ldots \ldots \ldots \ldots \ldots \ldots \ldots \ldots \ldots \ldots \ldots$

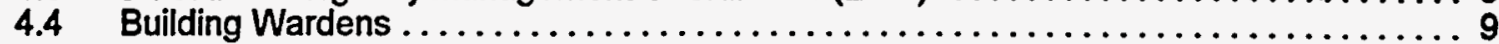

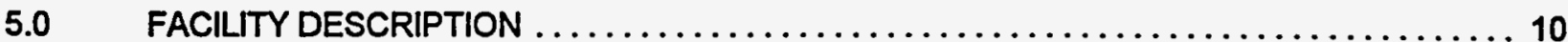

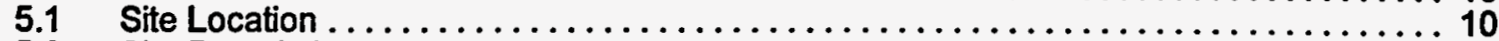

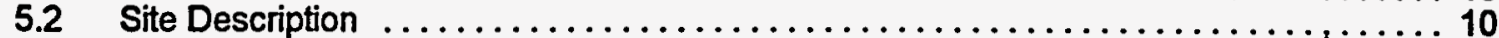

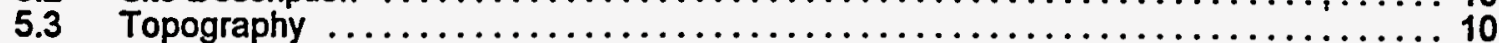

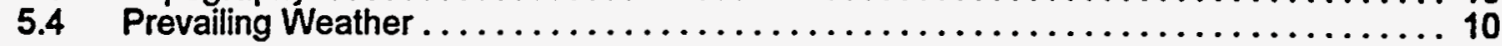

6.0 POTENTIAL CREDIBLE EMERGENCIES AND HAZARDS $\ldots \ldots \ldots \ldots \ldots \ldots \ldots \ldots \ldots$

7.0 EMERGENCY NOTIFICATION AND REPORTING PROCEDURES $\ldots \ldots \ldots \ldots \ldots \ldots \ldots \ldots, 11$

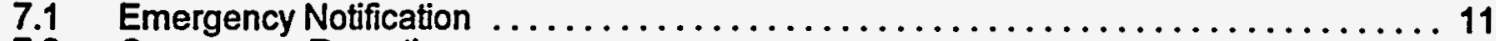

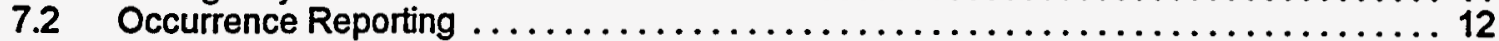

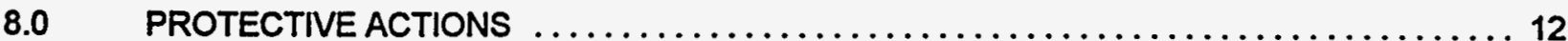

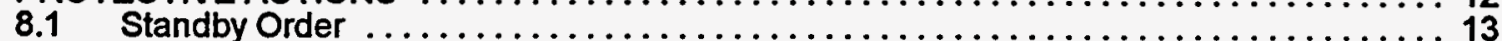

8.1 .1 Information Required $\ldots \ldots \ldots \ldots \ldots \ldots \ldots \ldots \ldots \ldots \ldots \ldots \ldots \ldots \ldots \ldots \ldots \ldots, 13$

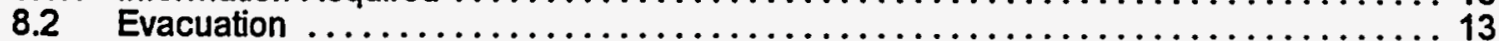

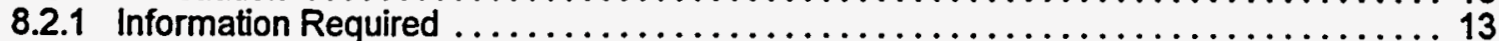

8.2 .2 Accountability $\ldots \ldots \ldots \ldots \ldots \ldots \ldots \ldots \ldots \ldots \ldots \ldots \ldots \ldots \ldots \ldots \ldots, 13$

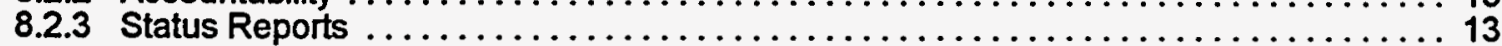

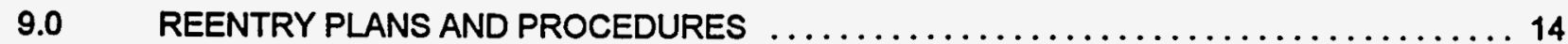

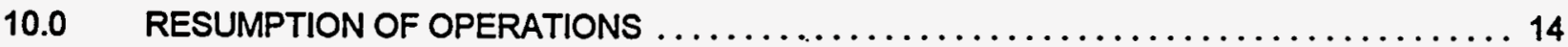

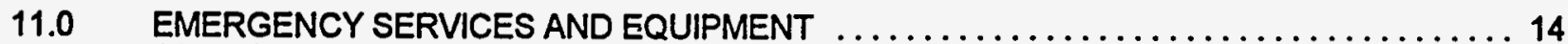

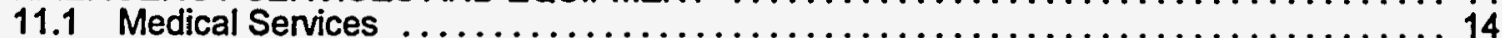

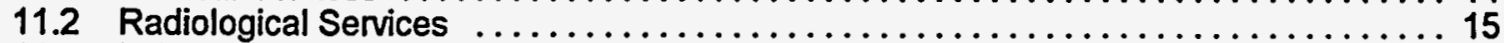

11.3 Industrial Hygiene Services $\ldots \ldots \ldots \ldots \ldots \ldots \ldots \ldots \ldots \ldots \ldots \ldots \ldots \ldots \ldots \ldots \ldots \ldots \ldots \ldots, 15$

11.4 Fire Protection Services ............................................. 15

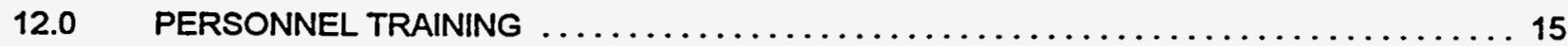

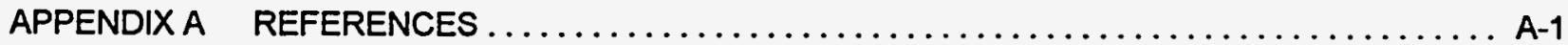

APPENDIX B EMERGENCY MANAGEMENT HAZARDS ASSESSMENT FOR DOUBLE TRACKS SOILS REMEDIATION PROJECT $\ldots \ldots \ldots \ldots \ldots \ldots \ldots \ldots \ldots \ldots \ldots \ldots \ldots \ldots \ldots \ldots, \ldots \ldots \ldots$

APPENDIX C STATUS REPORT OF EMERGENCY CONDITIONS $\ldots \ldots \ldots \ldots \ldots \ldots \ldots \ldots$ C-1

APPENDIXD EMERGENCY RESPONSE CHECKLIST $\ldots \ldots \ldots \ldots \ldots \ldots \ldots \ldots \ldots \ldots \ldots$ D-1 


\subsection{PURPOSE}

This document was prepared to satisfy requirements for emergency procedures as prescribed by DOE Order 151.1, "Comprehensive Emergency Management System"; Title 29 Code of Federal Regulations (CFR) Part 1926.35, "Employee Emergency Action Plan"; and Title 29 CFR 1910.38, "Employee Emergency Plans and Fire Protection Plans." This procedure discusses the mitigative and protective actions that designated BN Double Tracks Soils Remediation Project (DTRSP), Emergency Response Personnel will take in response to emergency situations. These emergency situations include fires; explosions; releases or spills of transuranic (TRU) waste; and releases or spills of hazardous waste or hazardous waste constituents to the air, soil, or surface water at the Double Tracks Soils Remediation Project on the Nellis Air Force Range (NAFR).

\subsection{SCOPE}

This procedure is designed to address a variety of potential emergencies at the DTSRP site identified in the "Environmental Restoration Site Specific Health and Safety Plan for the Double Tracks Site," dated May 17, 1996, and the "Emergency Management Hazard Assessment," for the DTSRP. These emergencies are listed in Section 6.0, "Potential Credible Emergencies". This procedure applies only to emergency response requirements specific to DTSRP site operations under the operational cognizance of Bechtel Nevada.

\subsection{DEFINITIONS}

\subsection{Alert}

A class of emergency within the Operational and Energy categories. Within the Operation Emergency category, an Alert represents events in progress or having occurred which involve an actual or potential reduction of the level of safety and protection. Any environmental release of hazardous materials are expected to be limited to a small fraction of the appropriate Protective Action Guide (PAG) or Emergency Response Planning Guide (ERPG) at facilities occupied by BN personnel. During an Energy Emergency, an Alert represents an event (a) which has occurred or is in progress, (b) that is noteworthy, (c) whose potential impacts are not expected to be serious, and (d) whose negligible long-term supply impact is anticipated.

\subsection{Building Warden}

A person assigned by facility coordinator to assist in carrying out assigned emergency management responsibilities. The current ratio for planning purposes is one (1) building warden per twenty (20) employees.

\subsection{Company .Compliance Oversight Organization}

An organization assigned responsibility for the oversight of Company activities to ensure compliance to contractual codes, standards, guidelines, orders, directives; e.g., U.S. Department of Energy (DOE) Orders; Occupational Safety and Health Administration 
(OSHA), National Fire Protection Association (NFPA), and Environmental Protection Agency regulations; and National Electrical Codes.

\subsection{Consequence Assessment}

The evaluation and interpretation of radiological or other hazardous materials measurements and other information to provide a basis for decision-making.

\subsection{Drill}

A supervised, "hands-on" instruction session for individuals or teams which develops, tests, or maintains a specific operational or emergency response capability. Drills may be used to prepare for exercises as well as to resolve deficiencies or develop improvements in specific functional areas identified in previous exercises. They are also used to develop skills and maintain proficiency among members of emergency response organizations.

\subsection{Emergency Action Level (EAL)}

Specific, predetermined, observable criteria used to detect, recognize, and determine the emergency class of Operational Emergencies. An EAL could be an instrument reading; an equipment status indicator; a measurable parameter, onsite or offsite; a discrete, observable event; results of analyses; or another observed phenomenon that indicates entry into a particular emergency class.

\subsection{Emergency Action Team (EAT)}

Team of personnel assigned duties as Facility Coordinator, or Wing Warden. These team members will ensure the emergency evacuation procedures are implemented during an emergency situation.

\subsection{Emergency Class}

A subset under the categories of emergency. This class further differentiates an emergency by the degree of severity depending on the actual or potential consequences of the emergency.

\subsection{Emergency Evacuation}

Immediate, orderly withdrawal of all personnel from one or more locations due to an emergency. Emergency evacuations may result from unforeseen incidents, onsite or offsite, involving releases of radioactivity, acts of nature, declared national emergencies, local emergencies, or other disasters.

\subsection{Emergency Management}

The development, coordination, and direction of planning, preparedness, and readiness assurance activities. 


\subsection{Emergency Operations Center}

A central facility from which management and support personnel carry out coordinated emergency response activities. The emergency operations center may be a dedicated facility or office, conference room, or other predesignated location having appropriate communications and informational materials to carry out the assigned emergency response mission, and may be located, where possible, in a secure and protected location.

\subsection{Emergency Plan}

A brief, clear, and concise description of the (a) overall emergency organization; (b) designation of responsibilities; and (c) procedures, including notifications, involved in coping with any or all aspects of a potential credible emergency.

\subsection{Emergency Planning Zone (EPZ)}

A geographic area surrounding a specific DOE facility for which special planning and preparedness efforts are carried out to ensure that prompt and effective protective actions can be taken to reduce or minimize the impact to onsite personnel, public health and safety, and the environment in the event of an Operational Emergency.

\subsection{Emergency Preparedness}

The indoctrination and training of personnel, acquisition and maintenance of resources, and exercising of the plans, procedures, personnel, and resources essential for emergency response.

\subsection{Emergency Response}

The implementation of planning and preparedness during an emergency involving the effective decisions, actions, and application of resources that must be accomplished to mitigate consequences and recover from an emergency.

\subsection{Emergency Response Organization}

The designated group(s) of personnel responsible for coping with and minimizing or mitigating the effects of an emergency.

\subsection{Emergency Response Planning Guideline (ERPG)}

A hazardous material personnel exposure level or range which, when exceeded by a short-term or acute exposure, will cause irreversible or other serious health effects in humans. ERPGs are approved by a committee of the American Industrial Hygiene Association. 


\subsection{Emergency Response Procedure}

The documented, orderly, and systematic steps taken to respond to, cope with, mitigate, terminate, and recover from an emergency.

\subsection{Evacuation Assembly Area}

A designated location where personnel congregate to obtain transportation and/or form a convoy for relocation to the staging area or other destination as designated by an authority [Emergency Operations Center (EOC), Mercury Emergency Center, or DOE Operations Coordination Center (OCC)].

\subsection{Event}

Any real-time occurrence or significant deviation from planned or expected behavior that could endanger or adversely affect people, property, or the environment.

\subsection{Exercise}

A comprehensive performance test of the integrated capability of most aspects in the emergency management program associated with the facility. Exercises test the adequacy and effectiveness of (a) organizational command and control, (b) implementation procedures, (c) notifications and communications networks, (d) emergency equipment, $(e)$ response organization personnel performance, and $(f)$ the overall emergency response program performance. Exercises must be designed and conducted for maximum realism and attempt to duplicate the sense of stress inherent in an actual emergency.

\subsection{Facility}

Any equipment, structure, system, process, or activity that fulfills a specific purpose. Examples include the NTS as a whole; storage areas and drilling and mining operations; e.g., tunnels, shafts, explosives magazines, construction sites, production or burial grounds; communications and data processing activities; testing laboratories; research laboratory; transportation activities; and accommodations for analytical examination of irradiated and unirradiated components.

\subsection{Facility Coordinator}

An individual or designee who has direct line responsibility for the operation of a facility or group of related facilities, including authority to direct physical changes to the facility.

\subsection{Full-participation Exercise}

Initiated by $D O E$, an exercise which demonstrates the integrated response capability of the facility emergency response organization and the DOE Program Office elements [both Headquarters (HQ) and Field Element] with responsibilities for emergency response, along with those regional federal, state, tribal, and local government agencies and private support organizations which elect to participate. 


\subsection{Functional Organization}

An organizational unit within the Company empowered with department-level, or above, responsibilities and authority [i.e., Labor Relations, Equal Employment Opportunity (EEO), etc.].

\subsection{Functional Organization Emergency Management Coordinator (FOEMC)}

A one-point contact for all emergency management-related activities. The designated individual is responsible for ensuring that (a) the organizational EMP is consistent with the BN EMP and is reviewed and updated annually or when changes in situation, organization, or requirements dictate; (b) the required emergency management training and exercises are conducted; (c) training and exercise documentation is provided to the Emergency Services Section (ESS) according to the BN EMP; and (d) actions taken to correct identified deficiencies or problems are reported.

\subsection{General Emergency}

One of the classes of emergencies in the Operational and Energy categories. Within the Operational Emergency category, a General Emergency represents events which are in progress or have occurred that involve (a) actual or imminent catastrophic failure of safety systems with potential for loss of confinement integrity, (b) catastrophic degradation of protective systems, or (c) catastrophic failure in safety or protection systems which could lead to substantial offsite impacts. Any environmental release of hazardous materials can reasonably be expected to exceed the appropriate PAG or ERPG exposure levels offsite. Within the Energy Emergency category, a General Emergency is an event which has occurred that has major energy supply impacts. Examples of such events are a major electrical energy system outage affecting consumers in more than two states or an earthquake affecting the United States (U.S.) or a U.S. territory that measures over 7.1 on the Richter Scale.

\subsection{Hazard}

A process, condition, or asset which has the potential to adversely impact the health and safety of personnel, the public, the environment, or national security. Hazards are divided into three classes:

- Low - Hazards which present minor onsite and negligible offsite impacts to people, the environment, or national security.

- Moderate - Hazards which represent considerable potential onsite impacts to the people or the environment, but at most, only minor offsite impacts to people, the environment, or national security.

- High - Hazards with the potential for onsite and offsite impacts to large numbers of persons or with the potential for major impacts to the environment or national security. 


\subsection{Hazards Assessment}

The process used to determine the extent and scope of emergency planning and preparedness activities. The scope of emergency management programs and the extent of emergency planning and preparedness required are based upon, and are commensurate with, the hazards and consequences associated with a specific facility.

\subsection{Incident Command}

The combination of facilities, equipment, personnel, procedures, and communications operating within a common organizational structure with responsibility for managing assigned resources to effectively accomplish the stated objectives pertaining to an incident.

\subsection{Indoctrination}

Instruction in the fundamentals and basic elements of the EMP, associated Company-, division-, and department-level procedures, etc., and relative job responsibilities and authority. Indoctrination is a general introduction to emergency management principles and does not include the detailed instruction where an individual needs to carry out emergency management assignments:

\subsection{Offsite}

The areas beyond the boundaries of the NTS.

\subsection{Offsite Staging Area}

A location situated a safe distance away from the emergency where personnel are convoyed to, assembled, and provided further instructions.

\subsection{Onsite}

Includes any area that has been established as a National Defense or National Security Area.

\subsection{Protective Action}

Physical measures such as evacuation or sheltering taken to prevent potential health hazards, resulting from a release of hazardous materials to the environment, from adversely affecting employees or the offsite population.

\subsection{Protective Action Guide (PAG)}

The radiation personnel exposure level or range beyond which protective action should be considered. PAG values should reflect a balance of risks and costs to onsite personnel, public health and safety, and the environment weighed against the benefits obtained from protective actions. 


\subsection{Radiological Control Manager}

The head of the Radiological Control Organization for each user company or laboratory at the NTS. The Radiological Control Manager shall have access to the respective company senior site executive for radiological control matters.

\subsection{Shelter}

A facility used to protect, house, and supply the essential needs of designated individuals during the period of an emergency. A shelter may or may not be specifically constructed for such use depending on the type of emergency and the specific programmatic requirements.

\subsection{Shutdown}

The term "shutdown" as used in this procedure has two distinct meanings. The first use provides for the quick and simple actions of facility occupants, while the second involves the more extensive efforts required for temporary or long-term isolation or closure of a facility.

\subsection{Site Area Emergency}

A class of emergency within the Operation and Energy Emergency categories. A Site Area Emergency represents events which are in progress or have occurred involving actual or likely failure(s) of safety or safeguard systems needed for the protection of BN personnel, public health and safety, the environment, or national security. An environmental release of hazardous materials is not expected to exceed the appropriate PAG or ERPG exposure levels offsite. Within the Energy Emergency category, a Site Area Emergency represents an event in which a substantial supply impact is anticipated.

\subsection{Standby Order}

Provides for a condition of increased readiness in a BN-occupied facility in response to a potentially serious incident or condition which is likely, but has not yet occurred. A Standby Order may result from such incidents as:

- A major fire or explosion in surrounding facilities, or in response to which emergency vehicles are utilizing the streets, driveways, or parking areas adjacent to the facility.

- Issuance of a severe weather phenomena watch or warning by the U.S. Department of Commerce, National Oceanographic and Atmospheric Administration (NOAA).

- A declaration of an Alert by another onsite facility or the U.S. Department of Energy, Nevada Operations Office (DOE/NV).

\subsection{Training}

The specific instruction providing sufficient detail, as necessary, to achieve suitable proficiericy in performing an assigned task. 


\subsection{Traffic Director}

An individual assigned to direct facility occupants to exits and facility assembly areas and/or evacuation assembly areas, convoy routes, and offsite staging areas. Traffic directors include uniformed security and law enforcement officers.

\subsection{AUTHORITIES AND RESPONSIBILITIES}

The DTSRP project management organizational structure is depicted in Figure.4-1. Authorities and responsibilities for those personnel having a functional role in emergency management are provided.

\begin{tabular}{|c|c|c|}
\hline Name & Title & Telephone \\
\hline Robert Dodge & BN Project Manager & $(702) 295-1632$ \\
\hline Michael D. Shotton & $\begin{array}{l}\text { BN Asst. Project Manager \& Site } \\
\text { Supervisor }\end{array}$ & (702) 295-1165 \\
\hline Craig Lyons & BN Site Health \& Safety Officer & (702) 295-0781 \\
\hline Dennis Finney & BN Construction Supervisor & (702) 2953724 \\
\hline Judy Schill & BN CQC Representative & (702) 295-6294 \\
\hline Karren Patton & BN Radiation Control Tech. Supervisor & (702) $295-4214$ \\
\hline Transportation & Sub-Contracted Services & TBD \\
\hline $\begin{array}{l}\text { Equipment Operators, Remediation } \\
\text { Technicians, and Sample Technician }\end{array}$ & Field Labor & TBD \\
\hline
\end{tabular}

Figure 4-1

Project Management Organizational Structure

\subsection{Project Manager}

The project manager is ultimately responsible for protecting the safety and health of workers and the general public, protecting the environment, and diminishing the risk or potential for an operational or nonoperational emergency. Responsibilities include:

- Overseeing the development, implementation, and maintenance of this procedure.

- Appointing a DTSRP Emergency Management Coordinator (EMC) and alternate.

- Serving as Incident Commander throughout an emergency or until relieved by arriving Emergency Response Organization (ERO) units.

- Serving as the interface between DTSRP personnel and responding emergency response personnel.

- Ensuring that Emergency Management indoctrination training is provided and documented for all DTSRP personnel, visitors, vendors, and subcontractors. 


\subsection{DTSRP Supervisors}

DTSRP Supervisors shall:

- Ensure implementation of this procedure during actual emergencies or drills.

- Assume the duties of the Project Manager if that individual is unavailable when an emergency occurs.

\subsection{DTSRP Emergency Management Coordinator (EMC)}

The DTSRP EMC shall:

- Serve as the principal point of contact for all Emergency Management related activities.

- Develop and maintain this procedure as required by the DOE/NVO Consolidated Emergency Management Plan, other governing DOE Orders, and applicable CFRs.

- Ensure that emergency management training and drills are conducted, documented and evaluated.

- $\quad$ Track the status and ensure actions are taken to correct deficiencies or problems identified during drills and programmatic audits or appraisals.

- Verify that identified emergency management deficiencies are corrected.

The primary and alternate EMCs for the DTSRP are:

\section{Primary Emergency Management Coordinators}

DOUBLE TRACKS EMC

NAME: $\quad$ Craig Lyons

Work: (702) 295-0781

DTSRP: $\quad$ (702) 295-8346

Home:

Radio Net:

Alternate Emergency Management Coordinators

\section{DOUBLE TRACKS Alternate EMC}

NAME: Dennis Finney

Work: $\quad$ (702) 295-3724

DTSRP: $\quad$ (702) 295-8346

Home:

Radio Net:

The EMCs are on call or onsite at all times. In the event of an emergency, the primary EMC should be contacted; if not available, an alternate EMC should be called.

\subsection{Building Wardens}

Building Wardens and alternates ( 1 building warden per 20 personnel) have been designated for areas and structures occupied during the project. Each building warden shall: 
- Maintain a roster of personnel assigned to their areas.

- Account for personnel and visitors located in their assigned areas, and report findings to the Project Manager upon notification of an emergency.

- Ensure evacuation route signs, emergency information, and notification requirements are posted in appropriate locations.

- Ensure emergency telephone lists and related documents are kept current.

\subsection{FACILITY DESCRIPTION}

\subsection{Site Location}

The Double Tracks Soils Remediation Project (DTSRP) (Nellis Air Force Range 71 North) is located in Stonewall Flat, west of the Tonopah Test Range. Range 71 North is currently used to evaluate weapons systems, train aircrews, and for radar bombing training. The nearest town is Goldfield, Nevada, located approximately 14 miles west of the DTSRP. The DTSRP site is located on an alluvial surface in Stonewall Flat. Stonewall Flat is bordered by the Cactus Range to the east, the Goldfield Hills to the northwest, and Stonewall Mountain to the south.

\subsection{Site Description}

The DTSRP site is relatively flat; surface runoff is toward the southwest. The elevation of the site is approximately $5,000 \mathrm{ft}$. above mean sea level. Vegetation is sparse, and desert pavement is present in areas where plants are absent. Blow-sand mounds occur beneath shrubbery. In bare areas, gravel constitutes an appreciable portion of the uppermost few centimeters of the soil (approximately 20 percent by weight); in desert mound, the uppermost few centimeters of soil consists of more than 90 percent sand.

\subsection{Topography}

The DTSRP site is located in the Great Basin of the Basin and Range physiographic province. The site is located in the Great Basin geologic province. This region is characterized by interior drainage and north-south-trending fault blocks that were formed by Late Cretaceous to early Tertiary extension, with rock ranging in age from Precambrian to Tertiary. Quaternary rock formations dominate the Stonewall Flat/DTSRP area. Dominant soils can be classified as alluvium and gravel. This valleyfill material consists of alluvial fan, fluvial, fanglomerate, and lakebed deposits.

\subsection{Prevailing Weather}

Precipitation levels on the DTSRP are low and run-off is intermittent. Annual precipitation in southern Nevada is very light and depends largely on elevation. A characteristic of desert climates is the temporal and spatial variability of precipitation. Topography contributes to this variability. For example, on the DTSRP, the mesas receive an average annual precipitation of nine inches which includes wintertime snow accumulations. The lower elevations receive approximately six inches of precipitation annually with occasional snow accumulations lasting only a matter of days. 
Precipitation usually falls in isolated showers with large variation in precipitation amounts within a shower area. Summer precipitation occurs mainly in July and August when the intense heating of the ground below moist air masses is transported northward from the tropical Pacific Ocean through the Gulf Coast of Mexico bringing widespread heavy precipitation to southern Nevada during September and/or October.

Average daily air temperatures are lowest in January $\left(35^{\circ} \mathrm{F}\right)$ and highest in August $\left(75^{\circ} \mathrm{F}\right)$. Large daily fluctuations in temperature are common, especially on the valley floors. Daily average minimum and maximum January temperatures at the DTSRP range from $-15^{\circ} \mathrm{F}$ to $67^{\circ} \mathrm{F}$, while July temperatures range from $40^{\circ} \mathrm{F}$ to $100^{\circ} \mathrm{F}$.

\subsection{POTENTIAL CREDIBLE EMERGENCIES AND HAZARDS}

The emergency procedures detailed in this document cover all potential credible emergencies and hazards as identified in the Double Tracks Soils Remediation Project (DTSRP) Emergency Management Hazard Assessment (EMHA), (see Attachment B). The DTSRP EMHA serves as the principal technical basis for all emergency management planning, preparedness, and response activities.

The principal hazards for the DTSRP are in the form of radionuclides present in the contaminated soil. The types of radiation associated with the contaminated soil are alpha, beta, and gamma. Credible emergencies include fires, floods, earthquakes, aircraft crashes, unexploded ordnance, and acts of terrorism.

\subsection{EMERGENCY NOTIFICATION AND REPORTING PROCEDURES}

\subsection{Emergency Notification}

The person who initially identifies an emergency at the DTSRP shall immediately notify a cognizant supervisor. If the emergency involves a release of radioactive or hazardous materials, the supervisor will call the Project Manager who will initiate any necessary offsite response notifications.

If the emergency is a fire, explosion, or involves personnel injury, the supervisor shall immediately notify the FOX 4 Net Coordinator via the MAYDAY/911 system. The FOX 4 Net Coordinator shall notify the Fire Protection Services and/or medical personnel, as required. The supervisor shall contact the Emergency Management Coordinator (EMC).

- The site supervisor contacts the FOX 4 NET (BLACK JACK) Coordinator through the MAYDAY/911 emergency notification system and describes the emergency.

- The site supervisor notifies the Emergency Management Coordinator (EMC) and the Project Manager.

If a hazardous material spill occurs, immediately notify a cognizant supervisor.

- The supervisor will notify the Assistant Project Manager.

- The Assistant Project Manager shall report all spills, leaks, and releases, no matter how insignificant, to the Project Manager. 
Information required by the response personnel:

- Name.

- The nature and location of the incident.

- The telephone number you are calling from or your net call number.

- Any associated injuries.

- $\quad$ The potential for fire.

- The name or United Nations (UN) placard number or waste stream identification number of the hazardous material released. (If applicable.)

- The size or volume of the release.

- The mitigating action(s) undertaken.

\subsection{Occurrence Reporting}

The basis for the distinction between a reportable occurrence as defined by DOE Order 232.1, "Occurrence Reporting and Processing of Operations Information" and the alert emergency class is contained in C.2.d.(1) thru (3) of the DOE Emergency Management Guide, Event Classification and Emergency Action Levels, dated June 26, 1992. The order definitions do not lend themselves to a quantifiable threshold between events which are considered reportable occurrences, as defined by DOE Order 232.1, "Occurrence Reporting and Processing of Operations Information", and the ALERT emergency class. To provide assistance in establishing this threshold, the following criteria have been developed:

(1) A rapid response which exceeds the capabilities of the normal operational organization is necessary.

(2) Involvement of the emergency response organization is necessary to assess conditions, perform mitigation, and manage and.implement protective actions. confines and require a time urgent response.

DOE Order 232.1 requires $B N$ to establish and maintain a system for reporting operations information related to DOE owned or operated facilities; processing information to identify the root causes of Off-Normal, Unusual, and Emergency Occurrences. The credible emergency scenarios listed below fall into the Emergency Occurrence category, and require the Project Manager to submit a Written Notification Report to DOE as required by DOE M 232.1-1, "Occurrence Reporting and Processing of Operations Information."

\subsection{PROTECTIVE ACTIONS}

In an emergency, the risk to personnel or to the public is not under control. Exposure may be limited by some form of intervention or protective action. The Protective Action Guides (PAGs) and Emergency Response Planning Guidelines (ERPGs) provide guidance to decision makers during an emergency and reduce potential risk or hazard to personnel. Protective actions include Stand-by Orders and Evacuation. 


\subsection{Standby Order}

Notification of Standby Order may be received via a FOX 4 Net Coordinator announcement, telephone, or messenger. Person(s) receiving notification shall initiate an "Emergency Condition Notification Record," see Attachment C.

\subsubsection{Information Required}

The following information must be relayed when making notification of a Standby Order:

- Name.

- $\quad$ Nature of the emergency (if drill or exercise, so indicate).

- Location.

Radio nets and telephone lines must be kept clear. These are to be used for transmitting emergency information only. Personnel will be assigned to assist visitors.

\subsection{Evacuation}

Notification to evacuate may be received via FOX 4 BlackJack Net Coordinator announcement, telephone, or messenger. Person(s) receiving notification will complete the "Emergency Condition Notification Record" (see Attachment C). The evacuation route from the DTSRP proceeds east across the Cactus Range to the TTR, north from the TTR on Sandia Drive (State Route 504) to the junction with U.S. Highway 6, west on U.S. Highway 6 to the intersection with U.S. Highway 95 in Tonopah, and south on U.S. Highway 95 to the NTS.

\subsubsection{Information Required}

The following information must be relayed when making notification to evacuate:

- Name. .

- Nature of the emergency (if drill or exercise, so indicate).

- Location of personnel evacuation assembly areas.

\subsubsection{Accountability}

To ensure personnel accountability:

- The cognizant EMC/alternate will account for the DTSRP personnel listed on the notification rosters.

- Accountability information will be relayed via FOX 4 NET Radio following evacuation, to the Project Manager through the Emergency Coordinator.

\subsubsection{Status Reports}

The Site Supervisor will provide status reports to the Project Manager when evacuations are complete and all personnel have been accounted for. 


\subsection{REENTRY PLANS AND PROCEDURES}

Reentry into the DTSRP will be a coordinated decision between DOE, DOD, and the Tonopah Test Range. Personnel assigned to the DTSRP will comprise the reentry team.

Where hazardous materials are involved, generally the plume will dissipate and will not cause harmful fallout. Because of the difference in the inherent hazard associated with radiological materials versus hazardous materials, different reentry and response actions are required. If an emergency occurs at the DTSRP, personnel will evacuate, fall back, and evaluate the situation. The Project Manager will consult closely with the Site Health and Safety Officer to ensure that personnel are properly protected prior to reentry operations.

The DOE, DOD, S\&HD, HPD, and the Double Tracks Project Manager shall determine whether reentry is advisable. Radiation detection instruments used to determine whether the site is safe to enter are available at the DTSRP. Evacuated personnel will be interviewed to obtain information about the emergency. No reentry shall be attempted until the situation has been thoroughly evaluated by the Project Manager. At that time, a reentry team may enter the area to determine the extent of damage and/or contamination and to determine requirements for placing the site back into operation.

Reentry into the DTSRP will be accomplished as follows:

- If it is determined by a health physicist that PPE is required, Personal Protective Clothing (PCs) and appropriate respiratory protective equipment will be issued to the reentry team. The team will-also be issued a portable radio to maintain communication with the cognizant health physicist. The team will be instructed to abort the reentry and exit the area in the event of a communications failure.

- The site will be surveyed with alpha-beta-gamma instruments, and the results communicated to the cognizant health physicist. Initially, the survey instruments will be set on their lowest scales. The results of the sampling will be used to help evaluate the seriousness of the accident and to develop plans for control and cleanup.

\subsection{RESUMPTION OF OPERATIONS}

Before operations resume, an investigation will be made to determine the cause of the incident. Only after a thorough investigation will clean-up operations and normal operations be initiated. The Project Manager will provide this information to the Administrator, Nevada Division of Environmental Protection.

\subsection{EMERGENCY SERVICES AND EQUIPMENT}

\subsection{Medical Services}

The BN Occupational Medicine Department provides medical services to the DTSRP. Two paramedics with a fully equipped ambulance will be available onsite for the duration of the project. Emergency medical transportation will be provided to Nye Regional Hospital. 


\subsection{Radiological Services}

Radiological services include the Radiological Assistance Team and dosimetry evaluation. For onsite emergencies, BN HPD technicians will evaluate personnel and facility dosimetry, and operate instrumentation to detect radioactive materials. Mobile decontamination equipment and services are available for the DTSRP as required.

\subsection{Industrial Hygiene Services}

The HPD/IHP (295-4560) has direct-reading instrumentation available along with trained personnel for determining chemical hazards. HPD/IHP personnel are also available for consultation for determining the level and type of PPE required for emergency response and reentry.

\subsection{Fire Protection Services}

Due to the DTSRP geographic location, fire response services will not be provided. Personnel are authorized to fight incipient stage fires. Incipient stage fire refers to a small fire or one that is in its initial stages. Further, the definition of a small fire is one that can be extinguished by one fire extinguisher.

\subsection{PERSONNEL TRAINING}

Emergency management indoctrination training and drills shall be conducted to ensure all personnel understand the emergency procedures and protective actions to be taken in the event of a natural or technological emergency at the DTSRP. Emergency management training records shall be kept until closure of the DTSRP. 


\section{APPENDIX A}

\section{REFERENCES}

Title 29 CFR 1910.120, "Hazardous Waste Operations and Emergency Response."

DOE Order 151.1, "Comprehensive Emergency Management System."

DOE Order 420.1, "Facility Safety."

DOE Order 232.1, "Occurrence Reporting and Processing of Operations Information."

DOE Order 5480.11, "Radiation Protection For Occupational Workers."

DOE Order 5820.2A, "Radioactive Waste Management"

DOE Notice 5500.5, "Emergency Preparedness Program and Notification System.."

DOT Emergency Response Guidebook.

10 CFR 835: "Occupational Radiation Protection".

Emergency Medical Response Plan for the Nevada Test Site.

DOE Emergency Management Guide, Event Classification and Emergency Action News, June 26, 1992.

NVO-325.

Bechtel Company Procedure A-9, "Reporting Emergencies and Responding to Fires."

Bechtel Company Procedure SP-07, "Accident/Incident Reporting and Investigations." 


\section{APPENDIX B}

\section{EMERGENCY MANAGEMENT HAZARDS ASSESSMENT FOR DOUBLE TRACKS SOILS REMEDIATION PROJECT}




\section{Bechtel Nevada}

APPENDIX B

EMERGENCY MANAGEMENT

HAZARDS ASSESSMENT

FOR

DOUBLE TRACKS

SOILS REMEDIATION PROJECT

Revision 0

June 17, 1996

Prepared By

Bechtel Nevada

Emergency Services Section 


\section{TABLE OF CONTENTS}

\section{SECTION}

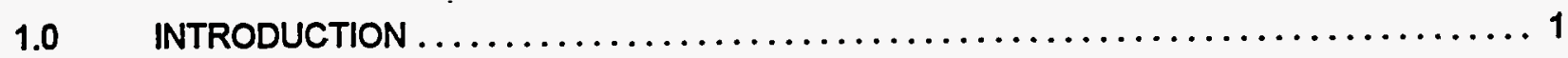

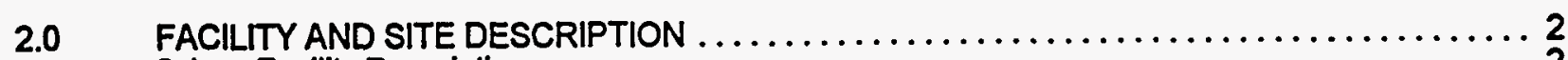

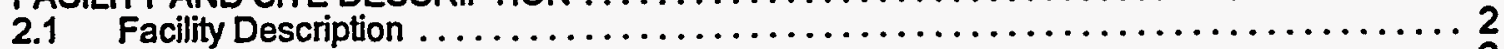

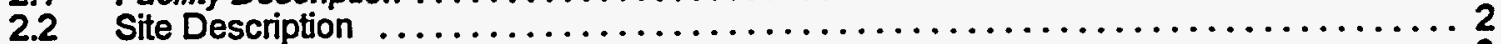

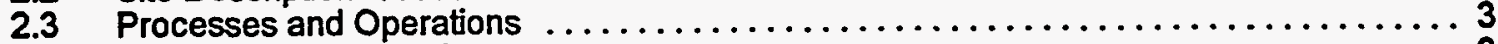

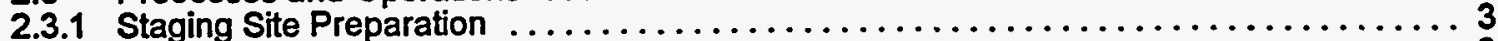

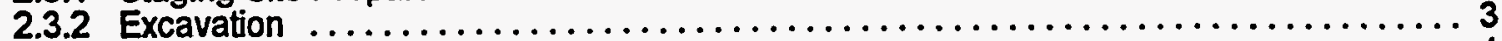

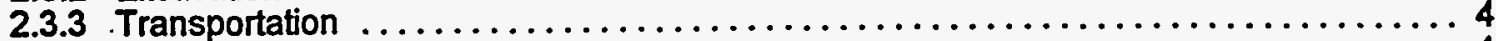

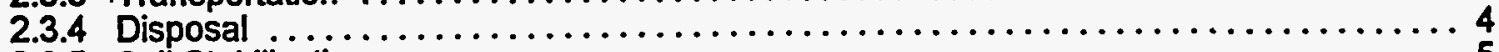

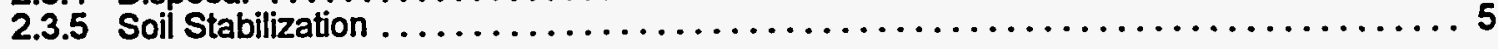

3.0 IDENTIFICATION AND SCREENING OF HAZARDS $\ldots \ldots \ldots \ldots \ldots \ldots \ldots \ldots \ldots \ldots \ldots$

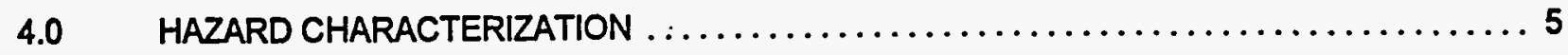

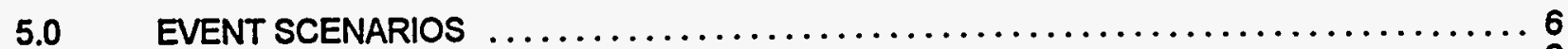

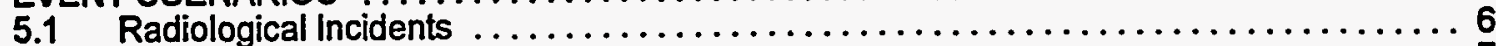

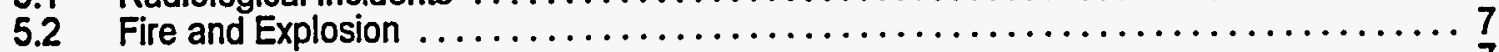

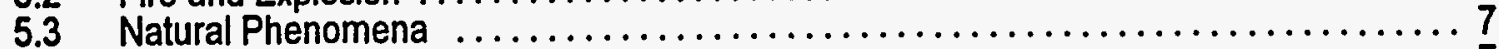

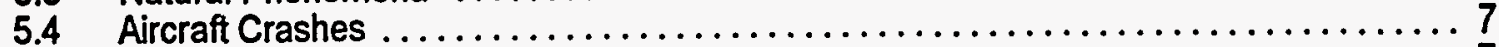

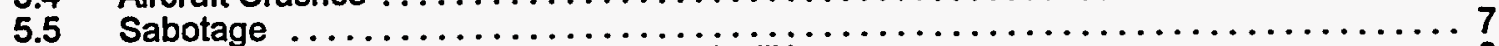

5.6 Exposure to Emergencies in Adjacent Facilities ........................... 8

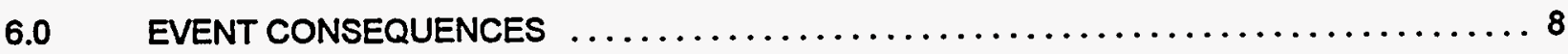

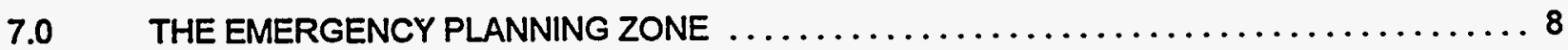

8.0 EMERGENCY CLASSES, PROTECTIVE ACTIONS AND EALS $\ldots \ldots \ldots \ldots \ldots \ldots \ldots .8$

9.0 MAINTENANCE AND REVIEW OF THIS HAZARDS ASSESSMENT $\ldots \ldots \ldots \ldots \ldots \ldots .$. 


\subsection{INTRODUCTION}

This report documents the hazards assessment for the Double Tracks Soils Remediation Project located on the Department of Defense (DOD) Nellis Air Force Range 71 North. The Emergency Management Hazard Assessment (EMHA) was developed in accordance with DOE Order 151.1, "Comprehensive Emergency Management System," and supporting guidance provided in the DOE Emergency Management Guide (EMG), "Guidance for Hazards Assessment," dated 06/92. This guide provides the methodology for the development EMHAs, which serve as the technical basis for all emergency planning, preparedness, and response activities. The screening thresholds listed in the Hazards Assessment Emergency Management Guide are:

- Threshold Planning Quantities (TPQs) from 40 CFR 355, Appendix A, for chemicals.

- Threshold values from 10 CFR 30.72 , Schedule $C$, for radioactive materials.

If a facility contains materials in excess of the screening thresholds, a consequence assessment is performed to determine if postulated releases would exceed predetermined levels beyond the site boundary. The EMG indicates that a Protective Action Guide (PAG) of 1 rem, or 5 rem for radionuclides with long biological half lives, shall be used. The PAG is a recommended Committed Effective Dose Equivalent (CEDE). If the potential exists for members of the general public or employees to be exposed, then protective actions (i.e., sheltering, evacuation, etc.) should be implemented.

ERPG- 1 is the maximum airborne concentration below which it is believed that nearly all individuals could be exposed up to one hour without experiencing other than mild transient adverse health effects or symptoms that could impair their abilities to take protective actions.

ERPG-2 is the maximum airborne concentration below which it is believed that nearly all individuals could be exposed up to one hour without experiencing or developing irreversible or other serious health effects or symptoms that could impair their abilities to take protective actions.

ERPG-3 is the maximum airborne concentration below which it is believed that nearly all individuals could be exposed up to one hour without experiencing or developing lifethreatening health effects.

If the established PAG or ERPG levels are exceeded at the facility or site boundary, the emergency would be classified as a Site Area Emergency, or General Emergency, respectively. The combination of postulated events and projected consequences are used to develop facility-specific EALs. EALs may be event based or symptom based, and are specific, observable criteria which personnel can equate to an emergency classification.

An EPZ is an area defined by geophysical boundaries that is developed using the results of the consequence assessment. The EPZ allows planning to be focused on those areas which are most likely to impacted in the event of an accident. In addition to the 
PAG/ERPG-2 levels discussed above, the consequence assessment projects the distance at which Early Severe Health Effects (ESHE), may occur for each postulated event scenario. The EMG lists 100 rem CEDE: or ERPG-3 as the dose or concentration at which ESHE may occur. Initially, the EPZ's are circles which are then confoured to geophysical boundaries. Minimum EPZ's are set as the greater distance to ESHE or 3.1 miles for a General Emergency classification; the greater distance to ESHE levels or 1.25 miles for a Site Area Emergency classification, and the greater distance to ESHE levels or $1 / 2$ mile for an Alert Emergency classification. Therefore, the EPZ is the Exclusion Zone Fence.

\subsection{FACILITY AND SITE DESCRIPTION}

\subsection{Facility Description}

The temporary work site facilities for the Double Tracks Soils Remediation Project were established for the sole purpose of remediating plutonium-contaminated soils. This work will be performed by the Bechtel Nevada Corporation under prime contract DEAC08-96NV11718 with the Department of Energy.

Double Tracks was part of Operation Roller Coaster. This Operation was conducted to provide data to establish criteria for transportation and storage of plutonium bearing weapons. The Double Tracks event was conducted in 1963 and involved the detonation of high explosives in a depleted uranium and plutonium bearing device. Ground deposition and airborne sampling arrays were employed to obtain data on the aerosol/particulate cloud, and to determine surface deposition phenomena. Three hundred dogs, sheep and burros were used during Double Tracks to study the lung retention of the plutonium aerosol.

The ground zero area consisted of a concrete pad 1 foot thick which measured $20^{\prime} X$ 20'. The surface soil was stabilized with "Golden Bear" oil-based emulsion to a radius of 50 feet. The debris in the vicinity of the ground zero pad was collected and buried nearby. The contaminated surface of the compacted areas around the ground zero area may have been disturbed by such activities to a radius of 125 yards.

\subsection{Site Description}

The Double Tracks Soils Remediation Project is located in on Range 71 North of the Nellis Air Force Range, northwest of the NTS. Range 71 North is located in Stonewall Flat, west of the TTR. Range 71 North is currently used to evaluate weapons systems, train aircrews, and for radar bombing training. The nearest town is Goldfield, Nevada, located approximately 14 miles west of the site.

The DTSRP is located on an alluvial surface in Stonewall Flat. Stonewall Flat is bordered by the Cactus Range to the east, the Goldfield Hills to the northwest, and Stonewall Mountain to the south. The DTSRP is relatively flat; surface runoff is toward the southwest. The elevation of the site is approximately $5,000 \mathrm{ft}$. above mean sea level. Vegetation is sparse, and desert pavement is present in areas where plants are absent. Blow-sand mounds occur beneath shrubbery. In bare areas, gravel constitutes an appreciable portion of the uppermost few centimeters of the soil (approximately 20 percent by weight); in desert mound, the uppermost few centimeters of soil consists of more than 90 percent sand. 
The site is located in the Great Basin geologic province. This region is characterized by interior drainage and north-south-trending fault blocks that were formed by Late Cretaceous to early Tertiary extension, with rock ranging in age from Precambrian to Tertiary. Quaternary rock formations dominate the Stonewall Flat/Double Tracks Soils Remediation Project area. Dominant soils can be classified as alluvium and gravel. This valley-fill material consists of alluvial fan, fluvial, fanglomerate, and lakebed deposits.

The soil in the project area was contaminated with transuranic elements by the Double Tracks test. Contamination levels vary with the distance from ground zero and as a function of wind direction at the time of the test. At the 200-pCi/g level and above, the real extent of contamination is estimated to be approximately 2.2 acres as illustrated by DOE Environmental Assessment Double Tracks Test Site Figure 3-1 "Total Transuranic Isotope Activity of Double Tracks Soil" dated December 1995.

\subsection{Processes and Operations}

The proposed action is a voluntary corrective action that includes establishment of a staging area for onsite project administration, operations, maintenance, and decontamination; excavation of plutonium contaminated soil in excess of $200 \mathrm{pCi} / \mathrm{g}$; transport of excavated soil through the TTR and on public highways to the NTS; disposal at the NTS; and soil stabilization.

The proposed action would involve clearing an area of 1.5 acres for a staging area, and remediating a contaminated area of 2.2 acres. The impact analysis is based on this total (bounding) area of disturbance. The five components of the project (staging site preparation, excavation, transportation, disposal, and soil stabilization) are described in the following paragraphs.

\subsubsection{Staging Site Preparation}

Site preparations will be required prior to the start of work. The U.S. Air Force (USAF) will schedule flight paths away from the work site during work hours. An area of about 1.5 acres will be cleared of vegetation for administrative trailers, maintenance facilities, and a decontamination area.

In addition, the Cactus Springs Road will require grading and compaction for use by trucks transporting soil from the project area to the disposal site at the NTS. Prior to the start of operations, generators will be brought to the site to supply power for administrative trailers and facilities.

\subsubsection{Excavation}

To date, no remediation level has been determined; however, assuming a cleanup level of $200 \mathrm{pCi} / \mathrm{g}$, the proposed action will involve the removal of approximately 1,620 cubic yards [yd $\left.\mathrm{y}^{3}\right]$ of soil. This volume does not account for the expansion of soil when disturbed by excavation, which is expected to contribute an additional 20 to 50 percent (volume) at the DTSRP. Excavation will start in the summer of 1996, with an expected duration of $60 \pm 30$ days. 
The excavation component consists of the use of four options: (1) a front-end loader, (2) a self-loading scraper to excavate and collect soil, and (3) a motor grader to windrow a thin cutting of soil and a scraper to remove the windrows. The actual excavation may be performed using a combination of these options. The excavation equipment will remain in the exclusion zone for the duration of the excavation, unless repair work dictates decontamination and removal.

Soil will be stockpiled at a location on the edge of the contaminated area in the contamination reduction zone. A front-end loader will transfer the soil from the stockpile to soil processing equipment which will remove material larger than $3 / 4$ inch in diameter. A small volume of bentonite will be added to the soil and the soil bagged into supersacks. The supersacks will be loaded into transportainers for shipment to the NTS Area 3 Radioactive Waste Management Site for disposal as low-level radioactive waste.

Support activities occurring concurrently with the soil removal action will include vehicle decontamination, dust suppression by application of water and possible chemical stabilizers, road maintenance, and air monitoring for health and safety purposes. During excavation work in the contaminated zone, personal air monitors will be worn by workers in compliance with the health and safety plan in effect at that time and work will be conducted in accordance with OSHA and DOE Orders. In addition, air monitoring stations will be established at the perimeter of the site to monitor dust generation.

\subsubsection{Transportation}

Making one round trip per work shift, trucks will travel, individually or in convoys, approximately $\mathbf{2 8 0}$ mi from the DTSRP to the disposal facility at the NTS. Routing will be east across the Cactus Range to the TTR, north from the TTR on Sandia Drive (State Route 504) to the junction with U.S. Highway 6, west on U.S. Highway 6 to the intersection with U.S. Highway 95 in Tonopah, and south on U.S. Highway 95 to the NTS.

Assuming that the effective capacity of each transport vehicle is $8.8 \mathrm{yd}^{3}$, an estimated $188 \pm 35$ loads will be required to transport the soil. The expected duration of loading and transporting soil is $60 \pm 30$ days. Waste will be packaged and shipped in accordance with applicable DOT regulations and NVO-325 waste acceptance criteria. Truck drivers would be trained and made aware of potential hazards along the transportation route. In preparation for waste transport, emergency services will be notified of the transportation routes and appropriate response procedures.

\subsubsection{Disposal}

At the NTS, DTSRP soil will be placed into the Area 3 Bulk Radioactive Waste Management Site (RWMS). Using a worst case soil expansion factor of 50 percent for the Double Tracks soil results in a total waste volume of approximately $2430 \mathrm{yd}^{3}$ for disposal. This is not a sufficient volume to require closure of existing cells at the Area 3 Bulk RWMS as the remaining volume if this cell is $203,820 \mathrm{yd}^{3}$. Transuranic waste, if produced, will be disposed of after the resolution of issues pertaining to disposal of the waste type. 


\subsubsection{Soil Stabilization}

Upon completion of site remediation, the site will be treated with chemical soil stabilizers to ensure short-term stabilization. Long-term stabilization and restoration of the site would be accomplished by establishing a permanent plant community. A revegatation plan has been developed.

\subsection{IDENTIFICATION AND SCREENING OF HAZARDS}

The DOE EMG, "Guidance for Hazards Assessment," states "Those materials for which the maximum facility inventory is less than the screening quantity may be eliminated from further consideration in the hazards assessment." The screening levels for chemicals that were used for this hazards assessment are the Threshold Planning Quantities (TPQs) defined in 40 CFR Part 355, Appendix A. The screening levels for radioactive materials are the quantities listed in 10 CFR 30.72 , Schedule $C$.

Preliminary evaluations of hazards screened out all other chemicals or materials from further consideration. The only hazardous materials identified that exceeded thresholds (10 CFR 30.72, Schedule C) are the radionuclides associated with weapons grade plutonium.

The hazardous materials stored, used, or produced at the DTSRP have been identified in the Site Specific Health and Safety Plan (SSHASP), dated May 17, 1996. The SSHASP lists the most common hazardous materials with the exception of radiological hazards that exceed the established safety and radiological controls.

\subsection{HAZARD CHARACTERIZATION}

A thorough characterization is required for each hazardous substance. Information required for the characterization includes: inventory of material, properties, and conditions of storage and use. Based upon the nature of the construction like activity at the TTR, there are no hazardous substances identified.

Double Tracks is known to be contaminated with plutonium, americium, and depleted uranium. The primary mode of exposure to personnel is inhalation. Respiratory protection will be required for those areas with soil concentrations exceeding 1,000 $\mathrm{pCi} / \mathrm{g}$. This will include all the area around Ground Zero inside the inner fence posts. No respirators will be required for the remainder of the remediation area unless personal air sample results or dust loading measurements exceed action levels. The ALARA goal for total planned inhalation exposure will be $100 \mathrm{mrem}$. Inhalation doses will be estimated and recorded daily from air sample results. Other work locations within the exclusion zone will be evaluated for respiratory protection requirements as equipment is positioned and operated.

Skin and clothing contamination presents a hazard to personnel. The ALARA goal for the DTSRP is no reportable skin or clothing contaminations. High activity metal fragments were detected and collected during the characterization of the site. They represent the highest potential for contamination, ingestion and inhalation exposures to personnel if not handled properly. Personnel will use handling tools to pick up fragments and place them in containers as soon as possible. 
All personnel are required to wear their TLDs when inside the exclusion zone. The TLDs are capable of measuring doses from the low-energy gamma and $x$-rays from the americium and plutonium although no reportable doses are expected based on previous TLD results after characterization studies.

The area within the original exclusion fence around Ground Zero will be posted as an Airbome Radioactivity Area and will require respiratory protection in addition to protective clothing. Other operations within the EZ such as the conveyor/bag loading system will be evaluated by air sampling and respiratory protection will be required as needed. The remaining areas within the EZ will require protective clothing with Personal Air Samplers on routine workers.

Respirators for radiological protection include a full-face respirator with a Powered Air Purifying Respirator (PAPR) unit with HEPA filters or a HEPA filter canister/full face respirator combination. Respirators for fugitive dust protection may be a half-mask with cotton dust filters.

Personal Air Samplers (Gillian GilAir 5 Pumps or ALPHA-1 air sample pumps) will be issued to most personnel entering the Exclusion Zone. This will be the primary surveillance instrument for estimating inhalation doses in the work environment. The pumps will run all shift with the filters collected at the end of the day and counted during off-hours. The results will be evaluated by the site Health and Safety coordinator to change protection levels in the work area to keep inhalation doses ALARA.

The Satellite air sampler will be stationed at the EZ fence within the trailer park and will run throughout the shift. The filter will be counted to assess any potential doses to support personnel from fugitive dust generated within the EZ.

\subsection{EVENT SCENARIOS}

\subsection{Radiological Incidents}

The principal radiological hazards for the DTSRP are the radionuclides present in the contaminated soil. The probability of a radiological incident within the Double Tracks Soils Remediation Project is remote based on the administrative controls and Personnel Protective Equipment (PPE) listed in Section 4, Hazard Characterization. The probability of a radiological incident during the transportation function of this project is credible. The resulting emergency classification involving a spill of radiological material on the public highway would be an Alert. In the event of a spill, the transporter is ultimately responsible for cleanup. However, if requested to assist either by an official from the transporter or by an appropriate emergency management person, BNC personnel will respond (on a cost-reimbursable basis) to assist with preliminary cleanup.

The types of radioactivity associated with this soil are alpha, beta, and gamma. Alpha radiation is an internal hazard. As long as radioactive material that emits only alpha particles remains outside the body, it will not cause damage. Once inside the body, lungs, stomach, or an open wound, there is no thick layer of skin to serve as a barrier and thus, damage results. Beta emitters are generally considered to be an internal hazard, although they can also be 
classified as an external hazard because they can produce burns when they come in contact with the skin. As an internal hazard, they require the same precautions as do alpha emitters. Radioactive materials that emit gamma rays are considered to be both internal and external hazards. Such materials can be located some distance from the body and emit radiation that would damage tissue as it passes through the body.

\subsection{Fire and Explosion}

The probability of fire within the DTSRP is remote. Primary emergency response is provided by onsite BN Emergency Medical Services. For evacuation purposes, personnel will evacuate to the entrance of the access road adjacent to the support services area. This area will serve as the Evacuation Assembly Area. The site supervisor will serve as Facility Coordinator (FC). The Project Manager will ensure evacuation instructions are provided to the personnel working the project. Information will be disseminated during "Tailgate Safety Meetings" conducted each morning before the personnel begin work.

\subsection{Natural Phenomena}

The probability of major damage to the DTSRP as a result of lightning, high winds or tornadoes, earthquakes, or floods is remote. Provisions for warning, preparation, and protective actions for severe natural phenomena are provided for through the U.S. Department of Commerce, National Oceanographic and Atmospheric Administration, Air Resources Laboratory (ARL)/Special Operations Research Division (SORD), and the (TTR Emergency Communications NET Number/All Net Announcements).

1. MERCURY NET 12 = EPA Response Net (tie/patch to NTS)

2. SANDIA NET

3. CEDAR NET = Security (CACTUS)

4. SIMPLEX NET

5. NET 85

6. FOX 4 NET = Air Force NET, Range Control with access to Black Jack.

\subsection{Aircraft Crashes}

Military and security helicopter and fixed-wing aircraft flight pattems near the DTSRP make it conceivable for an aircraft to crash into the facility. The likelihood of such an accident is extremely remote, but such an accident would be potentially catastrophic to life and property from impact, fire, and explosion. The FOX 4 Net will be used for notification purposes.

\subsection{Sabotage}

Due to the nature of operations at the Double Tracks Soils Remediation Project, and the security provided at the DTSRP, sabotage targets are very limited. Since there are no toxicological or radiological targets of significance associated with the facility or project operations, sabotage would be limited to an unlikely attempt to disrupt operations through acts of vandalism or arson. 


\subsection{Exposure to Emergencies in Adjacent Facilities}

There are no adjacent facilities; the nearest complex is over 20 miles away. The probability of major damage to the DTSRP as a result of a fire or an explosion in a neighboring complex is extremely remote.

\subsection{EVENT CONSEQUENCES}

All activities are confined to the DTSRP, with the exception of the transportation function.

\subsection{THE EMERGENCY PLANNING ZONE}

The results of the consequence analysis are to be used to develop a proposed Emergency Planning Zone (EPZ) for the DTSRP. The highest potential emergency class is an Alert. A credible event will produce consequences exceeding the early severe health effects (ESHE) threshold as far as the Exclusion Zone fence. The transporter is responsible for mitigating offsite spills with the assistance of BNC.

\subsection{EMERGENCY CLASSES, PROTECTIVE ACTIONS, AND EMERGENCY ACTION LEVELS}

The highest emergency class is an Alert. This classification is due to the possibility of inhalation of the airborne resuspended plutonium above the $100 \mathrm{mrem}$ threshold limit value. Based on the Personnel Protective Equipment (PPE) requirements for personnel working in this area, the probability of inhalation is remote.

\subsection{MAINTENANCE AND REVIEW OF THIS HAZARDS ASSESSMENT}

The Emergency Services Section Manager is responsible for ensuring that this assessment is reviewed annually and, whether revised or not, will be reissued with the new signatory date as a controlled document according to the provisions of Bechtel Nevada Corporation Procedure (132)A-11.14.1.

In addition, operations at this project will be continually evaluated and this document updated to ensure that current conditions are reflected herein. The maintenance of this hazards assessment in a near real-time manner is necessary to ensure that the Emergency Management Implementing Procedures, for which this hazards assessment provides a partial basis, are complete and correct. 


\section{APPENDIX C}

\section{STATUS REPORT OF EMERGENCY CONDITIONS}




\section{Bechtel Nevada}

\section{STATUS REPORT OF EMERGENCY CONDITIONS}

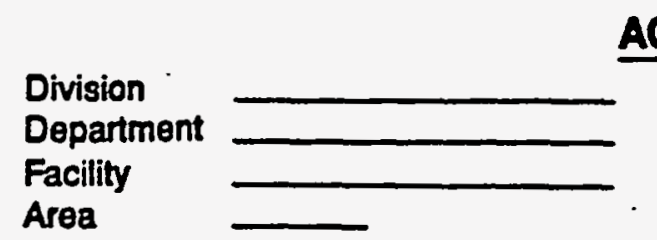

Complete this section to document the date and time that each of the following actions occur. The actions that must be completed depend on the type of emergency. For actions that are not applicable, write "N/A" in the date and time columns. The safe evacuation of personnel is of primary importance; therefore, this form should be completed as time and circumstances permit.

DATE

TIME

Alert Actions Initiated:

*Alert Actions Completed:

Take Cover Actions Initiated:

Take Cover Actions Completed:

Evacuation of Facility Initiated:

-Evacuation of Facility Completed:

Movement to Evacuation Assembly Area Initiated:

"Movement to Evacuation Assembly Area Completed:

"Movement to Offsite Staging Area Initiated:

- Movement to Oftsite Staging Area Completed:

"All Clear" Notification Received:

-Normal Operations Resumed:

As the emergency situation develops and following completion of each item noted with an asterisk ("), a verbal status report shall be made to your supervisor.

Reports shall also include any other critical information such as:

1. Number of injuries of tatalities.

2. Nature and exteint of exposures.

3. Nature and extent of property damage.

4. Current requirements for assistance. 


\section{OTHER ACTIONS OR SIGNIFICANT EVENTS}

Complete this section to document any other actions or significant events, such as additional instructions received or problems encountered. Write N/A if there were none.

\section{Print Name of Pareon Completing Racord}




\section{APPENDIX D}

\section{EMERGENCY RESPONSE CHECKLIST}




\section{Bechtel hevada \\ EMERGENCY RESPONSE CHECKLIST}

\section{DATE OF ACTION}

\section{ALERT TAKE COVER EVACUATION}

1. Condition Identified

2. Emergency Condition Notification Record (RE-6803) Prepared

3. Personnel Accounted For By Roster

4. Classified Material Secured

N/A

5. Files Locked

N/A N/A

6. Exterior Doors Windows Closed

N/A

7. Electrical Equipment Unplugged

N/A

8. Vehicles on Standby Ready

N N/A

9. Lights Tumed Off

N/A N/A

10. Heating and AC Tumed Off

N/A

11. Assure Personnel Have Evacuated

N/A N/A

12. Department/Division Office Notified

13. "Building Evacuated" Signs (Yellow Tape) Placed

N/A N/A

14. All Clear Received

15. Personnel Notified to Return to Work

N/A

16. Returning Personnel Accounted For

17. Returning Vehicles Accounted for

NA NIA

18. Status Report of Emergency Concitions (RE-6804) Prepared

Building or Facility Involved

Wing or Part of Building or Facility Involved 


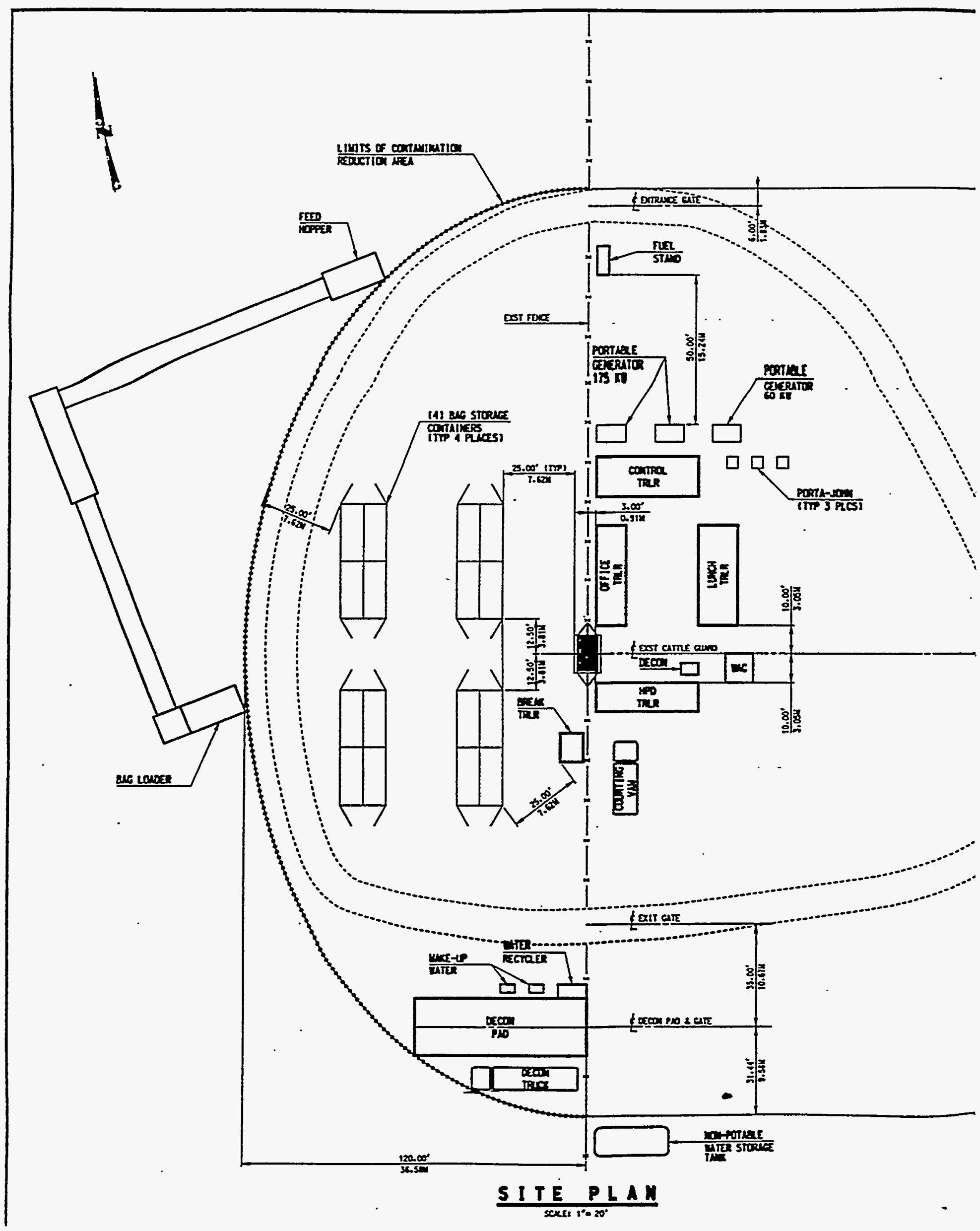




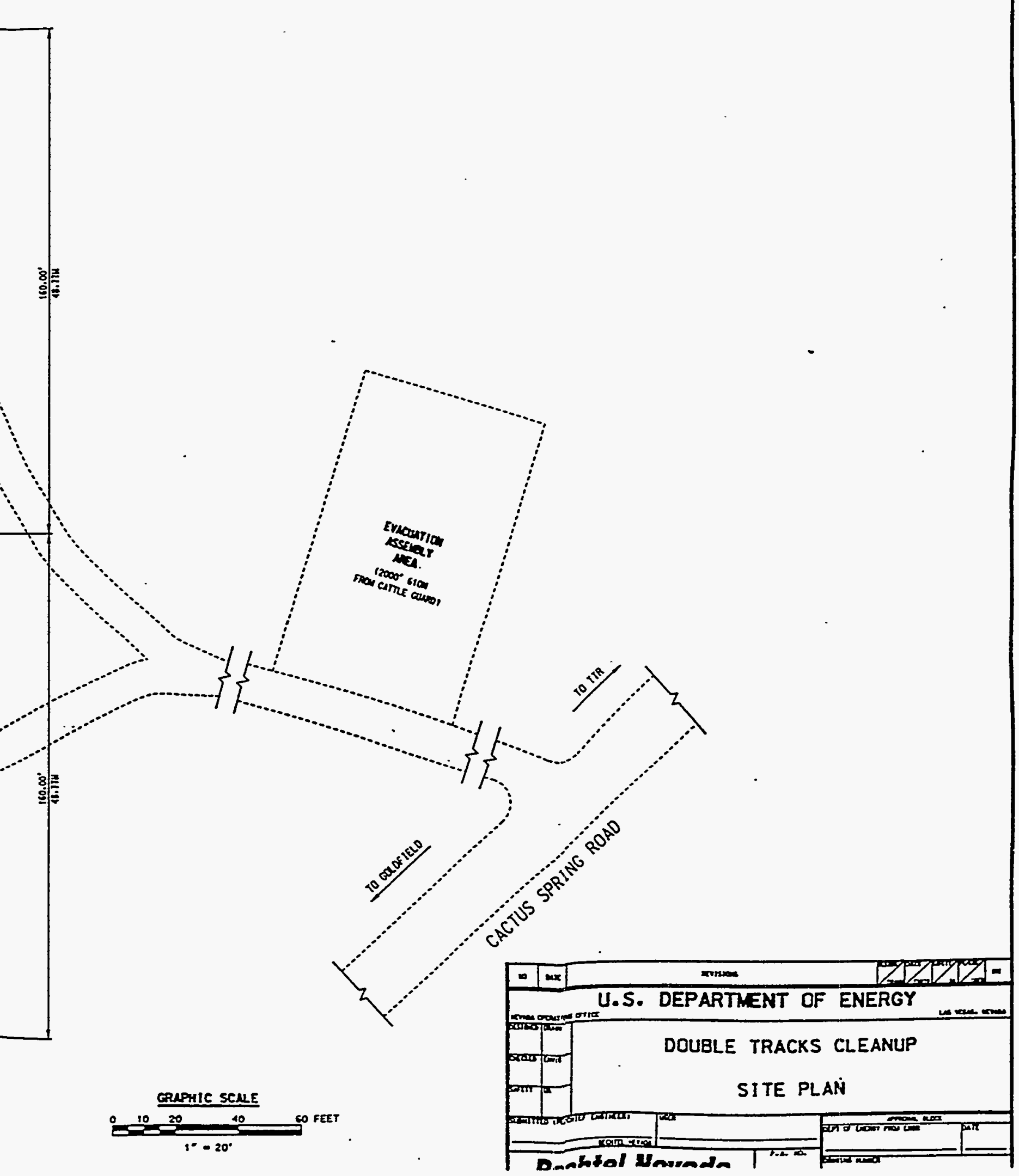


APPENDIX B

SAMPLING AND ANALYSIS PLAN 


\section{Bechtel Nevada}

- Mailing address: P.O. Box 98521

Las Vegas, NV 89193-8521

Express mail onty: 2621 Losee Road

North Las Vegas, NV 89030-4134

January 16, 1996

Mr. Dennis L. Armstrong

Waste Management Division

DOE Nevada Operations Office

Post Office Box 98518

Las Vegas, NV 89193-8521

Subject: Contract No. DEAC08-9.6NV11718

Sampling and Analysis Plan (SAP) for the Characterization of

Radioactively Contaminated Soil at the Double Tracks Site

Dear Mr. Ärmstrong:

Attached is the subject plan. Sampling under this SAP is scheduled for January 30,1996, so that characterization data can be provided to the Radioactive Waste Acceptance Program (RWAP) personnel by mid-April; and the excavation and disposal can begin on the planned June 1, 1996, date. The June 1, 1996, date is being driven by the Department of Energy/Nevada Operations Office Environmental Restoration Division.

In order to accommodate the January 30,1996, sampling date, by copy of this letter the RWAP personnel are being provided with a copy of the SAP to allow for as long a review period as possible. Comments should be submitted to Mark J. Krauss no later than January 23, 1996, so that any revisions to the SAP can be completed in time for sampling on January 30, 1996.

If you have any questions or need additional information, please contact Mark J. Krauss at 295-0685.

Sincerely,

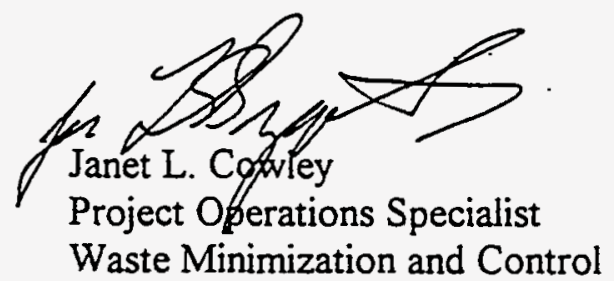

ЛLC:MJK:6:edh 
Dennis L. Armstrong

Page 2 of 2

January 16, 1996

Attachment: $\quad$ Sampling and Analysis Plan (SAP) for the Characterization of Radioactively Contaminated Soil at the Double Tracks Site

File No.:

Response Required: Yes

Due Date:

January 23, 1996

cc:

D. Schmidhofer, DOE/NV, w/a, M/S 505

bcc:

Communications Control, w/a, M/S NLV008

W. S. Birchfiel, w/o, M/S 622

M. A. Hallmark, w/o, M/S 622

A. M. Heidema, w/a, M/S 501

B. M. Imai, w/o, M/S 622

M. J. Krauss, w/o, M/S 622.

J. R. Kannard, w/a, M/S NLV-022

D. S. Long, w/a, M/S 580

C. L. Lyons, w/a, M/S 428

L. S. Sygitowicz, w/a, M/S 501 
DOUBLE TRACKS

SAMPLING AND ANALYSIS PLAN

NEVADA TEST SITE

JANUARY 1996

REVISION 1 


\title{
SIGNATURE PAGE
}

\author{
DOUBLE TRACKS
}

\section{SAMPLING AND ANALYSIS PLAN}

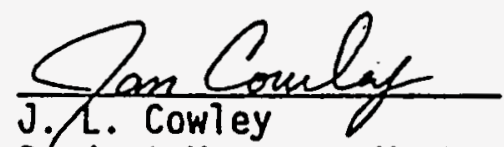

Project Manager, Waste Control

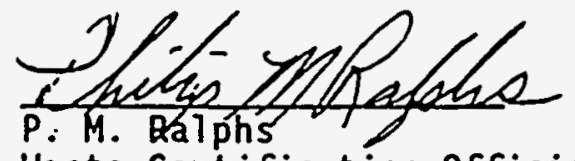

Waste Certification Official

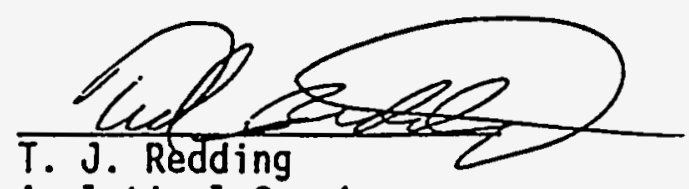

Analytical Services 


\section{TABLE OF CONTENTS}

1.0 Introduction $\ldots \ldots \ldots \ldots \ldots \ldots$ 1.1 Purpose ........................ . . . .

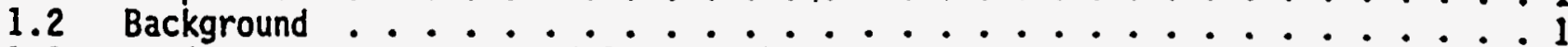

1.3 Project Organization and Responsibility. ............

1.4 Process Knowledge and Existing Analytical Data ...........6 6

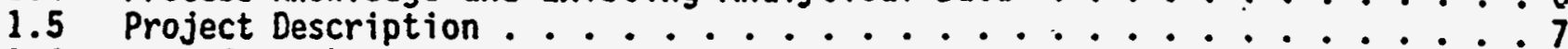

1.6 Use of Results ...................... . . . . . .

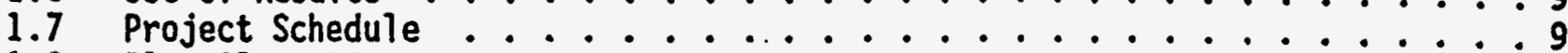

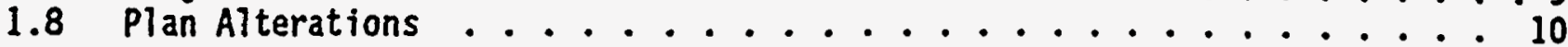

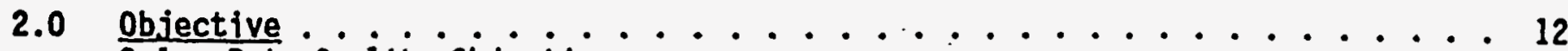

2.1 Data quality objectives . . . . . . . .

3.0 Sampling Technique ..................... 14

3.1 Sample Collection ................ 14

3.2 Volume, Technique, Preservation, and Equipment ......... 17

3.3 Number of Samples ................... 22

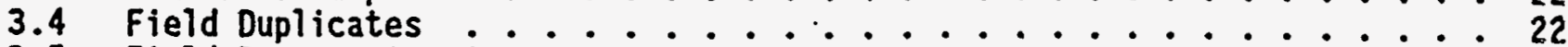

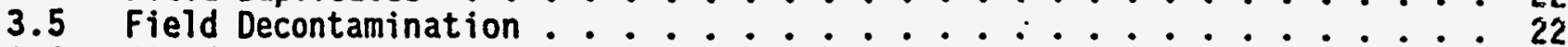

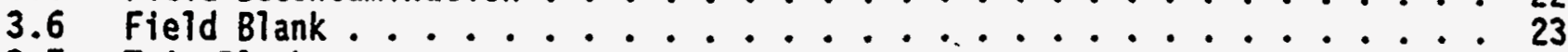

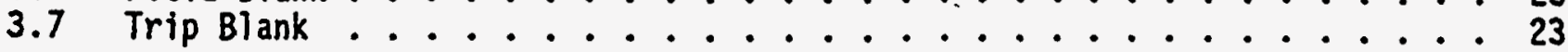

4.0 Required Analysis . . . . . . . . . . . . . . . . 23

4.1 Analytical Parameter Selection ............... 23

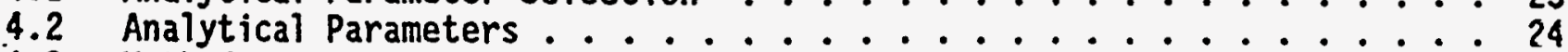

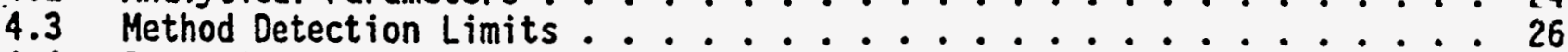

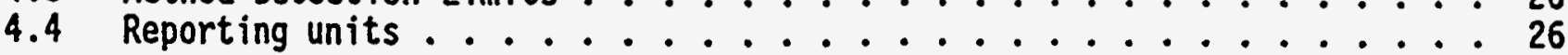

5.0 Data Reporting ..................... . . 26

5.1 Data Reporting Format . . . . . . . . . . . . . 26 .

5.2 Censored Data . . . . . . . . . 26

5.3 Field Duplicate Data Management ................ 26

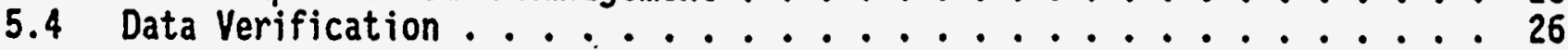

6.0 Statistical Evaluation of Results ................ 27

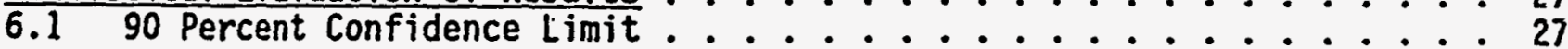

7.0 Quality Assurance . . . . . . . . . . . . . . . . 27

7.1 Field Notebook . . . . . . . . . . . . . . . 27

7.2 Sample Holding Times $\ldots \ldots \ldots \ldots$

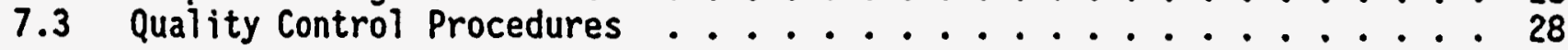




\subsection{Introduction}

\subsection{Purpose}

This sampling and analysis plan (SAP) provides the information required to obtain samples and analytical data for the 2,125 cubic yards (approximate volume) of radioactively contaminated soil located at the Department of Energy Nevada Operations Office (DOE/NV) Double Tracks Site. The sampling of the soil will be performed "in-situ" at the Double Tracks site and the data will be used to characterize a geographical area and depth of soil that will be excavated and disposed as radioactive waste. This SAP addresses characterization for hazardous waste constituents only (toxicity characteristic regulated metals, VOA's semi-VOA's, pesticides), radiological characterization will be performed on a "per package" basis as the waste soil is excavated and packaged. Further description of the radiological characterization system will be provided in the waste application developed for this waste stream. Sampling is not being performed for radioactive contamination due to the heterogeneous nature of the contamination in the soil and the inability to establish the activity per package of soil from sampling data.

The characterization of this soil is being performed to determine if the radioactively contaminated soil will meet the acceptance criteria of NVO-325 (Rev. 1) The Nevada Test Defense Haste Acceptance Criteria, Certification, and Transfer Requirements. If the soil is determined to meet the acceptance criteria for disposal as low level radioactive waste, the soil will be excavated and disposed at the Nevada Test Site.

The sampling and analysis are being performed for confirmatory information. There is no existing process knowledge information that would suggest that the soil is contaminated with any constituents that would require regulation of the soil as hazardous waste when generated as waste. However, no documented controls have been in place at the facility to prevent inadvertent contamination and therefore confirmatory sampling and analysis will be performed.

\subsection{Background}

The Double Tracks site is located northwest of the Nevada Test Site on the Nell is Air Force Range approximately 14 miles east of the town of Goldfield, Nevada. In Hay of 1963, a single test was performed on the site during which a chemical (trinitrotoluene) explosion was conducted which dispersed plutonium and uranium onto the surface of the desert. There was no nuclear yield from the detonation, but radioactive contamination is present at the site from the dispersed plutonium, depleted uranium, and trace amounts of other isotopes. Subsequent to the explosive test, a radiation exclusion zone was created to restrict access to the contaminated area. The exclusion zone is a five sided area roughly 3,000 feet in length and 750 feet in width. A wire strand fence was constructed around the zone to prevent inadvertent intrusion. The fence encompasses an area of approximately 44 acres (roughly equivalent to 2 million $\mathrm{ft}^{2}$ ). The area that will be characterized under this plan and eventually excavated and disposed as waste consists of a smaller area completely enclosed by this fence termed the excavation 
zone. A diagram of the site location is provided on the following page as Figure 1 showing the 5 sided exclusion zone and the smaller excavation zone within the exclusion zone.

Since the original test conducted in 1963, several radiological surveys have been conducted at the site. The most recent was performed by EG\&G Energy Heasurements in April and June of 1995. The purpose of the April effort was to gather in-situ data regarding the radionuclides and activities present in the soil as well as field test equipment to determine the most accurate and efficient method for surveying the entire exclusion zone. The survey included calibration of mobile radiological assay equipment (High Purity Germanium - HPGe detectors) mounted on a vehicle. This calibration was compared to the data produced by HPGe tripod mounted detectors placed in a fixed location. Additional work involved determining the plutonium-to-americium ratio for the contamination in the soil so that a field assessment of the photon emitting americium-241 radioisotope could be used to establish the plutonium content in the soil. The ability to determine depth of contamination was also evaluated using both Thermoluminescent Dosimetry (TLD) material sensitive to alpha particles and direct HPGe measurements taken as layers of soil were removed from the ground surface. The results of the April measurements were used to develop appropriate methods that could be used to assess the entire fenced area at the Double Tracks Site using mobile equipment.

The information developed from the April 1995 experiments was used as a bas is for the June 1995 survey of the fenced area. A vehicle (suburban) fitted with Sodium Iodide detectors was used to map the entire fenced area at the site. The data from these measurements were developed into a map which indicates the extent and location of radiological contamination within the fenced area.

The map developed from the June survey was used to determine the areal extent and depth of soil that will require excavation and disposal as radioactive waste. The map is provided as Figure 1 with the rectangular area of excavation (outlined by the black lines) shown inside the five sided radiation exclusion zone.

The geographical information used to establish the location of radiological readings within the fenced area was derived using Global Positioning System equipment. Included in the area to be characterized and eventually excavated and disposed as radioactive waste is a mound of soil located at ground zero (GZ) of the test. This mound was created after the test when soil excavated from a location near the test site was placed onto the concrete pad which had been used as the platform for conducting the test. This mound is approximately 4 feet in depth and will be excavated and managed as radioactive waste destined for disposal. The GZ was defined at the time of the test in 1963 as $37^{\circ} 42^{\prime} 22.52^{\prime \prime}$ north latitude and $116^{\circ} 59^{\prime} 14.23^{\prime \prime}$ west longitude. These coordinates were established on a coordinated system that has been refined since the test was conducted. The GPS equipment was calibrated using the revised coordinate system which required adjusting the 
original latitude and longitude of the GZ position. The coordinate established for $G Z$ during the 1995 radiological surveying effort is $37^{\circ} 42^{\prime} 21.95^{\prime \prime}$ north latitude and $116^{\circ} 59^{\prime} 17.80^{\prime \prime}$ west longitude. Sample locations will be based on the GZ coordinate established from the 1995 radiological survey.

Sampling has been conducted by International Technology (IT) corporation at the site for hazardous waste constituents (TCLP metals). The results of this sampling effort is provided in Section 1.4 of this plan.

The excavation and disposal of the waste soil from this project is expected to commence in June of 1996 and be complete by August 1996. Characterization of the soil prior to the excavation phase is planned to allow for excavation, packaging, and disposal of the waste all at one time without the need to wait for analytical data to be processed between waste packaging and waste disposal. The characterization data provided by this SAP will be used to determine the regulatory status (hazardous waste constituents only) and disposal options available prior to excavation.

\subsection{Project Organization and Responsibility}

The Waste Management Program has overall responsibility for ensuring completion of all sampling and analysis activities (from plan initiation through data validation).

The following table provides a listing of the key technical and quality assurance personnel involved in implementing this SAP. The reporting organization, responsibility and individual phone number is provided.

KEY TECHNICAL AND QUALITY ASSURANCE PERSONNEL

\begin{tabular}{|c|c|c|c|}
\hline IHDIVIDUAL & Organization & PHOHE RLABER & RESPOHSIBILITY \\
\hline Jan L. Cowley & Waste Managenent Prograxi & (702) 295.0377 & $\begin{array}{l}\text { Overall responsibility for } \\
\text { completion of characterization. }\end{array}$ \\
\hline Mark d. Krauss & Waste Management Progran & (702) 295-0685 & $\begin{array}{l}\text { Sampling plan development, } \\
\text { sampling, and characterization. }\end{array}$ \\
\hline Wally S. Birchfiel & Waste Management Progran & $(702) \quad 295-4772$ & $\begin{array}{l}\text { Sampling ptan development, } \\
\text { sampling, and characterization. }\end{array}$ \\
\hline Michelle A. Hallmark & Waste Management Progran & (702) $295-4811$ & $\begin{array}{l}\text { Sampling plan development, } \\
\text { sampling, and characterization. }\end{array}$ \\
\hline Boyd A. Inai & Waste Management Progran & (702) $295-4779$ & $\begin{array}{l}\text { Sampling plan development, } \\
\text { sampling, and characterization. }\end{array}$ \\
\hline Ted J. Redding & Analytical Services Section & (702) $295-7220$ & Data Verification \\
\hline Al R. Lathan & $\begin{array}{l}\text { Analytical Services Section } \\
\text { Chief }\end{array}$ & (702) $295-7472$ & Laboratory Manager \\
\hline Steven A. BoBo & Analytical Services Section & $(702) \quad 295-7141$ & Sarroler \\
\hline Phil M. Ralphs & Waste Certification office & $(702) \quad 295-5685$ & Surveillance of Sampling Activities \\
\hline
\end{tabular}

Figure 2 (following page) is a flow diagram of the process that will be followed to complete this sampling and analysis effort. 
DOUBLE TRACKS SAMPLING AND ANALYSIS FLOWCHART
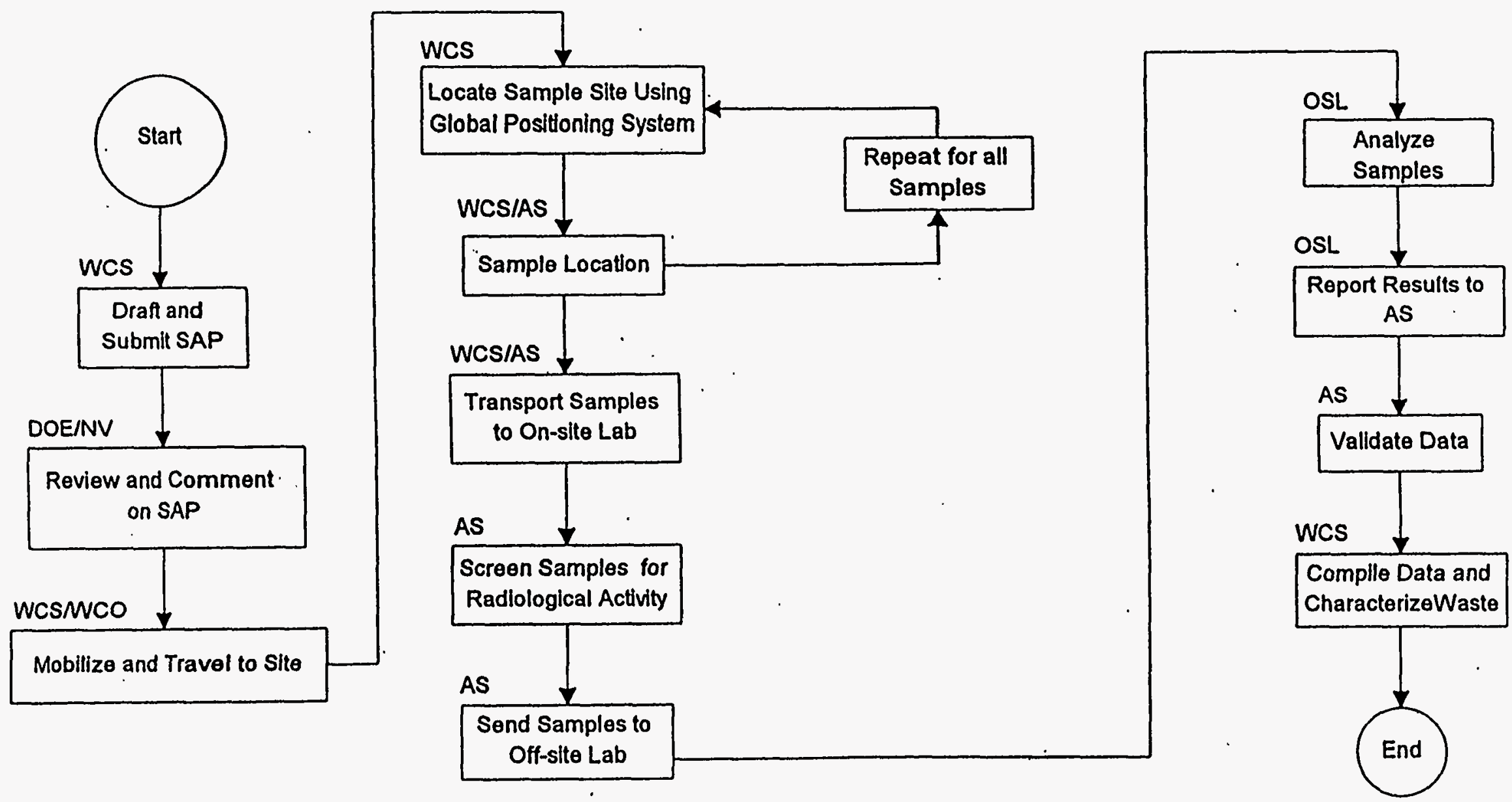

WCS - Waste Control Section

DOENV - U.S. Department of Energy / Nevada Operations

WCO - Waste Certification Official

AS - On-site Analytical Senvices

OSL - Off-sile Laboratory 


\subsection{Process Knowledge and Existing Analytical Data}

In 1994 and again in 1995, a sampling effort was conducted at the Double Tracks site by IT corporation. The sampling effort consisted of collecting surface soil samples from various random and targeted locations and performing analysis for radionuclides, total metals, and TCLP metals.

A total of seven locations were sampled for TCLP metals. The data was obtained to provide process knowledge and confirmatory information on the absence of regulated metal constituents in the undisturbed and disturbed portions of the site. The data is presented here to show in. general fashion the level of TCLP metal contamination present in the native soil within the radiological exclusion zone of the Double Tracks site. None of the seven samples showed TCLP metals contamination above the regulatory threshold and in fact a large majority of the metals were undetectable in the samples. The results of the analysis are provided in the following table.

\section{IT ANALYTICAL RESULTS 1994 and 1995 \\ DOUBLE TRACKS SURFACE SOIL - TCLP METALS}

\begin{tabular}{|c|c|c|c|c|c|c|c|c|}
\hline & $\begin{array}{c}\text { Location } \\
9\end{array}$ & $\begin{array}{c}\text { Location } \\
10 \\
\end{array}$ & $\begin{array}{c}\text { Location } \\
11\end{array}$ & Hot Spor & $\begin{array}{l}\text { Hot Spot } \\
3 \\
\end{array}$ & $\begin{array}{c}\text { Hot spot } \\
4\end{array}$ & Hot spot & $\begin{array}{l}\text { Regulatory } \\
\text { Threshold } \\
\end{array}$ \\
\hline As & 0.011 & 0.004 & 0.016 & 0.0078 & 0.0074 & 0.0092 & 0.0061 & 5.0 \\
\hline $\mathrm{Ba}$ & 0.45 & $0.200 v$ & 0.42 & 0.40 & 0.43 & 0.39 & 0.44 & $100.0^{\circ}$ \\
\hline cd & $0.005 \mathrm{U}$ & $0.005 \mathrm{U}$ & $0.005 u$ & $0.0024 U$ & $0.0024 u$ & $0.0024 u$ & $0.0024 u$ & 1.0 \\
\hline $\mathrm{Cr}$ & $0.020 \mathrm{U}$ & $0.020 u$ & $0.020 \mathrm{u}$ & $0.0047 \mathrm{U}$ & $0.0047 U$ & $0.0047 u$ & $0.0047 \mathrm{U}$ & 5.0 \\
\hline $\mathrm{Pb}$ & 0.008 & $0.003 \mathrm{U}$ & $0.003 \mathrm{U}$ & 0.0077 & 0.0050 & 0.0020 & 0.0022 & 5.0 \\
\hline $\mathrm{Hg}$ & $0.002 \mathrm{v}$ & $0.002 \mathrm{U}$ & $0.002 u$ & $0.00010 u$ & 0.00029 & 0.00012 & 0.00016 & 0.2 \\
\hline Se & 0.007 & 0.004 & 0.006 & 0.0096 & 0.0096 & 0.0091 & 0.0096 & 1.0 \\
\hline Ag & $0.010 u$ & $0.010 \mathrm{U}$ & $0.01 v$ & $0.0041 \mathrm{U}$ & $0.0041 U$ & $0.0049 \mathrm{U}$ & $0.0041 \mathrm{U}$ & 5.0 \\
\hline
\end{tabular}

This data provides a basis of information for the general area within the five sided radiological exclusion zone at the Double Tracks site. The data indicates that the soil within the exclusion zone does not contain quantities of metals that would require regulation of the soil as hazardous waste. This is the expected result for the soil in this area since the only industrial activity which is known to have occurred at the site is the 1963 weapons safety detonation test and this test did not have the potential to contaminate the site with any of the eight metals regulated as hazardous waste constituents.

However, since the sampling conducted by IT in 1994 and 1995 did not specifically target the excavation zone that has been defined, this plan will be implemented to obtain a sufficiently large population of 
randomily selected samples from within the excavation zone to confirm that the soil does not contain regulated quantities of TCLP metals, TCLP VOA's, TCLP semi-VOA's, and TCLP pesticides.

There have been no other industrial activities conducted at this site other than the 1963 detonation. There is no information avajlable from the description of the 1963 test or ensuing activities to suggest that any hazardous waste constituents were deposited on the ground or disposed at the site. The soil is known only to have been contaminated with radionuclides from the dispersal of plutonium and uranium.

However, there is also no documentation to show what the original test or any ensuing operations may have contributed to the soil surface in terms of contaminants: Therefore, as a precaution and to document the presumed absence of chemical contamination, it was determined that the following analysis would be performed on the soil samples; TCLP metals, TCLP VOA's, TCLP semi-VOA's, and TCLP pesticides. The results of these analyses are intended to provide confirmatory waste characterization data so that disposal as radioactive waste can be accomplished.

\subsection{Project Description}

Sampling and analysis will be performed to establish whether or not the soil contains hazardous waste constituents (metals, volatiles, semivolatiles, and pesticides) that would require it to be classified as hazardous waste. Characterization of radionuclides is beyond the scope of this SAP. Radionuclide characterization and quantification will occur in real time during excavation. The method used to characterize the radionuclide content of the soil will be described in a separate procedure to be prepared and approved prior to any excavation activities.

The sampling that will be conducted for this project will be performed on the soil as it exists at the Double Tracks site at the present time. The characterization is being performed in-situ so that when excavation of the soil is initiated, the characterization for hazardous waste constituents is complete and the waste may be excavated, packaged and sent for disposal without having to wait for laboratory sampling results.

As shown in Figure 1, the radiological exclusion zone at the Double Tracks site is bound by a fence that forms a long, narrow, five sided area. Although all of the area within the fence is radioactively contaminated from the 1963 test, only the portion bound by the rectangle indicated by dark black lines (the excavation zone) within the radiological exclusion zone will be excavated and disposed.

The excavation zone is 250 feet in width and 1500 feet in length. The excavation zone was conceptually divided into 3,750 individual 10 foot by 10 foot squares for the purposes of sampling. A diagram showing these divisions is provided as Figure. 3 on the following page. The squares can be referenced by use of the numbered grid system shown along the north and east boundaries of the excavation area. Along the north boundary, grid numbers are assigned sequentially to each 10 foot by 10 foot square with the number 1 assigned to the eastmost square and the 


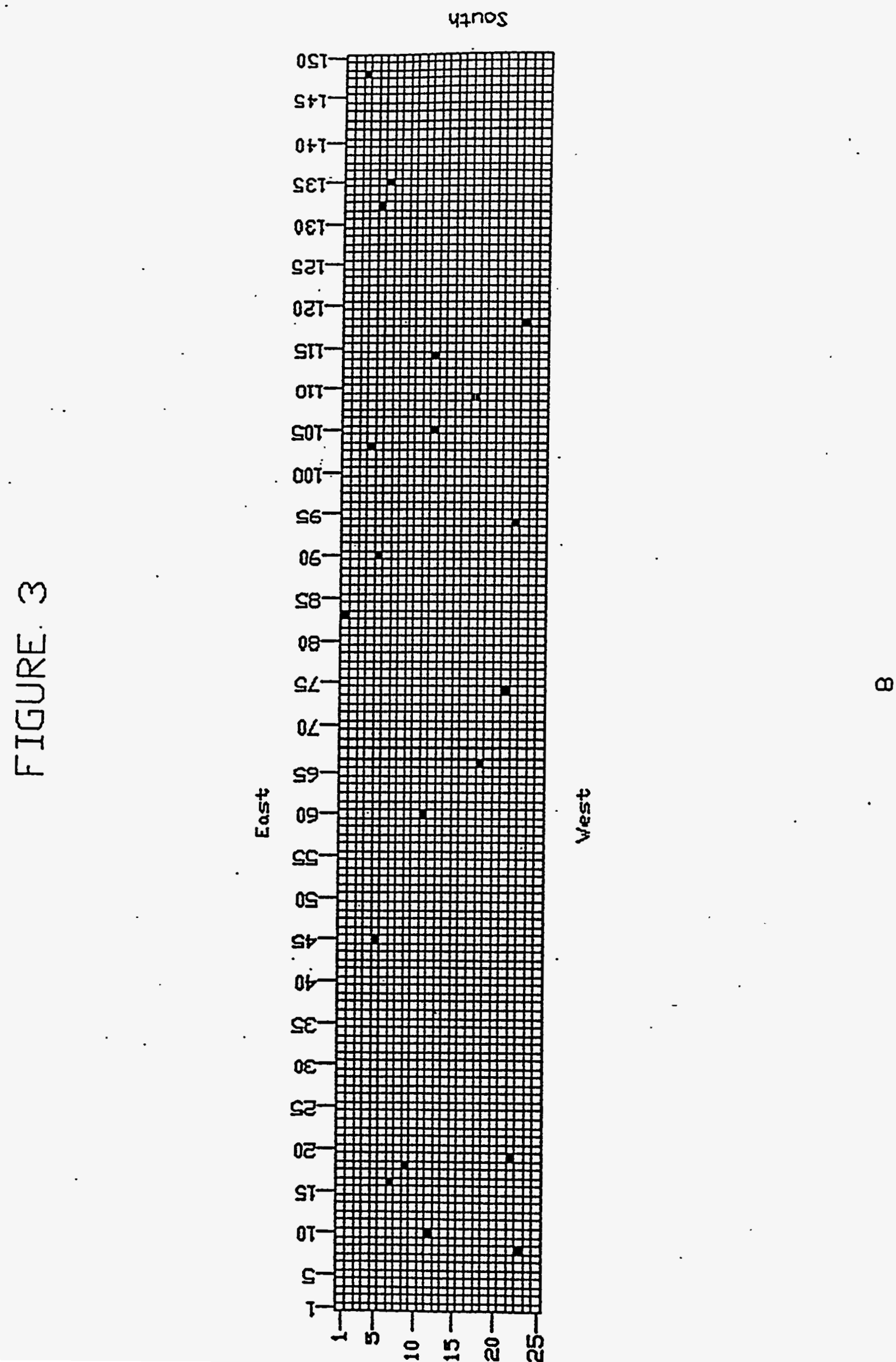


number 25 assigned to the westmost square. Along the east boundary, grid numbers are assigned sequentially to each 10 foot by 10 foot square with the number 1 assigned to the northmost square and the number 150 assigned to the southmost square. This grid pattern is used to identify and randomly select squares for sampling. The darkened squares indicate the sampling locations which have been chosen based on the random number selection described in Section 3.1 of this plan.

A total of 20 separate grid locations will be sampled. The randomly selected 10 foot square grid locations will be located at the site using a Global Positioning System receiver. The center of each 10 foot square grid location will be determined and the soil at this location will be sampled. If the sample location is outside of a 25 foot radius from ground zero, then the depth of sampling will be 6 inches. This depth was determined based on the expected depth of penetration of any heavy metal contaminant or any liquid which may have been disposed on the site. The soil outside of the 25 foot radius from ground zero is undisturbed and therefore any contaminant which may have been deposited on the surface could only penetrate into the soil column through natural processes and is not likely to exceed a depth of six inches.

Originally, a sampling depth of 2 feet was chosen, but upon discussion with DOE/NV personnel responsible for implementing the NTS Waste Acceptance Criteria, it was agreed that material obtained from a deep sample (i.e. 2 feet) could possibly dilute the sample with soil that had no potential for contamination. The depth of sampling was revised to include only the top 6 inches of soil so that any potential contaminants in the upper portion of the soil would be detected at the concentrations approximating what would have been deposited on the soil surface.

Sampling locations which are within the 25 foot radius of ground zero will be sampled to a depth of 4 feet since this is the depth of soil which has been disturbed and replaced on the ground zero location.

Mobilization and sampling will occur over a 2 day period in late January or early February 1996. Sampling will be performed by the Analytical Services Section sampler with assistance provided by Waste Control Section personnel. Once sampling is complete, the samples will be transported to the Analytical Services Section in Mercury, Nevada where the samples will be screened for radionuclide content and eventually shipped to an off-site laboratory for analysis.

\subsection{Use of Results}

Analytical data will be used to determine the regulatory status of the waste as radioactive waste or mixed waste by evaluating TCLP metals, TCLP VOA's, TCLP semi-VOA's, and TCLP pesticide contamination. The results along with a discussion of the characterization based on the sampling and available process knowledge will be presented in a characterization package which will be provided to the DOE/NV Radioactive Waste. Acceptance Program for review.

\subsection{Project Schedule}

A schedule of the sampling and analysis activities for the Double Tracks 
soil is provided in Figure 4. Please note that this schedule is a projection of review times, plan revision, and the sampling and analytical effort. The schedule may change as the project progresses.

\subsection{Plan Alterations}

Any deviations that are required during implementation of the plan or analysis of the data will be documented and dispositioned using the company defined deficiency reporting system. Any deviations will also be discussed in the characterization documentation (Material Evaluation Form) developed for this waste. 
Figure 4

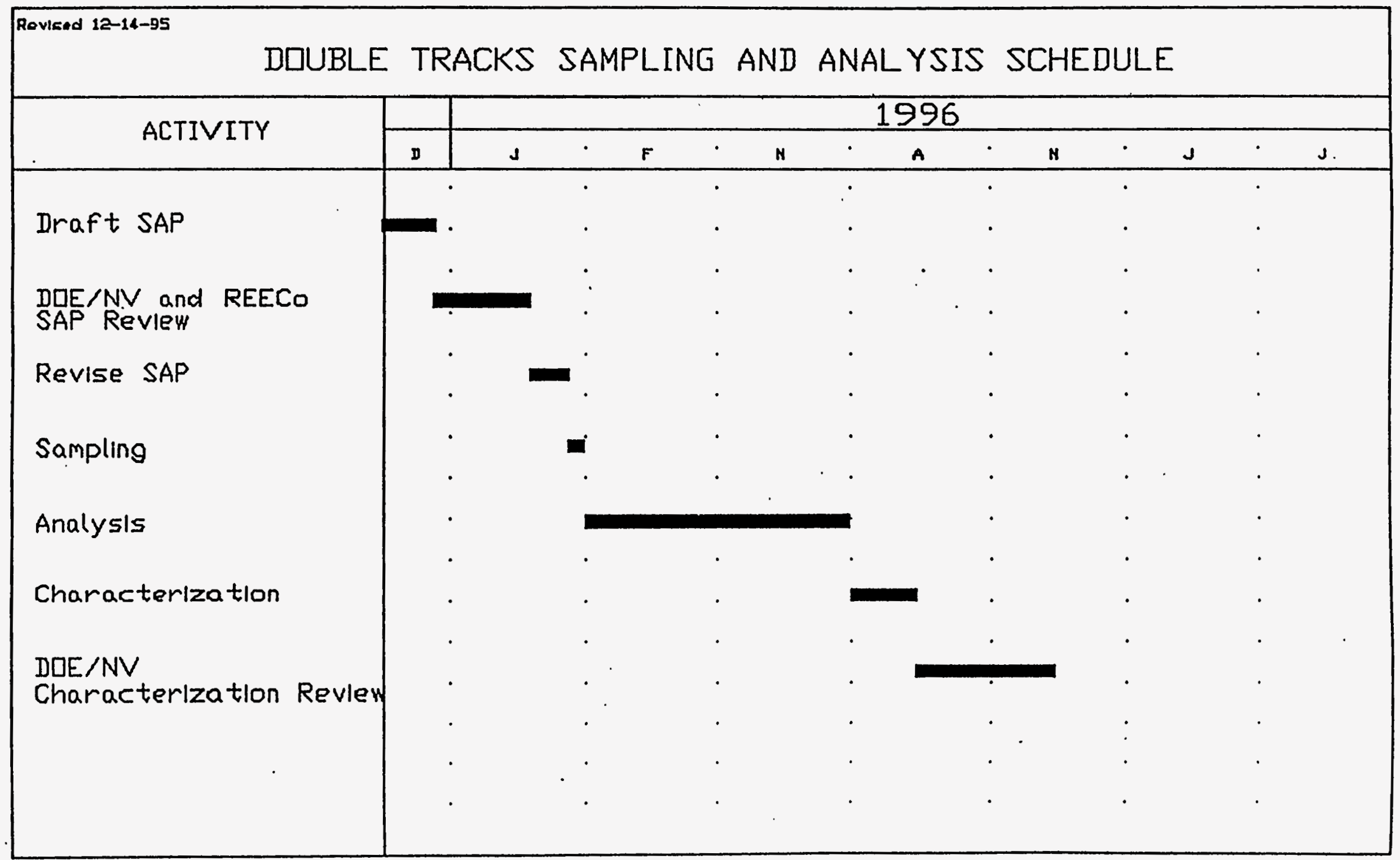




\subsection{Objective}

The primary objective of this sampling effort is to obtain data to provide characterization (hazardous waste constituents only) of the Double Tracks excavation zone so that proper disposal of the soil may be accomplished after characterization is complete.

\subsection{Data Quality Objectives}

\section{Precision}

Precision is a quantitative measure of data quality that refers to the reproducibility or degree of agreement among replicate or duplicate measurements of a parameter. Data precision is a function of field sampling precision and laboratory analytical precision. Precision will be determined by calculating the relative percent difference (RPD) between a sample and its duplicate. The RPD is calculated using the following formula:

$$
R P D=\frac{\left|C_{1}-C_{2}\right|}{\left(C_{1}+C_{2}\right) / 2} \times 100
$$

where: $\quad C_{1}=$ Analyte concentration in actual sample

$C_{2}=$ Analyte concentration in duplicate

The acceptable relative percent difference that will be used for this project is set at $35 \%$. This criteria is based on the homogeneity of the waste and the presumed likelyhood that analytes will be at or near the detection limit. If the RPD using the above formula for each sample and duplicate pair is less than $35 \%$, the sample will be considered valid and the sample value will be used to represent the waste.

If sample precision cannot be established from the sample and sample duplicate, then a decision will be made on the use of the data based on the proximity of the data value to the regulatory threshold and the added value that would be obtained from additional sampling.

\section{Accuracy}

Accuracy is a quantitative measure of data quality that refers to the degree of difference between measured or calculated values of a parameter and the true value of that parameter. The closer the measurement is to the true value, the more accurate the measurement. Accuracy is controlled primarily by the analytical laboratory through the preparation and analysis of laboratory quality control samples, including matrix spikes and standard reference materials. Analytical accuracy is dependent on the method of analysis, the analyte of interest, and the sampling matrix. 
The analytical laboratory will perform analysis of matrix spike samples and will provide the percent recovery of the spiked constituents as part of the quality assurance data. The validation of the data will include an evaluation of these recoveries and an indication by the laboratory of whether the percent recoveries were within accepted parameters. If percent recoveries are reported as being outside the accepted recovery limits, an assessment will be made regarding use of the data depending on proximity of the sample data values to the regulatory threshold. Additional sampling may be performed if percent recoveries are outside accepted recovery limits.

\section{Representativeness}

Representativeness is a qualitative measure of the degree to which the sampling effort achieves accuracy and precision. The design of the sample collection, with regard to sample selection, the number of samples taken, and sample management determines the representativeness of the sampling effort. Representativeness of samples and data will be ensured by adhering to the sampling and analytical protocols established in this plan and the sampling, sample handling, and data management procedures referenced herein.

\section{Comparability}

Comparability is a qualitative measure that expresses the confidence with which one data set can be compared to another. It will be achieved by adhering to specified analytical methods and laboratory and field sampling procedures. The same analytical laboratory will perform the specific analyses for all samples using the standard methods provided in Table 3 of this plan. Sample results will be reported in standard units to allow for comparison of the data.

\section{Completeness}

Completeness is a quantitative measure of data quality expressed as the percentage of valid or acceptable data obtained. The goal for completeness for this project is 90 percent. In order to determine if the data are adequate to meet the project objectives, analytical data from at least 18 of the 20 samples must be determined to be valid. If the 90 percent completeness goal is not obtained, resampling will be required. 


\subsection{Sampling Technique}

\subsection{Sample Collection}

The samples will be collected by using an auger device, sampling scoop, or trier to auger down into the soil to a depth of 6 inches at each specified sampling location. If the sampling location is within a 25 foot radius of the 1963 testing. location ground zero then the sampling depth will be 2 feet from the surface since a deeper excavation will be performed in the vicinity of the ground zero.

Figure 3 shows the 20 locations within the excavation area that will be sampled. These locations were chosen using two random number tables which are provided as Tables 1 and 2 and can be found on the following 2 pages. The first 20 random numbers from Table 1 were used to select the grid locations as numbered along the north side of the plot shown in Figure 3. These grid locations were coordinated with the grid locations chosen as the first 20 random numbers from Table 2 to select the 20 $10^{\prime} \times 10^{\prime}$ sections from within the excavation area to sample. The following is the list of randomly selected grid coordinates taken from tables 1 and 2 that were used to identify the plot locations that will be sampled:

\begin{tabular}{llllll} 
Item & \multicolumn{2}{l}{$\begin{array}{l}\text { Plot Coordinate } \\
\text { North }\end{array}$} & East & Item & \multicolumn{2}{c}{$\begin{array}{l}\text { Plot } \text { Coordinate } \\
\text { North }\end{array}$} \\
& & & & & \\
& 1 & 83 & 11 & 17 & 109 \\
1 & 5 & 45 & 12 & 12 & 114 \\
2 & 23 & 118 & 13 & 22 & 94 \\
3 & 5 & 90 & 14 & 12 & 105 \\
4 & 6 & 135 & 15 & 3 & 148 \\
5 & 7 & 16 & 16 & 12 & 10 \\
6 & 11 & 60 & 17 & 5 & 132 \\
7 & 21 & 74 & 18 & 4 & 103 \\
8 & 9 & 18 & 19 & 22 & 19 \\
9 & 23 & 8 & 20 & 18 & 66
\end{tabular}

The 20 selected plot locations are shown on Figure 3 as darkened areas. The 20 locations will be identified by latitude and longtitude prior to mobilizing for the sampling effort. A handheld Global Positioning System receiver will then be used to locate each sampling location based on the latitude and latitude position.

Once the sample location has been established, the sampler will prepare the sample container with proper labels. The sampling tool will then be inserted into the ground to a depth of 6 inches ( 2 feet for sampling locations within 25 feet of the ground zero). The sample tool

containing soil will then be withdrawn from the ground. The sampled soil will be removed from the sampling tool and placed into a sample container that is properly labeled. The lid will be placed onto the container and the container will be placed into a cooler which is 


\section{Table 1}

S00 Random Numbers 1-25

\begin{tabular}{|c|c|c|c|c|c|c|c|c|c|}
\hline 1 & 14 & 24 & 11 & 22 & 7 & 16 & 14 & 16 & 2 \\
\hline 5 & 11 & 16 & 7 & 17 & 3 & 10 & 7 & 16 & 14 \\
\hline 23 & 22 & 10 & 20 & 10 & 9 & 4 & 2 & 20 & 6 \\
\hline 5 & 11 & 16 & 24 & 22 & 14 & 9 & 1 & 10 & 3 \\
\hline 6) & 24 & 15 & 20 & 17 & 17 & 8 & 24 & 3 & 3 \\
\hline 7 & 16 & 4 & 20 & 15 & 15 & 7 & 21 & 16 & 17 \\
\hline 11) & 24 & 23 & 24 & 24) & 7 & 24 & 20 & 22 & 3 \\
\hline 21 & 7 & 1 & 15 & 20 & 14 & 10 & 14 & 5 & 16 \\
\hline 9 & 16 & 5 & 8 & 7 & 19 & 1 & 17 & 18 & 6 \\
\hline 23 & 21 & 16 & 10 & 23 & 5 & 15 & 6 & 11) & 10 \\
\hline 17 & 21 & 3 & 20 & 24 & 16 & 10 & 17 & 20 & 14 \\
\hline 12 & 11 & 22 & 1 & 14 & 9 & 13 & 25 & 22 & 9 \\
\hline 22 & 13 & 16 & 3 & 4 & 14 & 22 & 15 & 22 & 4 \\
\hline 12 & 10 & 11 & 7 & 12) & 10 & 24 & 11) & 25 & 15 \\
\hline 3 & 18 & 21 & 5 & 18) & 23 & 25 & 13 & 22 & 21 \\
\hline 12 & 6 & 3 & 24 & 15 & 2 & 1 & 21 & 22 & 6 \\
\hline 5 & 4 & 20 & 3 & 14 & 4 & 9 & 4) & 19 & 21 \\
\hline 4ा & 12 & 11 & 13 & 13 & 12 & 14 & 17| & 13 & 14 \\
\hline 22 & 20 & 9 & 18 & 8 & 4 & 31 & 23 & 23 & 18 \\
\hline 18 & 21 & 5 & 21) & 9 & 13 & 4 & 23 & 8 & 10 \\
\hline 17 & 18 & 14 & 11 & 20 & 17 & 19 & 191 & 2 & 18 \\
\hline 22 & 2 & 7 & 14 & 13 & 3 & 16 & 22 & 3 & 15 \\
\hline 18 & 2 & 1 & 10 & 13 & 7 & 6 & 8 & 21 & 5 \\
\hline 18 & 25 & 17 & 12 & 18 & 17 & 16 & 6) & 21 & 6 \\
\hline 16 & 10 & 7 & 5 & 6 & 9 & 8 & 4) & 15 & 18 \\
\hline 2 & 2 & 10 & 8 & 15 & 1 & 6 & 19 & 41 & 24 \\
\hline 13 & 7 & 21 & 23 & 15 & $8 \mid$ & 3 & 15 & 19 & 6 \\
\hline 7 & 16 & 1 & 25 & 7 & 19 & 9 & 10 & 9 & 15 \\
\hline 9 & 20 & 24 & 5 & 3 & 5 & 6) & 9) & 16 & 20 \\
\hline 13 & 2 & 3 & 9 & 16 & 15 & 23 & 21 & \begin{tabular}{l|l}
8 \\
\end{tabular} & 14 \\
\hline 22 & 18 & 18 & 12 & 19 & 16 & 16 & 3 & \begin{tabular}{l|l|}
8 \\
\end{tabular} & 22 \\
\hline 16 & 15 & 22 & 24 & 20 & 10 & 16 & 7 & 22 & 2 \\
\hline 23. & 12 & 19 & 21 & 13 & 9 & 16 & 8 & 7 & 2 \\
\hline 191 & 17 & 31 & 17 & 8 & 23 & 22 & 5) & 5 & 23 \\
\hline 15 & 6 & 5 & 20 & 13 & 11 & 22 & 16 & $8 \mid$ & 4 \\
\hline 1 & 13 & 2 & 24 & 4 & 20 & 10 & 20 & \begin{tabular}{|l|l|}
17 \\
\end{tabular} & 18 \\
\hline 7 & 2 & 4 & 18 & 5 & 9 & 13 & 7 & 9 & 21 \\
\hline 20 & 24 & 6 & 20 & 12 & 15 & 17 & 5) & 19 & 3 \\
\hline 7 & 17. & 4 & 4 & 14 & 13 & 12 & 20 & 8 & 2 \\
\hline 2 & 21 & 16 & 6 & 20 & 21 & 9 & 15 & 5. & 15 \\
\hline 21 & 1 & 13 & 2 & 3 & \begin{tabular}{l|l}
1 \\
\end{tabular} & 17 & 4 & 21 & 14 \\
\hline 18 & 23) & 23 & \begin{tabular}{|l|l|}
8 \\
\end{tabular} & 3 & 13 & 11 & 15 & 20 & 3 \\
\hline 3 & 15 & 7 & 12 & 25 & 22 & 9 & 21 & 20 & 4 \\
\hline 23 & 3 & 4 & 3 & 9 & 16 & 19 & 16 & 21 & 24 \\
\hline 4 & 13 & 7 & 23 & 201 & 7 & 8 & 8 & 13 & 10 \\
\hline 24) & 8 & 10 & \begin{tabular}{l|l}
6 \\
\end{tabular} & 9 & 17 & 14 & 16 & 9 & 17 \\
\hline 6 & 1 & 21 & 12 & 22 & 12 & 15 & 11 & 22 & 12 \\
\hline 19 & 11 & 11 & 8 & 23) & 20 & 7 & 22 & 21 & 18 \\
\hline 19 & 4 & 17 & 11 & 5 & 22 & 21 & 12 & 3 & 8 \\
\hline 20 & 23 & 16 & 17 & 14 & 17 & 81 & 20 & 23 & 12 \\
\hline
\end{tabular}




\section{Table 2}

500 Random Numbers 1.150

\begin{tabular}{|c|c|c|c|c|c|c|c|c|c|}
\hline 83 & 109 & 138 & 12 & 118 & 85 & 76 & 121 & 34 & 8 \\
\hline 45 & 70 & 12 & 49 & 23 & 79 & 143 & 49 & 16 & 58 \\
\hline 118 & 147 & 129 & 134 & 149 & 109 & 133 & 122 & 13 & 30 \\
\hline 90 & 15 & 115 & 7 & 99 & 34 & 3 & 23 & 12 & 108 \\
\hline 135 & 131 & 13 & 113 & 39 & 142 & 90 & 39 & 69 & 127 \\
\hline 16 & 59 & 24 & 149 & 17 & 64 & 90 & 67 & 8 & 56 \\
\hline 60 & 95 & 77 & 114 & 138 & 57 & 45 & 136 & 131 & 42 \\
\hline 74 & 98 & 145 & 124 & 24] & 120 & 149 & 85 & 92 & 122 \\
\hline 18 & 51 & .70 & 18 & 142 & 116 & 141 & 29 & 99 & 47 \\
\hline 8 & 117 & 100 & 92 & 56 & 4 & 128 & 72 & 88 & 14 \\
\hline 109 & 80 & 78 & 142 & 94) & 19 & 24 & 14 & 105 & 85 \\
\hline 114 & 43 & 115 & 22 & 14 & 48 & 52 & 126 & 37 & 84 \\
\hline 94 & 38 & 94 & 135 & 111 & 106 & 38 & 126 & 38 & 32 \\
\hline 105 & 133 & (19) & 12 & 3 & 117 & 119 & 106 & 52 & 40 \\
\hline 148 & 87 & 37 & 92 & 65 & 48 & 72 & 12 & 48 & 35 \\
\hline 10 & 41 & 31 & 43 & 16 & 70 & 33 & 48 & 58 & 61 \\
\hline 132 & 65 & 64 & 67 & 55 & 62 & 108 & 18 & 42 & 97 \\
\hline 103 & 88 & 32 & 18 & 14 & 4 & 74 & 76 & 142 & 106 \\
\hline 19 & 56 & 137 & 83 & 4 & 70 & 39 & 138 & 107 & 64 \\
\hline 66 & 92 & 41 & 32 & 140 & 145 & 127 & 53 & 131 & 21 \\
\hline 61 & 42 & 104 & 138 & 140 & 115 & 23 & 10 & 9 & 64 \\
\hline 140 & 64 & 10 & 10 & 4 & 128 & 22 & 59 & 118 & 140 \\
\hline 137 & 13 & 19) & 40 & 142 & 44 & 124 & 136 & 76 & 45 \\
\hline 53 & 21 & 1.44 & 62 & 51 & 143 & 89 & 54) & 121 & 15 \\
\hline 112 & 104 & 105 & 3 & 69 & 81 & 69 & 49 & 18 & 3 \\
\hline 28 & 120 & \begin{tabular}{l|}
9 \\
\end{tabular} & 34) & 58 & 118 & 23 & 8 & 131 & 26 \\
\hline 123 & 26 & 130 & 131 & 130 & 76 & 52 & 130 & 89 & 13 \\
\hline 64) & 96 & 136 & 117 & 35 & 125 & 25 & 105 & 132 & 101 \\
\hline 105 & 24) & 34 & 85 & 24 & 14 & 107 & 31 & 97 & 9 \\
\hline 96 & 23 & 4 & 143 & 33 & 113 & 103 & 128 & 145 & 56 \\
\hline 120 & 109 & 107 & 141 & 74 & 9 & 30 & 23 & 144 & 101 \\
\hline 138 & 129 & 41 & 68 & 13 & 61 & 15 & 91 & 139 & 135 \\
\hline 4 & 114 & 147 & 39 & 11 & 142 & 59 & 75 & 139 & 13 \\
\hline 36 & 109 & 97 & 136 & 83 & 45 & 67 & 29 & 127 & 78 \\
\hline 12 & 61: & 98 & 16. & 43 & 57 & 30 & 62 & 65 & 50 \\
\hline 112 & 96 & 25 & 142 & 110 & 38 & 36 & 108 & 105 & 25 \\
\hline \begin{tabular}{l|}
98 \\
\end{tabular} & 32 & 30 & 63 & 25 & 32 & 65 & 77 & 149 & 102 \\
\hline 128 & 29 & 130 & 102 & 96 & 82 & 27 . & 49 & 116 & 30 \\
\hline 85 & 56 & 19 & 69 & 104 & 136 & 25 & 1 & 34 & 15 \\
\hline 31 & 38 & 139 & 119 & 80 & 84 & 105 & 108 & 39 & 109 \\
\hline 94 & 132 & 44 & 58 & 97 & 76 & 139 & 78 & 47) & 37 \\
\hline 3 & 121 & 123 & 8 & 81 & 49 & 33 & 46 & 38 & 58 \\
\hline 130 & 114 & 110 & 57 & 92 & 89 & 74 & $\pi$ & 42 & 120 \\
\hline 12 & 20 & 15 & 60 & 41 & 76 & 1) & 137 & 87 & 11 \\
\hline 25 & 78 & 149 & 117 & 68 & 136 & 1) & 17 & 129 & 138 \\
\hline 28 & 102 & 95 & 71 & 11 & 122 & 51 & 22 & 27 & 146 \\
\hline 107 & 87 & 146 & 1 & 127 & 16 & 14 & 131 & 144 & 50 \\
\hline 50 & 62 & 25 & 55 & 122 & 9 & 57 & 129 & 120 & 143 \\
\hline 2 & 119 & 83 & 120 & 35 & 16 & 123 & 88 & 21 & 43 \\
\hline 81 & \begin{tabular}{|l|}
93 \\
\end{tabular} & 45 & 30 & 601 & 39 & 78 & 93) & 77 & 119 \\
\hline
\end{tabular}


maintained at $4^{\circ} \mathrm{C}\left( \pm 2^{\circ} \mathrm{C}\right)$. The sample tool will be bagged and stored for later decontamination. No field decontamination of sampling tools will be performed during this effort. A separate sampling tool will be used for each sample. This same process of sampling will be completed for all 20 samples and the 2 duplicates.

Sample traceability including chain-of-custody will be establistied and maintained according to methods specified in Company Procedure 4.2.8 "Chain-of-Custody." A statement of work will be submitted to the Analytical Services Section to initiate the sampling process. A copy of the Analytical Services Section "Statement of Hork/Sample Data Sheet," is provided in Figure 5. Chain-of-custody will be documented on the REECo "Laboratory Services Request and Chain-of-Custody form." A copy of the chain-of-custody form is provided in Figure 6.

3.2 Volume, Technique, Preservation, and Equipment

All sampling will be performed by Analytical Services Section personnel with assistance by Waste Control Section personnel in accordance with procedure AAHDH.D.01.01, "Environmental Sampling Guide."

The volume of sample required for each type of analysis is specified in Table 3, Section 4.2.

Samples will be placed into individual containers of the type specified for each analysis identified in Table 3. All glass containers used are made of borosilicate glass. The lids for these containers are teflon 1ined. Preservation will consist of shipping the samples in a cooler that is maintained at $4^{\circ}\left( \pm 2^{\circ}\right)$ Celsius.

The following is a list of equipment that will be used to complete sampling activities. The list does not include any of the radiological equipment required for personnel protection nor any of the equipment required to perform the physical work necessary to access the waste. sampling locations.

\section{Item}

Equipment List:

1. Stainless steel sampling augers.

2. Stainless stee] sampling scoops.

3. 250 milliliter borosilicate glass sample containers (1 each for TCLP metals analysis, TCLP Semi-VOA's analysis,. and TCLP pesticides).

4. 120 milliliter borosilicate glass sample containers (TCLP VOA's analysis)

5. Chain of Custody Forms.

6. Field logbook for recording the sampling event activities.

7. Kimwipes for decontaminating the external surface of sample containers.

8. Spray bottle containing water for decontaminating the external surface of sample containers.

9. Ice chest with ice to maintain temperature of the samples at $4^{\circ}\left( \pm 2^{\circ}\right)$ Celsius. 


\section{FIGURE 5}

Reynolds Electrical and Engineering Co.. Inc.

\section{STATEMENT OF WORKISAMPLE DATA SHEET}

\section{OENERM MOSECT NGSORCATION}

proxet ruse:

MOJECT HOENTHCATION KUMGER:

wORx ONDER MUMEER:

PROXCT MAMAGER TELEPHONE:
MEF MUMEER:

DefT: us:

WASTE GENERATON 10 :

L MOSECT ETE DENCAHTIN

Locanou:

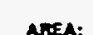

anomo:

NA

nook:

M/A

mowe:

offex:

ON STrE contact:

Prover

DETARED STE OESCOPTON:

MUTENSAL TO BE SAMRLO:

PMOCESS KNOWLOCE WFORMATINASUSPECT

CONTANHANTS:

\begin{tabular}{|c|c|c|c|}
\hline sen Ho: & $\mathbf{M} / \mathbf{A}$ & MSOS(4) MCLUDED: & $\mathbf{M} / \mathbf{A}$ \\
\hline
\end{tabular}

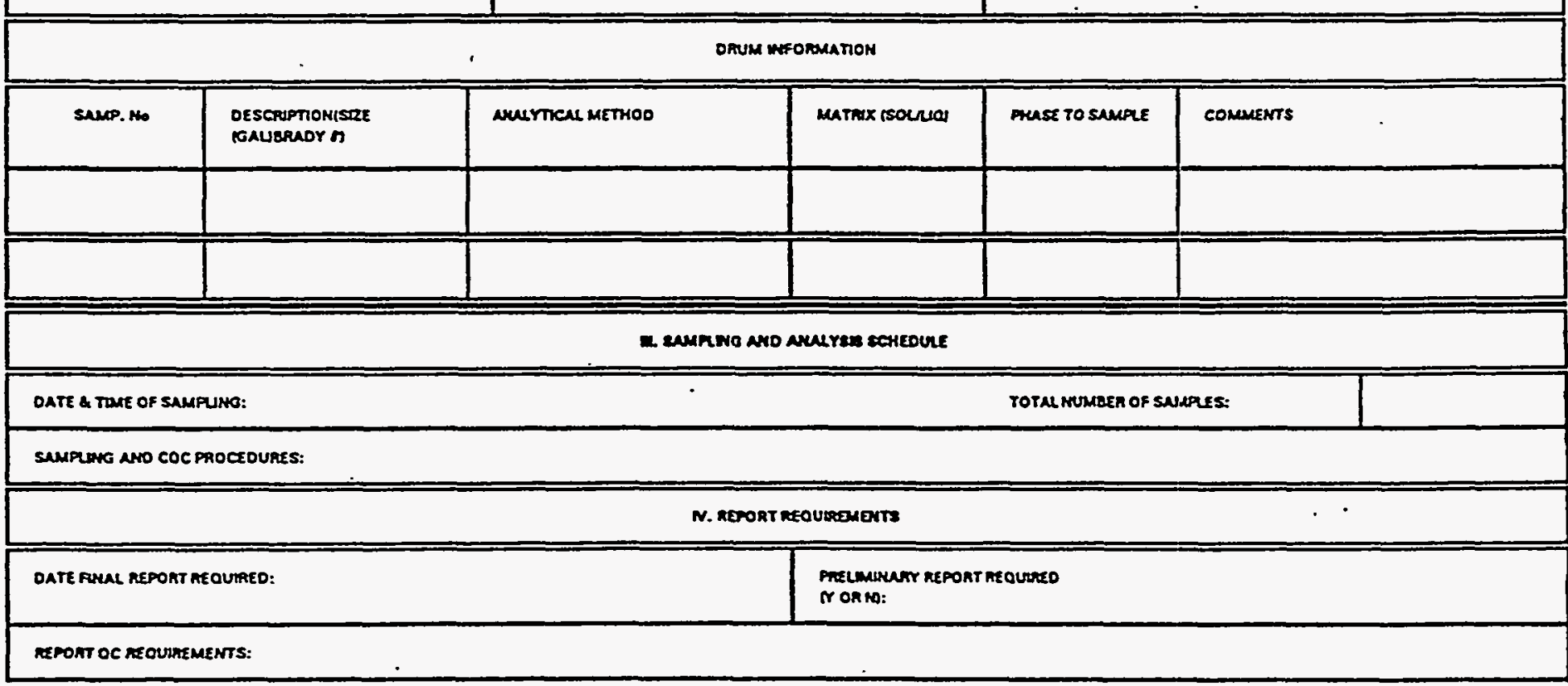




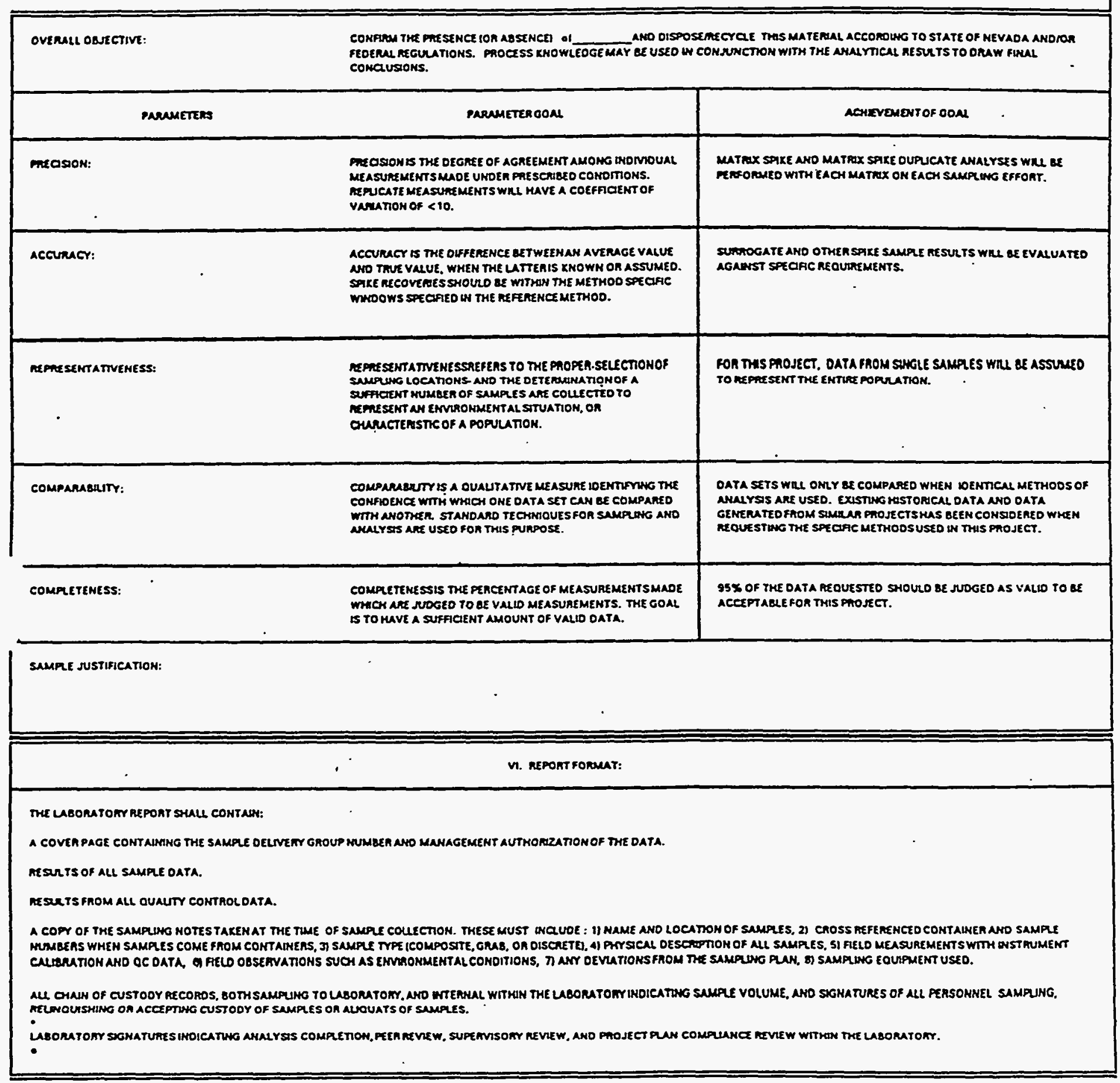




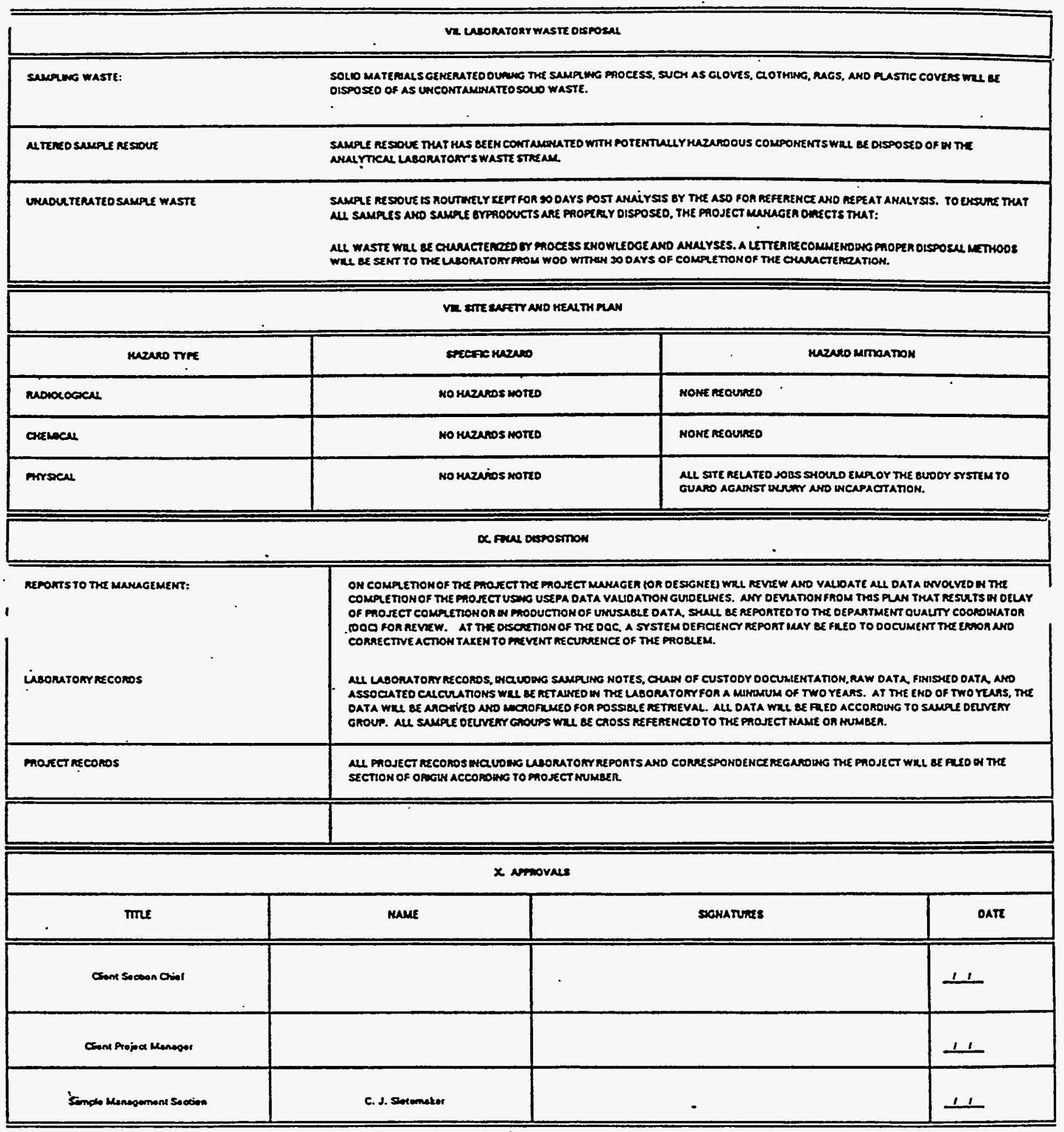

END OF PLAH 


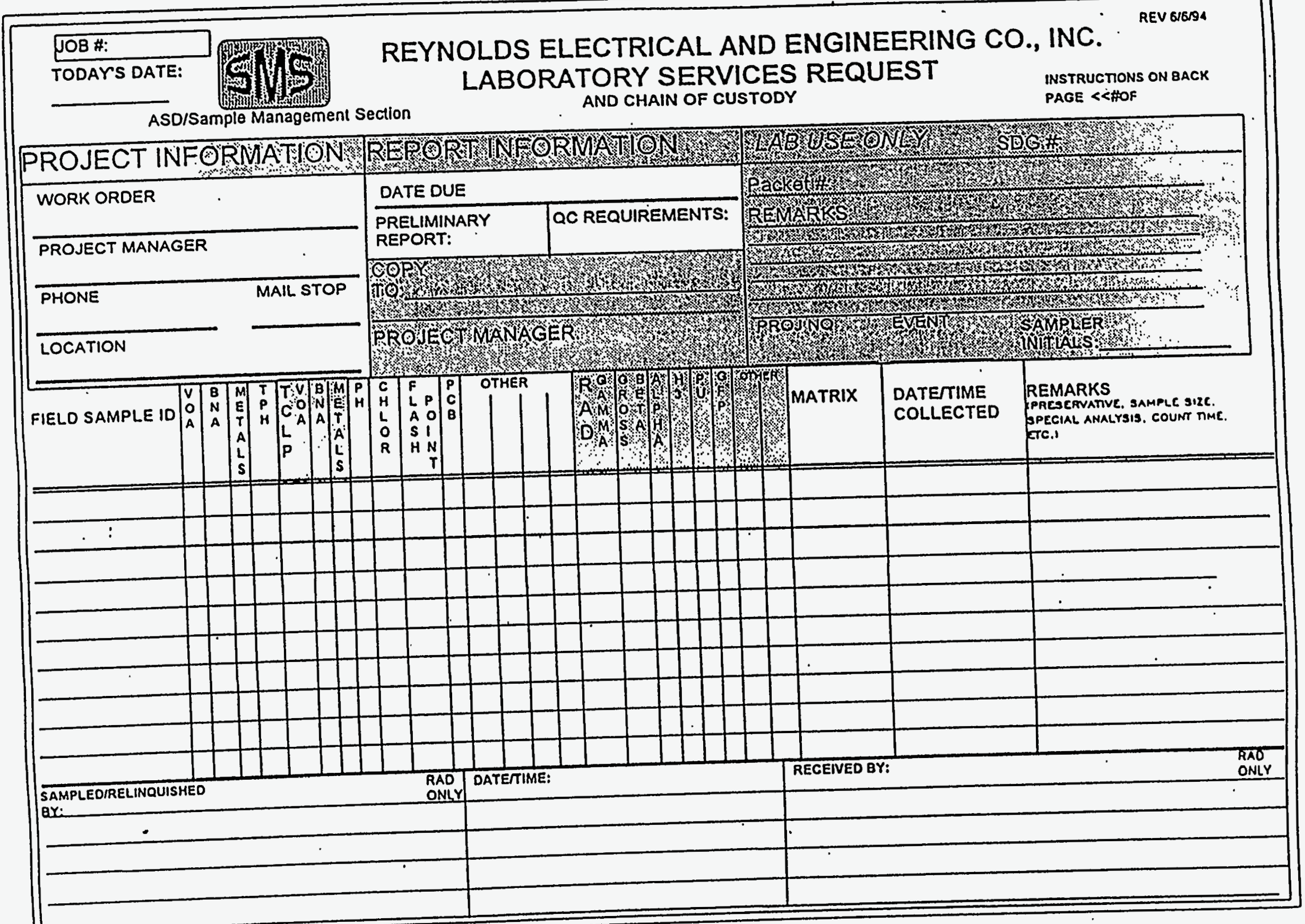




\subsection{Number of Samples}

Existing data is available from the sampling effort conducted by. IT in 1994 and 1995 that could potentially be used as a basis for determining the number of samples to be collected for this effort. However, the results of the IT effort showed that the level of metals contamination in the soil is trace quantity only. When this data is used along with "Equation 8" from SW-846, "Test Methods for Evaluating So7id Waste," to calculate the desired number of additional samples required to provide a data set with a normal distribution, the resulting number of additional samples is determined to be zero. This occurs because the IT results show that the soil only contains trace quantities of metals contamination all well below the regulatory threshold.

Since the purpose of this effort is to provide confirmatory data to indicate that the area of excavation is not contaminted with RCRA regulated metals, obtaining additional samples is necessary. Based on experience with previous sampling efforts and the size of the area being sampled, it was determined that 20 samples would be obtained from the 250 by 1500 foot area designated for excavation. Twenty samples will provide a sufficiently large data set to determine if the data have a normal distribution and also will allow for a recalcuation of the number of additional samples required if a normal distribution is not exhibited by the data set.

\subsection{Field Duplicates}

A field duplicate will be obtained along with the fifth and fifteenth samples obtained during this sampling effort. The duplicate sample will be collected adjacent to the fifth and fifteenth sample locations in the same manner as all other samples. The depth of sampling for the duplicate sample will be the same as the depth of sample for the original. The duplicate sample will be analyzed for each of the analyses specified in Section 4.2 of this plan. The results of the duplicate will be compared to the sample results to evaluate the precision of the sampling effort based on the relative percent difference between the sample value and the duplicate value.

\subsection{Field Decontamination of Sampling Equipment}

Field decontamination of sampling equipment will not be employed during this sampling effort. A new sampling tool. will be used for each sample obtained. Once the sample has been obtained the used sampling tool will be placed into a plastic bag and set aside. At the end of the project all of the bagged used sample devices will be removed from the project site and returned to the NTS for decontamination.

Field decontamination of the exterior of sample containers may be necessary. A spray bottle containing ordinary tap water, Alconox if required, and kimwipes will be available to decontaminate the exterior surface of sample bottles. 


\subsection{Field Blank}

Field Blanks are defined in Section Nine of SW-846 on pages NINE-61 through NINE-63 as "metal-and/or organic-free water aliquots that contact sampling equipment under field conditions and are analyzed to detect any contamination from sampling equipment, cross contamination from previously collected samples, or contamination from conditions during sampling (e.g. airborne contaminants that are not from the waste being sampled)." Field blanks will be obtained during sampling to determine if sampling equipment was contaminated prior to sampling. Prior to initiating the days sampling activities, a single rinsate will be collected from one of the sampling devices in an appropriate sample container. The field blank will be analyzed for the same parameters as the respective sample to determine if the sampling tools were contaminated prior to sampling.

\subsection{Trip Blank}

Trip blanks will be employed in each container used to transport samples from the sampling location to the laboratory in Mercury, Nevada. The trip blanks will be analyzed for TCLP VOA's, TCLP semi-VOA's, and TCLP pesticides. The trip blanks will consist of chemically pure water contained in sealed sampled containers transported to the sampling location and stored with the samples being returned to the laboratory for analysis. Once sealed at the laboratory prior to transport to the sample location, the containers are not opened until analysis is performed on the blanks.

\subsection{Required Analysis \\ - 4.1 Analytical Parameter Selection}

The material to be sampled is surface soil that is known to be contaminated with radionuclides and for which no evidence exists that hazardous waste constituents have ever been deposited on the soil. As previousiy discussed, it was determined that sampling and analys is for TCLP metals, TCLP VOA's, TCLP Semi-VOA's, and TCLP Pesticides as regulated under the toxicity characteristic as hazardous waste constituents would be performed to provide confirmatory data. This data will be used to determine the regulatory status of the soil as waste. It is anticipated that the results will confirm that none of the constituents are present in the soil at regulated quantities. Other constituents are not being eyaluated based on the knowledge that the onty industrial activity conducted at the site was the non-nuclear detonation of a device containing metali ic plutonium and uranium. There is no reason to expect that hazardous waste constituents are present in the soil, but analys is for TCLP metals, TCLP VOA's, TCLP semi-VOA's, and TCLP pesticides will be performed to provide confirmatory data.

In addition, the moisture content of the soil will be determined to provide a means of calculating the amount of absorbent material that will be added to the soil to inhibit free 1 iquid formation from the inherent moisture. 
4. Analytical Parameters - A total of 20 samples anc - duplicates will be analyzed under this effort. 1.. addition, 1 field blank obtained during the sampling effort will be analyzed. Thus a total of 23 field samples will be analyzed for the constituents identified in the table provided below. Quanterra Laboratories will be perform the TCLP metals, TCLP VOA's, TCLP Semi-VOA's, TCLP Pesticides, and moisture content analysis.

Table 3 - ANALYTICAL PARAMETERS

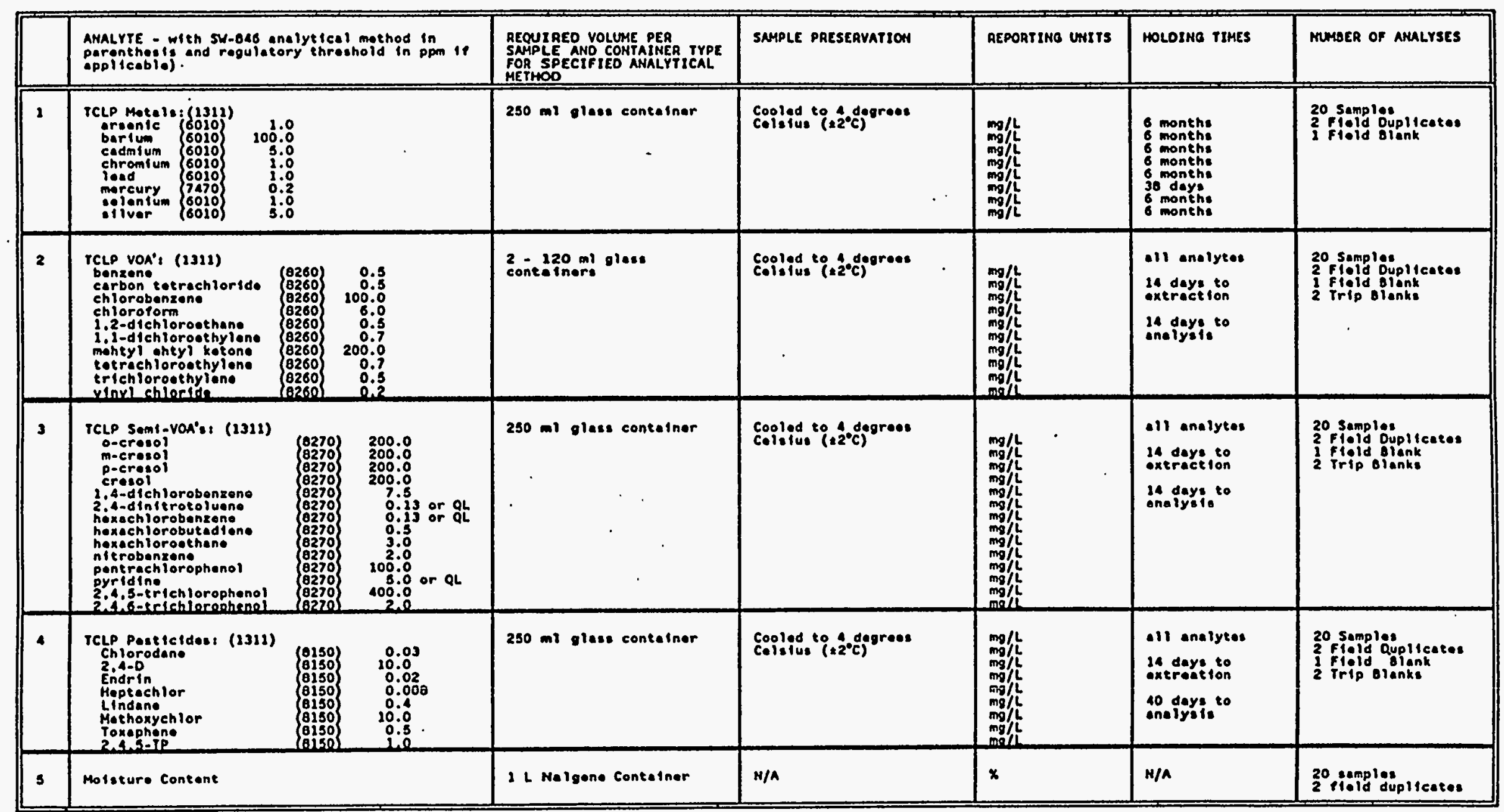




\subsection{Method Detection Limits}

The method detection limits for these constituents will be calculated using the procedure described in SH-846, Revision 1, Third Edition (reference page ONE - 25). Method detection limits calculated for the analyses will be included in the data package provided by the laboratory for the analytical effort. Once method detection limits have been calculated, they will be evaluated in relation to the regulatory threshold and an assessment of data viability can be made.

\subsection{Reporting units}

Reporting units are indicated in Table 3 of Section 4.2 of this plan.

\subsection{Data Reporting}

\subsection{Data Reporting Format}

In order to support the requirements of NYO-325 "NEVADA TEST SITE DEFENSE WASTE ACCEPTANCE CRITERIA, CERTIFICATION, AND TRANSFER REQUIREMENTS," data will be reported on modified Contract Laboratory Program (CLP) forms. These modified forms found are the same as the forms provided in the United States Environmental Protection Agency (USEPA) CLP Statement of Work except the CLP reference has been deleted.

\subsection{Censored Bata}

Censored data will be minimized to the fullest extent practical by having the laboratory report a numerical value for each analyte rather than "less than values" for data points that fall below the detection limit. In the event that the detection limit is reached and the data is reported as a "less than value," the data point is considered to be censored and the data will be assigned a value that is equal to the detection limit.

\subsection{Field Duplicate Data Management}

Field duplicate values will be compared with the actual sample value by calculating the Relative Percent Difference between the duplicate and the actual sample value. This calculation is described in Section 2.1 under precision. The data from duplicate values will be used to establish the precision achieved by the sampling effort.

\subsection{Data Verification}

Verification of all analytical results will be conducted by the REECo Environmental Services Department according to Analytical Services Procedure AAHDF.D.01.00, CLP "Inorganic Data Package Assembly and Review*. The results of the verification process are provided to the sample analysis requestor for use in characterizing the waste. 


\subsection{Statistical Evaluation of Results}

\subsection{Percent Confidence Limit}

Statistical evaluation of the data will be performed to ensure that the data is accurate within a specified confidence level. For this sampling effort, and generally for waste characterization under RCRA, a 90 percent confidence limit (one tailed) is required.

The confidence limit or interval will be calculated by first determining the mean value $\bar{X}$ of the data for each analyte. In order to determine data reliability, the standard deviation ( $s$ ) will be calculated to determine if the relationship between the mean value and the variance $\left(s^{2}\right)$ indicates that the data has a normal distribution. The confidence interval (CI) will then be calculated using the following equation:

$$
C I=\bar{X} \pm \frac{(t)(s)}{\sqrt{n}}
$$

where: $\quad t=~ " t "$ test value

$$
\begin{aligned}
& n=\text { the number of data points } \\
& s=\text { the standard deviation } \\
& \bar{x}=\text { the mean value of the data }
\end{aligned}
$$

Should the number of samples (twenty) prove to be insufficient to establish statistically acceptable data, additional samples will be obtained. The results from the additional sampling will be used along with the results from the original twenty samples to provide a large enough data base to provide statistically acceptable data. The number of additional samples required will be calculated by using the data from the twenty samples collected during this sampling effort to complete Equation 8 from Section 9 of SW-846.

If the data exhibits a normal distribution, the mean value plus the confidence interval will be compared to the regulatory threshold for each constituent to determine the regulatory status of the material.

\subsection{Quality Assurance}

\subsection{Field Notebook}

A field logbook will be maintained during the sampling effort to record the events that take place during sampling. The sampling activities will be recorded by the sampling personnel in the logbook, and will include the following information:

1. Name and location of sampling activities.

2. Cross referenced sample location and sample numbers.

3. Sample type (composite, grab; discrete). 
4. Physical description of all samples.

5. Field measurements taken.

6. Field observations.

7. Deviations from sampling plan.

8. Sampling equipment used.

\subsection{Sample Holding Times}

The holding times for the analytes that will be examined under this effort are indicated in Section 4.2 of this plan. When a sample is obtained, the current date and time will be recorded on the chain-ofcustody form for each sample. This form is used by analytical personnel to ensure that samples are analyzed within holding times. Sample collection times and analytical times will be reviewed as part of data verification and included in the data verification package.

\subsection{Quality Control Procedures}

The Analytical Services Section uses procedures to ensure that quality control is implemented during field sampling activities, sample management, and data management.

Quality control procedures used for the sampling, sample management, and data management activities are listed below. A copy of these procedures is maintained on file by the Analytical Services Section. Copies may be obtained by contacting the Analytical Services Section or the Waste Minimization and Control Section.

In addition, procedures and manuals used by the off-site analytical laboratory Quanterra are also on file with Analytical Services Section.

Sampling Procedure

AAHDH.D.01.01 Environmental Sampling Guide

\section{Analytical Quality Control Procedures}

AAHzZ.B.01.00

AAHZZ.B.03.00

AAHzZ.B.04.00

AAHzZ.B.06.00

AAHzZ.B.08.01

AAHzZ.B.08.02

AAHzZ.B.12.02

AAHzZ.B.13.00

AAHzZ.B.14.00

AAHDF.0.01.00
ASD Quality Implementing Procedure

Personnel Training and Qualification

Management Assessment

Control of Documents and Records

Quality Control Samples and Control Charts

Control of Data Discrepancies and Corrective Actions

Standards Traceability

Assessment of Data Usability

Independent Assessment

Inorganic Data Package Assembly and Review 



\section{APPENDIX C \\ ENVIRONMENTAL PROTECTION PLAN}




\section{CONTENTS}

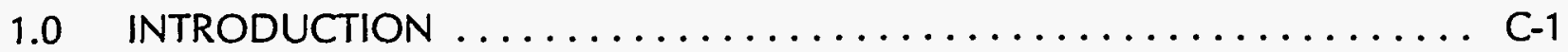

1.1 Site Location and Background $\ldots \ldots \ldots \ldots \ldots \ldots \ldots \ldots \ldots \ldots \ldots \ldots \ldots$

2.0 PRECONSTRUCTION SURVEY $\ldots \ldots \ldots \ldots \ldots \ldots \ldots \ldots \ldots \ldots \ldots \ldots \ldots \ldots \ldots \ldots \ldots \ldots$

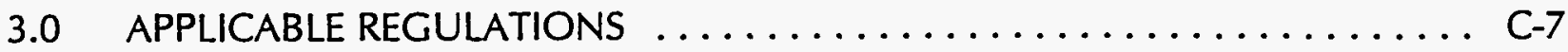

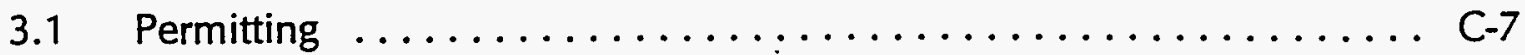

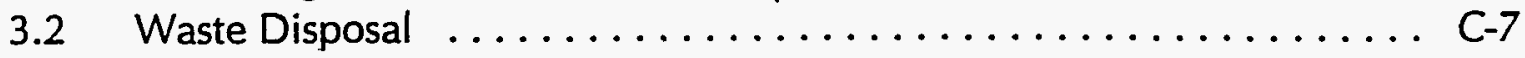

4.0 LAND RESOURCES PROTECTION $\ldots \ldots \ldots \ldots \ldots \ldots \ldots \ldots \ldots \ldots \ldots \ldots$

4.1 Protection of Facilities/Structures $\ldots \ldots \ldots \ldots \ldots \ldots \ldots \ldots \ldots$ C-9

4.2 Protection of Trees and Shrubs $\ldots \ldots \ldots \ldots \ldots \ldots \ldots \ldots \ldots \ldots \ldots \ldots \ldots$

5.0 PROTECTION OF WATER RESOURCES $\ldots \ldots \ldots \ldots \ldots \ldots \ldots \ldots \ldots \ldots \ldots \ldots \ldots \ldots$

6.0 PROTECTION OF FISH AND WILDLIFE RESOURCES $\ldots \ldots \ldots \ldots \ldots \ldots$.

7.0 PROTECTION OF AIR RESOURCES $\ldots \ldots \ldots \ldots \ldots \ldots \ldots \ldots \ldots \ldots \ldots \ldots \ldots \ldots \ldots \ldots \ldots$

$7.1 \quad$ Dust Control ..............................

8.0 ARCHAEOLOGICAL AND CULTURAL RESOURCES PRESERVATION . . . . . C

9.0 CORRECTIVE ACTION ........................... 19 


\subsection{INTRODUCTION}

This is the Environmental Protection Plan (EPP) for the interim corrective action at the DOUBLE TRACKS Test Site on Range 71 North of the Nellis Air Force Range (NAFR). The purpose of the EPP is to describe the methods and rationale to protect the environmental resources at DOUBLE TRACKS during interim corrective action activities of the low-level radioactive contaminated soil. This work is being performed under a DOE/NV Task Agreement Plan. This plan will provide site specific information for the following:

Preconstruction Survey

Applicable Regulations

Land Resources Protection

Water Resources Protection

Fish and Wildlife Resources Protection

Air Resources Protection

Archeological and Cultural Resources Preservation

Corrective Action

This plan has been prepared and will be implemented in accordance with applicable federal, state, and local laws, regulations and permits for protection of the environment.

\subsection{Site Location and Background}

The selected information contained in this paragraph was taken from the draft DOUBLE TRACKS Test Site Characterization Report, dated March 1996.

The DOUBLE TRACKS Test Site is located on Range 71 North of the NAFR, northwest of the Nevada Test Site (NTS) (Figure 1-1). The nearest town is Goldfield, Nevada, located approximately 22 kilometers $(\mathrm{km})(14$ miles [mi]) west of the site. By existing road through the Tonopah Test Range (TTR) and U.S. Highways 6 and 95, Goldfield is approximately $132 \mathrm{~km}(82 \mathrm{mi})$, and Mercury Nevada, is approximately $362 \mathrm{~km}(224 \mathrm{mi})$ from the DOUBLE TRACKS Test Site.

DOUBLE TRACKS was the first of four experiments that constituted Operation ROLLER COASTER. On May 15, 1963, weapons grade plutonium and depleted uranium were placed on a 2.4 - by 2.4 - meter $(\mathrm{m})(8$ - by 8 -foot [ft]) steel plate that was supported by a 6.1 - by $6.1 \mathrm{~m}$ (20- by $20-\mathrm{ft}), 0.3 \mathrm{~m}(\mathrm{ft})$-thick reinforced concrete pad. The radioactive material was dispersed using 54 kilograms (kg) (118 pounds [lbs]) of trinitrotoluene (TNT) explosive

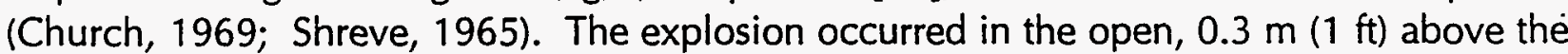
steel plate (Menker et al., 1966). No fission yield was detected from the test, and the total amount of plutonium deposited on the surface was estimated to be between 980 and 1,600 grams (Shreve, 1965). The test device was composed primarily of uranium-238 (U-238) and plutonium-239 (Pu-239). Menker et al. (1966) reported that the weight ratio of uranium to plutonium in the device was 4.35 . 
The objectives of the DOUBLE TRACKS experiment were to evaluate the dispersal of radionuclides in the environment and the uptake and fate of plutonium in several animal species. The experiment scattered radioactive material, earth, and other material (concrete and metal) into the air. The debris and most of the dirt fell to earth at relatively short distances. However, some of the finer grained material was spread over a larger area downwind, south of ground zero. The debris in the vicinity of ground zero and identified fragments to distances of 90 to $120 \mathrm{~m}$ (300 to $800 \mathrm{ft}$ ) were collected and buried near ground zero. Contaminated surface soil in the vicinity of ground zero reportedly was scraped to a depth of several inches and mounded, covered with clean dirt, and compacted. The steel plate was buried in the Clean Slates radiation disposal pit, but was later exhumed and transported to the NTS for analysis and disposal. Except for these post event activities, no decontamination of the site was reported.

Based on a site characterization designed to adequately characterize the nature and extent of contamination at the DOUBLE TRACKS Test Site, specific conclusions identified in the characterization report were:

Contaminants of potential concern in soil at the DOUBLE TRACKS Test Site are Am-241 and plutonium. Uranium and other non-radiological metals are present only in background concentrations.

In situ measurements indicate that typically most of the total transuranic activity. is present within the top $2.5 \mathrm{~cm}$ (1 in.) of the soil profile. Where significant amounts of plutonium (greater than $1,000 \mathrm{pCi} / \mathrm{g}$ ) are present, it can be assumed that the uppermost $5 \mathrm{~cm}$ ( 2 in). of the soil profile is contaminated. In the ground zero area, radiologically-contaminated soil and possibly test debris are buried. The depth of contamination in the mound may be as thick as $0.9 \mathrm{~m}$ $(3 \mathrm{ft})$ or $0.3 \mathrm{~m}(1 \mathrm{ft})$ below the surface.

The contamination of surface soil at DOUBLE TRACKS appears to have been caused by local fallout and debris from the experiment. Superimposed on this contamination pattern were relatively-large metallic fragments. These metallic fragments were the source of most of the radioactive hot spots activity identified during characterization.

The surface area with total transuranic activity greater than $200 \mathrm{pCi} / \mathrm{g}$ is approximately 8,780 square meters $\left(\mathrm{m}^{2}\right)\left(95,400 \mathrm{sq} \mathrm{ft}\left[\mathrm{ft}^{2}\right]\right)$, based on an in situ radiological survey.

The best estimate of the volume of contaminated soil to be removed from DOUBLE TRACKS is 1,243 cubic meters $\left(\mathrm{m}^{3}\right)\left(1,611 \mathrm{yd}^{3}\right)$, based on a cleanup level of $200 \mathrm{pCi} / \mathrm{g}$. This estimate does not take into account soil expansion during excavation. 
Based on the contaminants present, soil from the DOUBLE TRACKS Test Site would be classified. as low-level radioactive waste and not mixed low-level waste. Soil contaminated with Am-241 and plutonium did not exhibit toxicity characteristic, based on TCLP data.

The metallic fragments outside of ground zero are containerized inside the exclusion zone and represent a very small volume of transuranic material.

... volume reduction does not appear to be cost effective for the DOUBLE TRACKS Test Site because of the relatively small amount of soil requiring corrective action. 
This Page Intentionally Left Blank 


\subsection{PRECONSTRUCTION SURVEY}

Prior to beginning on-site construction activities, BN personnel and the appropriate U.S. government representatives or designee have conducted several joint surveys of the condition of existing trees, shrubs, grassed areas, and wildlife immediately adjacent to the area which may be affected by construction activities, equipment and material storage areas, and access routes. The surveys have helped develop a mutual understanding of the action to be taken to provide environmental protection. 
This Page Intentionally Left Blank 


\subsection{APPLICABLE REGULATIONS}

BN will comply with all applicable federal, state, and local laws and regulations to prevent any environmental damage arising from the interim corrective action of the low level radioactive contaminated soil at the DOUBLE TRACKS Test Site.

\subsection{Permitting}

The permits which are applicable to this scope of work are as follows:

State of Nevada Air Quality Operating Permits

State of Nevada Surface Disturbance Permit

State of Nevada Change of Location Forms

\subsection{Waste Disposal}

The only waste that is currently present is the low-level radioactive soil. Wastes that may be generated during the remediation activities are compactable radioactive waste (booties, gloves, filters), bulk waste (concrete pad) and packaged contaminated soil.

The contaminated soil will be screened and processed as described in the Interim Corrective Action Plan, Implementation Plan. Debris present in the soil > 3/4 in will be screened and replaced on the site for used in reclamation and revegetation. Decontamination water which results from the washing of the equipment will be processed and filtered through a recycler for unrestricted use. Residual water will be used for on-site dust control.

Radiological surveys will be conducted to identify any contaminated areas within the fence line. Areas of contamination will be excavated until surveys indicate the area is below $200 \mathrm{pCi} / \mathrm{g}$. 
This Page Intentionally Left Blank 


\subsection{LAND RESOURCES PROTECTION}

Except for designated work areas, storage areas, and access routes specifically assigned for use during construction activities, all land resources outside the limits for work will be preserved in their present condition. As much as practical, construction activities will be limited to areas defined by the plans and specifications. BN will provide wind erosion and rainwater controls for temporary stockpiles of low-level radioactive contaminated soil. Run-off controls will include the placement covers with anchors (if needed) over the stockpiled material and chemical stabilizers in the excavated area.

Any temporary equipment and materials storage areas will be identified in the implementation plan. Site vehicles will remain on designated access roads and will be prohibited from driving on land areas outside the work zones. Designated access roads will be identified. BN personnel will not use any areas on base property other than those designated for site activities.

\subsection{Protection of Facilities/Structures}

On-site temporary electrical and mechanical services and facilities will be protected. No permanent services or facilities exist. Temporary covering of exposed areas as will as temporary services or connections will be provided by $\mathrm{BN}$.

\subsection{Protection of Trees and Shrubs}

There are no significant trees, shrubs or bushes in the vicinity of the DOUBLE TRACKS Test Site. In any case, BN and subcontractor personnel will not deface, injure, or destroy trees or shrubs, or remove or cut them without prior authority from the appropriate U.S. gvernment representative. No ropes, cables, or guy wires will be attached to any existing trees or shrubs for anchorage. Precautions that will be taken to minimize the impact of construction activities on the existing vegetation will include but not be limited to:

Utilization of existing or temporary construction roads only

Closely supervised equipment operators with an emphasis placed on preservation of vegetation in nonwork areas

Proper guidance of heavy equipment and truck operators by site personnel to minimize damage to adjacent vegetation not directly affected by construction activities

Utilization of equipment appropriately designed and sized. 
This Page Intentionally Left Blank 


\subsection{PROTECTION OF WATER RESOURCES}

Water is approximately 500 feet below grade and there are no known surface waters or springs in the area. Protection of water resources will be accomplished by ensuring that the contaminated water resulting from decontamination activities will not be a source of contamination. Decontamination water will be collected, process, and reused. 
This Page Intentionally Left Blank 


\subsection{PROTECTION OF FISH AND WILDLIFE RESOURCES}

BN will take precautions at all times during remediation activities to minimize any disturbance to wildlife and their habitat adjacent to the project site. BN will minimize the actual work area as much as possible and practical to minimize impacts to wildlife.

There are no known endangered species on the project site. 
This Page Intentionally Left Blank 


\subsection{PROTECTION OF AIR RESOURCES}

Personnel and ambient air monitoring will be conducted as necessary in order to determine airborne contaminant levels. This ensures that respiratory protection is adequate to protect personnel against the contaminants that are encountered as well as assuring that harmful levels of airborne contaminants are not leaving the site.

\subsection{Dust Control}

BN will make every effort to ensure that the spread of dust is controlled and minimized to avoid nuisance and/or hazard to workers and to the surrounding area. BN personnel and subcontractors will take appropriate measures to control and minimize dust emissions at the site during interim corrective action activities. Dust emissions will be monitored. Temporary dust control will be addressed as necessary by any of the approved methods including spraying with nonpotable water, chemical stabilizers, or stopping work. 
This Page Intentionally Left Blank 


\subsection{ARCHAEOLOGICAL AND CULTURAL RESOURCES PRESERVATION}

No archaeological or cultural resources are known to exist on site, nor are they expected to be encountered. BN will make every effort to carefully preserve and immediately report items having historical or archaeological interest which are discovered in the course of work. Any employee may call a stop work to allow for investigation and protection of artifacts. The perimeter of the find as appropriately determined will immediately be delineated with caution tape to restrict access to the find site. The project manager will be responsible for contacting the federal, state, and local authorities to determine if the site may contain other important historical artifacts, and possible placement on the National Register of Historical Places. Field operations will not resume until the appropriate authority issues a written authorization to proceed. 
This Page Intentionally Left Blank 


\subsection{CORRECTIVE ACTION}

Should any of the preceding provisions not satisfy the standards established in the Scope of Work, BN will take prompt action to correct the situation upon receipt of notification from the appropriate official or BN's Quality Control Personnel. All corrective measures will be proposed in writing for review and approval prior to their initiation. Situations requiring immediate corrective action will be implemented as soon as possible. Written documentation of the action will be submitted within 24 hours of implementing the action. BN Quality Control Personnel may require that work be stopped to correct any violations of this plan. 


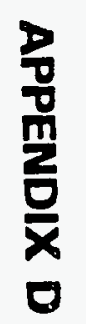


APPENDIX D

TRANSPORTATION 


\section{Transportation Plan}

A subcontractor licensed to transport low-specific activity radioactive waste will move the processed soil to the Nevada Test Site Area 3. Radioactive Waste Management Site using the following plan in accordance with U.S. DOT regulations.

- On the first day of transportation-operations, the subcontractor will have 10 tractor/trailer rigs available in the town of Tonopah, Nevada. Rigs will depart Tonopah to arrive at the DOUBLE TRACKS project site every half hour starting at 5 a.m.

- The rig will travel from Tonopah to the TTR main security gate where the driver will obtain an exchange badge.

- The driver will then proceed to the Sandia office where the driver will pickup a Bechtel-provided hand-held radio which will transmit and receive on Sandia and Fox 4 nets.

- The driver will proceed from the Sandia office south on the main paved road approximately five miles and turn west onto Cactus Springs Road (dirt). The driver will continue on Cactus Springs Road which becomes Sleeping Column Canyon Road.

- When the driver reaches the Cactus Springs Ranch, he will notify Cactus on the Sandia net that he is approaching the Cactus Springs Gate. (It is an approximate 10minute drive from the ranch to the gate. The radios are not capable of transmitting in the gate area.)

- The driver will switch to the Fox 4 net to monitor any instructions from Blackjack while on Range 71.

- The driver will check in at the site office trailer when arriving at the DOUBLE TRACKS project site. The trip from TTR to DOUBLE TRACKS will take no more than $2 \frac{1}{2}$ hours.

- At the DOUBLE TRACKS project site loading zone, Bechtel Nevada personnel will load one Sealand ${ }^{\circledR}$ container on to each rig. The required manifest and bill-oflading will be completed by the contractor before the load leaves the area. After the initial trip, the empty Sealand ${ }^{\circledR}$ container will be removed from the rig and will be replaced with a full container. A 25-ton forklift will be used to load and unload containers from the rigs. The loading/unloading process is expected to take no longer than one-half hour per rig. 
The Sealand ${ }^{\oplus}$ containers will be surveyed for external radiation prior to being removed from the exclusion zone. Containers which have external radiation above off site release limits will be decontaminated, then re-surveyed.

- The driver will return back to Tonopah using the same route. When passing the Cactus Springs Ranch, Cactus will be notified on the Sandia net that the rig has exited the Nellis Air Force Range. At the Sandia office, the driver will return the radio. Information on the shipment will be input into the Haztrack system. The contractor

will conduct a DOT Class 1 safety inspection prior to proceeding beyond the Sandia office. A Bechtel Nevada employee will observe the inspection. At the main security gate, the exchange badge will be returned.

- The driver will proceed to Mercury via Highway 95. At the main gate, the driver will obtain an NTS badge and have the bill-of-lading verified. The driver will park in the designated area in Mercury and spend the night.

- The next morning, the rigs will depart for the Area 3 RWMS in pairs every $1 \frac{1 / 2}{2}$ hours. The first pair of rigs must arrive at Area 3 RWMS no later than 7:30 a.m.

- At Area 3 RWMS, the Sealand ${ }^{\oplus}$ containers will be unloaded by Bechtel Nevada personnel. The palletized supersacks will be removed from the container while the container remains on the rig.

- After the containers are unloaded, the rig and container will be surveyed for radiation contamination and a radiological release and property removal form completed. The rig will return back to Mercury and depart through the main gate. The NTS badge will be returned to security at the main gate.

- The rig will return back to Tonopah on Highway 95. The rigs will be parked overnight in a designated area. The drivers will spend the night in Tonopah.

- The above sequence will be followed until all loads have been delivered to the NTS. The only exception to this sequence will that two loads of bulk low-level radioactively contaminated material will be delivered to Area. After the final trip to the Area 3 RWMS, the Sealand ${ }^{\circledR}$ containers will be delivered to the Area 6 decontamination facility for storage. 


\section{DRIVER'S VEHICLE INSPECTION REPORT}

CARAIER:

ADDRESS:

DATE:

TIME:

A.M

TRACTOR

TRUCK NO.

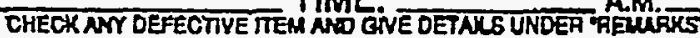
ODOMETER READING

$\square$ Air Compressor

$\square$ Horn

Air Lines

Baltery

Boody

Brake Accessories

Brakes, Parking

Brakes, Service

1 Clutch

$\square$ Coupling Devices

Defroster/Heater

Drive Line

$\square$ Engine.

Exhaust

Fitth Wheel

Frame and Assembly

Front Axle

Fusl Tanks

Generator

Lights

Head - Stop

Tail - Dash

Tum Indicators

$\square$ Mirrors

$\square$ Muffler

$\square$ Oil Pressure

Radiaior

Rear End

$\square$ Reflectors

$\square$ Satety Equipment

Fire Extinguisher

Reflective Triangles.

Flags - Flares - Fusees

Spare Bulbs \& Fuses

Spare Seal Beam $\square$ Suspension System

$\square$ Starter

$\square$ Steering

Tachograph

Tires

$\square$ Tire Chains

Transmission

$\square$ Wheols and Rims

Windows

$\square$ Windshield Wipers

$\square$ Other

TRAILER(S) NO. (S).

$\square$ Biake Connections
$\square$ Brakes
$\square$ Coupling Devices
$\square$ Coupling (King) Pin
$\square$ Doors

Remarks:

$\square$ Tarpaulin

$\square$ Tires

Q Whoels and Rims

$\square$ Other

\begin{tabular}{ll}
\hline \\
\hline \\
\hline \\
\hline \\
\hline
\end{tabular}

\section{口 CONDITION OF THE ABOVE VEHICLE IS SATISFACTORY}

DAIVER'S SIGNATURE:

DABOVE OEFECTS COARECTED

$\square$ ABOVE DEFECTS NEED NOT BE CORAECTED FOR SAFE OPERATION OF VEHICLE MECHANIC 6 SGGNATURE: DATE

DFIVEA'S SIGNATUAE: DNTE 


\section{BECHTEL NEVADA CORPORATION REQUEST FOR PROPOSAL (RFP) NO. 10-MB-96}

CONSTRUCTION SUBCONTRACT

\section{DOUBLE TRACKS HAZARDOUS MATERIAL TRANSPORTATION}

DATED ISSUED: June 4, 1996

If you have any questions, please contact Michael Brubaker at 702-295-7606.

A facsimile quotation is acceptable and may be telefaxed to the above individual at 702-295-6284.

A pre-proposal conference will be held on June 17, 1996, at 9 a.m., in the Bechtel Nevada Corporation facility at 2621 Losee Road, North Las Vegas, Nevada in the B-2 conference room. Proposals will be received until 4:30 p.m., June 21, 1996, local time. Any quotations received after that date may be considered nonresponsive.

\section{PROPOSAL MAY BE MAILED TO:}

Bechtel Nevada Corporation

Michael L. Brubaker, Mail Stop NTS310

Post Office Box 98521

Las Vegas, NV 89193-8521

Mailing address for express mail only is:

Bechtel Nevada Corporation

Michael L. Brubaker, Mail Stop NTS310

2621 Losee Road, Bldg.. B-3

North Las Vegas, NV 89030-4134

\section{STATEMENT OF WORK:}

See Attachment No. 1 
RFP NO. 10-MB-96

PAGE 2

THE FOLLOWING ENCLOSURES ARE AN INTEGRAL PART OF THIE TERMS AND CONDITIONS OF THIS RFP:

1. TERMS AND CONDITIONS FIXED-PRICED CONSTRUCTION

2. RIDER NO. 3, AFFIRMATIVE ACTION COMPLIANCE

3. RIDER NO. 7, SITE FACIIITIES AND TRAFFIC

4. RIDER NO. 9, COMPLIANCE WITH LABOR AGREEMENTS

5. RIDER NO. 12, GOVERNMENT-FURNISHED PROPERTY

6. RIDER NO. 16, SPECIAL EQUAL EMPLOYMENT OPPORTUNITY RESPONSIBIIITIES .

7. RIDER NO. 20, NTS EVACUATION/ACCESS REQUIREMENTS

8. RIDER NO. 22, CLEAN AIR AND WATER POLLUTION CONTROL ACT

9. SELLER CERTIFICATIONS AND REPRESENTATIONS

10. STATEMENT OF WORK-DOUBLE TRACKS HAZARDOUS MATERIAL TRANSPORTATION-ATTACHMENT NO. 1

11. SPECIAL CONDITIONS--DOUBLE TRACKS HAZARDOUS MATERIAL TRANSPORTATION--TONOPAH TEST RANGE AND NEVADA TEST SITE-ATTACHMENT NO. 2

12. TECHNICAL PROVISIONS--DOUBLE TRACKS HAZARDOUS MATERIAL TRANSPORTATION-- ATTACHMENT NO. 3

13. CONSIDERATION SCHEDULE-DOUBLE TRACKS HAZARDOUS MATERIAL TRANSPORTATION-- ATTACHMENT NO. 4

ALL REFERENCES TO REYNOLDS ELECTRICAL AND ENGINEERING CO., INC, SHALL BE INTERPRETED AS BECHTEL NEVADA CORPORATION.

\section{LOCATION OF WORK}

Nevada Test Site-located approximately 65 miles north of Las Vegas, Nevada

Tonopah Test Range--located approximately 250 miles north of Las Vegas, Nevada. 


\title{
RFP-10-MB-96
}

\section{PAGE 3}

\section{DATE OF AWARD}

The proposals are due on June 21,1996 . It is anticipated that the source selection and approval process will take approximately 10 days. Notice of Intent to Award is anticipated to be given on or about July 1, 1996. The successful proposal will have 10 days to provide the bonds required in Section II of the Terms and Conditions. Notice of Award and Notice to Proceed are anticipated to be given by July 10, 1996, with mobilization at the NTS to start on July 15, 1996.

\section{OUOTATION ACCEPTANCE PERIOD:}

The Offeror offers and agrees, if this quotation is accepted within 30 calendar days unless a different period is inserted by the Offeror from the date of opening of quotations, to provide all services/supplies upon which prices are quoted at the prices set opposite each item within the time limit specified in the performance schedule.

\section{PREPARATION OF PROPOSALS:}

Proposals to be considered acceptable to this solicitation shall comply with the following requirements:

1. Proposal shall be submitted to arrive at this office (as identified on page 1 of this RFP) by the time specified.

2. Each proposer shall provided two copies of the technical portion of the RFP and one copy of the Consideration Schedule and signed RFP documents.

3. All costs involved in the preparation of proposals shall be borne by the Offeror, and will not be the responsibility of the Contractor.

\section{NEVADA SALES/USE TAX}

Please indicate whether seller has current state of Nevada permit to collect Nevada sales/use tax. Yes [] No [ ].

If "yes," No.

\section{BUSINESS TYPE: (CHECK THOSE WHICH APPLY)}

\author{
\{ \} Large Business, \{ \} Small Business, \{ \} Small Disadvantaged Business, \\ \{ \} Women-Owned
}

[X] NOTICE OF SMALL DISADVANTAGED BUSINESS-SMALL DISADVANTAGED PURCHASE SET-ASIDE

\section{TECHNICAL INSTRUCTIONS}

See Attachment No. 3 


\section{RFP-10-MB-96}

PAGE 4

\section{PRICE INSTRUCTIONS}

Proposers shall submit their unit price and extended price for those items referenced on the consideration schedules in this RFP. See Attachment No. 4.

\section{BONDS}

PAYMENT AND PERFORMANCE BONDS WILL BE REQUIRED PURSUANT TO ARTICLE II, "BONDS" OF THE TERMS AND CONDITIONS FIXED-PRICE CONSTRUCTION.

\section{SUMMARY OF REOUIRED SUBMITTALS:}

1. Completed Request for Proposal including Consideration Schedule

2. Sellers Certifications and Representations

3. Technical Proposal

4. Certificate of Employment

\section{COMPANY:}

ADDRESS:

TERMS: CONTACT NAME:

PHONE: FAX NO.:

SIGNATURE: 


\author{
ATTACHMENT NO. 1 \\ BECHTEL NEVADA CORPORATION \\ REQUEST FOR PROPOSAL (RFP) 10-MB-96 \\ DOUBLE TRACKS HAZARDOUS MATERIAL TRANSPORTATION
}

\author{
STATEMENT OF WORK
}

CONSTRUCTION SUBCONTRACT

\title{
I. GENERAL
}

Bechtel Nevada Corporation (BNC) hereafter referred to as the "Contractor," is the Management and Operations Contractor for the Department of Energy (DOE) at the Nevada Test Site (NTS). As such, BNC has been tasked by DOE with the environmental assessment, transportation, and disposal of a large area of surface contaminated soil on the Nellis Air Force Base Range that is associated with historic NTS operations. BNC has completed the environmental phase of the project. The soil has been classified as low-specific-activity radiological waste.

The purpose of this RFP is for the selection of a subcontractor to provide tractors, trailers, and drivers to haul the hazardous material from its present location on the Tonopah Test Range to the disposal location on the NTS.

\section{SCOPE OF WORK}

The total amount of soil to be transported is approximately 43,740 cubic feet or 1620 cubic yards. The soil is located in an area known as "Double Tracks" on the Nellis Air Force Base Range. Contractor personnel will be responsible for gathering all the contaminated soil, placing it in 15- and 30-pound woven polypropylene (supersack) bags, placing the bags on pallets, and placing the pallets in 20 -foot Sealand cargo containers ( $8 \mathrm{ft} X 8 \mathrm{ft} X 20 \mathrm{ft}$ ). The only exception will be two Sealand containers that will be loaded with bulk low-level radioactive contaminated material. All materials will be provided by the Contractor. All loading and unloading of the material and the cargo containers will be the responsibility of the Contractor.

The Subcontractor shall be responsible for rigs (the term rig is in reference to a tractor and a trailer) and qualified drivers capable of hauling the Contractor-loaded Sealand containers (containing hazardous materials) from the point of origin to the disposal area(s) on the NTS in the manner detailed below. 


\section{ATTACHMENT NO. 1 \\ REQUEST FOR PROPOSAL (RFP) 10-MB-96 \\ DOUBLE TRACKS HAZARDOUS MATERIAL TRANSPORTATION PAGE 2 OF 6}

The following is the Contractor's recommended routing, including the number of rigs to be used, for the transportation of the material. In order to meet the Contracts Schedule, it is the intent of the contract to load 10 rigs a day and unload the same 10 rigs the next day. With 188 loads anticipated, on a six-day-a-week schedule with two days required for each run (10 rigs per run), the performance period is estimated to be 25 days. This time includes two days for mobilization. The mobilization period will include time for badging, securing housing, required training, and the preperformance meeting.

The following routing is based upon the Contractor's determination of the best routing to meet the schedule at 10 loads per day. The actual routes on the Tonopah Test Range (TIR) and the NTS are predetermined by the Contractor. The routing in-between the two locations is the suggested routing. If proposers wish to suggest an altemate routing, they may do so with a detailed description of the alternate routing.

\section{Contractor-Suggested Routing}

$\nabla$ On the first day of operations, the Subcontractor will have 10 rigs available in the town of Tonopah, Nevada. The two rigs shall depart Tonopah every half hour starting at 3:30 am. The route is east on Highway 6 for approximately 12 miles, turn right at the TTR sign, then approximately 18 miles to the entrance to the ITR Stop at the security guard gate, obtain an exchange badge, proceed south on the main (paved) road 7 miles to the Sandia office, pick up a Contractor-provided radio, proceed 5 miles to Cactus Springs Road (dirt), and tum right (west). It is estimated that this portion of the route will take no more than two and one-half hours. The first two trailers shall be at the Site by 6 a.m.

Cactus Springs Road ( 7.5 miles) and Sleeping Column Canyon Road ( 9.5 miles) are both single lane dirt roads. The roads are wide enough for a tractor/trailer and a car to pass on but not two tractors/trailers. There are turnouts every one-half mile on Canyon Road and every mile on Cactus Springs Road. The maximum grade on the road is 4 to 6 percent. The Contractor will be responsible for dust control and road maintenance.

$\nabla \quad$ At the Double Tracks Loading Zone Site, the Contractor will load on one Sealand container per rig. After the initial trip, the Contractor will first unload the empty container from the previous trip. The required manifest and bill of lading will be completed by the Contractor before the load leaves this area. The loading/unloading process is estimated to take no longer than one hour for two rigs. 


\section{ATTACHMENT NO. 1 REQUEST FOR PROPOSAL (RFP) 10-MB-96 \\ DOUBLE TRACKS HAZARDOUS MATERIAL TRANSPORTATION PAGE 3 OF 6}

$\nabla \quad$ After the Sealand container has been loaded, the rig will proceed back to Tonopah on the same route, dropping the radio off at the Sandia office and the badge back off at the Guard Shack. At the Sandia office, a qualified subcontractor personnel shall perform an inspection of the rig in accordance with 49 CFR 392.7, "Equipment Inspection and Use," and 396.11, "Driver Vehicle Inspection Report." (See Attachment No. 6). A copy of the Inspection Report will be provided to the Contractor. A Contractor Representative will be present during the inspections. The trip back to Tonopah is estimated to take no longer than two and one-half hours.

$\nabla$ From Tonopah, the rigs will proceed south on Highway 95 to the Mercury turnoff. This is approximately 150 miles. At Mercury, the drivers will stop at Guard Gate 100 to pick up an NTS badge and for verification of the bill of lading. The drivers will then park in the designated area in Mercury for the night and proceed to the disposal/off-loading area the next day. This portion of the trip is estimated to take no more than three hours to drive from Tonopah to Mercury and one-half hour to clear through Security and park the rigs for the night.

The total estimated time for the days' run is $91 / 2$ hours excluding $1 / 2$ hour for lunch. This routing calls for the drivers to stay in Tonopah the first night and in Mercury the second night. Drivers shall conduct tire inspections once every two hours or 100 miles of travel, whichever is less, in accordance with 49 CFR 397.17. Driver shall not exceed the hours of service requirements (49 CFR 395).

$\nabla$ The following morning the rigs will depart every one-half hour in pairs starting at 6:30 a.m. to the Area 3 Radioactive Waste Management Site (RWMS) for unloading. The RWMS is approximately 35 miles from Mercury. It is anticipated to take no. longer than one hour to get from Mercury to Area 3.

$\nabla$ At Area 3 the.Sealand containers will be emptied (the pelletized sacks will be removed from the Sealand containers, the containers will remain on the rig). The rigs will be checked by the Contractor personnel for any contamination. All required paperwork will be completed and then the rigs will return to Mercury with the empty Sealand container. It is anticipated that the unloading, RadSafe check, and paperwork will take $21 / 2$ hours per each set of rigs. The trip back to Mercury is estimated to take no longer than an hour. 


\section{ATTACHMENT NO.1 \\ REQUEST FOR PROPOSAL (RFP) 10-MB-96. \\ DOUBLE TRACKS HAZARDOUS MATERIAL TRANSPORTATION PAGE 4 OF 6}

$\nabla$ The drivers will retum their badges to Security when exiting the NTS. The drivers will proceed back to Tonopah where they will park for the night. It should take no longer than three hours to drive from Mercury to Tonopah.

The total trip time for the drop off and retum run should take no longer than $7 \frac{1}{2}$ hours.

This same process will be followed until all the loads are delivered. The only exception will be two Sealand containers that will contain bulk low-level radioactively contaminated material that will be delivered to Area 6 . The route time should be the same as for the normal run. After the final trip for each of the containers, the Subcontractor will drop the containers at the Area 6 Decontamination Facility for storage.

\section{SUBCONTRACTOR REOUIREMENTS}

1. The Company: The Company shall be capable of providing the required number of tractors, trailers, support equipment, supervision, and drivers to perform the work within the schedule detailed above. All equipment and personnel shall be properly licensed, certified, and shall be mechanically and physically fit to perform the work required.

2. Equipment: All tractors and trailers shall be capable of excepting and hauling 20 -foot Sealand containers with an approximate load of 24,000 pounds. The trailers shall comply with 49 CFR 393.100 subparagraph (e), "Special-Rule for Intermodal Cargo Containers," The Subcontractor will have one backup tractor, trailer, and driver available at all times in case of rig breakdown. All required support vehicles, equipment, and personnel shall be immediately available to service the tractors and trailers for routine, required, and emergency repairs and services.

3. Drivers/Support Personnel: All drivers shall possess a valid commercial drivers licenses and have a Department of Transportation medical examination certificate current within the past two years. The Subcontractor shall submit a copy of the certification to the Contractor and have a current hazardous material certification. All support personnel shall be properly trained and experienced in the required vehicle maintenance. Onsite supervisory personnel shall have the experience and authority to make on-the-spot decisions, if required, in order to keep the operations performing on schedule.

During the mobilization period, the Contractor will provide to each onsite Subcontractor employees a one hour NVO-325 Awareness Session and a one-half hour Range Safety training. 


\section{ATTACHMENT NO. 1 \\ REQUEST FOR PROPOSAL (RFP) 10-MB-96 \\ DOUBLE TRACKS HAZARDOUS MATERIAL TRANSPORTATION \\ PAGE 5 OF 6}

4. Operational Support. The Subcontractor shall be responsible for coordinating all requirements for fuel, oil, etc., for the vehicles and all transportation, housing, and meals for the Subcontractor personnel.

5. Union Requirements. This is a Construction Subcontract and the Subcontractor shall be responsible for all coordination with the Contractor's designated trade unions. This includes but not limited to paying of all required hourly rates and benefits, using of union personnel, adherence to shift and drivers' time requirements, and submittal of certified.payrolls to the Contractor.

6. Safety and Department of Transportation (DOT) Requirements: Even though the Contractor will perform a Pre-Award Inspection of the proposed vehicles, it is the Contractor's responsibility to ensure that all vehicles meet the DOT requirements for transporting of hazardous materials. This includes but is not limited to a

Subcontractor inspection of all rigs prior to their departure from the TTR. This is to be done at the Sandia offices after leaving the loading zone. This inspection shall be equivalent to a post-trip driver vehicle inspection report (a North American Level 1) The Contractor will observe the inspections.

7. Routing: All drivers shall adhere strictly to the routes laid out by the Contractor on the NTS and the TIR Going off road is strictly prohibited. Using or crossing the runway at the TIR is prohibited. Offsite routing once agreed on, between the Contractor and the Subcontractor, is to be adhered to by all drivers. No altemate routes shall be taken without prior notification to the Contractor.

\section{CONTRACT RESPONSIBILITIES}

1. Prior to award, Contractor personnel will perform a North American Level 1 inspection of the purposed successful proposers proposed vehicles to be used. This will be done at the proposer's facilities and be conducted per DOE Order 460.1, "DOE Motor Carrier Evaluation Program Plan and Program Procedures."

2. The Contractor will not be responsible for providing any support for the subcontract except as listed herein.

3. The Contractor will make available housing and meals at the NTS as detailed in the Special Conditions Section SC-16.

4. The Contractor will establish available parking areas in Mercury, Nevada.

5. The Contractor will be responsible for completing all required manifest and bill of lading.

6. The Contractor will be responsible for all loading and unloading of material. 


\section{ATTACHMENT 1 REQUEST FOR PROPOSAL (RFP) 10-MB-96 \\ DOUBLE TRACKS HAZARDOUS MATERIAL TRANSPORTATION PAGE 6 OF 6}

7. The Contractor will provide hand-held radios to the Subcontractor while on the TTR

8. The Contractor will provide administrative assistance in the form of preoperation meetings, coordination with badging requirements at NTS and TTR, and onsite routing including being responsible for all onsite road conditions. The Subcontractor will provide a list of drivers, training records, vehicle identification and licence number to the Contractor for badging and onsite clearances.

V. WEATHER AND ONSITE CONDITIONS

In July and August the average high temperatures at the NTS and TTR is 100 degrees with minimal rain. All route roads are paved except the last 17 miles to the loading zone. This road is dirt with grades up to 6 degrees.

\section{INVOICING}

As the performance period for the subcontract is less than 30 days, the Subcontractor shall invoice for the entire work after satisfactory completion. The Contractor will retain 10 percent of the invoiced amount until verification of insurance payments, union benefits, and certified payrolls has been completed. If the Subcontractor has completed the above as required, closeout should not take over 45 days. 
ATTACHMENT NO. 2

BECHTEL NEVADA CORPORATION

UNDER PRIME CONTRACT NO. DE-AC08-96NV11718

WITH THE UNITED STATES OF AMERICA

ACTING THROUGH THE UNITED STATES

DEPARTMENT OF ENERGY

LAS VEGAS, NEVADA

SPECIAL CONDITIONS

FOR

DOUBLE TRACKS HAZARDOUS MATERIAL TRANSPORTATION

TONOPAH TEST RANGE (TTR)

and

NEVADA TEST SITE (NTS) 
INDEX

PARAGRAPH NO. DESCRIPTION PAGE

SC-01 SUBCONTRACTOR QUALITY ASSURANCE (QA) REQUIREMENTS SC-01

SC-02 PERFORMANCE OF WORK SC-01

SC-03 ACCOMPLISHMENT OF WORK SC-01

$\begin{array}{ll}\text { SC-04 SAFETY AND HEALTH PLAN SC-02 } & \end{array}$

SC-05 RIDER 9 AND DAVIS-BACON ACT SC-02

SC-06 SITE SECURITY SC-03

SC-07 APPROVAL OF SUBCONTRACTOR'S PERSONNEL · SC-04

SC-08 APPROVAL OF SUBCONTRACTOR'S EQUIPMENT SC-04

SC-09 STATE INDUSTRY INSURANCE SYSTEM CERTIFICATES (SIIS) SC-04

SC-10 RADIOLOGICAL SAFETY · SC-04

SC-11 CONTAMINATION OF EQUIPMENT SC-05

SC-12 STATEMENT OF ACKNOWLEDGMENT FLOWDOWNS SC-05

SC-13 OPERATION DIRECTIVES OF.THE NV TEST CONTROLLER SC-05

$\begin{array}{ll}S C-14 & \text { CLEAN AIR ACT SC-06 }\end{array}$

SC-15 PROGRESS STATUS MEETINGS SC-06

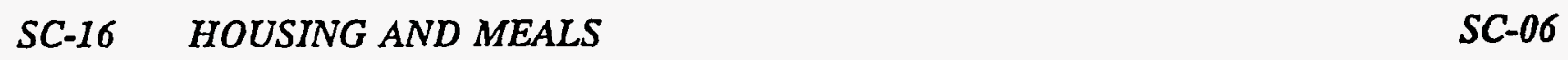

SC-17 SITE CLEANUP SSC-06

$\begin{array}{ll}\text { SC-18 REFUSE DISPOSAL } & \text { SC-07 }\end{array}$

SC-19 PROTECTION OF EXISTING STRUCTURES \& MATERIALS SC-07

SC-20 PRESERVATION OF ANTIQUITIES, WILDLIFE, \& LAND AREAS SC-07 
PARAGRAPH

$S C-21$

$S C-22$

$S C-23$

$S C-24$

$S C-25$

$S C-26$

$S C-27$

$S C-28$
DESCRIPTION

OCCURRENCE REPORTING

STORAGE OF EQUIPMENT AND MATERIALS

CONTRACTOR-FURNISHED FORMS

CONTRACTOR

USER AGENCY AND OTHER INVOLVED ORGANIZATIONS

INVOICING

REQUIRED TRAINING

BACK CHARGE PROCEDURE
PAGE NO.

SC-07

SC-08

SC-08

$S C-08$

$S C-08$

$S C-09$

SC-09

$S C-09$ 
SC-01 SUBCONTRACTOR'S QUALITY ASSURANCE (QA) REQUIREMENTS

The final acceptance of the end product will be based on daily inspection of the work process to ensure compliance to the subcontract specifications. This inspection will be performed by a Contractor designated representative working in accordance with the BN QA program.

\section{SC-02 PERFORMANCE OF WORK}

A. The normal work schedule will be six days a week, Monday through Saturday with the hours to be established after award.

B. The Contractor is allowed to inspect all rigs at any time during operations.

C. If the Subcontract is delayed during performance because of a site emergency or operational delay as directed by the Contractor, he shall keep a log of lost time to the nearest 15 minutes for each person involved. This log will be signed by the Subcontractor's representative and by the Contractor, or his appointed representative.

D. The performance period for completion of the subcontract shall include final cleanup of the work areas as part of demobilization.

E. List of BNC holidays after April 1996:

Memorial Day--May 27

Independence Day--July 4

Labor Day-September 2

Veterans' Day - Friday, November 1

Thanksgiving - Thursday, November 28

Day after Thanksgiving--November 29

Christmas--December 25

New Year's Day-January 1, 1997

\section{SC-03 ACCOMPLISHMENT OF WORK}

A. The Subcontractor shall furnish sufficient personnel, and equipment and shall work such hours including overtime operations Saturday, Sunday, and holiday work as may be necessary to ensure the execution of the work in accordance with the approved progress schedule. If the Subcontractor falls behind the progress schedule, the Subcontractor shall take such steps as may be necessary to improve his progress, and the Contractor may require him to increase overtime operations and days of work all without additional cost to the Contractor. 
B. The Subcontractor shall be responsible for coordinating the work of lower-tier subcontractors (various trades) to avoid conflict in any phase of work. It is the Subcontractor's responsibility to ensure that all phases of the work are covered and included in the firm-fixed price.

C. Failure of the Subcontractor to comply with the requirements of the Contractor under this provision shall be grounds for determination by the Contractor that the Subcontractor is not executing the work with such diligence as will ensure completion within the time specified. Upon such determination, the Contractor may terminate the Subcontractor's right to proceed with the work or any separable part thereof in accordance with the Terms and Conditions, "Construction Subcontracts."

\section{SC-04 SAFETY AND HEALTH PLAN}

The Subcontractor shall follow all required Department of Transportation Safety \& Health Regulations.

\section{SC-05 RIDER 9}

A. All work performed by craft personnel on this subcontract will be by union craft personnel.

B. Any work to be performed by crafts covered by Rider 9 of the subcontract shall be paid exactly the amounts shown for the respective labor union agreement, no more or no less. The certified payrolls shall reflect the following:

Individual's name

The craft

Worker designation-journeyman, foreman, apprentice, etc.

Group designation

The base rate and all applicable hourly benefit rates

The hours worked by straight time and overtime; time and one-half or double time

Subsistence rate

Any additional pay rate due to special work conditions, (hazard pay, welding premium, etc.)

Any in- and out-travel pay, if required 
Pursuant to Rider 9, the Subcontractor is required to submit weekly certified payrolls to the Contract Administrator (CA), completely filled out and signed by the Subcontractor or their lower-tier subcontractors. The Contractor will provide forms that can be used, or the Subcontractor may use their own forms with prior approval of the Contractor. Failure by the Subcontractor or their lower-tiers to submit proper certified payrolls will affect payments to the Subcontractor.

C. It is the Subcontractor's responsibility to determine the labor union requirements involved in this project, to contact the labor union to receive any details to the above information, and to obtain and sign the required short form labor agreement from each applicable union. The proposer, and the eventual subcontractor, must be sure to inform the unions that the work involved is at the NTS and the TIR as they have different agreements for work in Las Vegas, Nevada. It is the Subcontractor's responsibility to confirm with the unions what portion of the workforce to be used shall be regular employees of the Subcontractor and what portion must be taken out of the union hall. All coordination between the Subcontractor and the unions is the responsibility of the Subcontractor including, but not limited to, jurisdictional work allocations. Any questions on this issue should be directed to the Contractor in writing.

D. The Subcontractor shall provide daily transportation for their personnel as required by the Riders 9 agreement.

\section{SC-06 SITE SECURITY}

A. The jobsite at the NTS is within a DOE-secured area and at the TTR it is within a DOD-secured area. Subcontractor personnel must be U.S. citizens and a minimum of 18 years old. The Subcontractor must account for all badges issued (including lower-tier subcontractors). On all badges not.returned a charge of $\$ 200$ per badge will be deducted from the final payment.

B. The Subcontractor must furnish the Contractor the following information for each and every person working onsite 48 hours prior to commencing work onsite:

Name in Full

Social Security Number

Date of Birth

Place of Birth

Citizenship

C. The following items will not be permitted onsite:

1. Alcohol (except in housing and food facilities)

2. Drugs of controlled substances (without proper prescription)

3. Firearms and ammunition

4. Explosives and incendiaries 
5. Personal two-way radios (without written approval of the Contractor) including $\mathrm{CB}$ radios

6. Personal recording devices, copying devices, cameras, binoculars, telescopes, and other optical instruments (without written Contractor approval)

7. Pets, either wild or domestic

8. Personnel not onsite for job related activities.

D. The Subcontractor's vehicles shall be restricted to the routing established by the Contractor or as noted on the subcontract drawings.

SC-07 APPROVAL OF SUBCONTRACTOR'S PERSONNEL

All personnel furnished by the Subcontractor on this project shall be subject to the Contractor's approval and can be subject to replacement.

SC-08 APPROVAL OF SÜBCONTRACTOR'S EQUIPMENT

A. A list of all equipment that will be used on the project shall be submitted to the Contractor in the proposal. Changes to the list shall be reported to the Contract Administrator. The Contractor reserves the right inspect the equipment before contract award and during the performance phase. The preaward inspection will be in accordance with North American Level 1 inspection criteria. These inspections assure that the equipment will perform the proposed task and meet safety requirements. No equipment shall be substituted without approval of the Contractor.

B. Any equipment found to be in unsatisfactory operating condition, or deficient in any way, during the period of subcontract, as determined by the Contractor, shall be repaired to the satisfaction of the Contractor, or removed from the worksite, and replaced with approved equipment at no expense to the Contractor.

Nevada SIIS certificates are required on all lower-tier subcontractors as well as prime subcontractors prior to start of work. Final payment may not be made prior to receipt of final SIIS certificates.

\section{SC-10 RADIOLOGICAL SAFETY}

All Subcontractor and privately owned equipment, materials, and vehicles entering the NTS shall be subject to radiological monitoring. If it is determined that any materials, equipment, and vehicles must be decontaminated, the Contractor will furmish the necessary decontamination services. The Subcontractor agrees not to remove such contaminated materials, equipment, and vehicles until approval in writing is given by the Contractor to do so. 
In the event any of the Subcontractor's equipment becomes contaminated by radiation, the Contractor shall, at his expense, decontaminate and return such equipment to the Subcontractor within a reasonable time. Should the Contractor at its sole discretion, determine that such equipment cannot be decontaminated, the Contractor agrees to adjust the subcontract price so as to equitably compensate the Subcontractor for loss of any and all such equipment that cannot be decontaminated.

\section{SC-12 STATEMENT OF ACKNOWLEDGMENT FLOWDOWNS}

A form entitled Statement of Acknowledgment Flowdowns will be sent to the successful proposer with the Notice to Proceed letter. It will be the Subcontractor's responsibility to have all lower-tier subcontractors sign off on this form and a copy submitted to the Contractor prior to starting work to ensure compliance with the flowdown requirements of the Terms and Conditions, Construction.

\section{SC-13 OPERATION DIRECTIVES OF THE NV TEST CONTROLLER}

A. Evacuation the NV Test Controller, or his authorized representative, may in conjunction with a limited or general evacuation of the NTS, direct, with or without prior notice, either verbally or in writing, that the Subcontractor:

1. Evacuate all or any part of its employees including supervisory personnel;

2. Remove all or part of its equipment from the NTS or any part thereof; and

3. Not be permitted to enter the NTS or any part thereof, including access to the Subcontractor's property remaining on the NTS, because of NTS operational needs, requirements, or conditions. The NV Test Controller may issue such a directive from time-to-time and for such periods of time as he may deem necessary. For the purpose of and in accordance with this clause, the NV Test Controller, or his authorized representative, is authorized to act for and on behalf of the Contractor.

B. Failure to Comply If the Subcontractor refuses or fails to comply with a directive of the NTS Controller, issued pursuant to paragraph (A) above, the Contractor may terminate the Subcontract for default.

C. Subcontract Adjustment If a directive of the NV Test Controller issued pursuant to paragraph $(A)$ above, results in increased cost of performance or in a delay in the completion of the contract work. The Subcontractor shall notify the Contractor, in writing, within 10 days after the receipt of such directive and the Contractor shall equitably adjust the contract price (excluding profit) and/or time of performance and the Subcontract shall be modified in writing accordingly. 
All Subcontractor operations shall comply with the standards established under the Federal Clean Air Act and all provisions of the Nevada Air Quality Regulations.

SC-15 PROGRESS STATUS MEETINGS

A. Onsite construction progress meetings will be held weekly or as considered necessary by the Contractor. The primary purpose of these meetings shall be to review the progress schedules. The Subcontractor shall be prepared at these meetings to indicate the proposed work schedule for the period immediately following the meeting date and to indicate anticipated difficulties. The Subcontractor shall update the progress schedule. The updated schedule shall not extend beyond the completion date of the subcontract without prior approval by the Contractor.

B. The above-described construction progress meetings are designed to ensure diligent prosecution of the work in accordance with the approved progress schedule and the urgency of program requirements.

\section{SC-16 HOUSING AND MEALS}

Housing and meals are available at the Mercury Camp at established prices (see below).

\section{Room rate--\$25 per night}

$$
\begin{array}{ll}
\text { Food prices (average): } & \text { breakfast- } \$ 3.50(5: 30 \text { to } 7 \mathrm{am} .) \\
& \text { lunch- } \$ 4.75(11 \mathrm{am} . \text { to } 1 \text { p.m.) } \\
& \text { dinner- } \$ 5(5 \text { to } 7 \text { p.m.) (Mercury cafeteria) }
\end{array}
$$

$:$

Dinner at the Steak House averages between $\$ 12$ and $\$ 15$ (5:30 to 9 p.m.)

The Mercury cafeteria and Steak House is open Monday through Thursday; vending machines are available 24 hours a day, 7 days a week.

\section{SC-17 SITE CLEANUP}

The Subcontractor shall at all times keep the assembly, work; and storage areas free from the accumulation of loose debris and waste materials. On a daily basis the Subcontractor shall gather up all trash and place it in an acceptable confined storage area until it is hauled to the landfill or other designated area. Metal products shall be separated from other debris for hauling to the Mercury salvage yard. Upon completion of the work, the Subcontractor shall perform the final clean up of the project site and shall have removed all of its equipment, tools, and excess materials (that is not Contractor or Government property) so as to leave the site in a clean orderly condition that is acceptable to the Contractor. 
Any loose debris, waste material, excess material, or equipment that has blown onto the surrounding area or was left behind after completion that the Contractor has to pick up and haul away will be back charged to the Subcontractor.

SC-18 REFUSE DISPOSAL

Designated trash receptacles, sanitary landfills, or salvage yards on the NTS can be used by Subcontractor for disposal of loose debris, waste material, or metal products. The disposal of any free liquids are prohibited in the NTS landfills. The Subcontractor must obtain permission in order to dispose of refuse at any other onsite locations.

SC-19 PROTECTION OF EXISTING STRUCTURES \& MATERIALS

The Subcontractor shall protect all existing structures, traffic signs, and installations of any kind (including underground property or underground facilities that are properly indicated on drawing(s) or the existence of which is otherwise made known to the Subcontractor) against damage or interruption of service. The Subcontractor shall protect and preserve such trees and shrubs onsite that do not interfere with the work of this subcontract and shall be responsible for all damage to trees and shrubs due to his carelessness or negligence.

\section{PRESERVATION OF ANTIQUITIES, WILDLIFE, AND LAND AREAS}

Federal law provides for the protection of antiquities located on land owned or controlled by the U.S. Government. Antiquities include Indian graves, campsites, relics, and artifacts. The Subcontractor shall control the movements of its personnel and its lower-tier subcontractor's personnel at the jobsite to ensure that any existing antiquities discovered thereon will not be disturbed or destroyed by such personnel. It shall be the duty of the Subcontractor to report the existence of any antiquities so discovered. The Subcontractor shall also preserve all vegetation and protect all wildlife.

\section{SC-21 OCCURRENCE REPORTING}

The Subcontractor is responsible for reporting any unusual and off-normal occurrences. These occurrences consists of, but not limited to: fires, explosions, structure deficiencies, hazardous substances, occupational illnesses or injuries, transportation accidents, criminal acts, substance abuse and near-misses.

The Subcontractor shall, in case of fire, accidents, or other emergency situations call 911 on any NTS telephone immediately, then the Contract Administrator shall be notified of any referenced occurrences. BNC Occupational Safety \& Fire Protection at 295-071 l will be notified if Contract Administration NTS Section is unavailable.

A list of all pertinent Contract Administration personnel with telephone numbers will be fumished to the successful proposer with the Notice to Proceed letter. 
The Contractor will assign an area in Mercury for the Subcontractor to park equipment and materials. The Subcontractor will be responsible forlocating an area in Tonopah, Nevada, to park/store trucks and equipment.

SC-23 CONTRACTOR-FURNISHED FORMS

The Contractor will provide the Subcontractor with the Department of Energy (DOE) Forms 5480.2. "Occupational Safety and Health Protection, for DOE Contractors at Government-Owned Contractor-Operated Facilities, " and 5480.4, "DOE Contractor Employee Occupational Safety or Health Complaint." These Forms are to be posted on the Subcontractor's bulletin board. Also, provided will be OSHA Form 200, "Bureau of Labor Statistics Log and Summary of Occupational Injuries and Illnesses," and the "Monthly Accident Report, Form 293. The Subcontractor will be required to maintain the OSHA Form 200 at the jobsite and submit the Monthly Accident Report for his Company and all of his lower-tier subcontractors to the Contract Administrator by the fifteenth day of the month following the reported month.

Also, provided will be OSHA Form 200, "Bureau of Labor Statistics Log and Summary of Occupational Injuries and Illnesses," and the "Monthly Accident Report," Form 293. The Subcontractor will be required to maintain the OSHA Form 200 at the jobsite and submit the Monthly Accident Report for his Company and all of his lower-tier subcontractors to the Contract Administrator by the fifteenth day of the month following the reported month.

SC-24 CONTRACTOR

The Contractor will appoint an authorized representative and notify the Subcontractor of such appointment. The Contractor shall have the authority to establish controls for the work, to inspect the work for quality and for compliance with subcontract documents, and to recommend changes strictly in accordance with the Terms and Conditions Construction. The Field Coordinators and Inspectors assigned do not have the authority to make any commitments or authorize any changes that affect the subcontract costs, terms, or conditions; any such changes shall be referred to the cognizant Subcontract Administrator for action.

\section{SC-25 USER AGENCY AND OTHER INVOLVED ORGANIZATIONS}

The work covered under this subcontract is part of the ongoing work at the NTS and TTR. There are a number of other organizations involved in this program. Representatives of all these organizations will be at the jobsite from time-to-time; however, the Subcontractor shall take direction only from the Contractor. 


\section{SC-26 INVOICING}

Invoices will reflect the subcontract number, an explanation of the work performed, and the total amount due. Invoices shall be submitted to the Contract Administrator. Progress payments will be based on a percentage of the work completed and will reflected in the Subcontractor's progress schedule.

SC-27 REQUIRED TRAINING

Drivers shall have all DOT required certificates and training for work related to The is subcontract. The Subcontractor shall provide the Contractor with a copy of all required certifications and verifications of training.

\section{SC-28 BACK CHARGE PROCEDURE}

If the Subcontractor requests any materials or services of the Contractor that are not a part of the Contractor's contractual obligations, the Subcontractor will be required to sign BNC Form RE-0620 entitled Authorization for Materials or Services. This form, when signed and approved, establishes.a back charge work order number that provides a method for the Contractor to back charge the Subcontractor for these materials or services.

The invoicing for such costs are processed outside the subcontract; e.g., the Contractor's Finance \& Management Control Department will invoice the Subcontractor directly for these charges. All back charge invoices must be paid in full by the Subcontractor before final payment on the subcontract can be paid.

The Subcontractor is hereby notified that the Contractor back charges are fully loaded and expensive. This process should be used only when necessary and should be closely monitored. 


\section{ATTACHMENT NO. 3 \\ BECHTEL NEVADA CORPORATION \\ REQUEST FOR PROPOSAL (RFP) 10-MB-96}

\section{TECHNICAL PROVISIONS}

The following are the Technical Criteria for the referenced RFP. Each criteria will be evaluated on an acceptable/nonacceptable basis. All criteria are weighted equally. Each proposer shall submit as much data as necessary to demonstrate that they meet each of the criteria. The follow-on subcontract will be awarded to the responsive proposer with the lowest price proposal.

\section{CRITERIA:}

1. The proposers shall have and be able to verify three years experience in performing work of a similar nature and size as the work detailed in Attachment No. 1. Each proposer shall submit the names and telephone numbers of contacts to verify the required work over the last three years. The proposers shall list companies/agencies they have worked for and the dollar amount of the contract.

2. The proposer shall certify that they are able to provide the quality and quantity of personnel, equipment, and material specified in Attachment No. 1.

3. The proposers shall certify that they can meet the anticipated schedule requirements specified--July 8, 1996 through August 25, 1996.

Each proposer shall provide two copies of the response to the Technical Provisions. 


\section{BECHTEL NEVADA CORPORATION REQUEST FOR PROPOSAL (RFP) 10-MB-96 \\ DOUBLE TRACKS HAZARDOUS TRANSPORTATION}

\section{CONSIDERATION SCHEDULE}

\section{DESCRIPTION}

Round-trip hauls of one, 20-foot Sealand container per Scope of Work

\section{ESTIMATED}

QUANTITIES

188 round trips
UNIT PRICE

TOTAL PRICE

The above prices are understood to include all associated costs for the work detailed in the RFP Statement of Work and are not subject to escalation of any reason. The total not-to-exceed price is based on the estimated number of round trips (188). The final price shall be based on the actual number of trips authorized by the Contractor."

The Proposers are to list below a daily standby rate. This rate shall be used, if the Contractor directs the Subcontractor, for whatever reason the Contractor deems necessary to stop all activities and standbys. The rate is to include all associated costs for personnel and equipment to be in a standby status.

Daily Standby Rate $\$$ 
ATTACHMENT NO. 5 -: RFP 10-MB-96

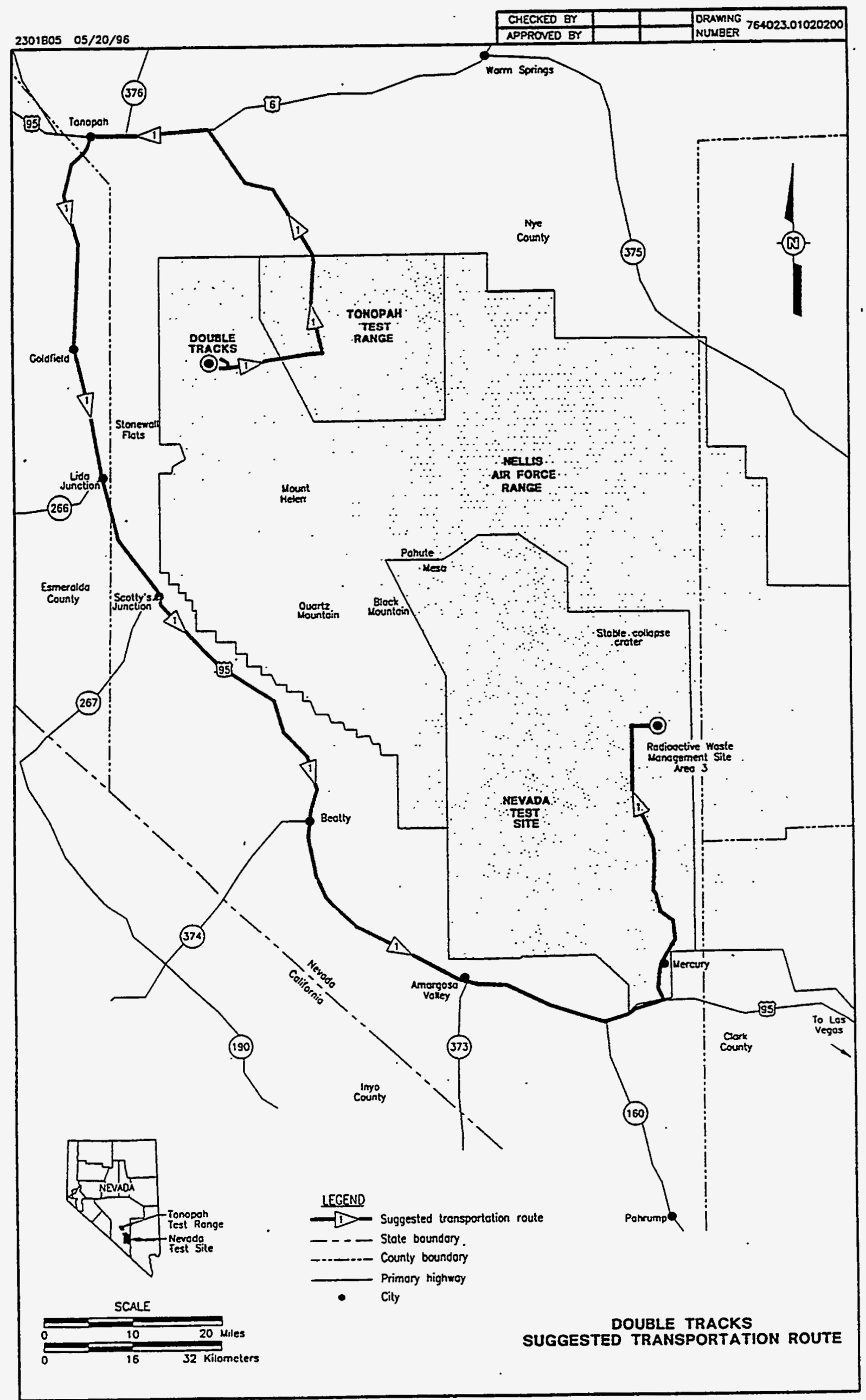




\section{ATTACHMENT NO. 6}

\section{DRIVER'S VEHICLE INSPECTION REPORT}

CARAIER:

A:DDRESS:

DATE:

TIME:

A.M.

P.M.

TRACTORI

TRUCKNO.

ODOMETER READING

$\square$ Air Compressor

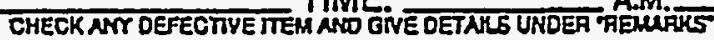

$\square$ Suspension System

$\square$ Air Lines

Baltery

$\square$ Bocy

$\square$ Erake Accessories

Brakes, Parking

Brakes, Service

Clutch

Coupling Devices

Defroster/Heater

Drive Line

Engine

Exhatist

Fitth Whoel

Frame and Assen:bly

Front Axle

$\square$ Fuel Tanks

$\square$ Generator

Hom

Lights

Head - Stop

Tail - Dash

Tum Indicators

$\square$ Mirrors

$\square$ Muffler

$\square$ Oil Pressure

$\square$ Radiator

$\square$ Rear End

$\square$ Reflectors

$\square$ Safery Equipment

Fire Extinguisher

Aeflective Triangles.

Flags - Flares - Fusees

Spare Bulbs \& Fuses

Spare Seal Beam $\square$ Starter

Steering

$\square$ Tachograph"

$\square$ Tires

$\square$ Tire Chains

$\square$ Transmission

$\square$ Wheols and Rims

$\square$ Windows

7 Windshield Wipers

$\square$ Other

TRAILER(S) NO. (S).

$\square$ B.ake Connections
$\square$ Brakes
$\square$ Coupling Devices
$\square$ Coupling (King) Pin
$\square$ Doors

Remarks:

\section{,}

Landing Gear

Lights - All

2 Roof

Suspension System

口Tarpautin

$\square$ Tires

Wheels and Rims

$\square$ Other



CONDITION OF THE ABOVE VEHICLE IS SATISFACTORY

DAVER'S SIENATURE:

口AGOVE DEFECTS CORAEĊTED

$\square$ ABOVE DEFECTS NEED NOT BE COAAECTED FOR SAFE OPERATION OF YEHICLE

MECI INNICS SIGHATURE: DATE

DRIVER'S SIGNATURE: DATE

ORIGINAL 



\section{APPENDIX E}

\section{AIR QUALITY OPERATING PERMITS}




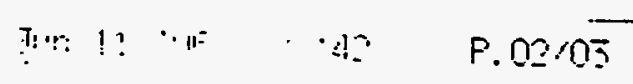

JNH-11-1995

$13128 \quad$ NUBOQBUEP FY 123
BTATE OF NEVADA
DEPARTMENT OF CONEERVATION AND NATURAL RESOURCES
ONISION OF ENVIRONMENTAL PROTECTION
BUREAU OF AIR QUALITY
333 WEST NYE LANE
CAREON CITY. NEVADA 89710

NO. 1476

\section{SITE SPECIFIC PERMIT ATTACHMENT}

Yenuld to: U.S. DEPARTMENT OF ENEROY, NEVADA OPERATIONS OFFICE

P.O. BOX 98518, LAS VEOAB, NV 89183-8618 !

Location: North $4090.3 \mathrm{~km}$. East $584.6 \mathrm{~km}$, UTM (Zone 1/1)

SIC Code: 1442

if granted a perantt to operste the lollowting embosion unit(s);

Doulde Trucke Propat

Find Hoppow,

Conmyor, Eubw-arosno, sere PK6001121

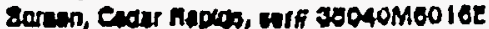

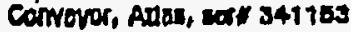

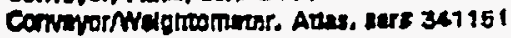

scarag Ein, Koiburo

Enoterete Kopper/Convayer, were 8a178814

Camant Ban (truck meuntudt, 8en" 18:1561 and 18:1562

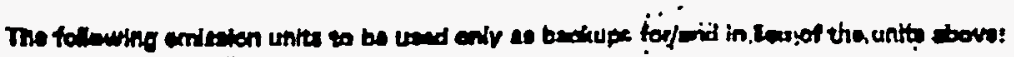

Conveyor, Kalburs

Cormulor, Nortwo. sert 349029

Comprow Welghtometar, Adte, eet 341152

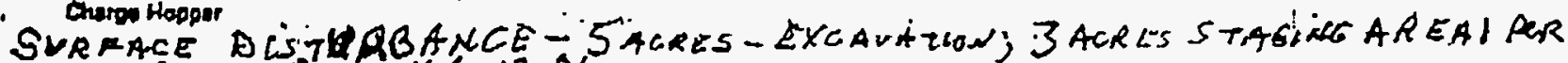

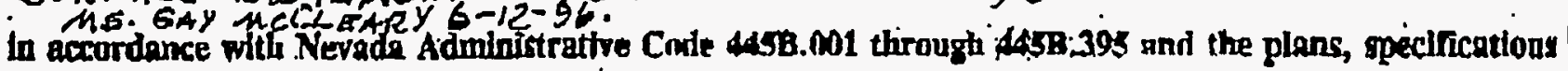
or other materials submitted.

\section{Restrictions:}

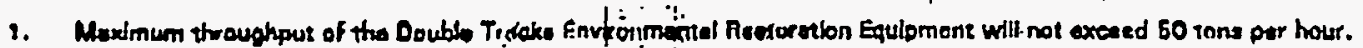

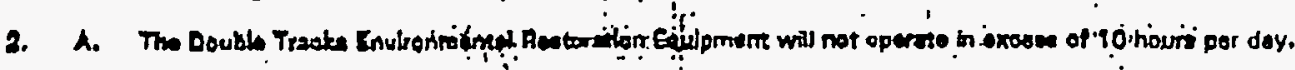

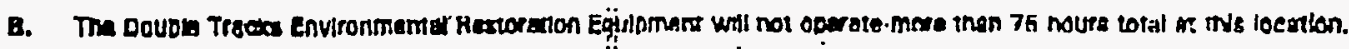

3. Tho dicoluerge of PMYO (a)

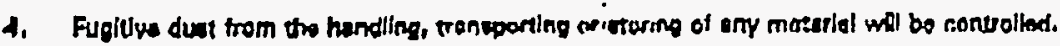

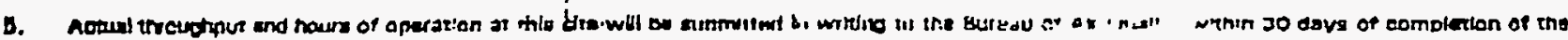
oparaton.

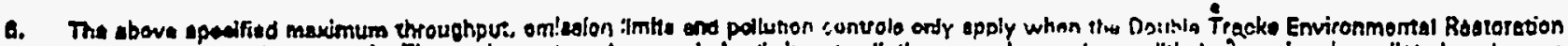

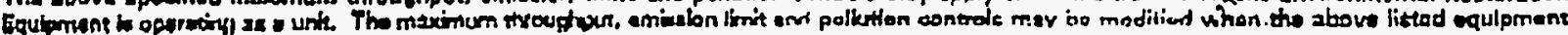

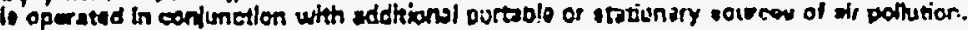

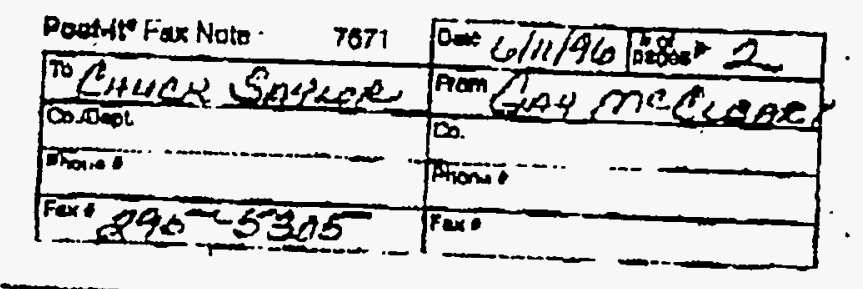

Pugs 1 of 2 


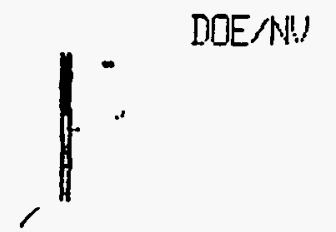

$$
\begin{gathered}
\text { F.T. :TI: } \\
\text { DEPARTMENT OF CONSERVATION AND NATURAL RESOURCES } \\
\text { DIVISION OF ENVIRONMENTAL PROTECTION } \\
\text { BUREAU OF AIR OUALITY } \\
\text { 333 WEST NYEILANE } \\
\text { CARSON CITY, NEVADA 89710 }
\end{gathered}
$$

\section{CARSON CITY, NEVADA 89710 \\ SITE SPECHFIC PERMIT ATTACHMENT \\ P.O. BOX 98518, LAS VEGAS, NV 89183-8618:}

Issued to: U.S. DEPARTMENT OF ENEREY, NEVADA OPERATIONS OFFICE

Lacation: North $4090.3 \mathrm{~km}$, East $584.6 \mathrm{~km}$, UTH (Zone 11)

SIC Code: 1442

Restrictlons Continued:

7. The sot of

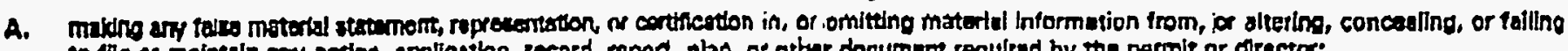

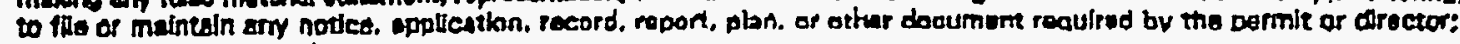
B. Faiting to nothy or report se required by the pormtt or droctex;

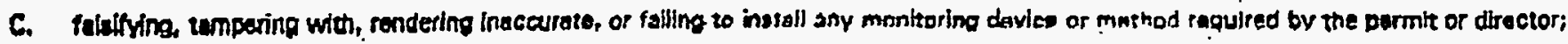
D. vialating any of the applicible provisione of Novad Adminlarative Codo.4488.001 trough 4488.395;

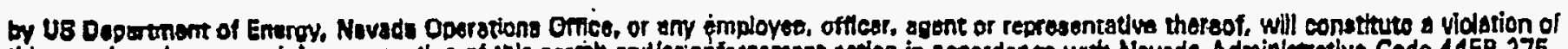

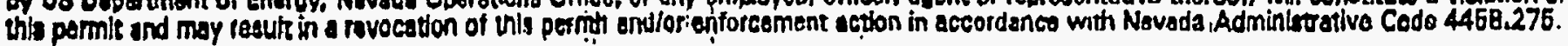

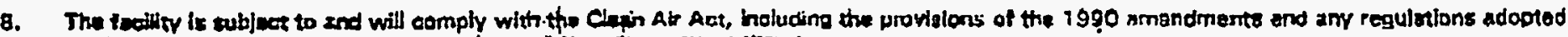

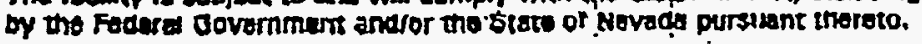

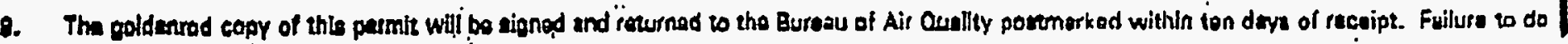
so will rasut in this pormit boing invalideted.

This permit:

1. Is non-transfarable in accocdence with Nerada Administrative Codo 44.53.287.

2. Is Lstred on condftion tho thie:holder.ailnws inspection of the presceises by authorized representatives of the department at any time during bonks of construction or operation, without prior notice.

3. Is issued on condition of acceptrince of all restrfictions and condftions contained on-this permit as evidenced by the sioning hereof by a responsible offlcidi.

Slgmatare Venue, Eozer

Issued by Don Del Porto, P.E. for Supervisor, Permitting

Bureau of Air Quality

m

Fhone (702) $687-4670$ Date
Siprature

Print Name

Responsible Official of

U.S Departnuent of Energy, NV Ops

Phone Date 


\section{APPENDIX F}

CHARACTERIZATION AND OPERATION OF THE CONVEYOR BELT NaI DETECTOR SYSTEM 


\section{CHARACTERIZATION AND OPERATION \\ of the \\ CONVEYOR BELT NaI DETECTOR SYSTEM}

\section{Purpose/Background}

The Double Tracks work will use a NaI detector system to monitor the amount of radioactivity traveling along a conveyor belt to the "Supersack" packages for later disposal. The NaI detector has been calibrated for operation at a range of heights above a 1"-deep layer of soil on a 26 "-wide conveyor belt.

The number of $60-\mathrm{keV}^{241} \mathrm{Am}$ gamma rays measured while the sack is being filled is directly related to the amount of activity which passed under the detector and into the sack. The americium activity loaded into each of the approximately 1000 Supersacks will be measured and the plutonium activity will be calculated based on the americium:plutonium ratio calculated from the characterization work last year. The sacks will then be loaded onto trucks and hauled to NTS.

\section{Description of Material on Conveyor System}

The conveyor system consists of several pieces of equipment which move the excavated material from the stockpile mound to the Supersacks. The material is loaded into a variable speed feed hopper by a small front-end loader. A conveyor belt transports the material to a vibrating platform which sends any material larger than $3 / 4^{\prime \prime}$ diameter to a separate stockpile. Soil and other material smaller than $3 / 4$ " will continue onto another conveyor belt to the second feed hopper. The output stream from this hopper will be regulated so the material on the final conveyor belt is no more than 1 " high and will occupy the center 26 " of the width of the belt. The $\mathrm{NaI}$ detector system sits at the end of this conveyor (about $3^{\prime}$ before the material falls into the Supersacks).

Requirements of the NaI detector system can be summarized in the following items.

(1) An earlier assessment of the activity at Double Tracks indicated that the activity is comprised of ${ }^{241} \mathrm{Am}$ and several isotopes of plutonium as well as the naturally occurring radionuclides present in the soil. The ratio between the plutonium and americium isotopes was measured as 16:1. Therefore, the activity of the waste stream can be monitored by measuring the ${ }^{241} \mathrm{Am}$ isotope's gamma rays.

(2) The Nal detector system must be able to monitor the americium activity in a layer of soil passing underneath as it is loaded into the Supersacks for later disposal. The desired accuracy for these measurements changes as a function of the activity. The goal is to not 
have any sacks with activities greater than the TRU waste limit of $100,000 \mathrm{pCi} / \mathrm{g}$ (or 0.1 $\mu \mathrm{Ci} / \mathrm{g}$ ). For measurements close to the limit, the system should have fairly tight accuracy, less than $10 \%$. For low activity sacks, the uncertainty can be much higher, as much as a factor of 2 .

(3) A normal-size Supersack will contain approximately $30 \mathrm{ft}^{3}$ of material. If the soil is assumed to have a density of $1.5 \mathrm{~g} / \mathrm{cm}^{3}$, then the mass of the material in the sack will be $1.27 \times 10^{6} \mathrm{~g}(-2800$ pounds). To stay below the TRU waste limit, the sack may contain $1.27 \times 10^{5} \mu \mathrm{Ci}$ of total activity $\left(7,940 \mu \mathrm{Ci}\right.$ of ${ }^{241} \mathrm{Am}$ using the TRU: $:{ }^{241} \mathrm{Am}$ ratio of $\left.16: 1\right)$.

(4) A smaller-size Supersack will be used in some instances. This bag holds $15 \mathrm{ft}^{3}$ of material (roughly $1 / 2$ of the larger sack).

(4). The americium activity is assumed to be dispersed throughout the soil mixture. Any chunks of material coated with americium (hot point sources) are assumed to be randomly distributed across the width of the conveyor belt. The 1"-thick soil layer was chosen to minimize the effects of gamma ray attenuation through the soil. At this thickness, the gamma rays emitted from americium at the bottom of the layer will be attenuated by about $1 / 2$ compared to those emitted at the top of the layer. For a distribution of americium which is uniformly distributed with depth, $70 \%$ of the emitted $60-\mathrm{keV}$ gamma rays will reach the detector without being scattered.

(5) The soil collected from the plume region, the linear area south of ground zero, consists primarily of sand and very fine gravel (typically less than 1/8" diameter). Plant material from this region should be removed by the 3/4" screen. Since the ATV and/or Kiwi detector systems covered this area last year and the planned depth of excavation in this area will be approximately 3 inches, there can be only an exceedingly small probability of the material containing small pieces of americium-encrusted metal. Any americium from this region can be assumed to consist of fine particles uniformly distributed throughout the mixture.

(6) The material which will be excavated from the mound area also consists primarily of sand and fine gravel, but has a higher probability of containing some larger gravel and/or small pieces of concrete. Since this area will be excavated to a depth of several feet, there is a high probability of finding small pieces of metal encrusted with americium such as what the ATV and Kiwi systems found on or near the surface. Small pieces may pass under the detector system; larger pieces will be diverted by the screening platform.

(7) While soil samples (several hundred grams; taken last year and discussed in the Double Tracks characterization report) exhibited activities 1-8 times the TRU waste limit, these samples were.collected from areas of high activity and in a manner to maximize the activity in the sample. The average activity of a large volume of soil (the volume of a Supersack) collected from the excavated areas will be much less than the average activity 
of the small samples collected and anaiyzed during the characterization expedition.

(8) The hot pieces found and analyzed during the characterization expedition were certainly beyond the TRU waste limit. However, nearly all of these pieces would be removed from our conveyor stream by the $3 / 4$ " screen. Of the smaller pieces which can fit through the screen, their activity is not likely to exceed $0.1 \mathrm{mCi}$ of ${ }^{241} \mathrm{Am}$. About one hundred of these could be loaded into one sack and still not exceed the activity limit for the sack.

\section{Characterization of the NaI Detector System}

The NaI detector is a 3"-diameter by 6"-long cylindrical crystal. The long axis of the crystal will be placed parallel to the width of the belt, so the detector will present a nearly rectangular cross section to the material it is measuring. It is surrounded by 0.040 " thick sheets of cadmium to shield its field of view. The detector, preamplifier, and shielding are surrounded by several inches of foam packing and housed inside an American Tourister briefcase for protection from the weather. The detector is powered by an external high voltage power supply and multichannel analyzer (MCA). This external unit will start and stop the counting and employs standard arithmetic peak extraction algorithms. The distance from the bottom of the crystal to the bottom of the briefcase is 2.25 inches. In the discussion which follows, the height above the belt (source) always refers to the height of the bottom of the briefcase.

The detector system has been calibrated at several heights above a small ${ }^{241} \mathrm{Am}$ source in the laboratory. The calibrations involve measuring the count rate for the point source at specific locations along the $x$ - and $y$-axis. This data is shown in Figure 1 . The response function of the system over the entire $(x, y)$-plane is then derived from these measurements. The response function is shown in Figure 2. It should be noted that the material on the conveyor belt will occupy the center $-13^{\prime \prime}$ to +13 " of this plot.

A uniform distribution of activity can be simulated from measurements of a single point source placed every 2" within the field of view. The number of counts recorded in 30 seconds by a 9.37 $\mu \mathrm{Ci}{ }^{241} \mathrm{Am}$ source spaced every $2 "$ over the field of view of the detector can be correlated with an activity on a moving conveyor belt. This uniform distribution is the same as the response function measurement discussed above, but with the field of view used to truncate the edges of the function. At the planned installation height of 7 ", the detector views the $26^{\text {" width of the belt }}$ and views 14" before and after its position along the belt. The uniform source is approximated by 14 rows of 13 point sources across the belt. If the measurements are made with a $9.37 \mu \mathrm{Ci}$ source for 30 seconds in each position, then the total 1,625,495 counts are obtained from the total activity of $1,705 \mu \mathrm{Ci}$.

$$
z_{7}=\frac{1,625,495 \text { counts }}{30 \text { seconds }} \times \frac{1}{14 \times 13 \times 9.37 \mu C i}=31.8 \frac{\text { counts } / \text { seconc }}{\mu C i}
$$


Similarly, if the detector were installed at 5 " above the belt, it would see 11 " before and after its position, so the uniform field consists of 11 rows of 13 sources. Even though the detector views a smaller area on the belt, it is closer and collects more gamma rays from the area it views.

$$
z_{5}=\frac{1,651,910 \text { counts }}{30 \text { seconds }} \times \frac{1}{11 \times 13 \times 9.37 \mu C i}=41.1 \frac{\text { counts } / \text { seconc }}{\mu C i}
$$

\section{Operation and Analysis of the NaI Detector System}

The amount of activity in a Supersack is calculated by taking the total number of counts in the americium photopeak window, dividing by the time of the measurement, subtracting the background count rate (determined at the beginning of each day), and then dividing by the conversion factor (for example, $\mathrm{C}_{7}$ ). To compensate for the loss of gamma rays by attenuation in the 1"-thick layer of soil, this activity should be divided by $70 \%(0.7)$ as described in item (4) above. When this result is divided by the mass of material in the sack, then the " $\mu \mathrm{Ci} / \mathrm{g}$ " value can be compared with the limits for TRU waste.

$$
\text { Activity }(\mu C i)=\left[\frac{\text { netAMcounts }}{\text { countingtime }}-\frac{(\text { daily }) \text { bkgcounts }}{\text { bkgcountingtime }}\right] \times \frac{1}{C_{7}} \times \frac{1}{0.7}
$$

For a uniform distribution, the speed of the belt will have no direct effect on the activity measurements. This factor enters the calculation through the amount of time required to fill the sack; a faster belt speed will decrease the amount of time spent counting, but the total number of counts will also be less. A uniform distribution of activity will produce the same "counts/second" regardless of the speed of the belt. The startup and stopping speed nonlinearities of the belt motion are too small to consider since the belt quickly reaches its operating speed.

The 3 feet of distance between the detector and the end of the conveyor belt is a source of error in the measurements. If the soil layer is 1 " high and 26" wide, then about 165 feet of length must pass the detector to fill a 30- $\mathrm{ft}^{3}$ volume. The 3-foot distance represents about $3 / 165(<2 \%)$ of the volume of soil which is loaded into each sack. (This small error is ignored in the calculations.)

The minimum detectable activity (MDA) of this detector system can only be precisely measured when the system is operating on the conveyor belt and looking at non-americium contaminated soil passing underneath. However, a reasonable estimate can be made from measurements in the lab. A 30-second background measurement collected $863 \pm 29$ counts in the ${ }^{241} \mathrm{Am}$ window with 0 net counts. If we take $3 \sigma$ as our definition of the MDA, then we can calculate the minimum activity detectable with this system. 


$$
M D A\left({ }^{241} \mathrm{Am}\right)=\frac{3 \times 29 \text { counts }}{30 \text { seconds }} \times \frac{\mu C i}{31.8 \text { counts } / \text { second }} \cong 0.09 \mu C i
$$

The MDA can be compared with the ${ }^{241} \mathrm{Am}$ activity in a Supersack at the TRU waste limit $(7,940$ $\mu \mathrm{Ci})$. The TRU limit is about 87,000 times the MDA.

For ease of operation while filling the Supersacks, it would be useful to be able to tell immediately whether a particular sack is above or below the TRU waste limit. Since the total activity of the sack is directly related to the amount of americium present, the following table lists the number of counts expected in a 30-second measurement for a $30-\mathrm{ft}^{3}$ sack and a $15-\mathrm{ft}^{3}$ sack. If the total ${ }^{241} \mathrm{Am}$ counts are above the listed value, then the activity in the sack is larger than the listed value

\begin{tabular}{rrrr}
\hline \hline $\begin{array}{l}\text { TRU Activity } \\
\text { Level ( } \mathrm{pCi} / \mathrm{g})\end{array}$ & $\begin{array}{c}{ }^{241} \mathrm{Am} \text { Activity } \\
\text { Level }(\mathrm{pCi} / \mathrm{g})\end{array}$ & $\begin{array}{c}{ }^{241} \mathrm{Am} \text { Counts in large } \\
\text { sack }\left(30 \mathrm{ft}^{3}\right)\end{array}$ & $\begin{array}{c}{ }^{241} \mathrm{Am} \text { Counts in small } \\
\text { sack }\left(15 \mathrm{ft}^{3}\right)\end{array}$ \\
\hline 200 & 12.5 & 15,100 & 7,550 \\
5,000 & 312.5 & 379,000 & 189,000 \\
100,000 & 6,250 & $7,570,000$ & $3,790,000$ \\
& & & \\
\hline
\end{tabular}




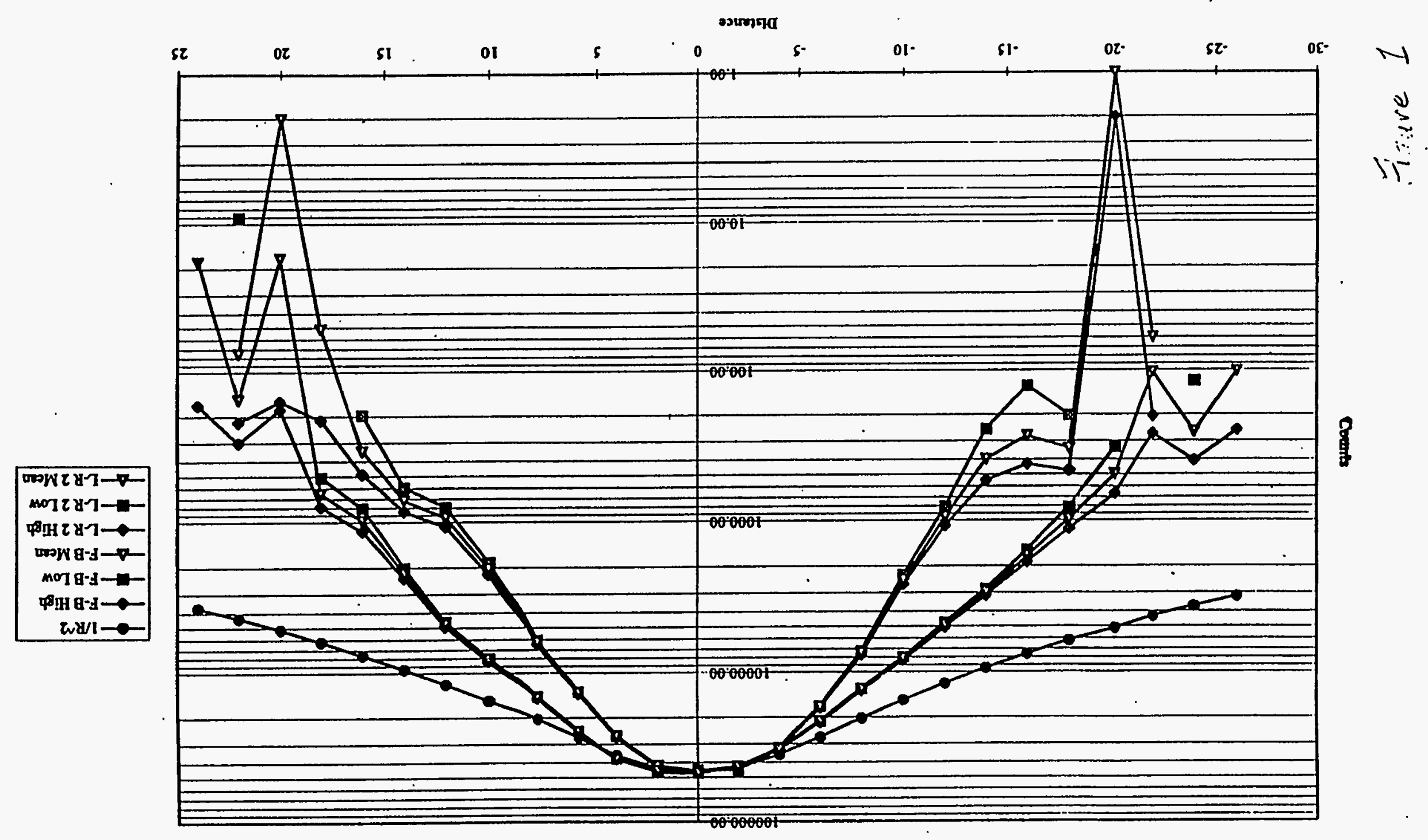

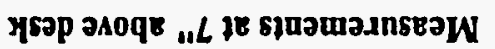




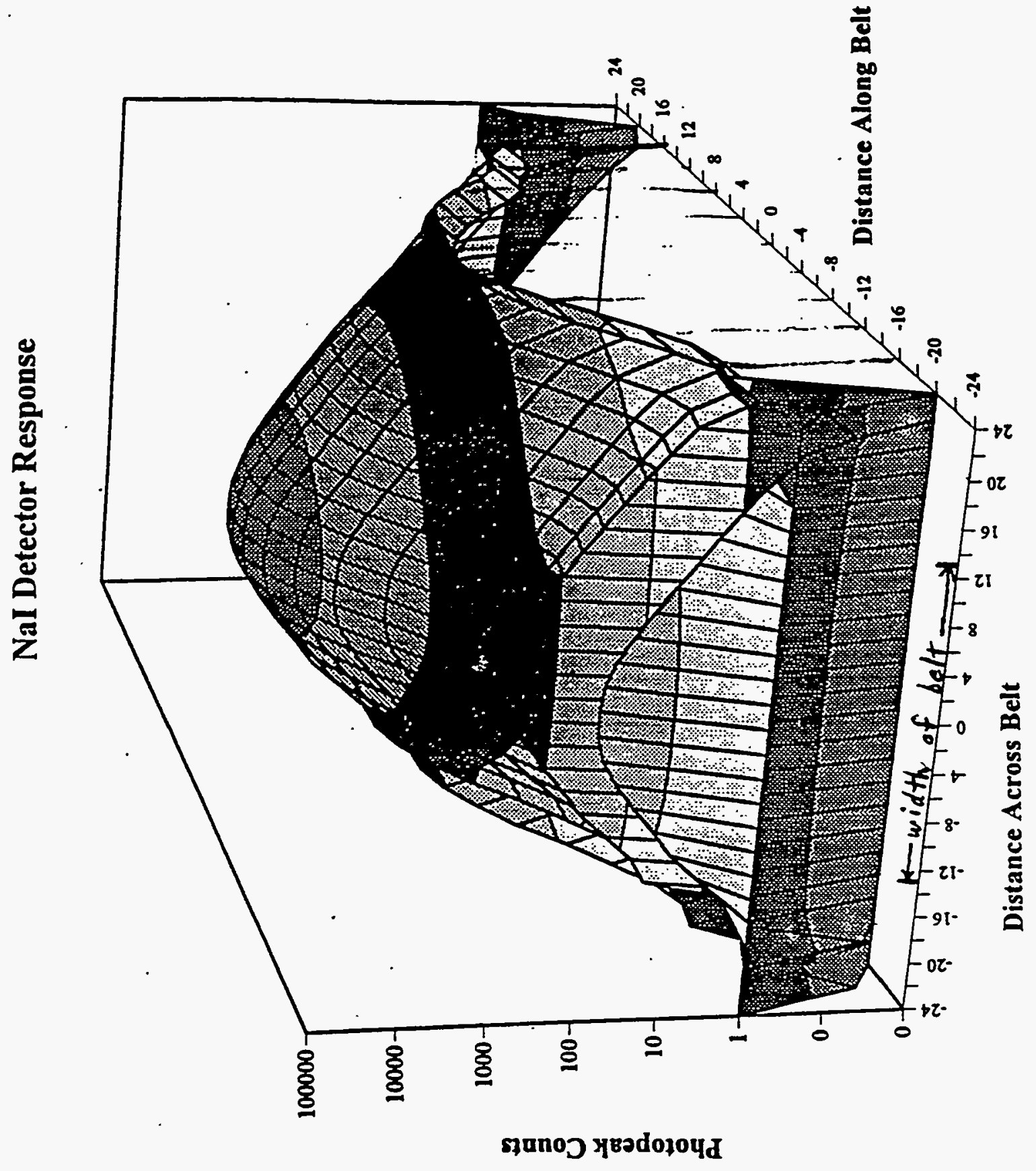

Figure 2 


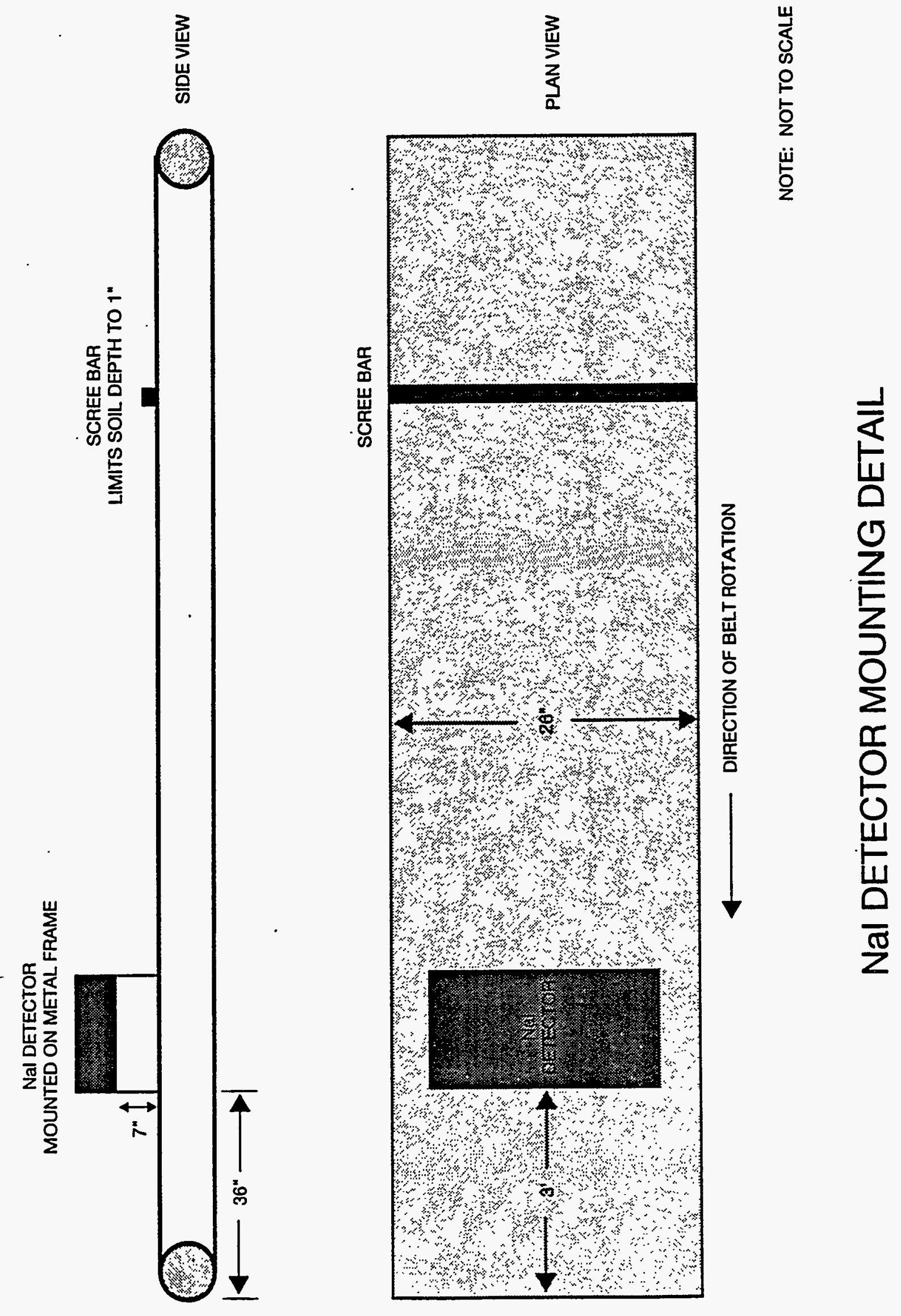




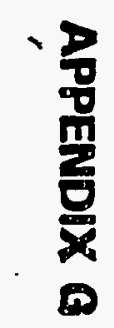

是 


\section{APPENDIX G \\ OPERATIONAL STIPULATIONS TO RECEIVE \\ SUPERSACK CONTAINERS AT NTS \\ UNDER NYO-325}




\section{Bechtel Nevada}

Mailing address: P.O. Box 98521

Las Vegas, NV 89193-8521

Express mail only: 2621 Losee Road

North Las Vegas, NV 89030-4134

E110-LSS-96-039

February 1, 1996

C. A. Shelton

Waste Management Division

DOE Nevada Operations Office

P.O. Box 98518

Las Vegas, NV 89193-8518

Subject: Contract No. DE-AC08-96NV11718

OPERATIONAL STIPULATIONS TO RECEIVE SUPER SACK CONTAINERS AT THE NEVADA.TEST SITE (NTS) RADIOACTIVE WASTE MANAGEMENT SITES UNDER NVO-325

In response to your verbal request, Waste Management Program operational personnel developed the following criteria for the use of super sacks as waste containers disposed at the NTS:

1. The sacks must be palletized. This will reduce handling time required to off-load the sacks.

2. The pallets should have at least four stringers and be of sufficient strength to support the filled sack without breaking. Four stringers will prevent the pallet slats from sagging in the middle.

3. The pallets should have a minimum of three slats on the bottom and a minimum of six slats on the top. The top of the pallet should be covered with a sheet of cardboard or some other method should be used to prevent the sack from sagging in between the slats where it could be punctured by the forklift tines.

4. The pallet should be of sufficient size to prevent overhang of the sack.

5. The sack must be banded to the pallet with a minimum of one band in each direction.

6. The sack must be closed in such a manner as to prevent leaking through the fill spout.

7. The NV-211 labels and all other required waste acceptance criteria marking/labeling must be on tags attached to the banding at the top of the sack.

8. If sacks are shipped inside a Sealand container, the maximum weight per sack must not exceed the following weights: 
C. A. Shelton

February 1, 1996

'age 2 of 2

Center of pallet to door

or rear of trailer

18 feet

16 feet

14 feet

12 feet
Weight of Sack

1700 lbs.

2100 lbs.

$2900 \mathrm{lbs}$.

3800 lbs.

If the sacks are shipped on an open flatbed trailer, the maximum weight per sack must not exceed 9,000 lbs.

Please be advised that these are only preliminary criteria, and they are subject to change once super sacks are actually received and material handling experience is gained. There are no technical specifications for the sacks themselves such as tinsel strength, sack or liner thickness, or ultraviolet.protection. This information was not available in a timely manner for this response.

If you need additional information, please call B. D. Becker at 295-6808.

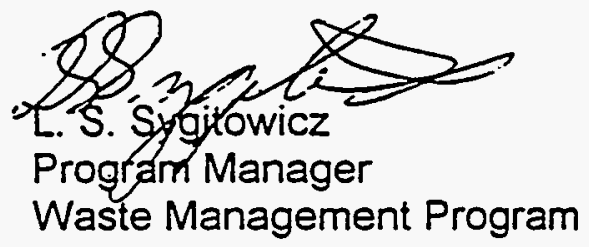

LSS:edh

cC: Correspondence Control, M/S NLV008

B. D. Becker, BN, M/S 285

J. L. Cowley, BN, M/S 738

E. D. Hatfield, BN, M/S 501

A. M. Heidema, BN, M/S 501

R. L. Dodge, BN, M/S 448

L. G. Duran, BN, M/S 285

E. F. Di Sanza, DOE/NV, M/S 505

W. A. Griffin, DOE/NV, M/S 505 


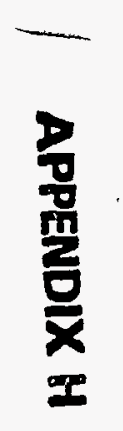


APPENDIX H

REMOTE SENSING LABORATORY

RADIOLOGICAL CLEANUP VERIFICATION PLAN 


\section{Remote Sensing Laboratory Radiological Cleanup Verification Plan}

\section{Purpose/Background}

The Bechtel Remote Sensing Laboratory (RSL) is responsible for surveying the site following soil removal to ensure that the area has been cleaned to below the designated activity levels.

The work will be accomplished using the Kiwi detection system and the Suburban Mast-mounted Ge detector system.

\section{Kiwi Detection System}

The Kiwi system is the result of mounting the detectors and data collecting system from our wellknown aerial system onto a Chevrolet Suburban vehicle. Six 2- x 4- x 16-inch NaI logs are housed in pods mounted on an angle-iron frame attached in place of the rear bumper. Signals from these detectors feed into a REDAR IV system bolted to the floor of the Suburban. Signals from the global positioning system (GPS) constellation of satellites, received by the antenna mounted above the detectors, are preprocessed by a John Chance unit before feeding into the REDAR system. In addition to the GPS signals, the antenna mounted on the roof of the Suburban receives a correction signal from a network of GPS stations around the country and relayed through a dedicated satellite for John Chance subscribers. This correction signal reduces the uncertainty in positioning the vehicle to about $1 / 2$ meter. The GPS data provides accurate location data for the radiological survey.

The Kiwi detectors are shielded on the back and sides with a sheet of cadmium, while the endmounted photomultiplier tubes and the vehicle itself provides shielding to the front of the detectors. This shielding is more than adequate for attenuating the $60-\mathrm{keV}$ gamma rays of ${ }^{241} \mathrm{Am}$, but does not significantly affect the higher energy radiation from the natural radioisotopes. The shielding produces a well-defined footprint for making assessments of the americium concentration in a given volume of soil. Thus, the ${ }^{241} \mathrm{Am}$ footprint of the stationary Kiwi system is about 3 meters ( 10 feet) in width and 1.2 meters ( 4 feet) long. With the Kiwi traveling at 2.2 meters/second ( $5 \mathrm{mph} ; 7$ feet/second), the footprint is about 3 meters ( 10 feet) wide by 3.4 meters (11 feet) long.

At the end of all excavation, packaging, and transportation operations, any soil which was excavated should have been removed from the site. In addition, all equipment will be removed from inside the fence. At this time, the Kiwi will conduct a survey over the whole area inside the fence to assess the levels of americium still remaining. The nominal line spacing will be 3 meters (10 feet) and the speed around $5 \mathrm{mph}$ ( 7 feet/second). The Kiwi will need about two days to cover the area. Another day is needed to complete the analysis of the data. If the Kiwi finds areas of high activity, the excavation and soil removal operations will be brought back in to complete
APPEN_H.WP6
Page 1
Printed: 14/Jun/96 
the work. Otherwise, if the levels are low, the equipment and crews will be released.

\section{Suburban Mast-Mounted Ge Detector System}

This measurement system consists of a collimated high-purity germanium $(\mathrm{Ge})$ detector suspended on a mast 7.5 meters ( 25 feet) above ground level (AGL). The detector and mast are attached to a 4-wheel drive vehicle (Chevrolet Suburban). The collimated detector views a circular area with a diameter of approximately 13 meters ( $43 \mathrm{feet})$.

This detector system will be used to make surveys after approximately $1 \frac{1 / 2}{2}$ inch thick lifts of soil have been scraped during the excavation phase. These measurements will provide a quick verification that the excavated areas are now below the clean-up level, and that further scraping is not required.

Following all excavation and soil-moving operations at the site, the Suburban Mast-Mounted Ge Detector System will be used to make a series of measurements at the same locations outside the exclusion zone fence as were measured during the July 1995 site characterization activities. These measurements will be compared with those taken in July 1995 before the cleanup activities began and will be used to verify that the actions inside the fence did not increase the contamination outside the fence. 
APPENDIX I

REVEGETATION PLAN 


\title{
DRAFT
}

\section{REVEGETATION AND MONITORING PLAN FOR THE DOUBLE TRACKS CLEAN-UP SITE}

\author{
Prepared for \\ U.S. Department of Energy \\ Nevada Operations Office \\ Environmental Restoration Division \\ Las Vegas, Nevada \\ Prepared by \\ EG\&G Energy Measurements, Inc. \\ Environmental Sciences Division \\ 101 Convention Center Drive \\ Las Vegas, Nevada 89109
}

August 1995 


\section{TABLE OF CONTENTS}

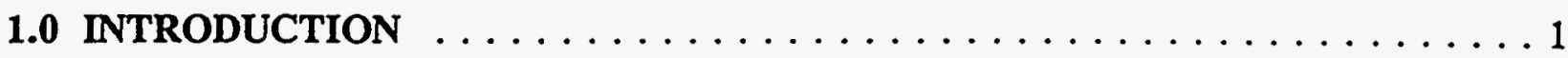

1.1 Project Description . . . . . . . . . . . . . . . . . . 1

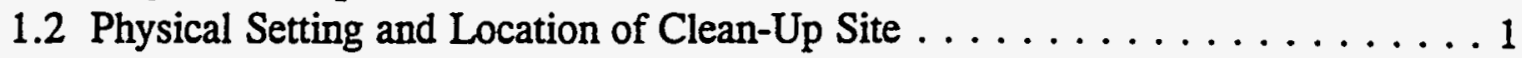

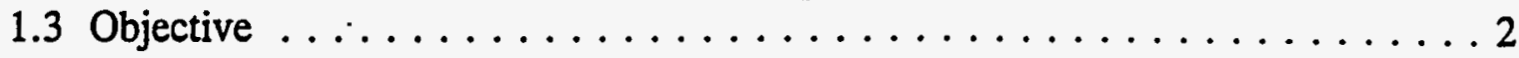

2.0 SHORT-TERM STABILIZATION $\ldots \ldots \ldots \ldots \ldots \ldots \ldots \ldots \ldots \ldots \ldots$

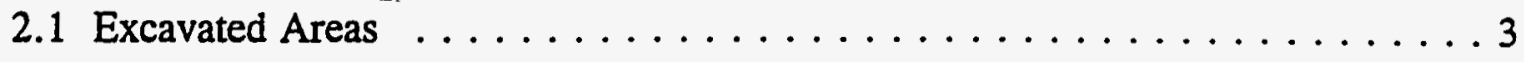

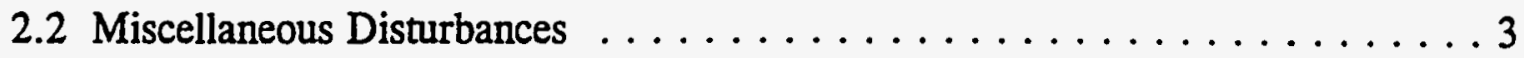

3.0 LONG-TERM STABILIZATION: REVEGETATION $\ldots \ldots \ldots \ldots \ldots \ldots \ldots$

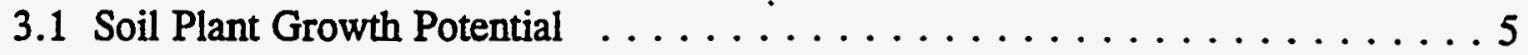

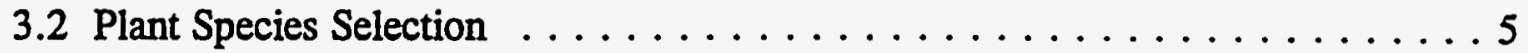

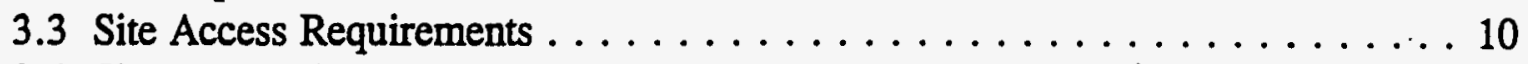

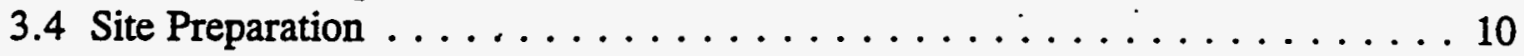

3.5 Soil Amendments . . . . . . . . . . . . . . . . . 10

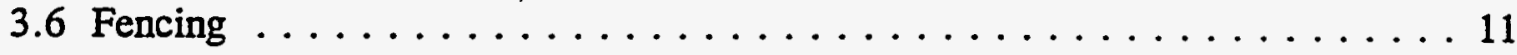

3.7 Reclamation Implementation $\ldots \ldots \ldots \ldots \ldots \ldots \ldots \ldots \ldots \ldots \ldots \ldots$

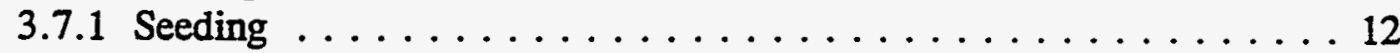

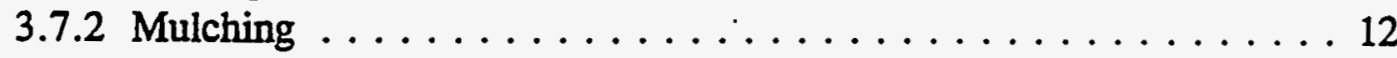

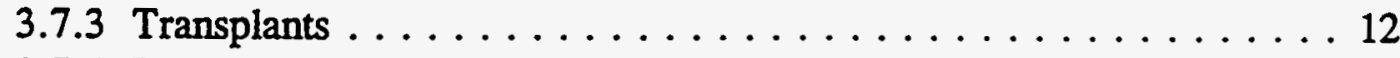

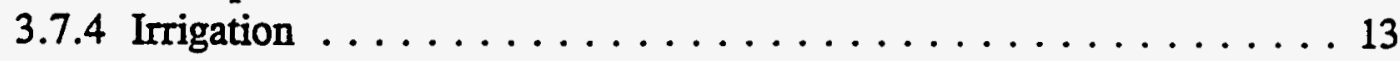

3.7.4.1 Irrigation Water Quality $\ldots \ldots \ldots \ldots \ldots \ldots \ldots$

3.7.4.2 Irrigation System and Design $\ldots \ldots \ldots \ldots \ldots \ldots$

4.0 REVEGETATION SUCCESS MONITORING $\ldots \ldots \ldots \ldots \ldots \ldots \ldots$

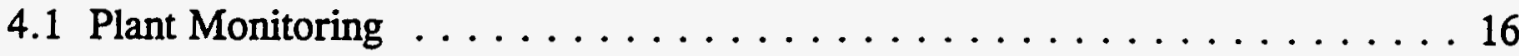

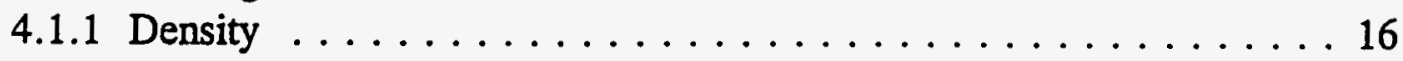

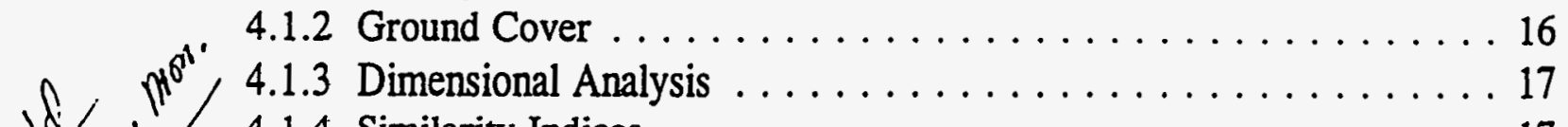

4.1 .4 Similarity Indices $\ldots \ldots \ldots \ldots \ldots \ldots \ldots \ldots \ldots \ldots \ldots$

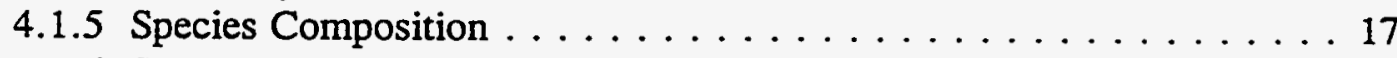

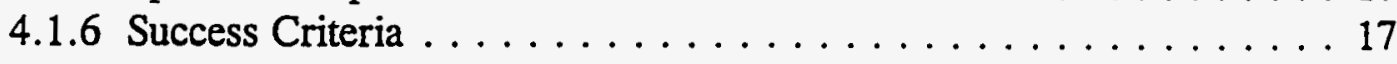

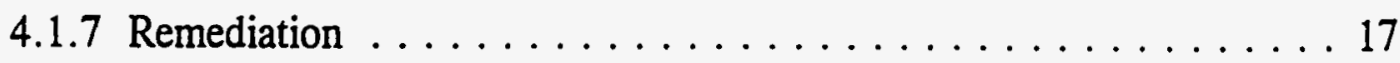

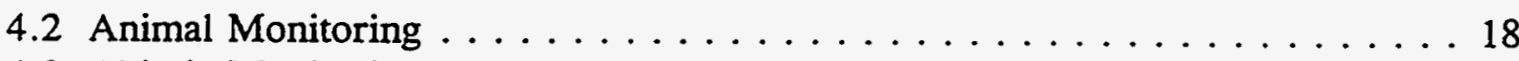

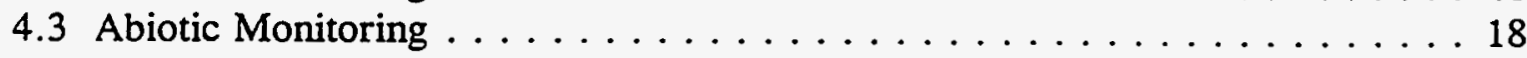

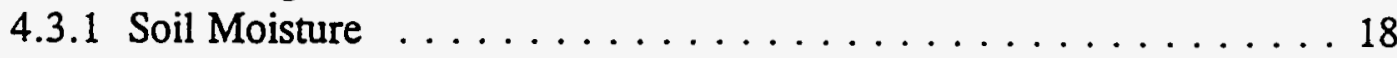

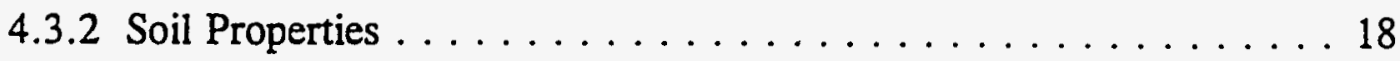




\section{LIST OF TABLES}

TABLE

PAGE

1. Soil parameters as they relate to topsoil suitability for use in revegetation (adapted from USDA 1979a).

2. List of erennial and annual species found in the reference area established near the Double Tracks site on the Nellis Air Force Range (NAFR) $\ldots \ldots \ldots 8$ 


\section{LIST OF FIGURES}

EIGURE

PAGE

1. Location of the reclamation trial site area and reference area at the Double Tracks Pu clean-up area. . . . . . . . . . . . . . . . 7 


\subsection{INTRODUCTION}

This document is a draft reclamation plan for short-term and long-term stabilization of land disturbed by activities associated with interim clean-up of radionuclide-contaminated surface soil at the Double Tracks site. The document has been prepared at this time to provide general reclamation practices and procedures that will be followed during restoration of the clean-up site. Reclamation demonstration plots were established at the site in the fall of 1994 to evaluate the performance of several native species and irrigation strategies. Results of the study at Double Tracks, as well as the results from numerous studies conducted at other sites (Area 11 and Area 19 of Nevada Test Site [NTS]), will be summarized and incorporated into a final reclamation plan for the interim clean-up of the Double Tracks site. The final reclamation plan will be completed in FY96.

\subsection{Project Description}

Surface soils at Double Tracks were contaminated as a result of the detonation of a device containing plutonium and depleted uranium using chemical explosives (Church, 1969; Shreve, 1965). The total amount of plutonium deposited on the site was between 980 and 1,600 grams (Shreve, 1965) and was scattered downwind, south of the detonation site or ground zero. The current distribution of the ground contamination has recently been mapped (EG\&G, 1995a) and an.area approximately 1 hectare ( 2 acres) in size has tentatively been targeted for excavation. The depth of soil excavated will depend on the level of contamination. In the least contaminated areas, approximately $15 \mathrm{~cm}$ (6 in) of soil will be removed. Near ground zero, where contamination levels are highest, approximately $91 \mathrm{~cm}(36 \mathrm{in})$ of soil will be removed. In addition to the disturbance associated with soil excavation, an unknown number of hectares, but probably less than 2 hectares ( 5 acres), will be disturbed by the construction of staging areas, support facilities, and activities in soil sampling areas.

\subsection{Physical Setting and Location of Clean-Up Site}

The Double Tracks clean-up site is located northwest of NTS on Range 71N of the Nellis Air . Force Range (NAFR). Goldfield, Nevada is located approximately $22 \mathrm{~km}$ (14 miles) directly west of the site. Access from Goldfield is via dirt roads. Typical access to the site is through the north gate of the Tonopah Test Range (TTR), west from the main air field through Cactus Springs Pass and northwest through NAFR to the site. It is approximately $48 \mathrm{~km}$ ( 30 miles) from Tonopah to the north gate and then another $32 \mathrm{~km}$ ( 20 miles) to the Double Tracks site. The site is located on the northwest edge of Stonewall Flat on an alluvial fan extending off the western slopes of the Cactus Spring Mountains. The elevation of the site ranges from $1,487 \mathrm{~m}$ $(4,879 \mathrm{ft})$ to $1,584 \mathrm{~m}(5,197 \mathrm{ft})$. Common vascular plant species found on the site include greasewood (Sarcobatus vermiculatus), bud-sage (Artemisia spinescens), winterfat (Ceratoides lanata), desert pepperweed (Lepidium fremontii), and shadscale (Atriplex confertifolia). Soils are predominantly gravelly sandy loams and gravely loams (Leavitt, 1978). Average annual precipitation at Goldfield is $11.8 \mathrm{~cm}$ (5.22 inches) (unpublished, Office of the Nevada State Climatologist). 


\subsection{Objective}

The objective of this document is to provide general procedures for short-term and long-term stabilization of soils that will be disturbed during interim clean-up of contaminated soils at the Double Tracks site. Stabilization is critical to prevent any resuspension of residual Pu and to reestablish wildlife habitat. Short-term stabilization during the excavation of the site will minimize Pu resuspension, thus reducing health hazards for workers and the public. Longterm stabilization will also reduce Pu resuspension, and is critical in returning the site to predisturbance conditions, thus providing habitat for local wildlife, and complimenting the other actions being taken to release the site for future use (IT Corporation, 1995). 


\subsection{SHORT-TERM STABILIZATION}

Short-term stabilization will be conducted as contaminated soils are excavated. The duration of this phase would be as long as the excavation process takes, which may be several days or several months. Short-term stabilization may continue after soil excavation is completed, depending on the time of year. For example, if excavation is completed outside the window for revegetation (October 1 to November 30), then short-term stabilization must extend until the site can be revegetated. Short-term stabilization will continue on an as needed basis until vegetation becomes established.

Short-term soil stabilization will be used on excavated areas and may be used on miscellaneous disturbances. Excavated areas are those tracts of Pu-contaminated land where contaminated soil will be removed. Miscellaneous disturbances are areas disturbed prior to or during activities related to clean-up support operations. Soils disturbed during these support activities should be stabilized to reduce fugitive dust and reduce any health risks to workers. Some of the miscellaneous disturbances will become stabilized by natural soil crusting and establishment of native vegetation. These types of disturbances generally would not receive short-term soil stabilization.unless it is deemed necessary. Disturbances created during cleanup activities such as temporary roads, road shoulders, staging areas, equipment parking and loading areas, drill pads, etc. may require stabilization following disturbance depending on future use of the site.

\subsection{Excavated Areas}

Shor-term soil stabilization will occur immediately after excavation of the contaminated soil. Application of chemicals, as part of short-term stabilization, generally requires a pre-wetting of the soil. If soils exposed after excavation are not adequately wet, they may have to be sprayed with additional water following excavation. Immediately after excavation or within an hour after the application of additional water, the disturbed soil will be treated with a dustcontrol chemical. Depending on which chemical is selected, application will be with either a hydromulcher or tanker-truck. The chemical will probably be applied at twice the manufacturer's rate to ensure maximum soil stabilization. The chemical will require a curing time of one to several days. After curing, the soil surface should be resistant to some light foot traffic, but repeated vehicular traffic may require reapplication of the chemical to properly stabilize the soil. The specific type of soil stabilizing compound, rate, and method of application will be defined in the final reclamation plan developed for this site.

\subsection{Miscellaneous Disturbances}

Miscellaneous disturbances will be treated as per the excavated areas above. Miscellaneous disturbances that receive vehicular traffic should be treated with products that are resistant to traffic. To reduce costs associated with hauling water for dust suppression, the use of trafficresistant products on roads and other traffic areas is essential at the Double Tracks site. These 
products require much less water than a water-only soil-stabilization treatment and have an effective longevity of one to several months. Examples of traffic resistant products include: petroleum byproducts, wood byproducts, and salts. These products should be applied to a compacted soil surface. Most require a pre-wetting treatment, although some products must be incorporated into the soil. 


\subsection{LONG-TERM STABILIZATION: REVEGETATION}

Long-term stabilization of areas excavated for Pu removal is critical in order to minimize fugitive dust, reduce $\mathrm{Pu}$ resuspension, restore the site to predisturbance conditions, and reestablish habitat for wildlife. The primary objective of long-term stabilization is to establish a stable plant cover that will reduce wind and water erosion and provide wildlife cover. To increase the potential for successful reclamation, soil plant growth potential must be identified, appropriate plant species selected, appropriate site preparation techniques used, soil amendments added (if needed), and the proper revegetation strategy implemented. The following discussion outlines the procedures that will be used for revegetation of the Double Tracks clean-up site.

\subsection{Soil Plant Growth Potential}

The layer of exposed soil on the excavated areas at Double Tracks should have physical and chemical characteristics that will support plant growth. Soils having parameters similar to those in the good suitability class in Table 1 provide the best media for plant growth. Soil texture and coarse fragment percentage parameters are probably the most important because they directly influence the available water retention capacity, permeability, and structure. For the purposes of this plan, the assumption is made that the uppermost layer $(30 \mathrm{~cm}$ [12 in]) of soil after excavation will have parameters consistent with those in the good suitability class.

Prior to reclamation of the site, approximately 20 random samples of soil will be collected outside the contaminated area. Soil samples will be taken at depths corresponding to the different depths of soil removed from the excavated area. Soil samples will be analyzed for key physical and chemical properties. Results from the laboratory analyses will determine the kind and amounts of soil amendments, if any, needed to increase the plant growth potential.

\subsection{Plant Species Selection}

To determine naturally occurring plants near the Double Tracks site, vascular plant density and cover data were collected in July 1995 from fifteen, $50-\mathrm{m}$ (164 ft) transects located in a reference area (Figure 1). The reference area is located approximately $125 \mathrm{~m}(410 \mathrm{ft})$ northwest of the field reclamation site and $300 \mathrm{~m}(984 \mathrm{ft})$ northeast of the northeast corner of the fence surrounding the contaminated area. Density (absolute) was determined by averaging the number of plants occurring in five random $2 \times 2-\mathrm{m}$ quadrats on each of the 15 transects (Table 2). Relative percent density was calculated for each species by dividing the absolute percent density for a particular species by the total absolute percent density for all species combined. Relative density can be used to identify the proportion of an individual species' density in the total plant density of a site. 
Table 1. Soil parameters as they relate to topsoil suitability for use in revegetation (adapted from USDA 1979a). Parameters are listed in order of relative importance.

\begin{tabular}{||l|l|l||}
\hline \multirow{2}{*}{ Soil Parameter } & \multicolumn{2}{|c|}{ Suitability } \\
\cline { 2 - 4 } & \multicolumn{1}{|c|}{ Good } & Fair \\
\hline Soil Texture & $\begin{array}{l}\text { Fine sandy loam, very fine } \\
\text { sandy loam, loam, silt loam, } \\
\text { sandy loam }\end{array}$ & $\begin{array}{l}\text { Clay loam, sandy clay loam, } \\
\text { silty clay loam }\end{array}$ \\
\hline $\begin{array}{l}\text { Coarse fragments (>2mm; \% by } \\
\text { weight) }\end{array}$ & 0 to 10 & 10 to 20 \\
\hline $\begin{array}{l}\text { Available water retention capacity } \\
\text { (cm/cm) }\end{array}$ & More than 0.40 & 0.20 to 0.40 \\
\hline Permeability (cm/hr) & 1.5 to 15.2 & 0.5 to 1.5 \\
\hline Soil Salinity (EC; mmhos/cm) & $<3$ & 3 to 6 \\
\hline $\begin{array}{l}\text { Alkalinity (Exchangeable Sodium } \\
\text { Percentage) }\end{array}$ & $<4$ & 4 to 8 \\
\hline Soil pH & 6.1 to 7.8 & $\begin{array}{l}5.1 \text { to } 6.1 \\
7.9 \text { to } 8.4\end{array}$ \\
\hline Organic Matter (\%) & $>1.5$ & 0.5 to 1.5 \\
\hline Soil Structure & Granular, crumb & Platy, block, prismatic \\
\hline
\end{tabular}

Plant cover was determined at the Double Tracks site using a point-intercept method. Cover (absolute), defined as the percentage of ground surface area covered by the canopy of a particular species, was recorded for each perennial species along the transects (Table 2). Relative percent cover was calculated for each species by dividing the absolute percent cover for a particular species by the total absolute percent cover for all species (Table 2).

Density and cover data (Table 2) will aid in determining the species and proportion oi each species to be included in the seed mix, and/or transplants used in revegetation of the Double Tracks site. Only native perennial species of shrubs, grasses and forbs will the used for revegetation. Annual plant species will not be included because they will not provide a longterm, stable vegetative cover at the site. Other criteria that will be used to seles: spevies for revegetation include: 1) previous success in establishing the species either by seeding or transplanting, 2) the ability to collect seed from native species in environments simular to the Double Tracks site, and 3) the commercial a vailability of seed from species adapted to the Double Track environs. The specific species list, proportions of species in the seed mix. and/or the species and number of transplants, will be defined in the final reclamation plan developed for the Double Tracks clean-up site. 


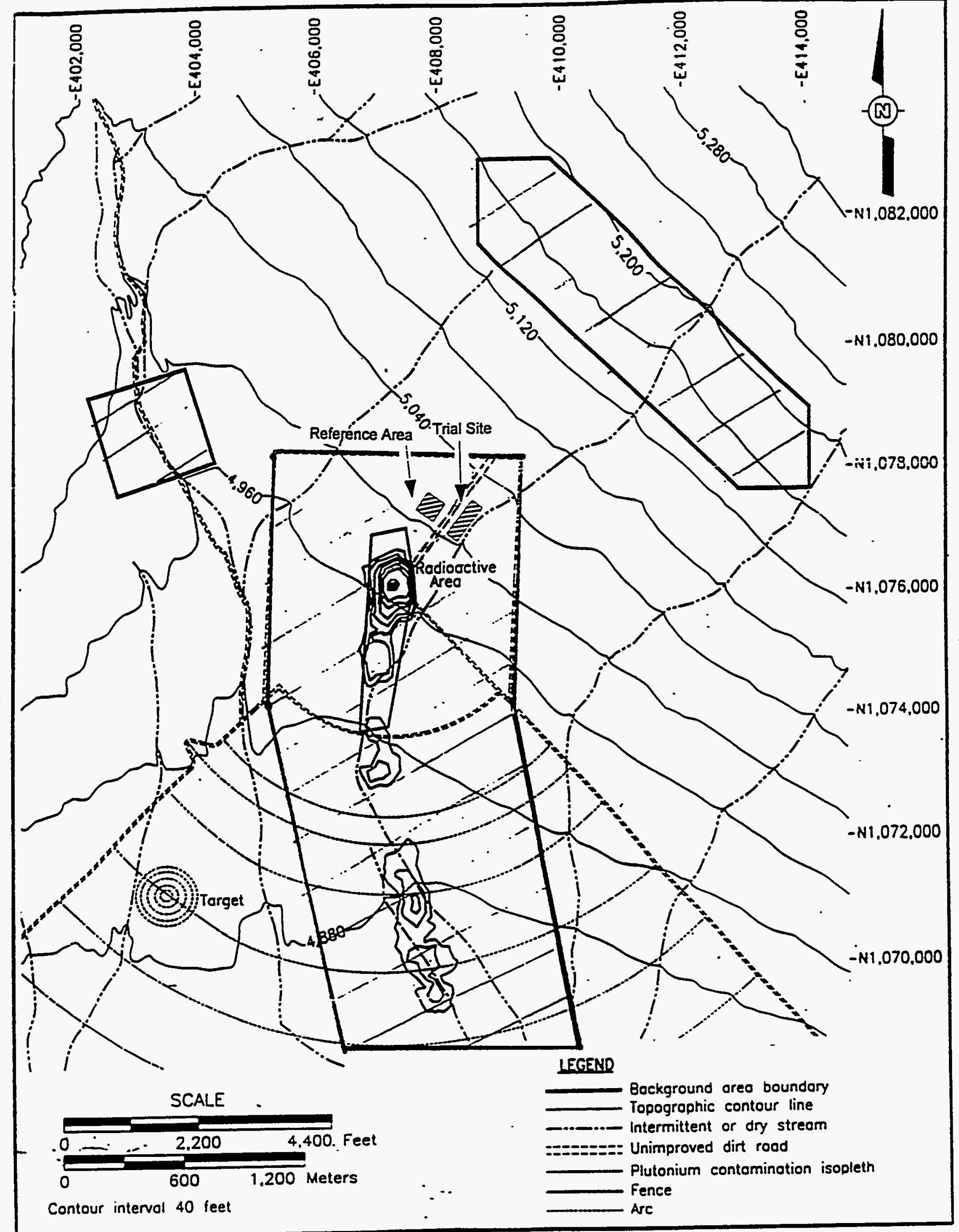

Figure 1. Location of the reclamation trial site area and reference area at the Double Tracks Pu-cleanup area. 
Table 2. List of perennial and annual species found in the reference area established near the Double Tracks site on the Nellis Air Force Range (NAFR). Percent density and cover values are given for species encountered on fifteen transects established in the reference area. Information regarding the use of these species in studies at the site, commercial availability of seed adpated to the area, and seed collection feasibility are given.

\begin{tabular}{|c|c|c|c|c|c|c|c|c|}
\hline \multirow[b]{2}{*}{ Sçientific Name } & \multirow[b]{2}{*}{ Common Name } & \multicolumn{2}{|c|}{ Density } & \multicolumn{2}{|c|}{ Cover } & \multirow{2}{*}{$\begin{array}{c}\text { Used in } \\
\text { Study at } \\
\text { Double } \\
\text { Tracks Site }\end{array}$} & \multirow{2}{*}{$\begin{array}{c}\text { Seed } \\
\text { Commerciall } \\
y \\
\text { Available } \\
\end{array}$} & \multirow{2}{*}{$\begin{array}{c}\text { Seed } \\
\text { Collection } \\
\text { Feasible }\end{array}$} \\
\hline & & Absolute & Relative & Absolute & Relative & & & \\
\hline Perennial species & & & & & & & & . \\
\hline Arnemisia spinescens & Bud-sage & 1.013 & 48.18 & 3.067 & 25.99 & no & no & yes \\
\hline Atriplex confertifolia & Shadscale & 0.287 & 13.63 & 1.133 & 9.60 & yes & yes & yes \\
\hline Ceratoides lanata & Winterfat & 0.000 & 0.00 & 0.000 & 0.00 & yes & yes & yes \\
\hline Chrysothamnus nauseosus & Rubber räbbitbrush & 0.003 & 0.16 & 0.000 & 0.00 & yes & yes & yes \\
\hline Ephedra nevadensis & Nevada Mormon tea & 0.003 & 0.16 & 0.067 & 0.57 & no & yes & yes \\
\hline Ephedra viridis & Green Ephedra & 0.000 & 0.00 & 0.067 & 0.57 & no & yes & yes \\
\hline Eriogonum fasciculatum & California buckwheat & 0.000 & 0.00 & 0.067 & 0.57 & yes & yes & yes \\
\hline Erioneuron pulchellum & Fluff grass & 0.120 & 5.71 & 0.000 & 0.00 & no & no & yes \\
\hline Hymenoclea salsola & Burrobrush & 0.003 & 0.16 & 0.000 & 0.00 & yes & yes & yes \\
\hline Kochia americana & Gray Molly & 0.007 & 0.32 & 0.000 & 0.00 & no & no & yes \\
\hline Lepidium fremontii & Desert pepperweed & 0.380 & 18.07 & 2.467 & 20.90 & no & no & yes \\
\hline Eycium andersonii & Box thorn & 0.003 & 0.16 & 0.000 & 0.00 & yes & yes & yes \\
\hline sycium pallidum & Wolfberry & 0.100 & 4.75 & 1.067 & 9.04 & no & no & yes \\
\hline Oryzopsis hymenoides & Indian ricegrass & 0.090 & 4.28 & 0.000 & 0.00 & yes & yes & yes \\
\hline Sarcobatus vermiculatus & Greasewood & 0.093 & 4.44 & 3.733 & 31.64 & yes & yes & yes \\
\hline Sitanion hystrix & Bottlebrush squirreltail & 0.000 & 0.00 & 0.000 & 0.00 & yes & yes & yes \\
\hline Sphaeralcea ambigua & Globemallow & 0.000 & 0.00 & 0.000 & 0.00 & yes & yes & yes \\
\hline Stanleya pinnata & Desert princesplume & 0.000 & 0.00 & 0.133 & 1.13 & no & no & yes \\
\hline & Totals & 2.103 & 160.0 & 11.800 & 100.0 & $=$ & & . \\
\hline
\end{tabular}


Table 2. Continued

\begin{tabular}{|c|c|c|c|c|c|c|c|c|}
\hline \multirow[b]{2}{*}{ Scientific Name } & \multirow[b]{2}{*}{ Common Name } & \multicolumn{2}{|c|}{ Density } & \multicolumn{2}{|c|}{ Cover } & \multirow{2}{*}{$\begin{array}{c}\text { Used in } \\
\text { Study at } \\
\text { Double } \\
\text { Tracks Site }\end{array}$} & \multirow{2}{*}{$\begin{array}{c}\text { Seed } \\
\text { Commerciall } \\
y \\
\text { Available }\end{array}$} & \multirow{2}{*}{$\begin{array}{c}\text { Seed } \\
\text { Collection } \\
\text { Feasible }\end{array}$} \\
\hline & & Absolute & Relative & Absolute & Relative & & & \\
\hline Annual Species & & & & . & & & & \\
\hline Astragalus lentiginosus & Freckled milkvetch & 0.437 & & 0.333 & & & & \\
\hline Chaenactis stevioides & Steves duskymaiden & 0.000 & & 7.133 & & & & \\
\hline Cryptantha pterocarya & Winged cryptantha & 0.000 & & 0.200 & & . & & \\
\hline pomopsis polycladon & Internode gilia & 0.000 & & 0.067 & & & & \\
\hline Nama pusillum & Small leaf nama & 0.000 & & 0.067 & & & & \\
\hline Denothera primiveris & Evening primrose & 0.000 & & 0.067 & & & & \\
\hline Lepidium species & & 0.000 & & 0.533 & & & & \\
\hline
\end{tabular}


Collection of seed from locales having a climate that is similar to the Double Tracks site will most likely be required for the perennial species in Table 2 . Seed collection should occur at the optimum ripening time for a species and within a time period that will allow the seed to stay viable until planting (USDA 1979b). Seed required for seeding should be collected the

year prior to reclamation. Seed needed to grow transplants should be collected the year prior to the date that transplants will be grown in a greenhouse. For example, if transplants will be needed for reclamation in February 1998, the transplants would have to be grown in a greenhouse during 1997, thus requiring seed collection during the fall/winter of 1996 and spring/summer of 1997. If seed collection from locales similar to Double Tracks is not feasible, the seed would be purchased from commercial sources, if available, and if seed is considered adapted to the environs of the Double Tracks site. Request for seed purchased from commercial sources would carry the stipulation that seed origin be from Mojave and/or Great Basin desert environments.

\subsection{Site Access Requirements}

The Double Tracks site should have an access with a width of at least $5 \mathrm{~m}$ (15 ft). Equipment that will be required at the site includes farm tractors, road graders, disks, a harrow, four wheel drive trucks, a seed drill, a hydromulcher, and a strawblower.

\subsection{Site Preparation}

Site preparation should begin shortly before the window for revegetation. For the Double Tracks site, reclamation by seeding should occur between October 1 and November 30 . During this period, conditions are more favorable for meeting germination requirements of the seeded species. Site preparation should occur in late September. If soils are compacted after excavation, the compaction should be alleviated by ripping, disking, and/or harrowing : These site preparation techniques increase water infiltration, and provide a firm seedbed for good soil-to-seed contact (Munshower, 1994).

\subsection{Soil Amendments}

Soils will be monitored before and after revegetation to determine if soil amendments are needed to enhance germination and establishment of seeded and/or transplanted species. The type and amount of soil amendment needed, if any, will be based on the physical and chemical properties of the top $30 \mathrm{~cm}$ (12 in) of the exposed soil. Types of soil amendments could include 1) macro- or micronutrient additions (e.g., fertilizers), 2) organic matter additions; 3) water-holding copolymers, and 4) remedies for sodic soils such as gypsum.

If soils are limiting in a particular nutrient, fertilizers may be applied to improve the soil nutrient status. For seeded areas, fertilizers would be applied at the appropriate rate with a fertilizer spreader. Addition of fertilizer may occur at the time of site preparation, or after plants have established. For nutrients such as nitrogen, application at the time of site 
preparation may benefit only annual plant species because germinating perennial species are generally not influenced by soil nitrogen content. However, once perennial species become established, nitrogen additions may be required to enhance long-term establishment.

Soils in the Mojave and Great Basin deserts are generally low in organic matter. Since the top portion of the soil at the Double Tracks site will be removed, most or all of the organic matter will be removed. Therefore, organic matter additions may be required. Mulches used during reclamation can provide needed organic matter to soils. Since the Double Tracks site will be mulched after seeding, other organic matter amendments may not be needed. If additional organic matter amendments are required, the type and rate will be determined at the time of reclamation.

Polyacrylamide gel crystals may be added to the remaining soil at the Double Tracks site. Polyacrylamide gel application can improve the water holding capacity in the upper layer of the soil. Polyacrylamide gels (cross-linked polymer gels) can absorb 40 to 500 times their weight in water. At NTS, polyacrylamide applications have been successful in increasing the numbers of germinating perennial species over areas not receiving the polyacrylamide application (EG\&G/EM 1994, 1995a, and unpublished data). Polyacrylamide gel crystals are applied at $24 \mathrm{~kg} / \mathrm{ha}(20 \mathrm{lbs} / \mathrm{ac})$ to the surface of the soil prior to or during seeding and then harrowed into the soil. Polyacrylamide crystals can be spread with a fertilizer spreader, or can be mixed into the seed and spread with a seed drill.

If soils are high in sodium, gypsum may be used to improve sodic conditions. Gypsum applications can reduce sodium absorption ratios, increase infiltration, allow salts to be leached deeper in the soil and reduce soil crusting (Munshower 1994). After the soil analyses results are received from the laboratory, gypsum requirements, if any, will be determined.

\subsection{Fencing}

The fence currently surrounding the contaminated area at Double Tracks should be left in place to reduce the effects of herbivory on plant establishment. The base of the fence should

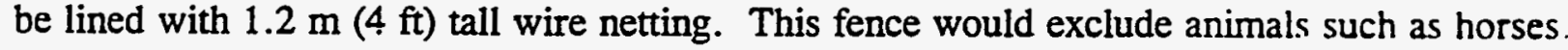
burrows, antelopes, and rabbits, but would not exclude small rodents. The fence should remain in place for a minimum of five years, which should be sufficient tume for plants to become established and able to withstand the effects of herbivory.

\subsection{Reclamation Implementation}

The reclamation strategy that will be employed at the Double Tracks site could involve using combinations of seeding, transplanting, and supplemental irrigation to increase plant establishment during the first year and reduce the chances of reclamation failures. For the purpose of this draft reclamation plan, a specific strategy will not be outlined. However, various options that may be employed will be discussed. The specific reclamation 
implementation strategy that will be employed will be outlined in the final reclamation plan, and will be based on the results of field demonstration plots at Double Tracks, Area 11 and Area 19.

\subsubsection{Seeding}

The Double Tracks site should be seeded at some time during the reclamation window (October 1 to November 30). The preferable month for seeding is November. Seeding at this time would ensure that dormancy-breaking requirements for germination of most seeded species would be met. Additionally, seed would be in the ground prior to winter precipitation and freezing temperatures.

If irrigation is used, the site would be broadcast-seeded at a rate of approximately 21 pure live seed (PLS) $\mathrm{kg} / \mathrm{ha}$ (18.7 lbs/ac). If the site will not be irrigated, it would be broadcast-seeded at a rate of 42 pure live seed (PLS) $\mathrm{kg} / \mathrm{ha}(37.5 \mathrm{lbs} / \mathrm{ac})$. The area would be seeded with a tractor-drawn seed drill having seedboxes that accommodate small, fluffy, and large seeds. The disk openers on the drill would be elevated off the ground to allow seeds to be broadcast over the soil surface. After the seed is broadcast, the site would be harrowed with a tractordrawn drag harrow to cover the seeds and improve soil-seed contact.

\subsubsection{Mulching}

Immediately after seeding, the site will be mulched with grain straw. Mulching protects the soil surface from wind and water erosion, and also provides a more favorable microenvironment for seedling establishment. The mulch will be applied evenly to the soil surface with a truck-drawn strawblower. The mulch will then be attached to the soil surface via crimping or a tackifying agent.

Crimping would be accomplished using a tractor drawn disk-crimper. Crimping holds the straw in place, thus reducing erosion. Crimping incorporates a portion of the straw into the soil that, over time, can improve the amount of organic matter in the soil. The direction of crimping should be perpendicular to the slope.

Tackifying the mulch would be accomplished using a hydromulcher containing a mixture of water and a tackifying agent such as physillium powder (e.g., M-Binder ${ }^{\circledR}$ ). This mixture would be applied evenly to the mulch-covered soil surface. The specific type and rate of tackifying agent, if used, will be given in the final reclamation plan.

\subsubsection{Transplants}

Plant species that are seeded may also be transplanted. Transplanting could occur during the late winter after seeding, or in subsequent years to increase species diversity on the site. The number of transplants per hectare for each species would be determined from the following: 1) 
relative cover and density (Table 2) of the species in the native plant community; 2) desired percentage of a species density as transplants; 3 ). past success in establishment of the species from seeding or transplanting; and 4) the availability of transplants from either commercial nurseries or contract growers. The specific species and number of transplants, if any, will be given in the final reclamation plan.

Near the time of transplanting, transplants would be sent from a grower to a holding facility, and later transported to the Double Tracks site. Once transplants are brought to the site, holes for transplants ( 20 to $30 \mathrm{~cm}$ [8.to $12 \mathrm{in}$ ] in depth) would be dug with a tractor-mounted auger. The holes would be drilled in a clumped pattern, and the transplants planted in mixed-species groups that mimic the natural vegetation surrounding the Double Track site.

\subsubsection{Irrigation}

One of the most limiting factors, if not the most limiting factor, for successful seed germination and plant establishment is the availability of water. Precipitation amounts fluctuate from year to year at the Double Tracks site and extended periods of drought conditions could result in the complete failure of long-term soil stabilization attempts. Preliminary results from reclamation field study plots established at Double Tracks and at other sites on NTS suggest that irrigation improves seedling densities. However, at NTS, the determination as to whether or not the effects of irrigation continue to provide a benefit and plants become established is still undocumented. The assumption is made that water will be available at the Double Tracks site for use in irrigation of the reclaimed area. The assumption is also made that the quality of the available water will be sufficient for use in irrigation.

\subsubsection{Irrigation Water Quality}

Prior to installation of an irrigation system, the water source must be tested to determine the quality of the water. If the water quality is poor, actions must be taken to amend the water to improve the quality. Ludwig et al. (1976) lists four basic criteria for evaluating water quality for irrigation purposes:

1. Total soluble salt content (salinity hazard)

2. Relative proportion of sodium cations to other cations (sodium hazard)

3. Bicarbonate anion concentration as related to.calcium plus magnesium cations

4. Concentration of elements that may be toxic

Total soluble salt is measured by electrical conductivity (EC). For irrigation water, the EC should not exceed $1.5 \mathrm{mmhos} / \mathrm{cm}$ (Lugwig et al., 1976). However, soil solutions should not have an EC greater than 4 mmhos/cm (Ries and Day, 1978).

The relative proportion of sodium cations is measured by the sodium adsorption ratio (SAR). Ludwig et al. (1976) recommend that the SAR for irrigation water not exceed 10; however, if 
the soil has appreciable amounts of gypsum this measure can be exceeded. Devitt (1989) recommends using the adjusted SAR which accounts for varying levels of carbonates and bicarbonates in the water. No upper limits have been defined for the adjusted SAR measurement; however, Devitt has used water with adjusted SAR values of 15 with no apparent plant growth problems (Devitt, D.A., personal communication, 1994).

Water high in bicarbonate will tend to precipitate calcium carbonate and magnesium carbonate when the soil solution concentrates through evapotranspiration. This increases the SAR, which in turn, will increase the sodium hazard of the water to a level greater than that indicated by the SAR value. No upper limits were found for bicarbonates, however, adjusted SAR does account for bicarbonate levels.

Devitt (1989) lists boron as one micronutrient that is essential for plant growth, but it becomes toxic to plant growth at levels exceeding $1 \mathrm{ppm}$. Fluoride is another element that limits plant growth when levels exceed $1 \mathrm{ppm}$ (Devitt, D.A., personal communication, 1994).

\subsubsection{Irrigation System and Design}

The irrigation system used at the Double Tracks site will most likely be a solid set sprinklertype system designed to produce an even distribution of water across the entire reclaimed area. Sprinkler heads will be selected so as to apply water at the optimal rate and spray pattern. The sprinkler heads chosen will have a droplet size that maximizes distribution of water to the soil, minimizes runoff, and reduces wind drift. The specific irrigation system design will be described in the final reclamation plan.

Application of irrigation will include three implementation periods: pre-irrigation, germination irrigation, and establishment irrigation. Pre-irrigation is the application of water to recharge the soil profile prior to germination of the seeded species. This recharge will encourage deep rooting and establishment of the seeded plants. Pre-irrigation will be implemented during late fall or winter after seeding, and will consist of the addition of approximately $80 \mathrm{~mm}$ ( $3.15 \mathrm{in}$.) of water to the soil over a 2 to 3 -week period. Frequency of application will be based on climate conditions at the time of implementation.

Germination irrigation is defined as supplemental irrigation applied to initiate germination and seedling emergence. Germination irrigation can be adjusted by changing the amount applied during an irrigation event, the frequency of the events, and the duration of an irrigation event. The application level of each of these germination irrigation variables is generally determined by calculating soil infiltration and evapotranspiration rates. These rates are calculated using various soil and climatic parameters. Soil moisture cells will be placed in the upper $5 \mathrm{~cm} \mathrm{(2}$ in) of soil to aid in these determinations. Until these parameters are known, the optimal application levels cannot be determined. Germination irrigation would be initiated during March or April. 
Establishment irrigation is the application of supplemental water following germination and seedling emergence. Establishment irrigation is used to supplement pre-irrigation by recharging the soil profile to encourage deep-rooting and survival of seedlings. It is also used to aid in establishment of transplants. As with germination irrigation, optimal application levels for establishment irrigation are dependent upon soil and climatic parameters. Typically, establishment irrigation would be initiated soon after seedling emergence and consist of the application of approximately 25 to $50 \mathrm{~mm}(0.98$ to $1.97 \mathrm{in}$.) of water every two weeks until midsummer. 


\subsection{REVEGETATION SUCCESS MONITORING}

The objectives of revegetation success monitoring are to monitor plants and site colonization by animals to determine whether reclamation has been successful. The success of reclamation will be determined by comparing plant and animal characteristics of the revegetated area to an adjacent reference area over time.

\subsection{Plant Monitoring}

Plant monitoring will be conducted on the reclaimed Double Tracks site. Vegetation data for both perennial and annual species was collected from transects in the reference area in 1995. This data was collected to serve as a baseline for species selection and to set preliminary goals for reclamation success. After reclamation has occurred on the Double Tracks site, transects similar to those in the reference area will be established in the reclaimed area. This will allow statistical comparisons of plant parameters to be made between the reclaimed area and reference area, and will aid in determining reclamation success. Specific plant parameters that will be measured include density, cover, and plant dimensions.

\subsubsection{Density}

Plant density will be measured to determine numbers of established plants, seedling emergence and plant survival. Density will be determined by recording the number of individual plants of each species occurring within each of five $4-\mathrm{m}^{2}\left(43.1 \mathrm{ft}^{2}\right)$ quadrats located along each permanent transect. Plant density will be sampled after each growing season during the first, third, fifth, and tenth year following reclamation.

\subsubsection{Ground Cover}

Ground cover is determined from the proportion of the ground surface covered by each of three categories: 1) living, above ground vegetation, 2) dead vegetative material (litter), and 3) soil particles.(4 size classes). Each of these cover parameters is expressed as a percentage of the total area of measurement (Chambers and Brown, 1983). Ground cover data will be collected during the third, fifth and tenth growing seasons.

Cover data will be collected using the point-intercept sampling method. Point-intercept sampling is a vegetation cover measurement technique that uses a theoretical vertical line drawn between the observer's eye and a point on the ground. The theoretical line intercepts some form of ground cover (e.g., a plant, litter, soil particle.). Cover is determined using a cover-point optical point projection device (COPPD) (Buchner, 1985). The COPPD is positioned approximately $1 \mathrm{~m}$ (39 in) above the ground and the plant species, litter, or soil particle (bareground, gravel, cobble, or rock) intercepted by the theoretical vertical. line is recorded. Cover parameters would be determined from fifty line intercepts or points recorded along each $50-\mathrm{m}(163 \mathrm{ft})$ transect. 


\subsubsection{Dimensional Analysis}

An assessment of growth and production of seeded and transplanted plant species is needed to determine whether plant growth in the reclaimed area is approaching that of the reference area. Dimensional analysis is a field method that can be used for this assessment. Dimensional analysis is a nondestructive technique that utilizes the dimensions of the plant canopy to estimate biomass (Etienne, 1989). After the third, fifth and tenth growing seasons, the height, greatest width, and the width perpendicular to the greatest width of each plant found within 1 $\mathrm{m}$ of the center line of each $50-\mathrm{m}$ transect will be measured and the volume calculated. Volume will be corrected for the growth form (shape) of the plant. Biomass will then be estimated using regression techniques.

\subsubsection{Similarity Indices}

Similarity indices provide a means of mathematically comparing two different plant communities, and can provide a more appropriate comparison of the diversity of reference and reclaimed areas than other diversity indices (Chambers and Brown, 1983). Similarity indices will be calculated in year three, five, and ten for both the reference area and the reclaimed area from either density, cover or biomass data.

\subsubsection{Species Composition}

Composition data will be derived from density and/or cover data. Composition will be calculated for the reference and reciaimed areas in the third, fifth, and tenth growing season after revegetation.

\subsubsection{Success Criteria}

In order to determine whether revegetation efforts on the Double Tracks site are successful. revegetation success criteria or standards must be developed. The success criteria stated helnuare standards for revegetation success only. They also indirectly serve as standards for erosion control.

Reclamation of the Double Tracks site will be considered successful, if after ter. years. plant density, cover, production, and the diversity of the reclaimed areas are 70, if that measured on the reference area. Density and production will only consider those species that were seeded, or if not seeded, native to the plant community surrounding the Double Tracks stte.

\subsubsection{Remediation}


Remediation, which involves some site preparation, re-seeding, and re-mulching of a site, will only be considered if the reclamation of the site is not on track to meet the success criteria. Both vascular plant cover and density will be considered in determining the need for remedial reclamation. Vascular plant cover will be measured in the third, fifth and tenth years after reclamation. Data collected in year five will be used to evaluate the need for remedial reclamation. If vascular plant cover is below approximately $50 \%$ of the amount of cover on the reference area, remedial action may be necessary to ensure that reclamation success criteria are met. Plant density for the area surrounding the Double Tracks site is approximately 2.1 plants $/ \mathrm{m}^{2}\left(0.19\right.$ plants $\left./ \mathrm{ft}^{2}\right)$. To attain this density by the fifth growing season, a density of at least 10 seedlings $/ \mathrm{m}^{2}\left(0.46\right.$ seedlings $\left./ \mathrm{ft}^{2}\right)$ of seeded species, is necessary after the first growing season. If the density of seeded plant species is significantly less than this after the first growing season or less than 2.1 plants $/ \mathrm{m}^{2}$ after the third or fifth growing season some form of remediation must be conducted to meet the success criteria by the tenth growing season.

\subsection{Animal Monitoring}

During vegetation sampling, passive animal indicators along each transect will be recorded. The number of ant mounds, mammals by species, reptiles by species, birds by species, plants grazed by species, scat by species and small mammal burrows will be counted and recorded. Passive animal indicators will be used to determine if the revegetated cover is being used by wildlife.

\subsection{Abiotic Monitoring}

\subsubsection{Soil Moisture}

Soil moisture data is needed to determine amounts and frequency of germination and establishment irrigation, and to determine possible causes of reclamation failure. Soil moisture, in the top $5 \mathrm{~cm}(2 \mathrm{in})$ of soil, will be monitored with soil moisture cells (resistance blocks) connected to a datalogger.

\subsubsection{Soil Properties}

Soil on the reclaimed area.may change over time as plants become established, soil amendments are added, or as salts build up from irrigation waters, etc. Soils in the reclamation trial site will be monitored for soil conditions that may cause poor vascular plant establishment and/or growth. If such conditions are observed, soil samples may be retrieved from the top $30 \mathrm{~cm}$ (12 inches) of soil and analyzed for key physical and chemical properties. The soil analyses will be used to identify the cause of poor growing conditions and also assist in developing remedial action(s). 


\subsection{LITERATURE CITED}

Buchner, D.L. 1985. Point intercept sampling in revegetation studies: maximizing objectivity and repeatability. In: Proceedings of American Society for Surface Mining and Reclamation Meeting, October 1985, pp. 110-113.

Chambers, J.C., and R.W. Brown. 1983. Methods for Vegetation Sampling and Analysis on Revegetated Mined Lands. USDA Forest Service Intermountain Forest and Range Exp. Sta. Gen. Tech. Rep. INT-151, Ogden, Utah. 57 pp.

Church, H.W., 1969. Cloud Rise from High-Explosives Detonations, SC-RR-68-903, Sandia National Laboratories, Albuquerque, NM.

Devitt, D.A. 1989. Supplemental irrigation in the reclamation of soils. Reclamation of Mining - Disturbed Lands in the Great Basin. Nevada Cooperative Extension Shourtcourse. October 3-4, 1989. Reno, NV.

Devitt, D.A., Personal communication. 1994. Telephone call between Dr. Dale Devitt, University Nevada Las Vegas, and Kevin Blomquist, EG\&G Energy Measurements. May, 1994.

EG\&G/Energy Measurements. 1994. Yucca Mountain biological resources monitoring program, progress report Oct. 1992 - Dec. 1993. EG\&G/EM Las Vegas Area Operations Report No.11265-1073 UC-708. 69 pp.

EG\&G Energy Measurements. 1995a. Survey results of June, 1995 sampling of Double Tracks. (Report in preparation).

EG\&G/Energy Measurements. 1995b. Yucca Mountain biological resources monitoring program, progress report January 1994 - Dec. 1994. EG\&G/EM Las Vegas Area Operations Report No.11265-1136 UC-808. 79 pp.

Etienne, M. 1989. Non destructive methods for evaluating shrub biomass: a review. Acta Oecologica/OEcologia Applicata 10:115-128.

IT Corporation. 1995. Double Tracks Corrective Action Plan. (Preliminary). DOE/NV-UC700.

Leavitt, V.D. 1978. Soil Surveys and Profile Descriptions of Plutonium-Contaminated Areas on the Test Range Complex in Nevada, 1970-1977 in Selected Environmental Plutonium Research Reports of the NAEG, M.G. White and P.B. Dunaway, Eds. NVO-192, Las Vegas, NV. 
Ludwig, A.E., G.W. Hergert, and W.T. Franklin. 1976. Irrigation water quality criteria. Colorado State University Extension Service. Service in Action Sheet no. 506. 2 pp.

Munshower, F.F. 1994. Practical Handbook of Disturbed Land Revegetation. Lewis Publishers, Boca Raton, FL. 265 pp.

Ries, R.E. and A.D. Day. 1978. Use of irrigation in reclamation in dry regions. In: F.W. Schaller and P. Sutton (Ed) Reclamation Of Drastically Disturbed Lands. Amer. Soc. Agron. Madison, Wisconsin.

Shreve, Jr., J.D. 1965. Operation Roller Coaster, Scientific Director's Summary Report. DASA-1644. Sandia-National Laboratories, Albuquerque, NM.

USDA Forest Service. 1979a. User guide to soils. U.S.D.A. Forest Service General Technical Report INT-68. Intermountain Forest and Range Experiment Station, Ogden, Utah, U.S.A. 80 pp.

USDA Forest Service. 1979b. User guide to vegetation. U.S.D.A. Forest Service General Technical Report INT-64. Intermountain Forest and Range Experiment Station, Ogden, Utah, U.S.A. 85 pp. 


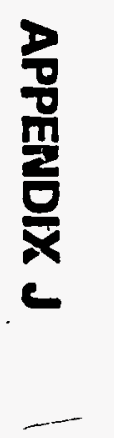


APPENDIX J

SOIL EXCAVATION METHODS

COMPARISON PLAN 


\section{Soil Excavation Methods Comparison Plan}

A motor grader and a scraper will be used to excavate the contaminated soils at the Double Tracks project site. The purpose of the plan is to objectively compare the equipment and excavation procedures based on cost effectiveness, speed of excavation, the amount of air borne dust generated, and accuracy of cut to remove only the thin layer of contaminated soil present on much of the site. The evaluation will be conduced using the following plan.

Two equal areas will be laid out within the contaminated soil plume. The areas will be similar in levelness of topography, amount of vegetation, and other variables which may have an impact on excavation. The coordinates of each of these areas will be measured.

The soil will be wetted with water in the same manner and amount as is anticipated for excavation of the entire site.

Each piece of equipment will attempt to remove a $1^{1 / 2}$ inch thick layer of soil over the designated area. The motor grader will blade the soil into windrows which will be picked up using a frontend loader and placed in a stockpile. The scraper will also attempt to remove a $1 \frac{1}{2}$ inch thick layer of soil and deposit the material in a stockpile. It is anticipated that a front-end loader will also be needed to assist the scraper in creating a stockpile of soil. The time required to excavate and stockpile soil using each piece of equipment will be recorded. Such factors as the logistics of accomplishing this task and the degree of operator skill will noted.

A comparison of the amount of dust produced will be based on the visual observation of personnel such as the site supervisor, the construction supervisor, and/or the site health and safety officer.

The accuracy of cut is important is minimizing the volume of soil to be disposed. After each pass of the either the blade or the scraper, a straight edge (such as a $2 \times 4$ ) will be placed perpendicular to the cut so that depth measurements in reference to the straight edge can be taken. Measurement will be taken at one to two foot intervals along the straight edge and at approximately 10 foot intervals along the length of the cut.

The excavation operations will be video taped for future comparison, to document the amount of dust generated by each method, and for documentation of operational details that can not be easily quantified by taking measurements. 


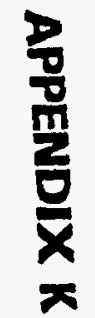




\section{APPENDIX K}

AIR MONITORING PLAN

$\checkmark$ 


\title{
WORK PLAN \\ for \\ Particulate and Meteorological Mcasurements at Double Tracks, TTR
}

\author{
John L. Bowen \\ Energy and Environmental Engineering Center \\ Deser Research Instutute \\ P.O. Box 60220, 5625 Fox Ave. \\ Reno, NV 89506
}

June 12, 1996

\section{Introduction}

Excavation of soil contaminated with plutonium at the site on the Tonopah Test Rangt (TIR) of the Double Tracks safety shot conducted as part of Operation Roller Coaster has been scheduled by Bechtel, Nevada to begin 24 Junk 1996. From 24 June through 3 July, soil will be removed from the area affected by the safery shot to a nearly central processing location. From 26 June to 12 August, soil will be proccssed for transport to a storage area.

This work plan describes the measurements of airborne particulate matter and metcorological variables that the Energy and Environmental Engineering Center (EEEC) of the Desen Kesearch Instiute (DRI) will make during and after remediation efforts.

EEECIDRI personnel will be onsite to deploy and operate equipment during the excavation period. It is anticipated that TTR personnel will be available to uperate samplers after the excavaton period. A tentative schedule is included at the end. The final dates will depend on Berhel's schedule.

\section{During Excavation of Contaminated Soil}

Porable $\mathrm{PM}_{1 \mathrm{n}}$ samplers will be deployed outside the exclusion zone area to collert samples of airbome particulate matter during excavation operations. The samplers will be placed on what is expected to be the prevailing upwind and downwind sides of the excavarion area. The backgruund monitnring conducted during the past year has shown that the prevalling winds dunng the summer tend to fall into two directions: southerly and northerly. Southerly winds are generally inore prevalent during daylight hours while northerly winds occur more often during mghrame hours. Summer meteorologital cunditions. however, may not have set in by the end of June as shown by data from June and July, 1995 when the dichoromy of directions did not occur as nordherly winds persisted during most hours from 22 June through 4 July. 1095. 'The simpler single prevailing direction is not being planned for at this time. 
Bechtel's current operational plan calls for soil movement to occur from 0400 to 1400 PDT so that workers will not be exposed to maximum daytime temperatures. Because the wind direction is likely to switch during this period of time trom the northerly to southerly directions, the collecrion of resuspended parriculate matter will be a combination of background air and air that has passed over the operations area. To measure the effect of the operations alone. background information will have to be subtracted from the samples and samples adjusted for time of background and non-background air. An additional sampler will be set up al a lucation with little impact from any of the operations including general traffic in the area to collect a backsround sample. This site will probably have to be to the cast or west of the excavation area. Meteorological data will to be used to determine when the wind is from background directions or from operations directions for the various samplers.

Samples of airborne particulate matter with acrodynamic diameters less than $10 \mu \mathrm{m}\left(\mathrm{PM}_{10}\right)$ will be collccted during the period of operations. A total of 7 portable $\mathrm{PM}_{30}$ samplers of the type used during the background sampling will be deployed outside the radiation controlled area. Two samplers will be placed to the south of the excavation area; two samplers will be placed to the north of the excavation area; and one background sampler will be placed to the east or west of the excavation area. These samplers are battery operated and can be programmed to collcct samples at times that coincide with the operations. Airbome particulate matter is collected on $47 \mathrm{~mm}$ diameter Teflon filters. At a flow ratc of $5 \mathrm{lpm}$, these samplers collect enough mass to determine mass concentration but probably not enough for low levels of radioactive material.

Meteorological equipment will be deployed in the vicinity to collect wind speed, wind direction, temperature, relative humidity, and pressure. Data will be collected and stored as 15minute and 1-hour averages in the data logger and in storage madules. Storage modules will be recumed at regular intervals to Reno for processing, validation, and interpretation.

Filters will be initially weighed in Reno and sent to the field in Petri dishes. Filters will be loaded into holders at TTR. During ute excavation period, unexposed filters will be installed on the samplers the previous diay. The samplers will be programmed in collect samples during uperations. Filter holders will be removed from samplers after operations.

It is expected that Bechtel personnel will be able to perform field tests on the filter holders and samplers for the level of radioactivity. For those samples with acceptuble levels of radioactivity, the exposed filters will be removed from holders, placed in. Pemi dishes, and returned to EEECIDRI's Reno Laboratory for final weighing. If the level of radioactivity is not acceptable, the samples and holders will have to be segregated for weighing at a location to be determined and decontamination.

Following ner mass determination, concentration of airborne particulate matter will be calculated from mass loading, sampler flow rate, and elapsed time of the sample. Filters will be saved for possible further analyses. 
During operations, the filter loadings and mass concentrations will be reviewed to detcrmine if dust is being emitted during operations. Personnel in the field will be informed of the interim results. A final report of the particulate and meteorological data will he generated. Included in the report will he pariculate concentrations at the various locations during the operations along with winds during the time.

\section{After Removal of Contaminated Soil at Double Tracks}

After contaminated soil is removed from Double Tracks, porable $P M_{1 n}$ samplers will be deployed in the vicinity to deremine (1) the effect of the disturbed soil on the anroum of airborne particulate matter and (2) the effectiveness of controls to stabilize the disturbed soil.

Two sets of 24-hour filtcr samples will be collected each week for one year. Sampler's will be deployed to the north and south of the disturbed area to collect samples along the line of the predominate daytime and nightrime wind directions and to the east or west for background. A total of 7 filter samples will be collcstci each week: north and south samples on one day, north and south samples with one collocated sample on the other day, background samples on each day. An additional filter will be exposed to the air each week as a field blank. Filrers will be weighed before exposure in EEEC/DRI's Reno Laboratory, loaded into filter holders, shipped to the TTR, exposed, shipped back to Renn, and weighed for net mass. Concentrations will be calculated from the net mass, flow rate, and exposure duration. Filters will be saved for possible further analyses:

Meteorological data will be collected as 15-minute and 1-hour averages in the :1ab logger and in storage modules. Storage modules will be returned at regular interials in Reno tor processing, validation, and interpretation.

It is anticipated that TTR persunnél will continue to operate the samplers is they did during the background monitoring. This involves visiting the site, installing and remuving filter holders. checking the operations of the samplers and meteorological equipment. :unt inrpme exposed filters. The site will require weekly visits to change filters.

Quarterly data reports of the particulate and metcorological data w: Included in the reports will be particulate concentrations at the sample dav ... . . 5........e. meteorological data. 
Schedule for

Particulate and Meteorological Measurements at Double Tracks, TTR

\section{Dependent on Bcchtel Schedule}

Deploy equipment for collection during Excavation

June $19-20$

Collect samples during Excavation

June $24-$ July $3^{2}$

Move equipment for collection after Excavation

July 3

Collect samples after Excavarion

July, 1996 - July 1997

Samples may not be collected on cither June $29 / 30$ or June $30 / 5$ uly 1 . 


\section{Double Tracks \\ Interim Corrective Action Plan \\ Distribution List}

U.S. Department of Energy Nevada Operations Office

Copies

D.S. Afong, M/S 505

M. L. Sanchez, M/S 505

1

S. D. Bonnell, M/S 505

Technical Information Resource Center, M/S 505

Public Reading Facility, M/S NLV040

\section{U.S. Department of Energy}

Office of Scientific and Technical Information

P.O. Box 62, Oak Ridge, TN 37831

\section{Nevada Department of Environmental Protection}

Paul Liebendorfer

NDEP Capitol Complex

333 West Nye Lane

Carson City, NV 89170

Chuck Bulick

NDEP

555 East Washington, Suite 4300

Las Vegas, NV 89101

\section{Bechtel Nevada}

J. R. Kannard, M/S NLV022

D. K. Cowser, M/S NLV082

M. D. Shotton, M/S NLV082

Correspondence Control, M/S NLV008

\section{IT Corporation}

R. Eastman, M/S 439

R. Silver, M/S 439

\section{Desert Research Institute}

R. Jacobsen, M/S 433 